\title{
Comparative Analysis of PFOS and PFOA Toxicity on Sertoli Cells
}

\author{
HT Wan ${ }^{1}, \mathrm{KP} \mathrm{Lai}^{2 \#}$, and Chris KC Wong ${ }^{1 *}$ \\ Croucher Institute for Environmental Sciences, Department of Biology, Hong Kong Baptist University, \\ Hong Kong SAR, China. ${ }^{2}$ Guanxi Key Laboratory of Tumor Immunology and Microenvironmental \\ Regulation, Guilin Medical University, Guilin, PR China
}

${ }^{\#}$ Co-corresponding author, Dr. KP Lai

Address: Guanxi Key Laboratory of Tumor Immunology and Microenvironmental Regulation, Guilin Medical University, Guilin, PR China

Phone: (852) 34424716

Email address: kengplai@cityu.edu.hk

*Corresponding author, Dr. Chris KC Wong

Address: Department of Biology, Hong Kong Baptist University.

Phone: (852) 3411-7053

Email address: ckcwong@hkbu.edu.hk.

Keywords: Transcriptome, Immunofluorescence, Cytoskeleton, Sertoli cell-cell junction, Resveratrol 
Supplementary Figure S1. Immunofluorescent Staining of Actin, Basal Ectoplasmic Specification (ES) Proteins (N-cad/ $\beta$-cat) and Tight Junction (TJ) protein ZO-1, in Rat Primary Sertoli Cells. Effects of PFOA (20-80 $\mu \mathrm{M}, 24 \mathrm{hr})$ treatment on the localization of (A) actin (red), (B) N-cad (red) and $\beta$-cat (green) and (C) ZO-1 (green). The noticeable effects on the organization of actin, and the localization of the Sertoli cell-cell junction proteins were observed in PFOA treatment. The cells were counterstained with DAPI (blue).

(A)
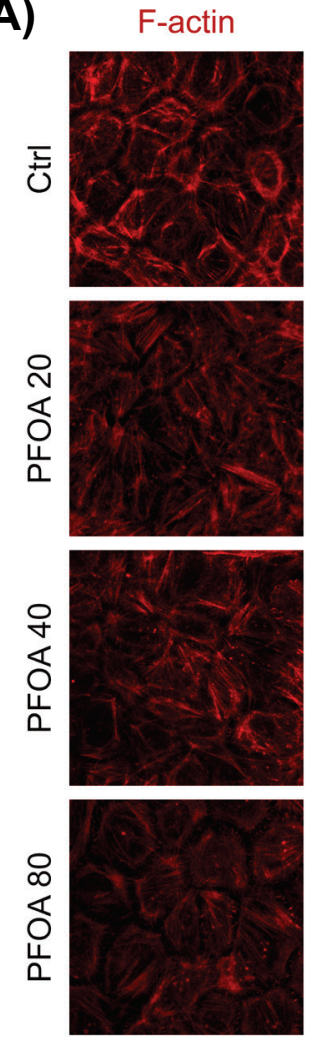

(C)
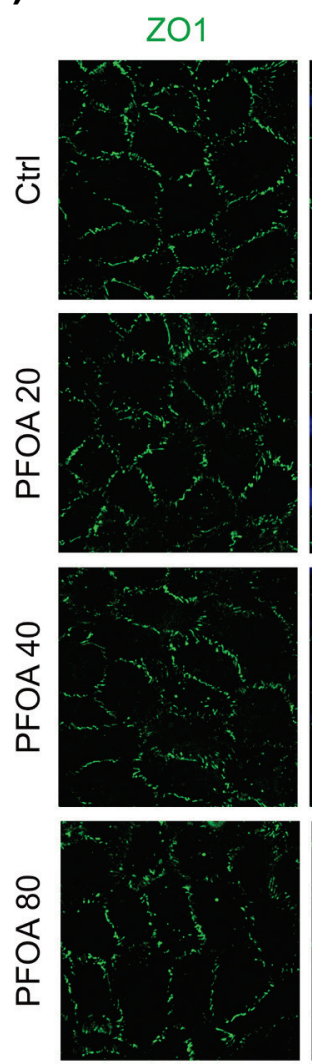

(B)
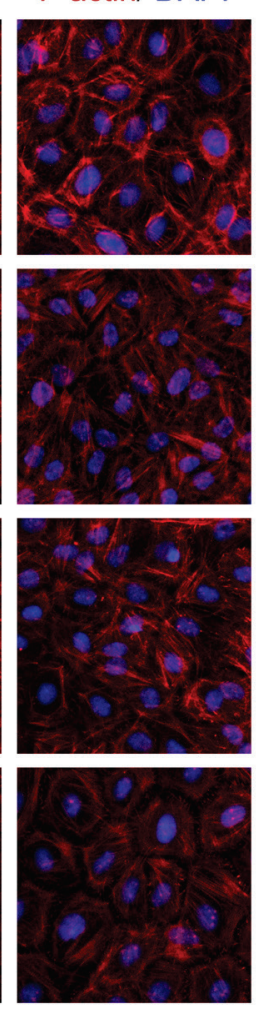

ZO1/ DAPI
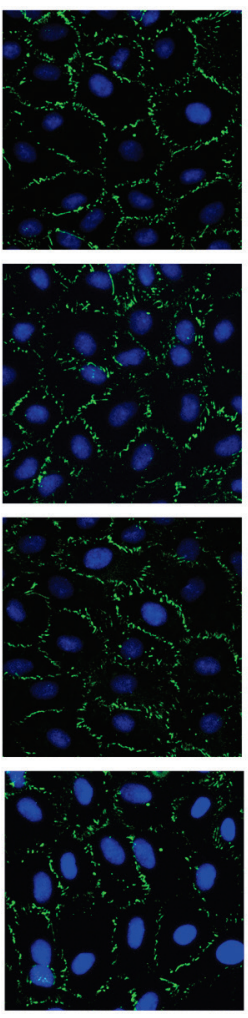
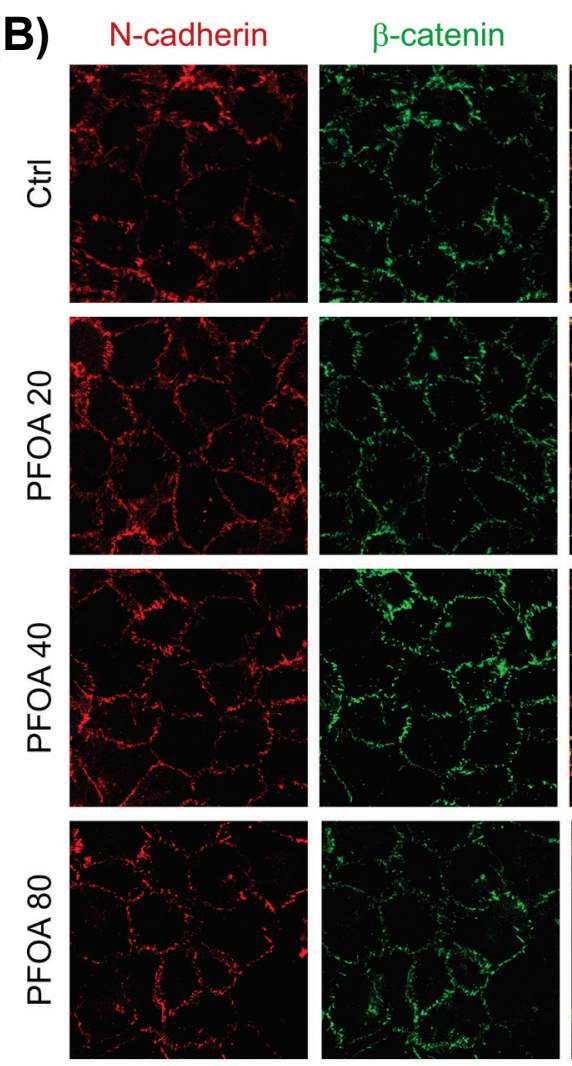

\section{$\mathrm{N}$-cadherin/} $\beta$-catenin

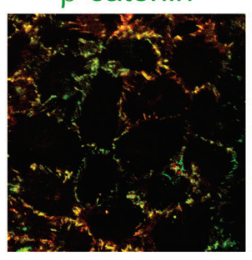

Merge/DAPI
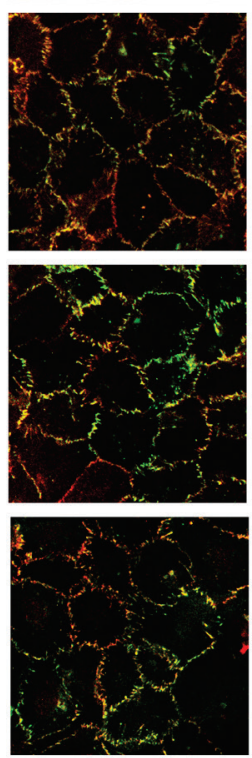
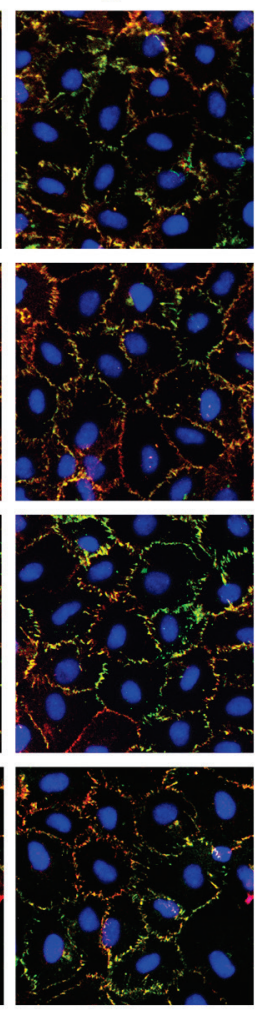
Supplementary Table S1. DEGs in sertoli cells caused by PFOA treatment.

\begin{tabular}{|c|c|c|c|c|}
\hline Symbol & $\begin{array}{c}\log 2 \\
\text { Ratio(PFOA/C } \\
\text { trl) }\end{array}$ & p-value & Kegg Orthology & Biological Process \\
\hline Pmch & -4.022717569 & $\begin{array}{c}0.004851 \\
03\end{array}$ & $\begin{array}{l}\text { K05229//pro-melanin- } \\
\text { concentrating hormone }\end{array}$ & $\begin{array}{c}\text { GO:0007595//lactation;GO:0009409//response to } \\
\text { cold;GO:0002027//regulation of heart } \\
\text { rate;GO:0032227//negative regulation of synaptic } \\
\text { transmission, dopaminergic;GO:0042593//glucose } \\
\text { homeostasis;GO:0045776//negative regulation of blood } \\
\text { pressure;GO:0042756//drinking } \\
\text { behavior;GO:0048168//regulation of neuronal synaptic } \\
\text { plasticity;GO:0046005//positive regulation of circadian } \\
\text { sleep/wake cycle, REM sleep;GO:0007631//feeding } \\
\text { behavior;GO:0007204//positive regulation of cytosolic } \\
\text { calcium ion concentration;GO:0007268//chemical synaptic } \\
\text { transmission;GO:0007218//neuropeptide signaling } \\
\text { pathway;GO:0007611//learning or memory }\end{array}$ \\
\hline LOC691895 & -3.964401073 & $\begin{array}{c}0.005995 \\
67\end{array}$ & $\begin{array}{l}\text { K00522//ferritin heavy } \\
\text { chain [EC:1.16.3.2] }\end{array}$ & $\begin{array}{c}\text { GO:0006826//iron ion transport;GO:0006880//intracellular } \\
\text { sequestering of iron ion }\end{array}$ \\
\hline Sntg1 & -3.550565319 & $\begin{array}{c}0.001196 \\
38\end{array}$ & $\begin{array}{c}\text { K20251//glutamate } \\
\text { receptor-interacting } \\
\text { protein;K12196//vacuolar } \\
\text { protein-sorting-associated } \\
\text { protein } 4\end{array}$ & NA \\
\hline Cilp & -3.286329168 & $\begin{array}{c}0.004177 \\
62\end{array}$ & $\begin{array}{c}\text { K19031//cell migration- } \\
\text { inducing and hyaluronan- } \\
\text { binding protein } \\
\text { [EC:3.2.1.35] }\end{array}$ & $\begin{array}{l}\text { GO:0043569//negative regulation of insulin-like growth } \\
\text { factor receptor signaling pathway }\end{array}$ \\
\hline
\end{tabular}




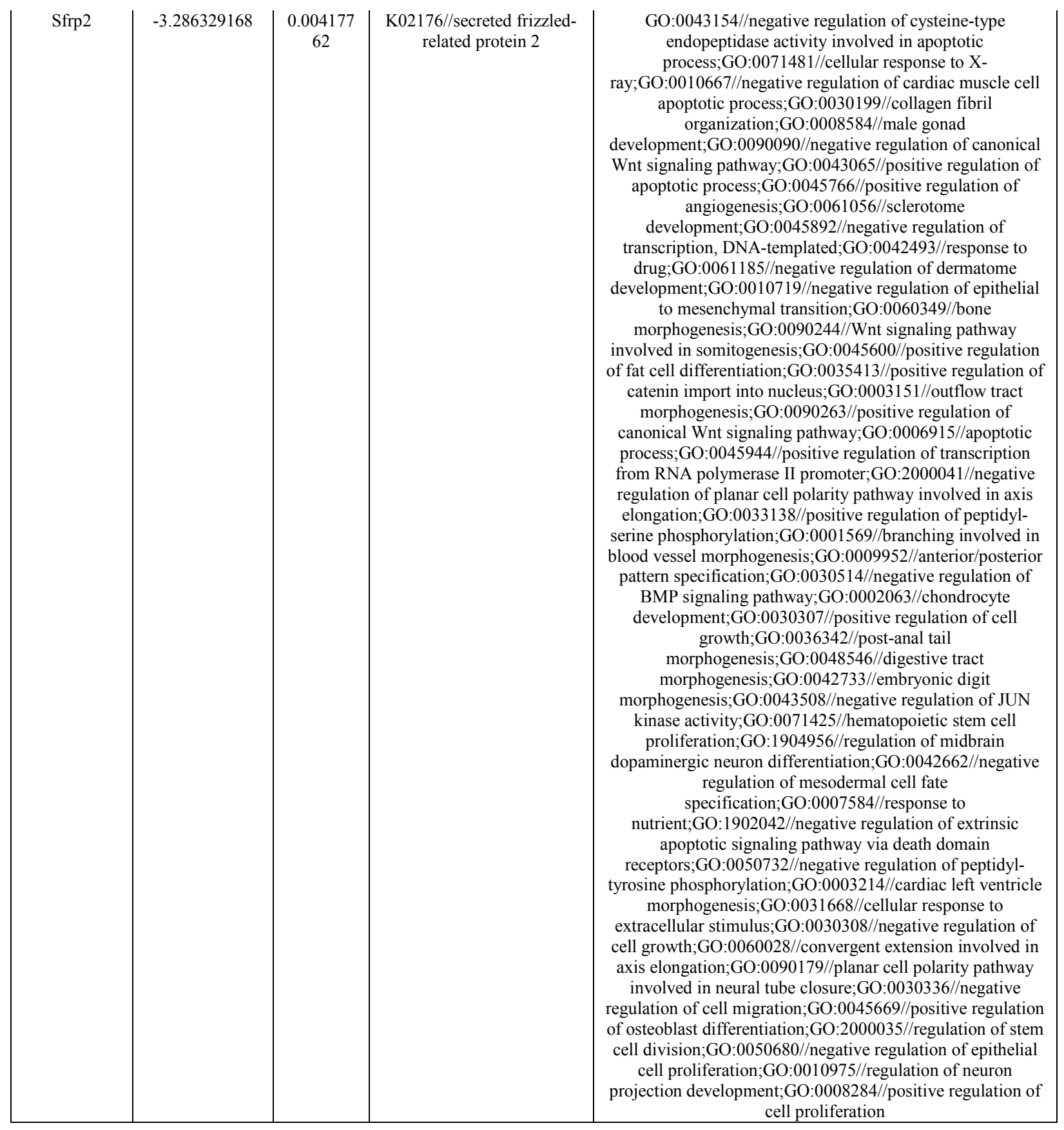




\begin{tabular}{|c|c|c|c|c|}
\hline Nrxn2 & -3.286329168 & $\begin{array}{c}0.004177 \\
62\end{array}$ & K07377//neurexin & $\begin{array}{c}\text { GO:0097116//gephyrin clustering involved in postsynaptic } \\
\text { density assembly;GO:0035176//social } \\
\text { behavior;GO:0007165//signal } \\
\text { transduction;GO:0097104//postsynaptic membrane } \\
\text { assembly;GO:0007416//synapse } \\
\text { assembly;GO:0042297//vocal learning;GO:0007155//cell } \\
\text { adhesion;GO:0007269//neurotransmitter } \\
\text { secretion;GO:0097118//neuroligin clustering involved in } \\
\text { postsynaptic membrane assembly;GO:0030534//adult } \\
\text { behavior;GO:0007268//chemical synaptic } \\
\text { transmission;GO:0071625//vocalization } \\
\text { behavior;GO:0097119//postsynaptic density protein } 95 \\
\text { clustering }\end{array}$ \\
\hline Slc24a1 & -3.181170938 & $\begin{array}{c}0.006213 \\
79\end{array}$ & $\begin{array}{c}\text { K13749//solute carrier } \\
\text { family } 24 \\
\text { (sodium/potassium/calcium } \\
\text { exchanger), member } 1\end{array}$ & $\begin{array}{c}\text { GO:0070588//calcium ion transmembrane } \\
\text { transport;GO:0060292//long term synaptic } \\
\text { depression;GO:0060291//long-term synaptic } \\
\text { potentiation;GO:0050896//response to } \\
\text { stimulus;GO:0007601//visual } \\
\text { perception;GO:0006874//cellular calcium ion homeostasis }\end{array}$ \\
\hline Agxt2 & -3.134326075 & $\begin{array}{c}0.007792 \\
75\end{array}$ & $\begin{array}{c}\text { K00827//alanine- } \\
\text { glyoxylate transaminase / } \\
\text { (R)-3-amino-2- } \\
\text { methylpropionate-pyruvate } \\
\text { transaminase [EC:2.6.1.44 } \\
\text { 2.6.1.40] }\end{array}$ & $\begin{array}{c}\text { GO:0019265//glycine biosynthetic process, by } \\
\text { transamination of glyoxylate;GO:0045429//positive } \\
\text { regulation of nitric oxide biosynthetic } \\
\text { process;GO:0009436//glyoxylate catabolic } \\
\text { process;GO:0019481//L-alanine catabolic process, by } \\
\text { transamination }\end{array}$ \\
\hline
\end{tabular}




\begin{tabular}{|c|c|c|c|c|}
\hline Lgr5 & -3.134326075 & $\begin{array}{c}0.007792 \\
75\end{array}$ & $\begin{array}{l}\text { K04308//leucine-rich } \\
\text { repeat-containing G } \\
\text { protein-coupled receptor } 5\end{array}$ & $\begin{array}{c}\text { GO:0007186//G-protein coupled receptor signaling } \\
\text { pathway;GO:2001013//epithelial cell proliferation involved } \\
\text { in renal tubule morphogenesis;GO:0009994//oocyte } \\
\text { differentiation;GO:0042127//regulation of cell } \\
\text { proliferation;GO:0048839//inner ear } \\
\text { development;GO:0001942//hair follicle } \\
\text { development;GO:0090263//positive regulation of canonical } \\
\text { Wnt signaling pathway }\end{array}$ \\
\hline Matk & -3.051863915 & $\begin{array}{c}0.000303 \\
71\end{array}$ & $\begin{array}{l}\text { K08888//megakaryocyte- } \\
\text { associated tyrosine kinase } \\
\text { [EC:2.7.10.2] }\end{array}$ & NA \\
\hline Hoxb8 & -2.964401073 & $\begin{array}{c}0.000548 \\
62\end{array}$ & $\begin{array}{c}\text { K09308//homeobox protein } \\
\text { HoxB/C/D8 }\end{array}$ & $\begin{array}{c}\text { GO:0009952//anterior/posterior pattern } \\
\text { specification;GO:0021516//dorsal spinal cord } \\
\text { development;GO:0008344//adult locomotory } \\
\text { behavior;GO:0006351//transcription, DNA- } \\
\text { templated;GO:0045638//negative regulation of myeloid cell } \\
\text { differentiation;GO:0000122//negative regulation of } \\
\text { transcription from RNA polymerase II } \\
\text { promoter;GO:0007275//multicellular organism } \\
\text { development;GO:0048704//embryonic skeletal system } \\
\text { morphogenesis;GO:0019233//sensory perception of } \\
\text { pain;GO:0007625//grooming behavior;GO:0048705//skeletal } \\
\text { system morphogenesis }\end{array}$ \\
\hline Cox4i2 & -2.701366667 & $\begin{array}{c}0.000228 \\
62\end{array}$ & $\begin{array}{l}\text { K02263//cytochrome c } \\
\text { oxidase subunit } 4\end{array}$ & $\begin{array}{c}\text { GO:0071456//cellular response to } \\
\text { hypoxia;GO:0006123//mitochondrial electron transport, } \\
\text { cytochrome c to oxygen }\end{array}$ \\
\hline
\end{tabular}




\begin{tabular}{|c|c|c|c|c|}
\hline Madcam1 & -2.549363574 & $\begin{array}{l}0.000705 \\
77\end{array}$ & $\begin{array}{l}\text { K06779//mucosal vascular } \\
\text { addressin cell adhesion } \\
\text { molecule } 1\end{array}$ & $\begin{array}{c}\text { GO:0043113//receptor clustering;GO:0050900//leukocyte } \\
\text { migration;GO:0030216//keratinocyte } \\
\text { differentiation;GO:0050901//leukocyte tethering or } \\
\text { rolling;GO:0007568//aging;GO:0007160//cell-matrix } \\
\text { adhesion;GO:0007155//cell } \\
\text { adhesion;GO:0034113//heterotypic cell-cell } \\
\text { adhesion;GO:0007229//integrin-mediated signaling } \\
\text { pathway;GO:0002687//positive regulation of leukocyte } \\
\text { migration }\end{array}$ \\
\hline Cd53 & -2.276846893 & $\begin{array}{c}0.000147 \\
32\end{array}$ & K06489//CD53 antigen & $\begin{array}{l}\text { GO:0040008//regulation of growth;GO:0007166//cell } \\
\text { surface receptor signaling pathway;GO:1901741//positive } \\
\text { regulation of myoblast fusion }\end{array}$ \\
\hline Cdh6 & -2.227435479 & $\begin{array}{c}0.000302 \\
1\end{array}$ & $\begin{array}{l}\text { K06798//cadherin 6, type } \\
\text { 2, K-cadherin }\end{array}$ & $\begin{array}{c}\text { GO:0007156//homophilic cell adhesion via plasma } \\
\text { membrane adhesion molecules }\end{array}$ \\
\hline Tbx1 & -2.018848857 & $3.52 \mathrm{E}-07$ & K10175//T-box protein 1 & $\begin{array}{c}\text { GO:0009952//anterior/posterior pattern } \\
\text { specification;GO:0048844//artery } \\
\text { morphogenesis;GO:0001525//angiogenesis;GO:0035909//ao } \\
\text { rta morphogenesis }\end{array}$ \\
\hline Adralb & -1.81239798 & $\begin{array}{c}0.006216 \\
11\end{array}$ & $\begin{array}{l}\text { K04136//adrenergic } \\
\text { receptor alpha-1B }\end{array}$ & $\begin{array}{c}\text { GO:0019229//regulation of } \\
\text { vasoconstriction;GO:0043410//positive regulation of MAPK } \\
\text { cascade;GO:0055117//regulation of cardiac muscle } \\
\text { contraction }\end{array}$ \\
\hline
\end{tabular}




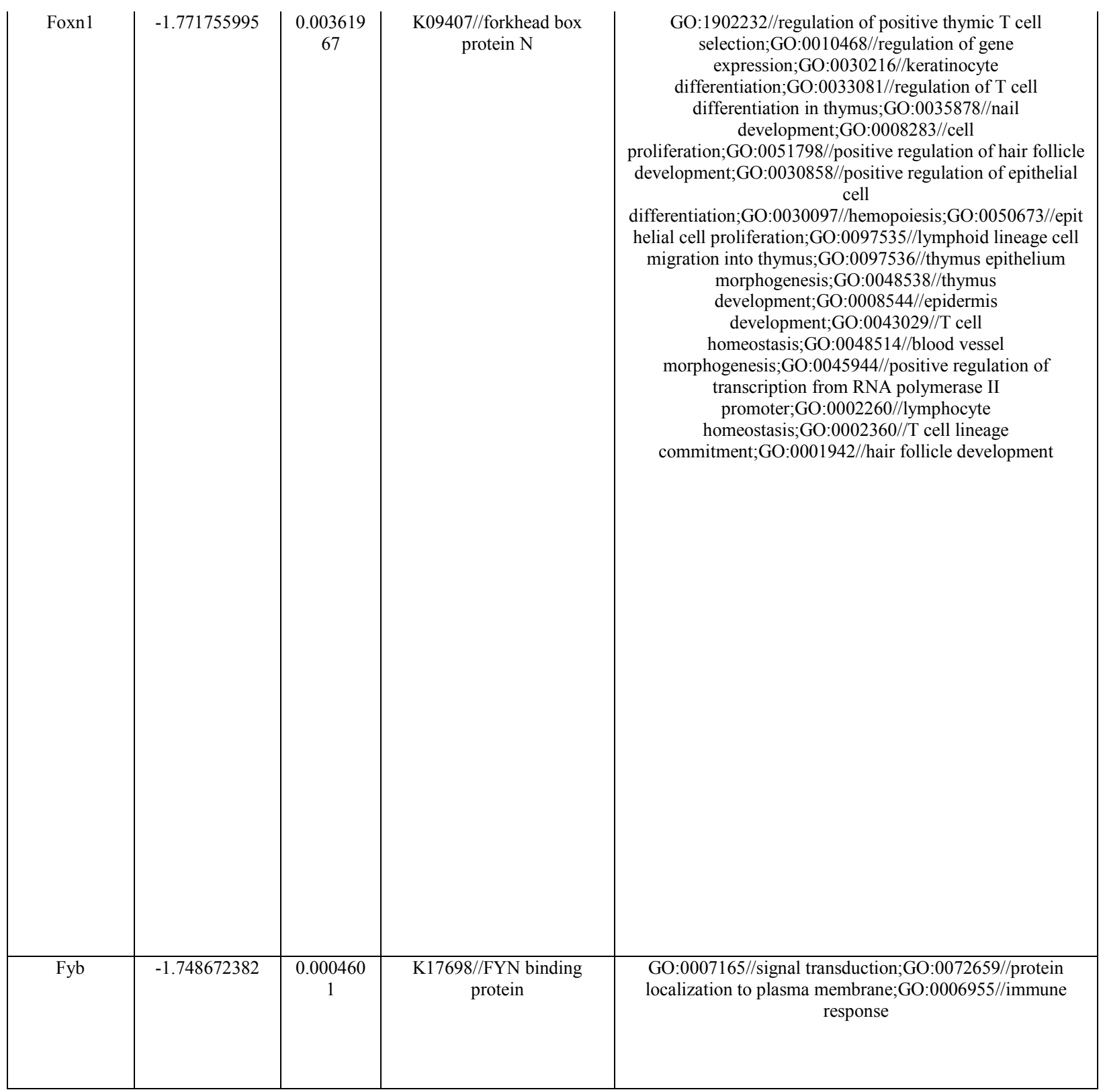




\begin{tabular}{|c|c|c|c|c|}
\hline Gckr & -1.72993582 & $\begin{array}{c}0.000271 \\
53\end{array}$ & NA & $\begin{array}{c}\text { GO:0006006//glucose metabolic } \\
\text { process;GO:0000060//protein import into nucleus, } \\
\text { translocation;GO:0009750//response to } \\
\text { fructose;GO:0051594//detection of } \\
\text { glucose;GO:1901135//carbohydrate derivative metabolic } \\
\text { process;GO:0001678//cellular glucose } \\
\text { homeostasis;GO:0070328//triglyceride } \\
\text { homeostasis;GO:0034504//protein localization to } \\
\text { nucleus;GO:0033132//negative regulation of glucokinase } \\
\text { activity;GO:1903300//negative regulation of hexokinase } \\
\text { activity;GO:0046415//urate metabolic } \\
\text { process;GO:0033133//positive regulation of glucokinase } \\
\text { activity }\end{array}$ \\
\hline Mrap2 & -1.712613373 & $\begin{array}{c}0.002833 \\
7\end{array}$ & NA & $\begin{array}{l}\text { GO:0007631//feeding behavior;GO:0006112//energy reserve } \\
\text { metabolic process;GO:0030819//positive regulation of } \\
\text { cAMP biosynthetic process;GO:0034394//protein } \\
\text { localization to cell surface;GO:0097009//energy homeostasis }\end{array}$ \\
\hline
\end{tabular}




\begin{tabular}{|c|c|c|c|c|}
\hline Hnflb & -1.701366667 & $\begin{array}{c}0.000723 \\
85\end{array}$ & $\begin{array}{c}\text { K08034//transcription } \\
\text { factor 2, hepatocyte nuclear } \\
\text { factor 1-beta }\end{array}$ & 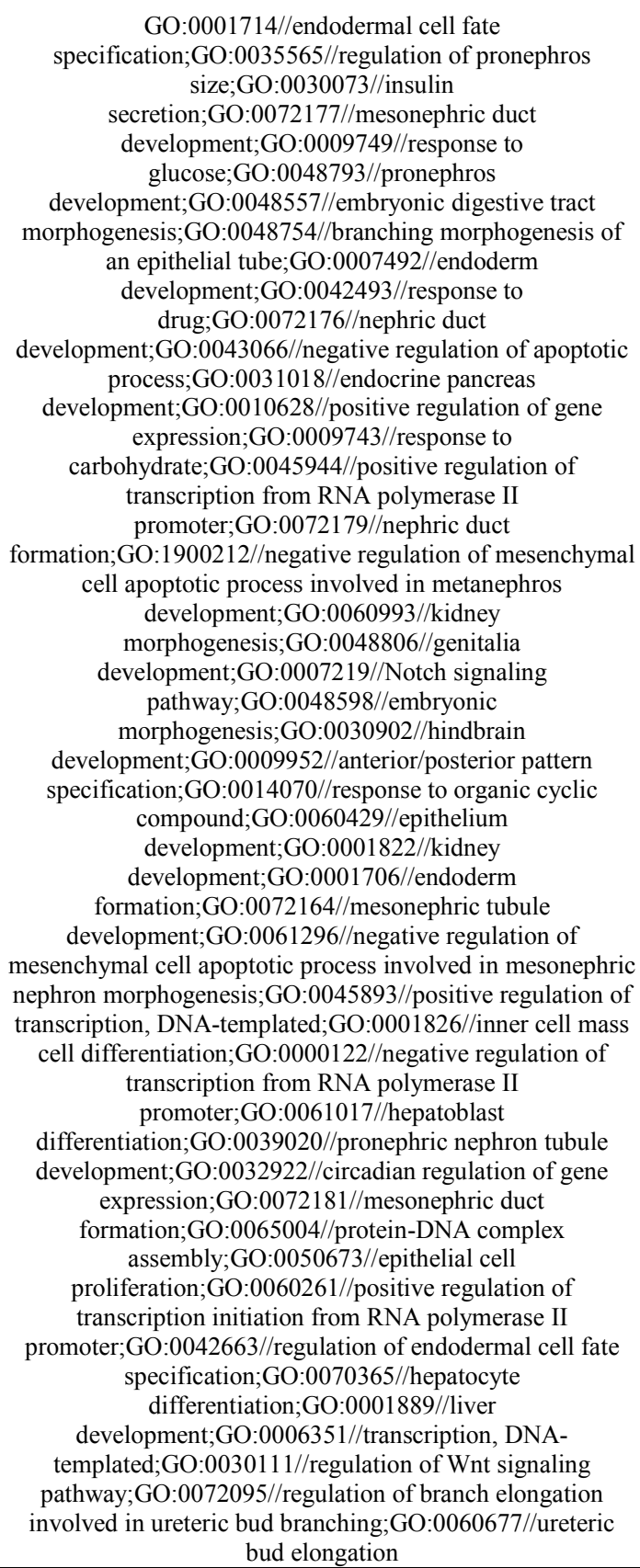 \\
\hline Mybpc1 & -1.634252472 & $\begin{array}{c}0.000387 \\
83\end{array}$ & $\begin{array}{l}\text { K12557//myosin-binding } \\
\text { protein C, slow-type }\end{array}$ & NA \\
\hline Myo16 & -1.601830994 & $\begin{array}{c}0.001758 \\
83\end{array}$ & K17481//myosin XVI & $\begin{array}{c}\text { GO:0021549//cerebellum development;GO:0048812//neuron } \\
\text { projection } \\
\text { morphogenesis;GO:0014065//phosphatidylinositol 3-kinase } \\
\text { signaling;GO:2000134//negative regulation of G1/S } \\
\text { transition of mitotic cell cycle;GO:0008285//negative } \\
\text { regulation of cell proliferation }\end{array}$ \\
\hline
\end{tabular}




\begin{tabular}{|c|c|c|c|c|}
\hline Ece2 & -1.549363574 & $\begin{array}{c}0.004700 \\
55\end{array}$ & $\begin{array}{l}\text { K01415//endothelin- } \\
\text { converting enzyme } \\
\text { [EC:3.4.24.71] }\end{array}$ & $\begin{array}{c}\text { GO:0016486//peptide hormone } \\
\text { processing;GO:0007507//heart } \\
\text { development;GO:0010002//cardioblast } \\
\text { differentiation;GO:0007420//brain development }\end{array}$ \\
\hline Crhr2 & -1.549363574 & $\begin{array}{c}0.008186 \\
15\end{array}$ & $\begin{array}{l}\text { K04579//corticotropin } \\
\text { releasing hormone receptor } \\
2\end{array}$ & $\begin{array}{c}\text { GO:0007205//protein kinase C-activating G-protein coupled } \\
\text { receptor signaling pathway;GO:0042423//catecholamine } \\
\text { biosynthetic process;GO:0045777//positive regulation of } \\
\text { blood pressure;GO:0021854//hypothalamus } \\
\text { development;GO:0007166//cell surface receptor signaling } \\
\text { pathway;GO:0014064//positive regulation of serotonin } \\
\text { secretion;GO:0032811//negative regulation of epinephrine } \\
\text { secretion;GO:0007015//actin filament } \\
\text { organization;GO:0019233//sensory perception of } \\
\text { pain;GO:0030819//positive regulation of cAMP biosynthetic } \\
\text { process;GO:0043950//positive regulation of cAMP-mediated } \\
\text { signaling;GO:0061179//negative regulation of insulin } \\
\text { secretion involved in cellular response to glucose } \\
\text { stimulus;GO:0090281//negative regulation of calcium ion } \\
\text { import;GO:0070372//regulation of ERK1 and ERK2 } \\
\text { cascade;GO:0010628//positive regulation of gene } \\
\text { expression;GO:0046882//negative regulation of follicle- } \\
\text { stimulating hormone secretion;GO:0007631//feeding } \\
\text { behavior;GO:2000252//negative regulation of feeding } \\
\text { behavior;GO:0032755//positive regulation of interleukin-6 } \\
\text { production;GO:0043951//negative regulation of cAMP- } \\
\text { mediated signaling;GO:0071385//cellular response to } \\
\text { glucocorticoid stimulus;GO:0033685//negative regulation of } \\
\text { luteinizing hormone secretion;GO:0048630//skeletal muscle } \\
\text { tissue growth;GO:0010629//negative regulation of gene } \\
\text { expression;GO:0030816//positive regulation of cAMP } \\
\text { metabolic process;GO:0010700//negative regulation of } \\
\text { norepinephrine secretion;GO:0060291//long-term synaptic } \\
\text { potentiation;GO:0030818//negative regulation of cAMP } \\
\text { biosynthetic process;GO:0021549//cerebellum } \\
\text { development;GO:0007186//G-protein coupled receptor } \\
\text { signaling pathway;GO:2000293//negative regulation of } \\
\text { defecation;GO:0010460//positive regulation of heart } \\
\text { rate;GO:0016525//negative regulation of } \\
\text { angiogenesis;GO:0051092//positive regulation of NF- } \\
\text { kappaB transcription factor activity;GO:0032874//positive } \\
\text { regulation of stress-activated MAPK } \\
\text { cascade;GO:0035482//gastric } \\
\text { motility;GO:0030855//epithelial cell differentiation }\end{array}$ \\
\hline Stac2 & -1.549363574 & $\begin{array}{c}0.008186 \\
15\end{array}$ & $\begin{array}{c}\text { K19862//NCK adaptor } \\
\text { protein 2;K12171//E3 } \\
\text { ubiquitin-protein ligase } \\
\text { SH3RF } \\
\text { [EC:2.3.2.27];K06114//spe } \\
\text { ctrin alpha;K04705//signal } \\
\text { transducing adaptor } \\
\text { molecule } \\
\end{array}$ & GO:0035556//intracellular signal transduction \\
\hline Naaladl1 & -1.49491579 & $\begin{array}{c}0.004159 \\
41\end{array}$ & $\begin{array}{c}\text { K01301//N-acetylated- } \\
\text { alpha-linked acidic } \\
\text { dipeptidase [EC:3.4.17.21] }\end{array}$ & NA \\
\hline Actl7a & -1.459165765 & $\begin{array}{c}0.002116 \\
28 \\
\end{array}$ & $\begin{array}{c}\text { K05692//actin beta/gamma } \\
1\end{array}$ & NA \\
\hline
\end{tabular}




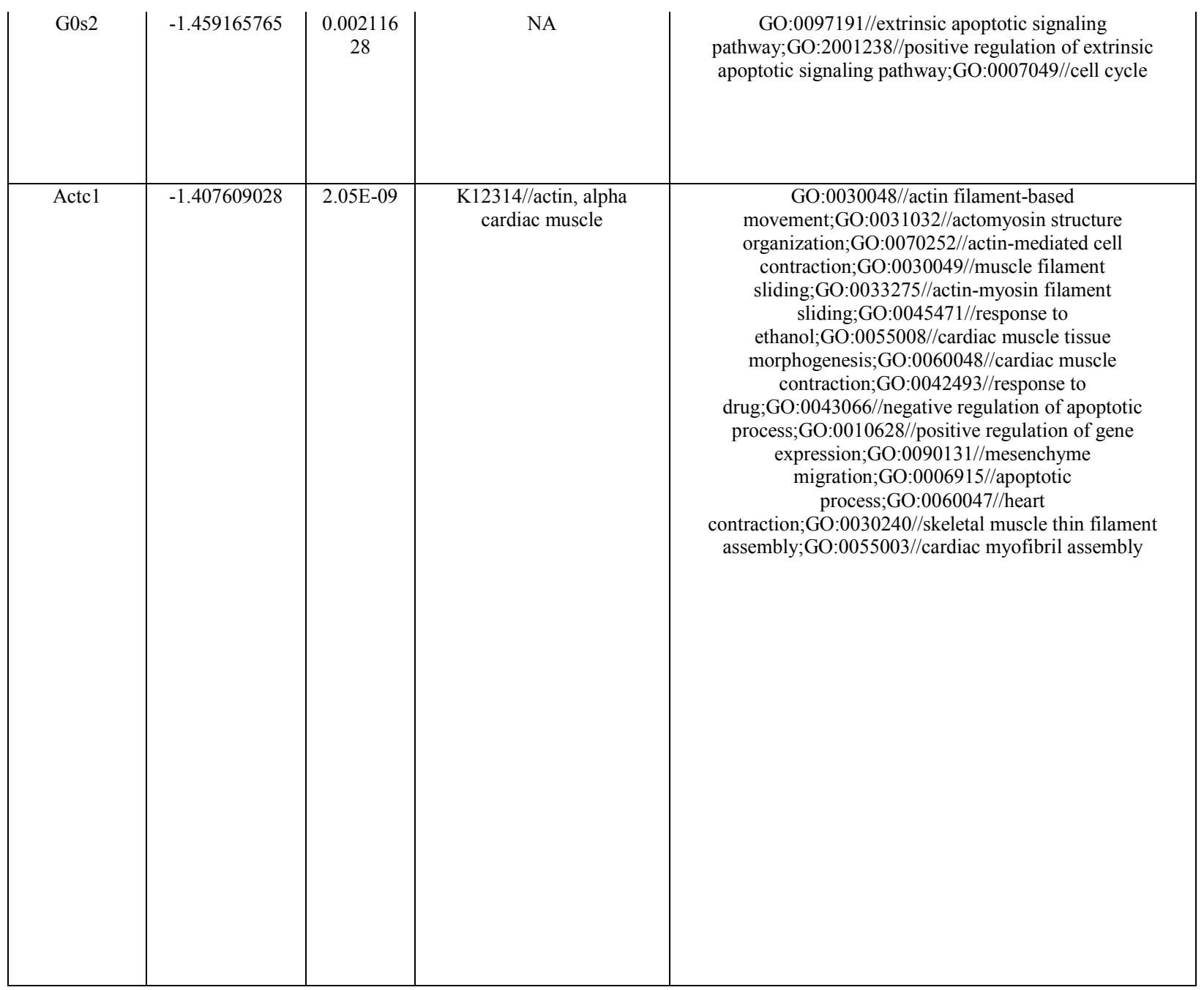




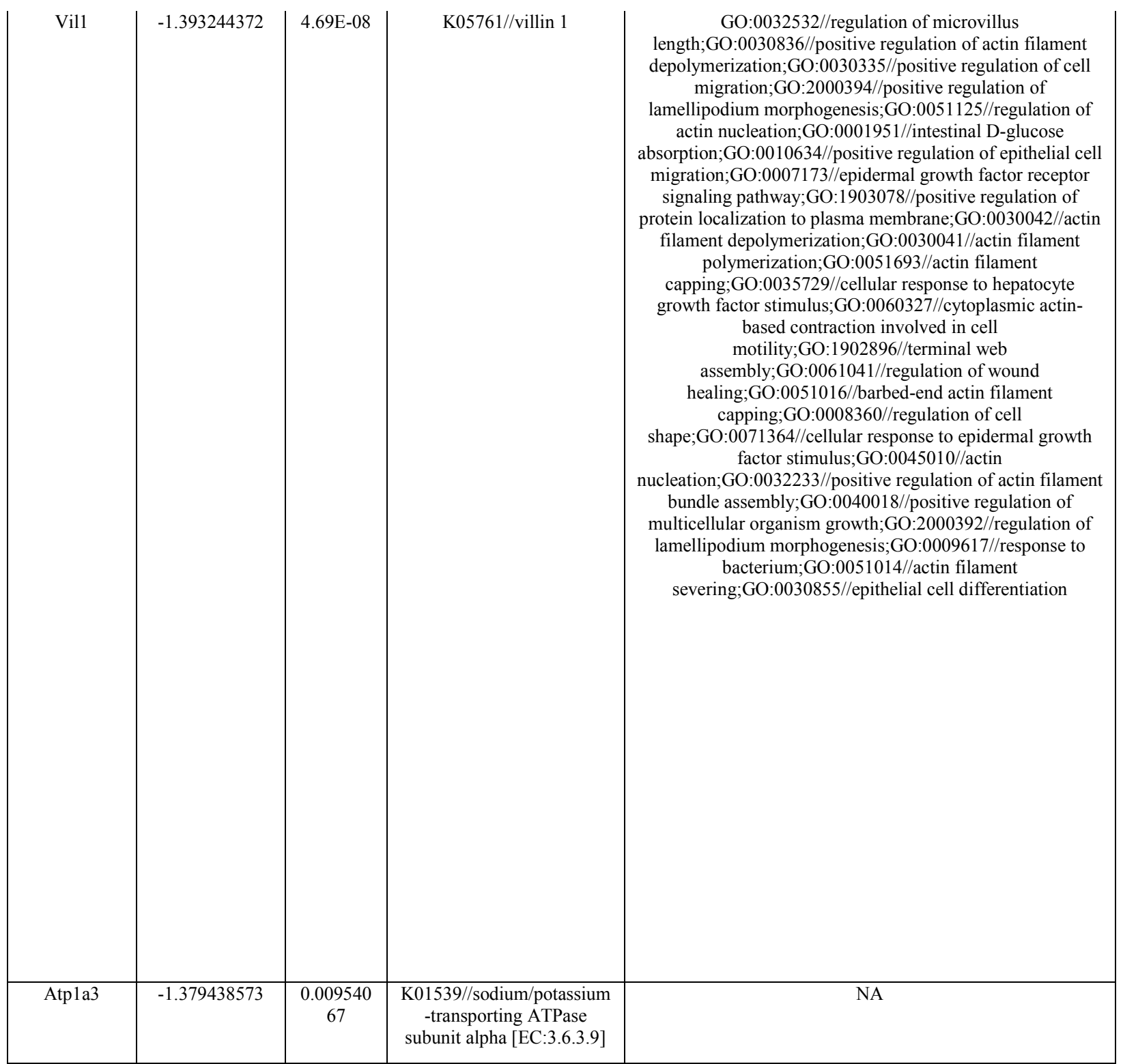




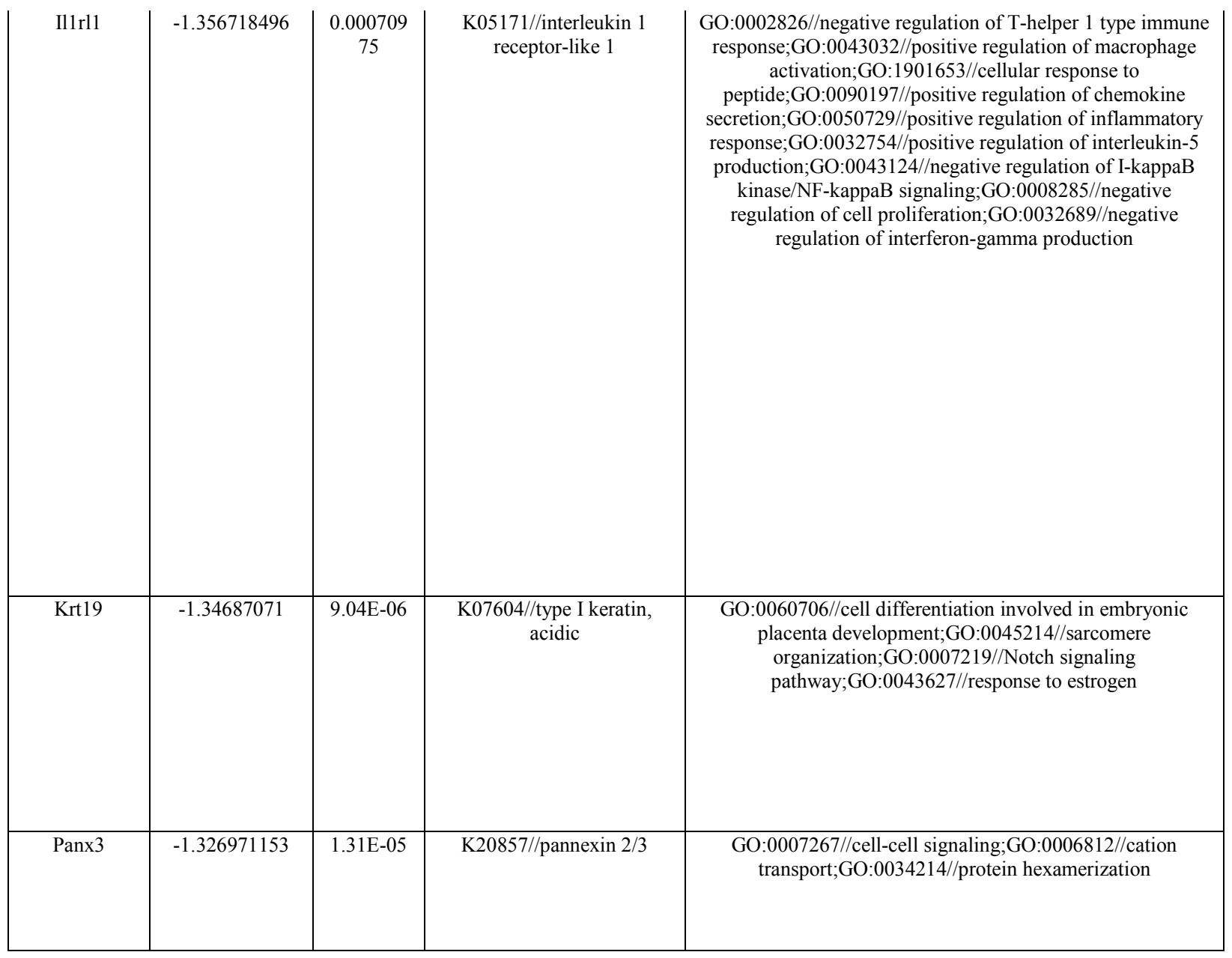




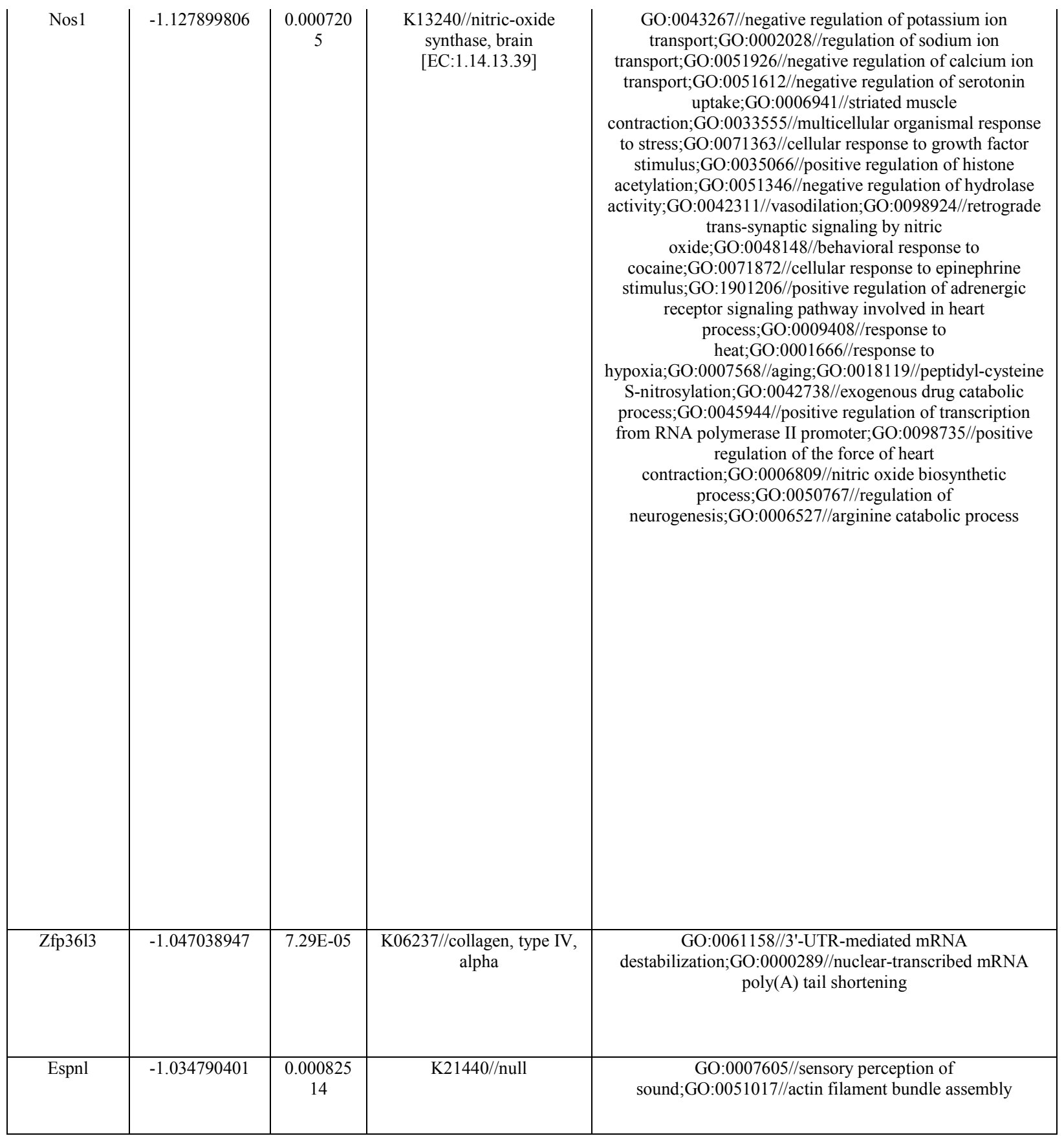




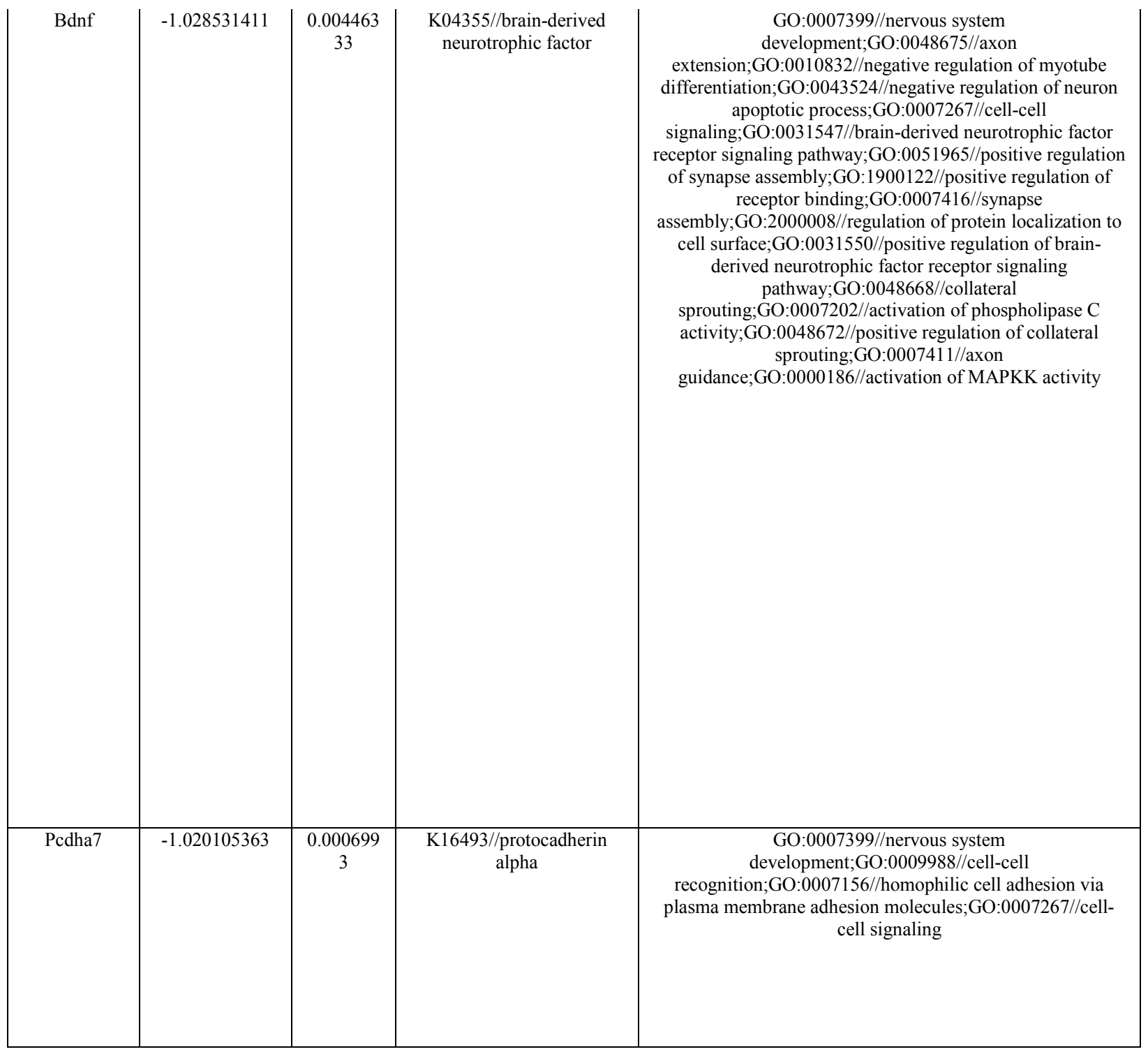




\begin{tabular}{|c|c|c|c|c|}
\hline Musk & -1.002536202 & $1.07 \mathrm{E}-05$ & $\begin{array}{l}\text { K05129//muscle, skeletal, } \\
\text { receptor tyrosine kinase } \\
\text { [EC:2.7.10.1] }\end{array}$ & $\begin{array}{c}\text { GO:0060041//retina development in camera-type } \\
\text { eye;GO:0050731//positive regulation of peptidyl-tyrosine } \\
\text { phosphorylation;GO:0007528//neuromuscular junction } \\
\text { development;GO:0006355//regulation of transcription, } \\
\text { DNA-templated;GO:0010629//negative regulation of gene } \\
\text { expression;GO:2000541//positive regulation of protein } \\
\text { geranylgeranylation;GO:0014850//response to muscle } \\
\text { activity;GO:0051602//response to electrical } \\
\text { stimulus;GO:0060291//long-term synaptic } \\
\text { potentiation;GO:0008582//regulation of synaptic growth at } \\
\text { neuromuscular junction;GO:0001934//positive regulation of } \\
\text { protein phosphorylation;GO:0071340//skeletal muscle } \\
\text { acetylcholine-gated channel } \\
\text { clustering;GO:0032224//positive regulation of synaptic } \\
\text { transmission, cholinergic;GO:0043525//positive regulation } \\
\text { of neuron apoptotic process;GO:0043113//receptor } \\
\text { clustering;GO:0030154//cell } \\
\text { differentiation;GO:0048678//response to axon } \\
\text { injury;GO:0010628//positive regulation of gene } \\
\text { expression;GO:0046777//protein } \\
\text { autophosphorylation;GO:0007613//memory;GO:1904395//p } \\
\text { ositive regulation of skeletal muscle acetylcholine-gated } \\
\text { channel clustering;GO:0007275//multicellular organism } \\
\text { development;GO:0090102//cochlea } \\
\text { development;GO:0045887//positive regulation of synaptic } \\
\text { growth at neuromuscular junction }\end{array}$ \\
\hline Mir351 & 1.006452581 & $\begin{array}{c}0.003517 \\
59\end{array}$ & NA & NA \\
\hline $\mathrm{Ccl} 2$ & 1.011553453 & $1.05 \mathrm{E}-10$ & $\begin{array}{l}\text { K14624//C-C motif } \\
\text { chemokine } 2\end{array}$ & $\begin{array}{c}\text { GO:0043615//astrocyte cell } \\
\text { migration;GO:0061844//null;GO:0031100//animal organ } \\
\text { regeneration;GO:0001525//angiogenesis;GO:0006874//cellul } \\
\text { ar calcium ion homeostasis;GO:0007568//aging }\end{array}$ \\
\hline Tsen3411 & 1.026442678 & $3.04 \mathrm{E}-07$ & $\begin{array}{l}\text { K15323//tRNA-splicing } \\
\text { endonuclease subunit } \\
\text { Sen34 [EC:3.1.27.9] }\end{array}$ & $\begin{array}{l}\text { GO:0000379//tRNA-type intron splice site recognition and } \\
\text { cleavage }\end{array}$ \\
\hline Muc19 & 1.034943305 & $\begin{array}{c}0.004657 \\
13\end{array}$ & K22020//null & $\begin{array}{c}\text { GO:0002244//hematopoietic progenitor cell } \\
\text { differentiation;GO:0060689//cell differentiation involved in } \\
\text { salivary gland development;GO:0050728//negative } \\
\text { regulation of inflammatory response }\end{array}$ \\
\hline
\end{tabular}




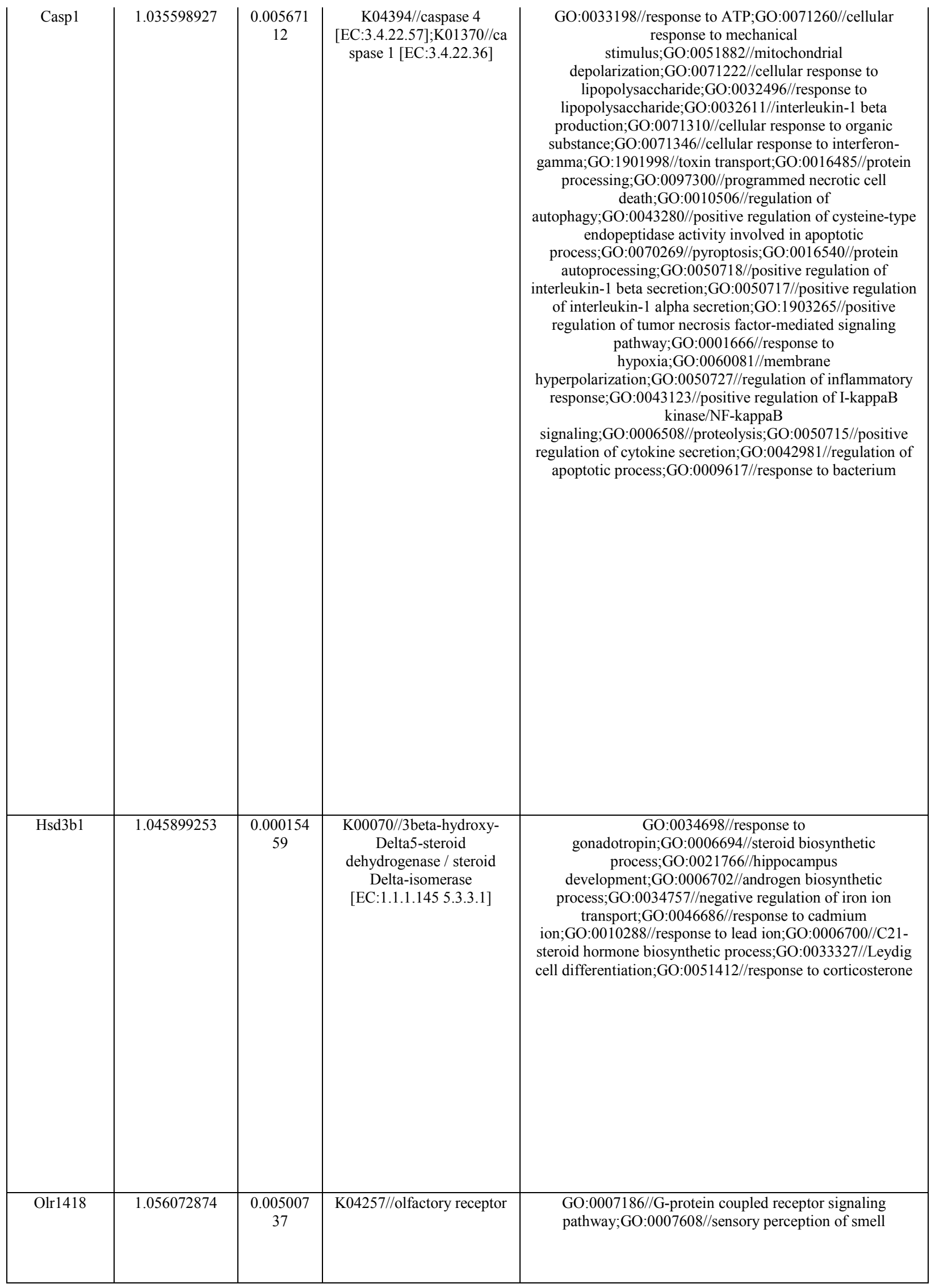




\begin{tabular}{|c|c|c|c|c|}
\hline Magea11 & 1.069151486 & 7.51E-09 & $\begin{array}{l}\mathrm{K} 12464 / / \text { melanoma- } \\
\text { associated antigen D1 }\end{array}$ & NA \\
\hline Mycbpap & 1.069546259 & $\begin{array}{c}0.004056 \\
33\end{array}$ & NA & $\begin{array}{l}\text { GO:0030154//cell differentiation;GO:0007605//sensory } \\
\text { perception of sound;GO:0007275//multicellular organism } \\
\text { development;GO:0007268//chemical synaptic } \\
\text { transmission;GO:0007283//spermatogenesis }\end{array}$ \\
\hline II1r2 & 1.069546259 & $\begin{array}{c}0.004056 \\
33\end{array}$ & $\begin{array}{l}\text { K04387//interleukin } 1 \\
\text { receptor type II }\end{array}$ & $\begin{array}{c}\text { GO:0010955//negative regulation of protein } \\
\text { processing;GO:0050712//negative regulation of interleukin-1 } \\
\text { alpha secretion;GO:2000660//negative regulation of } \\
\text { interleukin-1-mediated signaling } \\
\text { pathway;GO:1900016//negative regulation of cytokine } \\
\text { production involved in inflammatory response }\end{array}$ \\
\hline Fscn2 & 1.077419102 & $\begin{array}{c}0.009101 \\
95\end{array}$ & $\mathrm{~K} 17455 / /$ fascin $1 / 2$ & $\begin{array}{c}\text { GO:0009653//anatomical structure } \\
\text { morphogenesis;GO:0016477//cell } \\
\text { migration;GO:0030036//actin cytoskeleton } \\
\text { organization;GO:0007163//establishment or maintenance of } \\
\text { cell polarity;GO:0051017//actin filament bundle } \\
\text { assembly;GO:0042462//eye photoreceptor cell development }\end{array}$ \\
\hline Grasp & 1.099729264 & $\begin{array}{c}0.002363 \\
89\end{array}$ & $\begin{array}{l}\text { K04465//nuclear receptor } \\
\text { subfamily } 4 \text { group A } \\
\text { member } \\
1 ; \text { K08789//microtubule- } \\
\text { associated serine/threonine } \\
\quad \text { kinase [EC:2.7.11.1] }\end{array}$ & $\begin{array}{c}\text { GO:0006886//intracellular protein } \\
\text { transport;GO:0007165//signal } \\
\text { transduction;GO:0008104//protein localization }\end{array}$ \\
\hline Mroh7 & 1.109599508 & $\begin{array}{c}0.004295 \\
61\end{array}$ & $\begin{array}{c}\text { K09291//nucleoprotein } \\
\text { TPR }\end{array}$ & NA \\
\hline LOC691215 & 1.16684346 & $6.51 \mathrm{E}-06$ & NA & NA \\
\hline
\end{tabular}




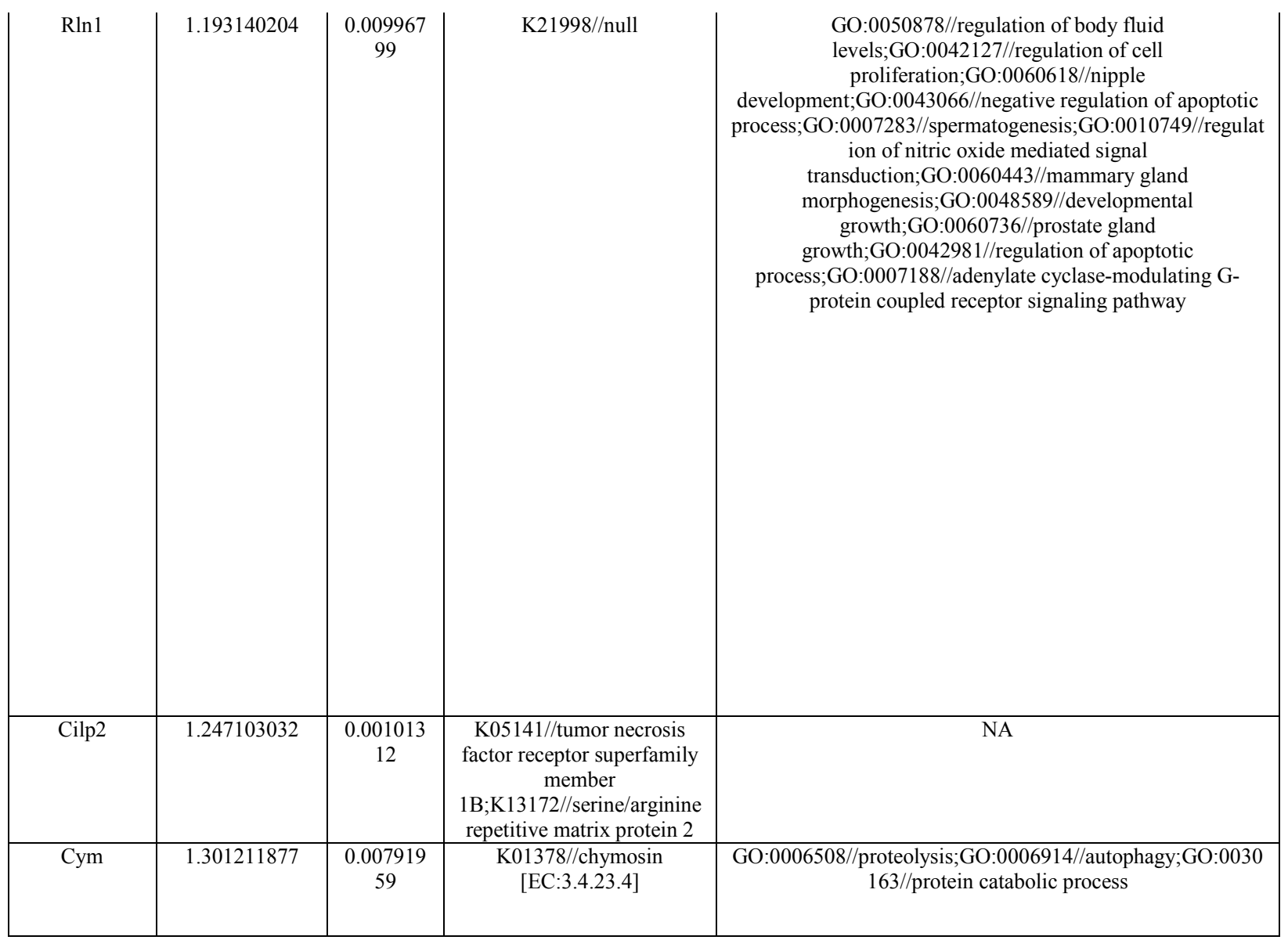




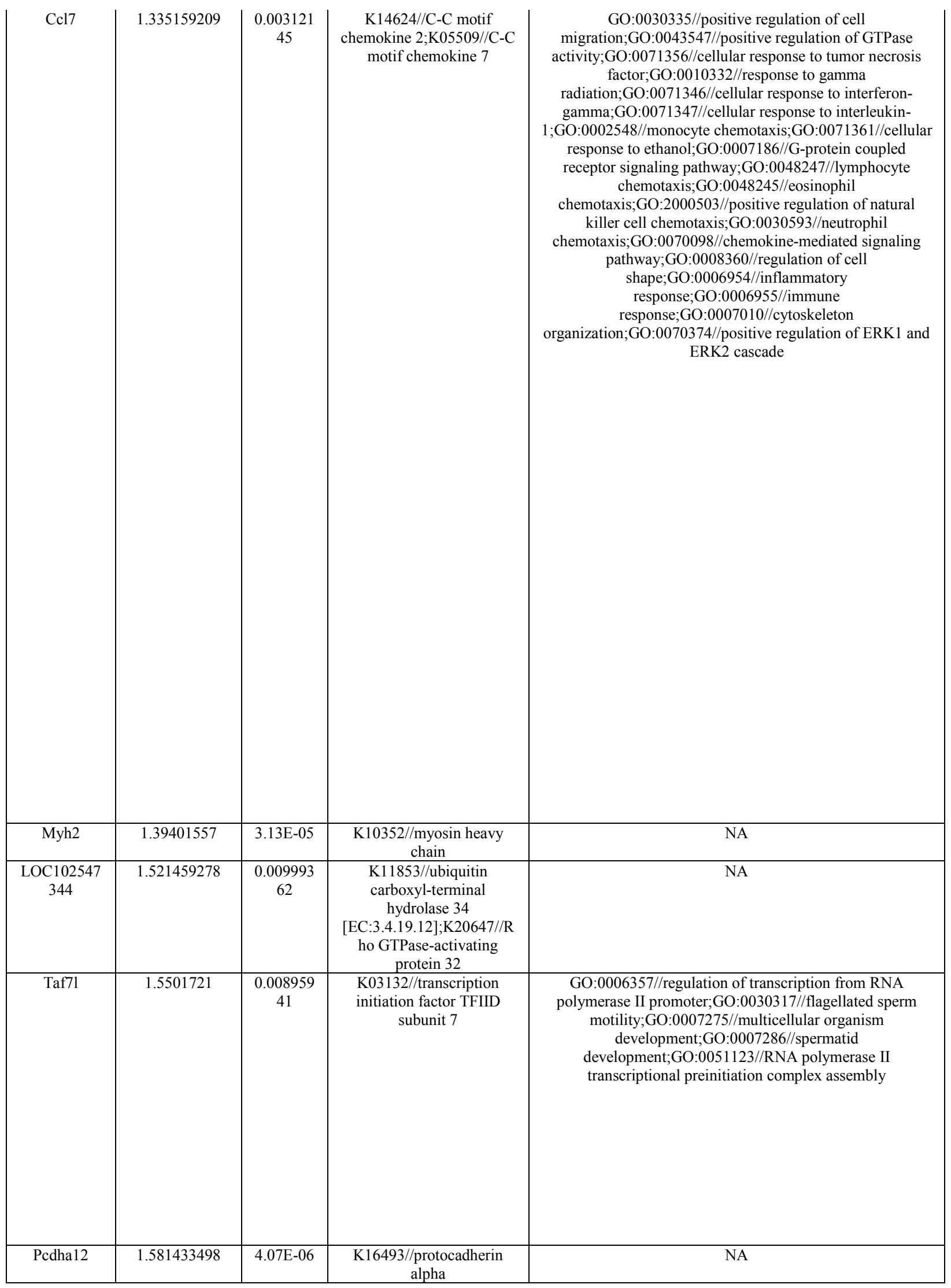




\begin{tabular}{|c|c|c|c|c|}
\hline Comp & 1.698563939 & 0.00652 & $\begin{array}{c}\text { K04659//thrombospondin } \\
2 / 3 / 4 / 5\end{array}$ & $\begin{array}{c}\text { GO:0007155//cell adhesion;GO:0060173//limb } \\
\text { development;GO:0030198//extracellular matrix } \\
\text { organization;GO:0003417//growth plate cartilage } \\
\text { development;GO:0043066//negative regulation of apoptotic } \\
\text { process;GO:0006915//apoptotic process }\end{array}$ \\
\hline Angpt14 & 1.727398205 & $\begin{array}{l}9.43 \mathrm{E}- \\
125\end{array}$ & $\begin{array}{c}\text { K08767//angiopoietin-like } \\
4\end{array}$ & $\begin{array}{l}\text { GO:0051005//negative regulation of lipoprotein lipase } \\
\text { activity;GO:0030154//cell } \\
\text { differentiation;GO:0009267//cellular response to } \\
\text { starvation;GO:0001525//angiogenesis;GO:0051260//protein } \\
\text { homooligomerization;GO:0043066//negative regulation of } \\
\text { apoptotic process;GO:2000352//negative regulation of } \\
\text { endothelial cell apoptotic process;GO:0001666//response to } \\
\text { hypoxia;GO:0070328//triglyceride } \\
\text { homeostasis;GO:0019216//regulation of lipid metabolic } \\
\text { process;GO:0043086//negative regulation of catalytic } \\
\text { activity;GO:0045834//positive regulation of lipid metabolic } \\
\text { process;GO:0051259//protein oligomerization }\end{array}$ \\
\hline Atp4a & 1.801133673 & $\begin{array}{c}0.007349 \\
61\end{array}$ & $\begin{array}{c}\mathrm{K} 01542 / / \mathrm{H}+/ \mathrm{K}+- \\
\text { exchanging ATPase alpha } \\
\text { polypeptide [EC:3.6.3.10] }\end{array}$ & NA \\
\hline Tex101 & 1.842953849 & $\begin{array}{c}0.002474 \\
4\end{array}$ & K06552//CD177 antigen & $\begin{array}{c}\text { GO:0050731//positive regulation of peptidyl-tyrosine } \\
\text { phosphorylation;GO:0002696//positive regulation of } \\
\text { leukocyte activation;GO:1901317///regulation of flagellated } \\
\text { sperm } \\
\text { motility;GO:0009566//fertilization;GO:0051281//positive } \\
\text { regulation of release of sequestered calcium ion into } \\
\text { cytosol;GO:0097722//sperm motility;GO:0007339//binding } \\
\text { of sperm to zona pellucida }\end{array}$ \\
\hline Vom2r19 & 1.864230508 & $\begin{array}{c}0.005031 \\
96\end{array}$ & $\begin{array}{l}\text { K04612//calcium-sensing } \\
\text { receptor;K04613//vomeron } \\
\text { asal } 2 \text { receptor }\end{array}$ & NA \\
\hline Tmprss3 & 2.014679831 & $\begin{array}{c}0.001492 \\
75\end{array}$ & $\begin{array}{c}\text { K09634//transmembrane } \\
\text { protease serine } 3 \\
\text { [EC:3.4.21.-] }\end{array}$ & NA \\
\hline
\end{tabular}




\begin{tabular}{|c|c|c|c|c|}
\hline Klhl41 & 2.094492616 & $\begin{array}{c}0.000327 \\
19\end{array}$ & $\begin{array}{c}\text { K10473//kelch repeat and } \\
\text { BTB domain-containing } \\
\text { protein } 5 / 10\end{array}$ & $\begin{array}{c}\text { GO:0045214//sarcomere organization;GO:0016567//protein } \\
\text { ubiquitination;GO:0045661//regulation of myoblast } \\
\text { differentiation;GO:0048741//skeletal muscle fiber } \\
\text { development;GO:0030239//myofibril } \\
\text { assembly;GO:0035914//skeletal muscle cell } \\
\text { differentiation;GO:0031275//regulation of lateral } \\
\text { pseudopodium assembly;GO:2000291//regulation of } \\
\text { myoblast proliferation;GO:2001014//regulation of skeletal } \\
\text { muscle cell differentiation }\end{array}$ \\
\hline Hmgcs2 & 2.207604239 & $1.58 \mathrm{E}-43$ & $\begin{array}{c}\text { K01641//hydroxymethylglu } \\
\text { taryl-CoA synthase } \\
\text { [EC:2.3.3.10] }\end{array}$ & $\begin{array}{c}\text { GO:0008299//isoprenoid biosynthetic } \\
\text { process;GO:0016126//sterol biosynthetic process }\end{array}$ \\
\hline Hist1h2ba & 2.280221295 & $\begin{array}{c}0.004352 \\
17\end{array}$ & K11252//histone H2B & $\begin{array}{c}\text { GO:0071674//mononuclear cell } \\
\text { migration;GO:0035093//spermatogenesis, exchange of } \\
\text { chromosomal proteins;GO:0006325//chromatin } \\
\text { organization;GO:0006334//nucleosome } \\
\text { assembly;GO:0051099//positive regulation of } \\
\text { binding;GO:0031639//plasminogen } \\
\text { activation;GO:0006337//nucleosome } \\
\text { disassembly;GO:0006954//inflammatory response }\end{array}$ \\
\hline Dazl & 2.782832856 & $6.28 \mathrm{E}-09$ & $\begin{array}{l}\text { K12741//heterogeneous } \\
\text { nuclear ribonucleoprotein } \\
\text { A1/A3;K13126//polyadeny } \\
\text { late-binding } \\
\text { protein;K13098//RNA- } \\
\text { binding protein } \\
\text { FUS;K14411//RNA- } \\
\text { binding protein Musashi }\end{array}$ & $\begin{array}{c}\text { GO:0007147//female meiosis II;GO:0070935//3'-UTR- } \\
\text { mediated mRNA stabilization;GO:0045836//positive } \\
\text { regulation of meiotic nuclear division;GO:0001556//oocyte } \\
\text { maturation;GO:0007283//spermatogenesis;GO:0045948//pos } \\
\text { itive regulation of translational initiation;GO:0007281//germ } \\
\text { cell development;GO:0007275//multicellular organism } \\
\text { development }\end{array}$ \\
\hline Hfm1 & 3.205523928 & $\begin{array}{c}0.006501 \\
31\end{array}$ & $\begin{array}{l}\text { K15271//ATP-dependent } \\
\text { DNA helicase } \\
\text { HFM1/MER3 } \\
\text { [EC:3.6.4.12] }\end{array}$ & $\begin{array}{c}\text { GO:0000712//resolution of meiotic recombination } \\
\text { intermediates;GO:0048477//oogenesis;GO:0010501//RNA } \\
\text { secondary structure } \\
\text { unwinding;GO:0007283//spermatogenesis }\end{array}$ \\
\hline
\end{tabular}




\begin{tabular}{|c|c|c|c|c|}
\hline Epsti1 & 3.842953849 & $\begin{array}{c}0.009984 \\
21\end{array}$ & K18626//trichohyalin & NA \\
\hline Gjb5 & 3.842953849 & $\begin{array}{c}0.009984 \\
21\end{array}$ & $\begin{array}{l}\text { K07624//gap junction } \\
\text { protein, beta } 5\end{array}$ & $\begin{array}{c}\text { GO:1905867//null;GO:0060713//labyrinthine layer } \\
\text { morphogenesis;GO:0007154//cell } \\
\text { communication;GO:0060708//spongiotrophoblast } \\
\text { differentiation;GO:0060707//trophoblast giant cell } \\
\text { differentiation }\end{array}$ \\
\hline Sh3rf2 & 4.205523928 & $\begin{array}{c}0.002679 \\
71\end{array}$ & $\begin{array}{l}\text { K12171//E3 ubiquitin- } \\
\text { protein ligase SH3RF } \\
\text { [EC:2.3.2.27] }\end{array}$ & $\begin{array}{c}\text { GO:0016567//protein ubiquitination;GO:0010923//negative } \\
\text { regulation of phosphatase activity }\end{array}$ \\
\hline LOC681419 & 4.651486001 & $\begin{array}{c}0.000333 \\
95\end{array}$ & NA & NA \\
\hline
\end{tabular}


Supplementary Table S2. DEGs in sertoli cells caused by PFOS treatment.

\begin{tabular}{|c|c|c|c|c|}
\hline Symbol & $\begin{array}{c}\log 2 \\
\text { Ratio(PFOS/ } \\
\text { Ctrl) }\end{array}$ & p-value & Kegg Orthology & Biological Process \\
\hline Il10ra & -5.39 & $1.99 \mathrm{E}-06$ & $\begin{array}{l}\text { K05134//interleuk } \\
\text { in } 10 \text { receptor } \\
\text { alpha }\end{array}$ & $\begin{array}{c}\text { GO:0032496//response to lipopolysaccharide;GO:0050807//regulation of } \\
\text { synapse organization }\end{array}$ \\
\hline Olr59 & -4.19 & $1.76 \mathrm{E}-13$ & $\begin{array}{l}\text { K04257//olfactory } \\
\text { receptor }\end{array}$ & $\begin{array}{l}\text { GO:0045777//positive regulation of blood pressure;GO:1900135//positive } \\
\text { regulation of renin secretion into blood stream;GO:0071398//cellular } \\
\text { response to fatty acid }\end{array}$ \\
\hline Сyp2b2 & -4.13 & 0.0034485 & $\begin{array}{c}\text { K07412//cytochro } \\
\text { me P450 family } 2 \\
\text { subfamily B } \\
{[\text { EC:1.14.14.1] }}\end{array}$ & $\begin{array}{c}\text { GO:0014070//response to organic cyclic } \\
\text { compound;GO:0051592//response to calcium ion;GO:0018933//nicotine } \\
\text { metabolic process;GO:0010038//response to metal ion;GO:0017144//drug } \\
\text { metabolic process;GO:0019373//epoxygenase P450 } \\
\text { pathway;GO:0007568//aging }\end{array}$ \\
\hline Pmch & -4.05 & 0.0045225 & $\begin{array}{l}\text { K05229//pro- } \\
\text { melanin- } \\
\text { concentrating } \\
\text { hormone }\end{array}$ & $\begin{array}{l}\text { GO:0007595//lactation;GO:0009409//response to } \\
\text { cold;GO:0002027//regulation of heart rate;GO:0032227//negative } \\
\text { regulation of synaptic transmission, dopaminergic;GO:0042593//glucose } \\
\text { homeostasis;GO:0045776//negative regulation of blood } \\
\text { pressure;GO:0042756//drinking behavior;GO:0048168//regulation of } \\
\text { neuronal synaptic plasticity;GO:0046005//positive regulation of circadian } \\
\text { sleep/wake cycle, REM sleep;GO:0007631//feeding } \\
\text { behavior;GO:0007204//positive regulation of cytosolic calcium ion } \\
\text { concentration;GO:0007268//chemical synaptic } \\
\text { transmission;GO:0007218//neuropeptide signaling } \\
\text { pathway;GO:0007611//learning or memory }\end{array}$ \\
\hline Cyp2c11 & -3.90 & 0.0001664 & $\begin{array}{l}\text { K17720//cytochro } \\
\text { me P450 family } 2 \\
\text { subfamily C }\end{array}$ & NA \\
\hline
\end{tabular}




\begin{tabular}{|c|c|c|c|c|}
\hline & & & $\begin{array}{l}\text { polypeptide } 18 \\
\text { [EC:1.14.14.1] }\end{array}$ & \\
\hline Gpr39 & -3.86 & 0.0089599 & $\begin{array}{c}\mathrm{K} 08412 / / \mathrm{G} \\
\text { protein-coupled } \\
\text { receptor } 39\end{array}$ & $\begin{array}{l}\text { GO:0032024//positive regulation of insulin secretion;GO:0002024//diet } \\
\text { induced thermogenesis;GO:0000187//activation of MAPK } \\
\text { activity;GO:0060455//negative regulation of gastric acid } \\
\text { secretion;GO:0071294//cellular response to zinc } \\
\text { ion;GO:0035774//positive regulation of insulin secretion involved in } \\
\text { cellular response to glucose stimulus;GO:0051281//positive regulation of } \\
\text { release of sequestered calcium ion into cytosol;GO:0042593//glucose } \\
\text { homeostasis;GO:0030641//regulation of cellular pH;GO:0035483//gastric } \\
\text { emptying;GO:0008343//adult feeding behavior;GO:0019216//regulation } \\
\text { of lipid metabolic process;GO:0042632//cholesterol } \\
\text { homeostasis;GO:0042391//regulation of membrane potential }\end{array}$ \\
\hline Myo16 & -3.80 & $3.39 \mathrm{E}-07$ & $\begin{array}{c}\text { K17481//myosin } \\
\text { XVI }\end{array}$ & $\begin{array}{l}\text { GO:0021549//cerebellum development;GO:0048812//neuron projection } \\
\text { morphogenesis;GO:0014065//phosphatidylinositol 3-kinase } \\
\text { signaling;GO:2000134//negative regulation of G1/S transition of mitotic } \\
\text { cell cycle;GO:0008285//negative regulation of cell proliferation }\end{array}$ \\
\hline Sntg1 & -3.58 & 0.0010792 & $\begin{array}{l}\text { K20251//glutamat } \\
\text { e receptor- } \\
\text { interacting } \\
\text { protein;K12196//v } \\
\text { acuolar protein- } \\
\text { sorting-associated } \\
\text { protein } 4\end{array}$ & NA \\
\hline $\begin{array}{c}\text { LOC685 } \\
391\end{array}$ & -3.53 & 0.0015077 & $\begin{array}{l}\text { K10997//null;K04 } \\
453 / / \mathrm{Max} \\
\text { protein;K08035//f } \\
\text { orkhead box } \\
\text { protein A2, } \\
\text { hepatocyte } \\
\text { nuclear factor 3- } \\
\text { beta;K18492//insu } \\
\text { lin gene enhancer } \\
\text { protein ISL-2 }\end{array}$ & NA \\
\hline
\end{tabular}




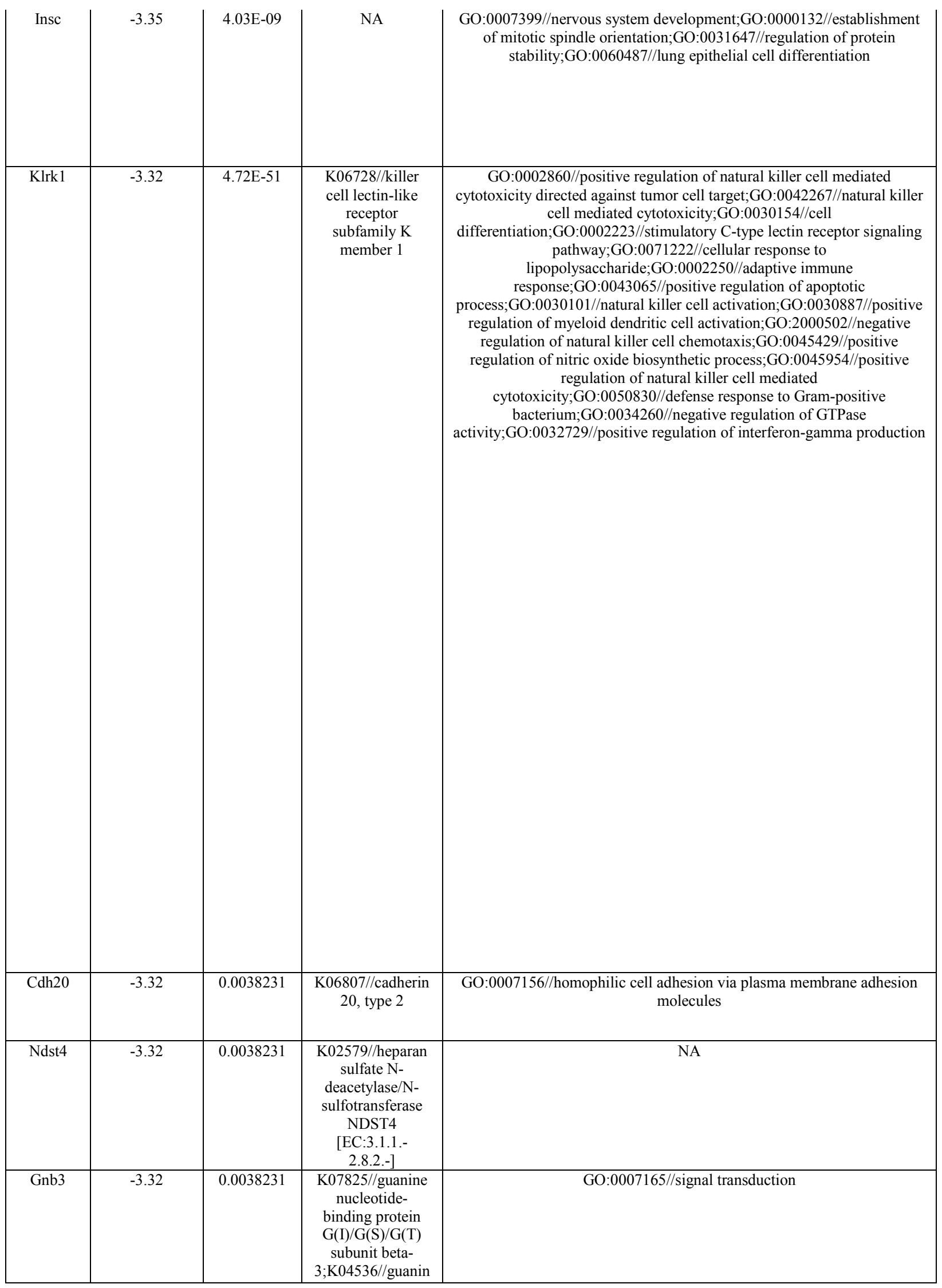




\begin{tabular}{|c|c|c|c|c|}
\hline & & & $\begin{array}{c}\text { e nucleotide- } \\
\text { binding protein } \\
G(\mathrm{I}) / \mathrm{G}(\mathrm{S}) / \mathrm{G}(\mathrm{T}) \\
\text { subunit beta-1 }\end{array}$ & \\
\hline Pcdhac1 & -3.22 & $1.90 \mathrm{E}-05$ & $\begin{array}{c}\text { K16493//protocad } \\
\text { herin alpha }\end{array}$ & $\begin{array}{c}\text { GO:0007399//nervous system development;GO:0007155//cell } \\
\text { adhesion;GO:0007156//homophilic cell adhesion via plasma membrane } \\
\text { adhesion molecules;GO:0007267//cell-cell signaling }\end{array}$ \\
\hline Dnali1 & -3.17 & 0.0070054 & $\begin{array}{l}\text { K10410//dynein } \\
\text { light intermediate } \\
\text { chain, axonemal }\end{array}$ & GO:0003341//cilium movement \\
\hline D114 & -3.17 & 0.0071845 & K06051//delta & $\begin{array}{c}\text { GO:0003222//ventricular trabecula myocardium } \\
\text { morphogenesis;GO:0090051//negative regulation of cell migration } \\
\text { involved in sprouting angiogenesis;GO:0003209//cardiac atrium } \\
\text { morphogenesis;GO:0072554//blood vessel } \\
\text { lumenization;GO:0045747//positive regulation of Notch signaling } \\
\text { pathway;GO:0003344//pericardium morphogenesis;GO:0035924//cellular } \\
\text { response to vascular endothelial growth factor } \\
\text { stimulus;GO:0007601//visual perception;GO:0010629//negative } \\
\text { regulation of gene expression;GO:0000122//negative regulation of } \\
\text { transcription from RNA polymerase II promoter;GO:0061074//regulation } \\
\text { of neural retina development;GO:0060579//ventral spinal cord } \\
\text { interneuron fate commitment;GO:0061314//Notch signaling involved in } \\
\text { heart development;GO:0008285//negative regulation of cell } \\
\text { proliferation;GO:1903588//negative regulation of blood vessel } \\
\text { endothelial cell proliferation involved in sprouting } \\
\text { angiogenesis;GO:0001525//angiogenesis;GO:0035912//dorsal aorta } \\
\text { morphogenesis;GO:0010596//negative regulation of endothelial cell } \\
\text { migration;GO:0010628//positive regulation of gene } \\
\text { expression;GO:0003208//cardiac ventricle } \\
\text { morphogenesis;GO:0044344//cellular response to fibroblast growth factor } \\
\text { stimulus;GO:2000179//positive regulation of neural precursor cell } \\
\text { proliferation;GO:0001974//blood vessel } \\
\text { remodeling;GO:0045746//negative regulation of Notch signaling } \\
\text { pathway;GO:0030217//T cell differentiation;GO:0007219//Notch } \\
\text { signaling pathway;GO:0043537//negative regulation of blood vessel } \\
\text { endothelial cell migration;GO:0001569//branching involved in blood } \\
\text { vessel morphogenesis;GO:0050767//regulation of neurogenesis }\end{array}$ \\
\hline
\end{tabular}




\begin{tabular}{|c|c|c|c|c|}
\hline Agxt2 & -3.17 & 0.0071845 & $\begin{array}{l}\text { K00827//alanine- } \\
\text { glyoxylate } \\
\text { transaminase / } \\
\text { (R)-3-amino-2- } \\
\text { methylpropionate- } \\
\text { pyruvate } \\
\text { transaminase } \\
\text { [EC:2.6.1.44 } \\
2.6 .1 .40]\end{array}$ & $\begin{array}{c}\text { GO:0019265//glycine biosynthetic process, by transamination of } \\
\text { glyoxylate;GO:0045429//positive regulation of nitric oxide biosynthetic } \\
\text { process;GO:0009436//glyoxylate catabolic process;GO:0019481//L- } \\
\text { alanine catabolic process, by transamination }\end{array}$ \\
\hline Lgr5 & -3.17 & 0.0071845 & $\begin{array}{l}\text { K04308//leucine- } \\
\text { rich repeat- } \\
\text { containing G } \\
\text { protein-coupled } \\
\text { receptor } 5\end{array}$ & $\begin{array}{c}\text { GO:0007186//G-protein coupled receptor signaling } \\
\text { pathway;GO:2001013//epithelial cell proliferation involved in renal } \\
\text { tubule morphogenesis;GO:0009994//oocyte } \\
\text { differentiation;GO:0042127//regulation of cell } \\
\text { proliferation;GO:0048839//inner ear development;GO:0001942//hair } \\
\text { follicle development;GO:0090263//positive regulation of canonical Wnt } \\
\text { signaling pathway }\end{array}$ \\
\hline Sez612 & -3.17 & 0.0071845 & $\begin{array}{l}\text { K17495//CUB } \\
\text { and sushi domain- } \\
\text { containing } \\
\text { protein;K10362// } \\
\text { myosin XVIII }\end{array}$ & $\begin{array}{c}\text { GO:0021680//cerebellar Purkinje cell layer } \\
\text { development;GO:0090036//regulation of protein kinase C } \\
\text { signaling;GO:0008344//adult locomotory behavior;GO:0060074//synapse } \\
\text { maturation }\end{array}$ \\
\hline $\begin{array}{l}\text { RGD156 } \\
5283\end{array}$ & -3.17 & 0.0071845 & $\begin{array}{l}\text { K16513//carboxyl } \\
\text {-terminal PDZ } \\
\text { ligand of neuronal } \\
\text { nitric oxide } \\
\text { synthase protein }\end{array}$ & $\begin{array}{l}\text { GO:0030154//cell differentiation;GO:0007342//fusion of sperm to egg } \\
\text { plasma membrane;GO:0007283//spermatogenesis }\end{array}$ \\
\hline Lipi & -3.17 & 0.0071845 & $\begin{array}{l}\text { K19404//phosphat } \\
\text { idic acid- } \\
\text { selective\&\#160;p } \\
\text { hospholipase A1 } \\
\text { [EC:3.1.1.-] }\end{array}$ & GO:0016042//lipid catabolic process \\
\hline Slc6a7 & -3.17 & 0.0071845 & $\begin{array}{c}\text { K05038//solute } \\
\text { carrier family } 6 \\
\text { (neurotransmitter } \\
\text { transporter, amino } \\
\text { acid) member } \\
\text { 5/7/9/14 }\end{array}$ & $\begin{array}{c}\text { GO:0035524//proline transmembrane transport;GO:0015824//proline } \\
\text { transport }\end{array}$ \\
\hline Usp18 & -3.03 & 0 & $\begin{array}{l}\text { K11846//ubiquitin } \\
\text { carboxyl-terminal } \\
\text { hydrolase } 18 / 41 \\
\text { [EC:3.4.19.12] }\end{array}$ & $\begin{array}{c}\text { GO:0050727//regulation of inflammatory } \\
\text { response;GO:0006511//ubiquitin-dependent protein catabolic } \\
\text { process;GO:0035634//response to stilbenoid;GO:0016579//protein } \\
\text { deubiquitination }\end{array}$ \\
\hline
\end{tabular}




\begin{tabular}{|c|c|c|c|c|}
\hline Hoxb8 & -3.00 & 0.0004772 & $\begin{array}{l}\text { K09308//homeobo } \\
\text { x protein } \\
\text { HoxB/C/D8 }\end{array}$ & $\begin{array}{c}\text { GO:0009952//anterior/posterior pattern specification;GO:0021516//dorsal } \\
\text { spinal cord development;GO:0008344//adult locomotory } \\
\text { behavior;GO:0006351//transcription, DNA- } \\
\text { templated;GO:0045638//negative regulation of myeloid cell } \\
\text { differentiation;GO:0000122//negative regulation of transcription from } \\
\text { RNA polymerase II promoter;GO:0007275//multicellular organism } \\
\text { development;GO:0048704//embryonic skeletal system } \\
\text { morphogenesis;GO:0019233//sensory perception of } \\
\text { pain;GO:0007625//grooming behavior;GO:0048705//skeletal system } \\
\text { morphogenesis }\end{array}$ \\
\hline C1qtnf7 & -2.90 & 0.0008668 & $\begin{array}{l}\text { K06237//collagen, } \\
\text { type IV, alpha }\end{array}$ & NA \\
\hline Tmprss2 & -2.89 & $4.83 \mathrm{E}-261$ & $\begin{array}{c}\text { K09633//transme } \\
\text { mbrane protease } \\
\text { serine } 2 \\
\text { [EC:3.4.21.-] }\end{array}$ & $\begin{array}{c}\text { GO:0016540//protein } \\
\text { autoprocessing;GO:0006508//proteolysis;GO:0046598//positive } \\
\text { regulation of viral entry into host cell }\end{array}$ \\
\hline Bin2a & -2.80 & 0.0015704 & $\begin{array}{l}\text { K12309//beta- } \\
\text { galactosidase } \\
\text { [EC:3.2.1.23] }\end{array}$ & GO:0005975//carbohydrate metabolic process \\
\hline $\begin{array}{l}\text { Arhgap1 } \\
5\end{array}$ & -2.80 & 0.0015704 & $\begin{array}{l}\text { K20637//Rho } \\
\text { GTPase-activating } \\
\text { protein } 15\end{array}$ & GO:0007165//signal transduction;GO:0008360//regulation of cell shape \\
\hline Mx2 & -2.77 & 0 & $\begin{array}{l}\text { K14754//interfero } \\
\text { n-induced GTP- } \\
\text { binding protein } \\
\text { Mx1 }\end{array}$ & $\begin{array}{l}\text { GO:0051607//defense response to virus;GO:0003374//dynamin family } \\
\text { protein polymerization involved in mitochondrial } \\
\text { fission;GO:0061025//membrane fusion;GO:0034340//response to type I } \\
\text { interferon;GO:0045071//negative regulation of viral genome } \\
\text { replication;GO:0045087//innate immune response;GO:0009615//response } \\
\text { to virus;GO:0000266//mitochondrial fission }\end{array}$ \\
\hline Lgals5 & -2.76 & $9.69 \mathrm{E}-150$ & $\begin{array}{l}\text { K17522//galectin- } \\
5 ; \mathrm{K} 10093 / / \text { galecti } \\
\text { n-9 }\end{array}$ & $\begin{array}{l}\text { GO:0071346//cellular response to interferon- } \\
\text { gamma;GO:0007565//female pregnancy;GO:0098586//cellular response } \\
\text { to virus;GO:0070371//ERK1 and ERK2 cascade }\end{array}$ \\
\hline
\end{tabular}




\begin{tabular}{|c|c|c|c|c|}
\hline $\mathrm{I} 134$ & -2.73 & 0.0001923 & NA & $\begin{array}{l}\text { GO:0001934//positive regulation of protein } \\
\text { phosphorylation;GO:0045657//positive regulation of monocyte } \\
\text { differentiation;GO:0045651//positive regulation of macrophage } \\
\text { differentiation;GO:0045087//innate immune } \\
\text { response;GO:0008284//positive regulation of cell } \\
\text { proliferation;GO:0006954//inflammatory response }\end{array}$ \\
\hline Mx1 & -2.71 & 0 & $\begin{array}{c}\text { K14754//interfero } \\
\text { n-induced GTP- } \\
\text { binding protein } \\
\text { Mx1 }\end{array}$ & $\begin{array}{l}\text { GO:0003374//dynamin family protein polymerization involved in } \\
\text { mitochondrial fission;GO:0061025//membrane } \\
\text { fusion;GO:0051607//defense response to virus;GO:0009615//response to } \\
\text { virus;GO:0045087//innate immune response;GO:0000266//mitochondrial } \\
\text { fission }\end{array}$ \\
\hline Npas4 & -2.70 & 0.0028358 & $\begin{array}{l}\text { K14795//ribosoma } \\
1 \text { RNA-processing } \\
\text { protein } \\
36 ; \text { K09100//single } \\
\text {-minded }\end{array}$ & $\begin{array}{c}\text { GO:0071386//cellular response to corticosterone } \\
\text { stimulus;GO:0035176//social behavior;GO:0030154//cell } \\
\text { differentiation;GO:1904862//inhibitory synapse } \\
\text { assembly;GO:0060080//inhibitory postsynaptic } \\
\text { potential;GO:0007612//learning;GO:0045893//positive regulation of } \\
\text { transcription, DNA-templated;GO:0007616//long-term } \\
\text { memory;GO:0045944//positive regulation of transcription from RNA } \\
\text { polymerase II promoter;GO:0007614//short-term } \\
\text { memory;GO:0032228//regulation of synaptic transmission, } \\
\text { GABAergic;GO:0060079//excitatory postsynaptic } \\
\text { potential;GO:0048167//regulation of synaptic plasticity }\end{array}$ \\
\hline Tmem40 & -2.69 & 0.0001118 & $\begin{array}{c}\text { K11422//histone- } \\
\text { lysine } N- \\
\text { methyltransferase } \\
\text { SETD1 } \\
\text { [EC:2.1.1.43] }\end{array}$ & NA \\
\hline G0s2 & -2.63 & $5.46 \mathrm{E}-06$ & NA & $\begin{array}{c}\text { GO:0097191//extrinsic apoptotic signaling } \\
\text { pathway;GO:2001238//positive regulation of extrinsic apoptotic signaling } \\
\text { pathway;GO:0007049//cell cycle }\end{array}$ \\
\hline
\end{tabular}




\begin{tabular}{|c|c|c|c|c|}
\hline Oas1d & -2.59 & 0.0005768 & $\begin{array}{l}\text { K14216//2'-5'- } \\
\text { oligoadenylate } \\
\text { synthetase } \\
{[\text { EC:2.7.7.84] }}\end{array}$ & GO:0006955//immune response;GO:0051607//defense response to virus \\
\hline Sstr4 & -2.58 & 0.005101 & $\begin{array}{l}\text { K04220//somatost } \\
\text { atin receptor } 4\end{array}$ & $\begin{array}{c}\text { GO:0016477//cell migration;GO:0019369//arachidonic acid metabolic } \\
\text { process;GO:0030815//negative regulation of cAMP metabolic } \\
\text { process;GO:0071385//cellular response to glucocorticoid } \\
\text { stimulus;GO:0030900//forebrain development;GO:0007268//chemical } \\
\text { synaptic transmission;GO:0043410//positive regulation of MAPK } \\
\text { cascade;GO:0007187//G-protein coupled receptor signaling pathway, } \\
\text { coupled to cyclic nucleotide second messenger;GO:0008285//negative } \\
\text { regulation of cell proliferation }\end{array}$ \\
\hline Dkk2 & -2.58 & 0.005101 & K02165//dickkopf & $\begin{array}{c}\text { GO:0090090//negative regulation of canonical Wnt signaling } \\
\text { pathway;GO:0030178//negative regulation of Wnt signaling } \\
\text { pathway;GO:0007275//multicellular organism } \\
\text { development;GO:0016055//Wnt signaling } \\
\text { pathway;GO:0090263//positive regulation of canonical Wnt signaling } \\
\text { pathway }\end{array}$ \\
\hline Nlgn1 & -2.55 & $2.78 \mathrm{E}-07$ & $\begin{array}{c}\text { K07378//neuroligi } \\
n\end{array}$ & $\begin{array}{l}\text { GO:0071277//cellular response to calcium ion;GO:0048789//cytoskeletal } \\
\text { matrix organization at active zone;GO:0016339//calcium-dependent cell- } \\
\text { cell adhesion via plasma membrane cell adhesion } \\
\text { molecules;GO:0097113//AMPA glutamate receptor clustering }\end{array}$ \\
\hline
\end{tabular}




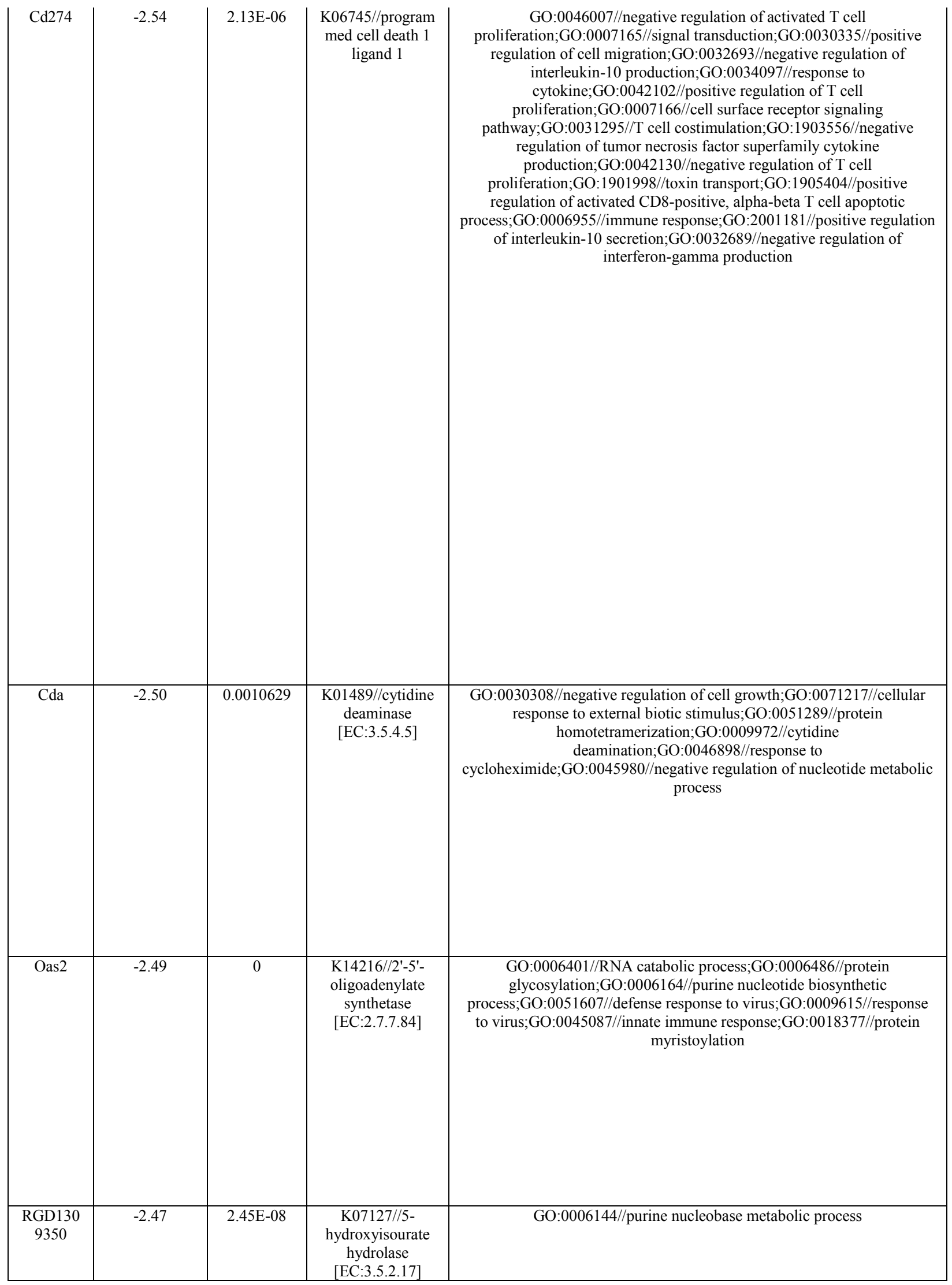




\begin{tabular}{|c|c|c|c|c|}
\hline Hsh2d & -2.43 & 4.22E-82 & $\begin{array}{c}\mathrm{K} 08273 / / \mathrm{SH} 2 \\
\text { domain protein } \\
\text { 2A;K06069//atypi } \\
\text { cal protein kinase } \\
\text { C iota type } \\
\text { [EC:2.7.11.13] }\end{array}$ & $\begin{array}{c}\text { GO:0042110//T cell activation;GO:0007165//signal } \\
\text { transduction;GO:0051902//negative regulation of mitochondrial } \\
\text { depolarization;GO:0002903//negative regulation of B cell apoptotic } \\
\text { process }\end{array}$ \\
\hline Isg15 & -2.42 & 0 & $\begin{array}{l}\text { K12159//ubiquitin } \\
\text { cross-reactive } \\
\text { protein }\end{array}$ & $\begin{array}{c}\text { GO:0032649//regulation of interferon-gamma } \\
\text { production;GO:0031397//negative regulation of protein } \\
\text { ubiquitination;GO:0051607//defense response to } \\
\text { virus;GO:0019941//modification-dependent protein catabolic } \\
\text { process;GO:0042742//defense response to } \\
\text { bacterium;GO:0034340//response to type I } \\
\text { interferon;GO:0030501//positive regulation of bone } \\
\text { mineralization;GO:0032020//ISG15-protein } \\
\text { conjugation;GO:0045071//negative regulation of viral genome } \\
\text { replication;GO:0045648//positive regulation of erythrocyte differentiation }\end{array}$ \\
\hline Phf11b & -2.39 & $4.38 \mathrm{E}-116$ & $\begin{array}{c}\text { K18494//histone- } \\
\text { lysine } \mathrm{N}- \\
\text { methyltransferase } \\
\text { SETDB2 } \\
\text { [EC:2.1.1.43] } \\
\end{array}$ & GO:0050776//regulation of immune response \\
\hline
\end{tabular}




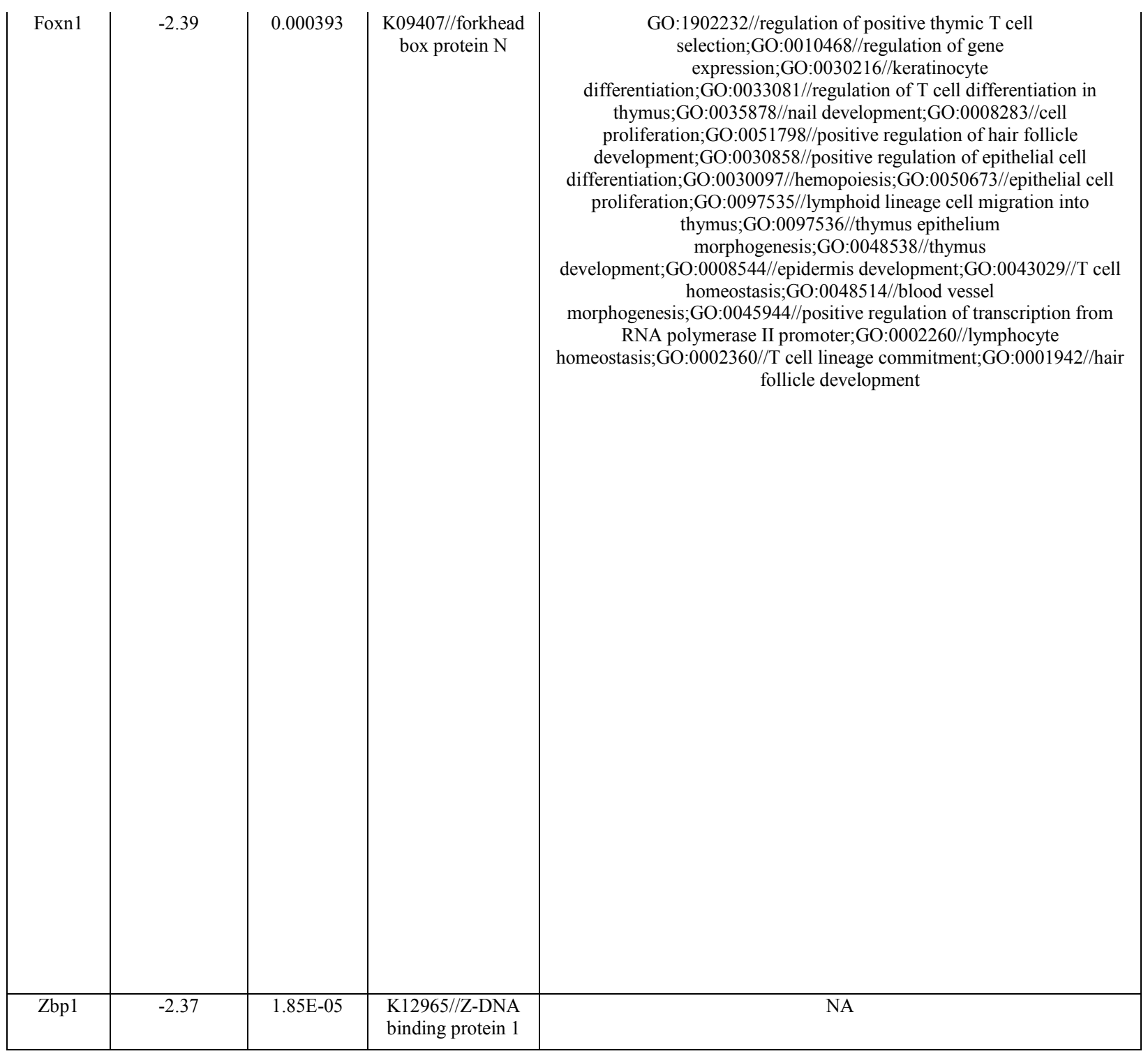




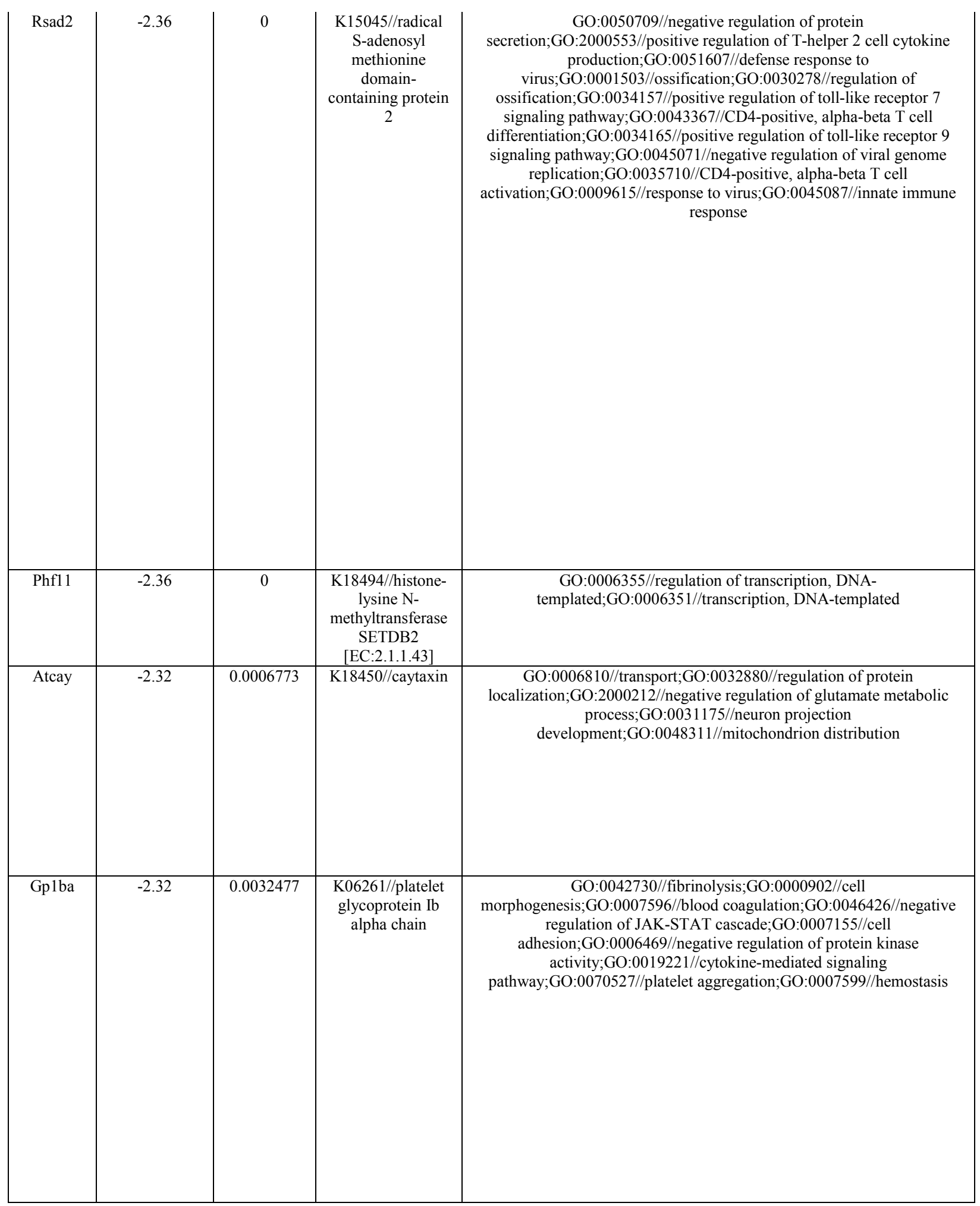




\begin{tabular}{|c|c|c|c|c|}
\hline Ifit3 & -2.30 & 0 & $\begin{array}{l}\text { K14217//interfero } \\
\text { n-induced protein } \\
\quad \text { with } \\
\text { tetratricopeptide } \\
\text { repeats 1 }\end{array}$ & $\begin{array}{l}\text { GO:0035634//response to stilbenoid;GO:0051607//defense response to } \\
\text { virus;GO:0043066//negative regulation of apoptotic } \\
\text { process;GO:0035458//cellular response to interferon- } \\
\text { beta;GO:0035457//cellular response to interferon- } \\
\text { alpha;GO:0045087//innate immune response;GO:0009615//response to } \\
\text { virus;GO:0008285//negative regulation of cell proliferation }\end{array}$ \\
\hline Cyp4f4 & -2.28 & 0.00092 & $\begin{array}{l}\text { K00490//cytochro } \\
\text { me P450 family } 4 \\
\text { subfamily } \mathrm{F} \\
{[\text { EC:1.14.14.1] }} \\
\end{array}$ & NA \\
\hline Gckr & -2.28 & $1.17 \mathrm{E}-05$ & NA & $\begin{array}{c}\text { GO:0006006//glucose metabolic process;GO:0000060//protein import } \\
\text { into nucleus, translocation;GO:0009750//response to } \\
\text { fructose;GO:0051594//detection of glucose;GO:1901135//carbohydrate } \\
\text { derivative metabolic process;GO:0001678//cellular glucose } \\
\text { homeostasis;GO:0070328//triglyceride homeostasis;GO:0034504//protein } \\
\text { localization to nucleus;GO:0033132//negative regulation of glucokinase } \\
\text { activity;GO:1903300//negative regulation of hexokinase } \\
\text { activity;GO:0046415//urate metabolic process;GO:0033133//positive } \\
\text { regulation of glucokinase activity }\end{array}$ \\
\hline Atp1a3 & -2.26 & 0.0002467 & $\begin{array}{l}\text { K01539//sodium/p } \\
\text { otassium- } \\
\text { transporting } \\
\text { ATPase subunit } \\
\text { alpha [EC:3.6.3.9] }\end{array}$ & NA \\
\hline Myom2 & -2.26 & 0.0002467 & $\begin{array}{l}\text { K12567//titin } \\
{[\text { EC:2.7.11.1] }}\end{array}$ & NA \\
\hline Rhox8 & -2.25 & $9.70 \mathrm{E}-07$ & $\begin{array}{l}\text { K18491//homeobo } \\
\text { x protein ESX1 }\end{array}$ & NA \\
\hline Stpg1 & -2.24 & $4.36 \mathrm{E}-06$ & NA & $\begin{array}{c}\text { GO:0043065//positive regulation of apoptotic } \\
\text { process;GO:0090073//positive regulation of protein homodimerization } \\
\text { activity;GO:1902110//positive regulation of mitochondrial membrane } \\
\text { permeability involved in apoptotic process }\end{array}$ \\
\hline
\end{tabular}




\begin{tabular}{|c|c|c|c|c|}
\hline Oasl2 & -2.22 & 0 & $\begin{array}{l}\text { K14608//2'-5'- } \\
\text { oligoadenylate } \\
\text { synthase-like } \\
\text { protein }\end{array}$ & $\begin{array}{l}\text { GO:0006955//immune response;GO:0006164//purine nucleotide } \\
\text { biosynthetic process;GO:0051607//defense response to } \\
\text { virus;GO:0009615//response to virus;GO:0045087//innate immune } \\
\text { response }\end{array}$ \\
\hline Notch3 & -2.22 & $6.89 \mathrm{E}-37$ & K20995//Notch 3 & $\begin{array}{l}\text { GO:0072104//glomerular capillary formation;GO:0006355//regulation of } \\
\text { transcription, DNA-templated;GO:0006351//transcription, DNA- } \\
\text { templated;GO:0042246//tissue regeneration;GO:0045665//negative } \\
\text { regulation of neuron differentiation;GO:0000122//negative regulation of } \\
\text { transcription from RNA polymerase II promoter;GO:0048844//artery } \\
\text { morphogenesis;GO:0030900//forebrain } \\
\text { development;GO:0048661//positive regulation of smooth muscle cell } \\
\text { proliferation;GO:0045944//positive regulation of transcription from RNA } \\
\text { polymerase II promoter;GO:0045596//negative regulation of cell } \\
\text { differentiation;GO:0048663//neuron fate } \\
\text { commitment;GO:0007219//Notch signaling pathway }\end{array}$ \\
\hline Abhd16b & -2.22 & 0.0056274 & $\begin{array}{l}\text { K08869//aarF } \\
\text { domain- } \\
\text { containing kinase }\end{array}$ & NA \\
\hline Oas1h & -2.22 & $5.24 \mathrm{E}-15$ & $\begin{array}{l}\text { K14216//2'-5'- } \\
\text { oligoadenylate } \\
\text { synthetase } \\
\text { [EC:2.7.7.84] } \\
\end{array}$ & GO:0006955//immune response;GO:0051607//defense response to virus \\
\hline Aoc3 & -2.19 & $2.86 \mathrm{E}-138$ & $\begin{array}{l}\text { K00276//primary- } \\
\text { amine oxidase } \\
\text { [EC:1.4.3.21] }\end{array}$ & $\begin{array}{l}\text { GO:0046677//response to antibiotic;GO:0007155//cell } \\
\text { adhesion;GO:1902283//negative regulation of primary amine oxidase } \\
\text { activity;GO:0009308//amine metabolic process }\end{array}$ \\
\hline Ly86 & -2.19 & $3.31 \mathrm{E}-05$ & NA & $\begin{array}{c}\text { GO:0031666//positive regulation of lipopolysaccharide-mediated } \\
\text { signaling pathway;GO:0045087//innate immune } \\
\text { response;GO:0006954//inflammatory response }\end{array}$ \\
\hline Gbp4 & -2.19 & 0 & $\begin{array}{c}\text { K20899//guanylat } \\
\text { e-binding protein } \\
1 / 3 / 4 / 7 \\
\end{array}$ & NA \\
\hline
\end{tabular}




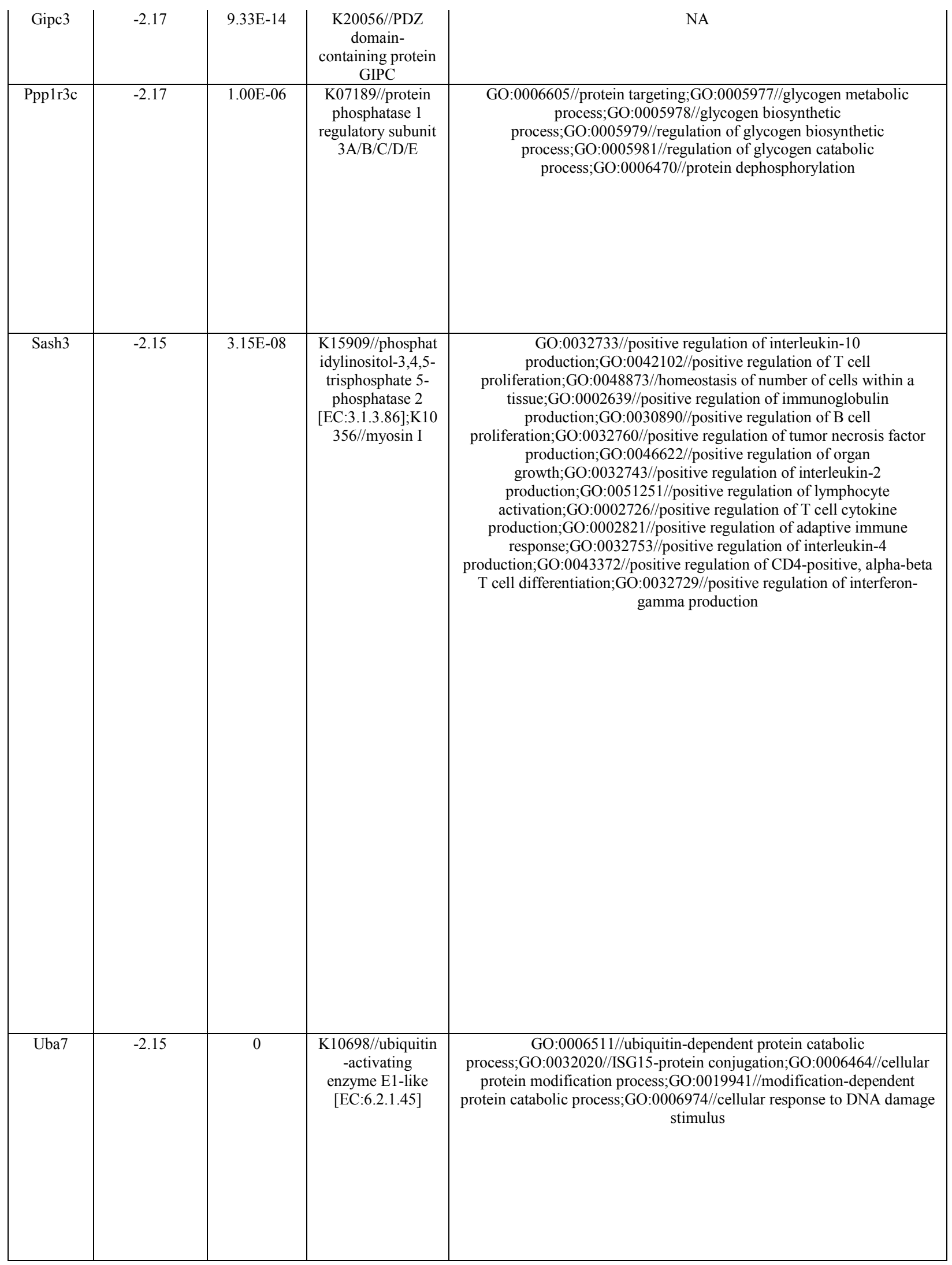




\begin{tabular}{|c|c|c|c|c|}
\hline Rgs4 & -2.14 & $6.86 \mathrm{E}-34$ & $\begin{array}{l}\text { K16449//regulator } \\
\text { of G-protein } \\
\text { signaling }\end{array}$ & $\begin{array}{l}\text { GO:0007186//G-protein coupled receptor signaling } \\
\text { pathway;GO:0008277//regulation of G-protein coupled receptor protein } \\
\text { signaling pathway;GO:0043547//positive regulation of GTPase } \\
\text { activity;GO:0045744//negative regulation of G-protein coupled receptor } \\
\text { protein signaling pathway;GO:0000188//inactivation of MAPK activity }\end{array}$ \\
\hline Ddx58 & -2.13 & 0 & $\begin{array}{c}\text { K12646//ATP- } \\
\text { dependent RNA } \\
\text { helicase DDX58 } \\
\text { [EC:3.6.3.14] }\end{array}$ & $\begin{array}{c}\text { GO:0032755//positive regulation of interleukin-6 } \\
\text { production;GO:0043330//response to exogenous } \\
\text { dsRNA;GO:0060760//positive regulation of response to cytokine } \\
\text { stimulus;GO:0030334//regulation of cell migration;GO:0035549//positive } \\
\text { regulation of interferon-beta secretion;GO:0045087//innate immune } \\
\text { response;GO:2000778//positive regulation of interleukin-6 } \\
\text { secretion;GO:0032728//positive regulation of interferon-beta } \\
\text { production;GO:0009597//detection of virus;GO:0071360//cellular } \\
\text { response to exogenous dsRNA;GO:0051607//defense response to } \\
\text { virus;GO:0032727//positive regulation of interferon-alpha } \\
\text { production;GO:0032757//positive regulation of interleukin-8 } \\
\text { production;GO:0010628//positive regulation of gene } \\
\text { expression;GO:1904469//positive regulation of tumor necrosis factor } \\
\text { secretion;GO:0032725//positive regulation of granulocyte macrophage } \\
\text { colony-stimulating factor production;GO:0039529//RIG-I signaling } \\
\text { pathway;GO:0045944//positive regulation of transcription from RNA } \\
\text { polymerase II promoter;GO:1902741//positive regulation of interferon- } \\
\text { alpha secretion;GO:0032480//negative regulation of type I interferon } \\
\text { production;GO:0009615//response to virus;GO:0002230//positive } \\
\text { regulation of defense response to virus by host;GO:0042993//positive } \\
\text { regulation of transcription factor import into nucleus }\end{array}$ \\
\hline
\end{tabular}




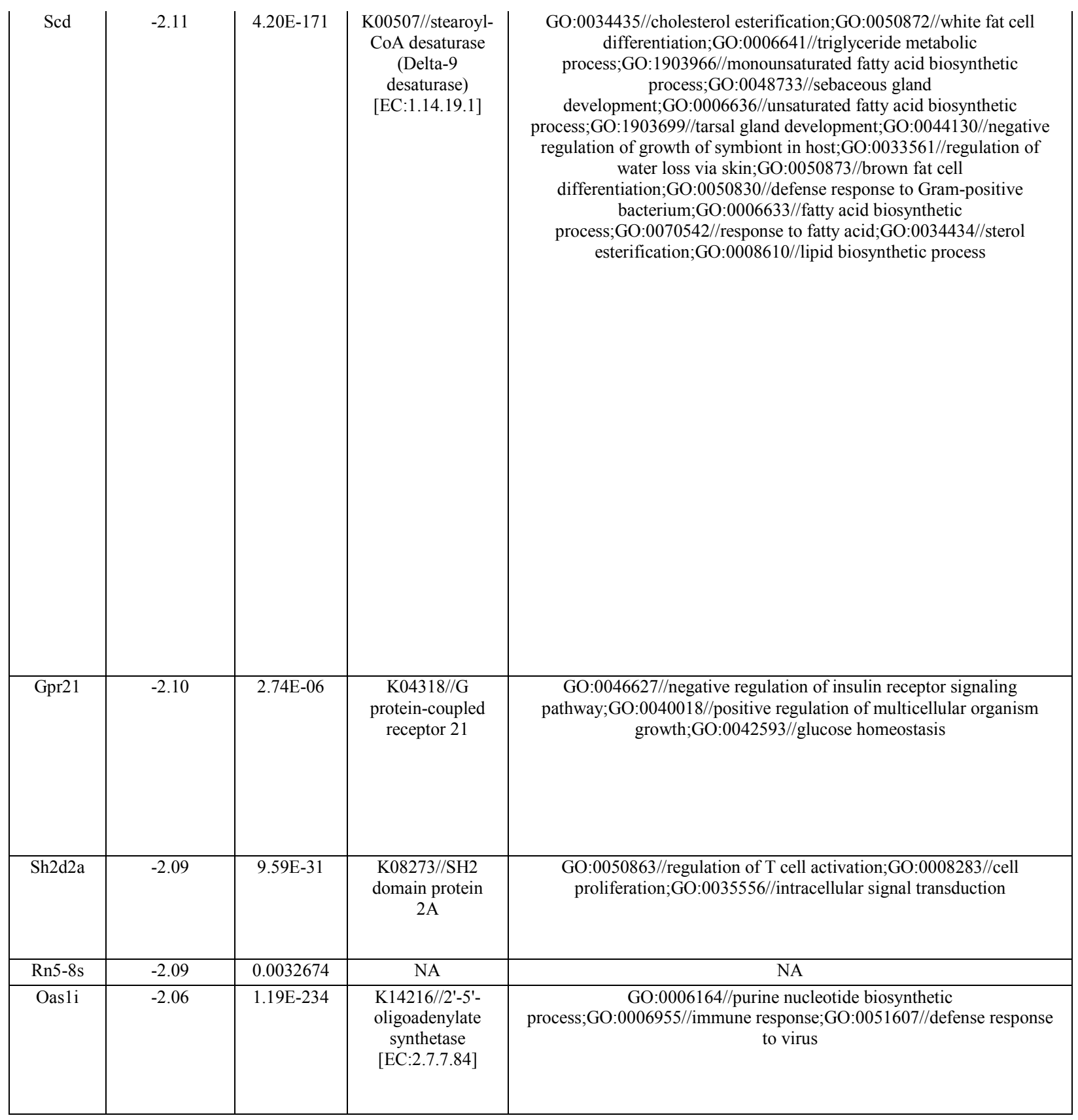




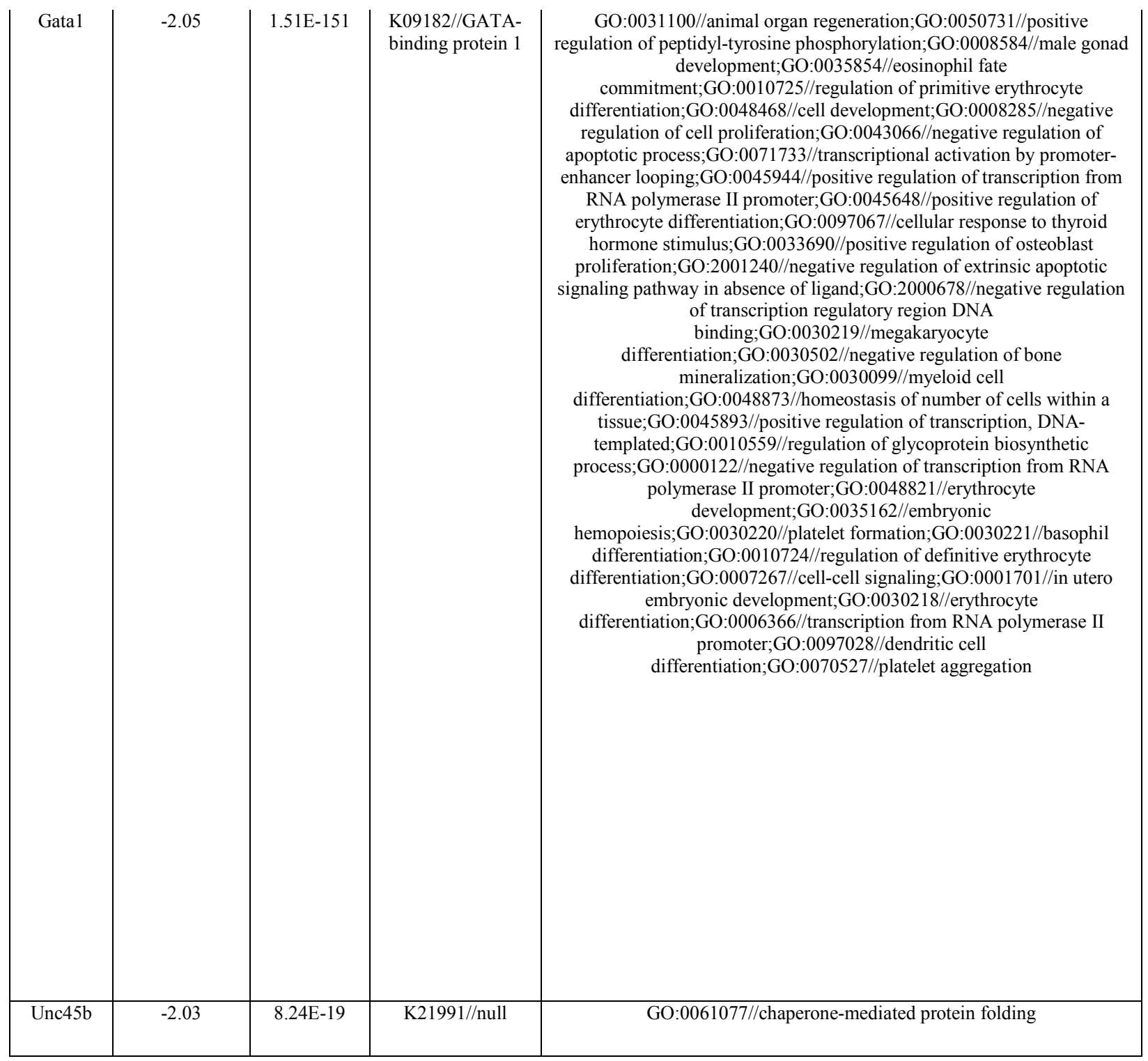




\begin{tabular}{|c|c|c|c|c|}
\hline Lgals9 & -2.03 & 0 & $\begin{array}{l}\text { K10093//galectin- } \\
\quad 9\end{array}$ & $\begin{array}{c}\text { GO:2000679//positive regulation of transcription regulatory region DNA } \\
\text { binding;GO:2000562//negative regulation of CD4-positive, alpha-beta T } \\
\text { cell proliferation;GO:0045089//positive regulation of innate immune } \\
\text { response;GO:0045185//maintenance of protein } \\
\text { location;GO:0032496//response to } \\
\text { lipopolysaccharide;GO:1900426//positive regulation of defense response } \\
\text { to bacterium;GO:0043322//negative regulation of natural killer cell } \\
\text { degranulation;GO:0010629//negative regulation of gene } \\
\text { expression;GO:0032823//regulation of natural killer cell } \\
\text { differentiation;GO:0001819//positive regulation of cytokine } \\
\text { production;GO:0050728//negative regulation of inflammatory } \\
\text { response;GO:0032760//positive regulation of tumor necrosis factor } \\
\text { production;GO:0010862//positive regulation of pathway-restricted } \\
\text { SMAD protein phosphorylation;GO:0002376//immune system } \\
\text { process;GO:0051353//positive regulation of oxidoreductase } \\
\text { activity;GO:0006935//chemotaxis;GO:2000406//positive regulation of T } \\
\text { cell migration;GO:2000778//positive regulation of interleukin-6 } \\
\text { secretion;GO:2001181//positive regulation of interleukin-10 } \\
\text { secretion;GO:0045591//positive regulation of regulatory T cell } \\
\text { differentiation;GO:1902714//negative regulation of interferon-gamma } \\
\text { secretion;GO:0007565//female pregnancy;GO:0043032//positive } \\
\text { regulation of macrophage activation;GO:0032732//positive regulation of } \\
\text { interleukin-1 production;GO:0010628//positive regulation of gene } \\
\text { expression;GO:0007157//heterophilic cell-cell adhesion via plasma } \\
\text { membrane cell adhesion molecules;GO:0032815//negative regulation of } \\
\text { natural killer cell activation;GO:0098586//cellular response to } \\
\text { virus;GO:0032722//positive regulation of chemokine } \\
\text { production;GO:0032689//negative regulation of interferon-gamma } \\
\text { production }\end{array}$ \\
\hline Ras12-9 & -2.02 & 0.0018778 & $\begin{array}{l}\text { K07936//GTP- } \\
\text { binding nuclear } \\
\text { protein Ran }\end{array}$ & $\begin{array}{c}\text { GO:0006913//nucleocytoplasmic transport;GO:0000054//ribosomal } \\
\text { subunit export from nucleus;GO:0006606//protein import into } \\
\text { nucleus;GO:0015031//protein transport }\end{array}$ \\
\hline Ece2 & -2.00 & 0.000699 & $\begin{array}{l}\text { K01415//endotheli } \\
\text { n-converting } \\
\text { enzyme } \\
\text { [EC:3.4.24.71] }\end{array}$ & $\begin{array}{c}\text { GO:0016486//peptide hormone processing;GO:0007507//heart } \\
\text { development;GO:0010002//cardioblast } \\
\text { differentiation;GO:0007420//brain development }\end{array}$ \\
\hline Cox4i2 & -2.00 & 0.0019708 & $\begin{array}{l}\text { K02263//cytochro } \\
\text { me c oxidase } \\
\text { subunit } 4\end{array}$ & $\begin{array}{c}\text { GO:0071456//cellular response to hypoxia;GO:0006123//mitochondrial } \\
\text { electron transport, cytochrome c to oxygen }\end{array}$ \\
\hline Popdc3 & -2.00 & 0.0056419 & $\begin{array}{l}\text { K21108//blood } \\
\text { vessel epicardial } \\
\text { substance }\end{array}$ & GO:0042391//regulation of membrane potential \\
\hline
\end{tabular}




\begin{tabular}{|c|c|c|c|c|}
\hline Oas1k & -1.98 & $7.35 \mathrm{E}-49$ & $\begin{array}{l}\text { K14216//2'-5'- } \\
\text { oligoadenylate } \\
\text { synthetase } \\
{[\text { EC:2.7.7.84] }}\end{array}$ & $\begin{array}{l}\text { GO:0006164//purine nucleotide biosynthetic } \\
\text { process;GO:0006955//immune response;GO:0051607//defense response } \\
\text { to virus }\end{array}$ \\
\hline Stc1 & -1.98 & $1.25 \mathrm{E}-69$ & $\begin{array}{l}\text { K11457//polyhom } \\
\text { eotic-like protein } \\
2\end{array}$ & $\begin{array}{l}\text { GO:0001886//endothelial cell morphogenesis;GO:0010596//negative } \\
\text { regulation of endothelial cell migration;GO:0003421//growth plate } \\
\text { cartilage axis specification;GO:0051926//negative regulation of calcium } \\
\text { ion transport;GO:0044070//regulation of anion } \\
\text { transport;GO:0035988//chondrocyte proliferation;GO:0090280//positive } \\
\text { regulation of calcium ion import;GO:1903403//negative regulation of } \\
\text { renal phosphate excretion;GO:0086004//regulation of cardiac muscle cell } \\
\text { contraction;GO:0006874//cellular calcium ion homeostasis }\end{array}$ \\
\hline Asb12 & -1.94 & 0.0004107 & $\begin{array}{l}\text { K10334//ankyrin } \\
\text { repeat and SOCS } \\
\text { box protein } 12\end{array}$ & GO:0035556//intracellular signal transduction \\
\hline Vsig2 & -1.93 & $1.50 \mathrm{E}-09$ & $\begin{array}{l}\text { K06791//immuno } \\
\text { globulin } \\
\text { superfamily, } \\
\text { member } 11 \\
\end{array}$ & NA \\
\hline Tuba8 & -1.92 & 0.0032944 & $\begin{array}{l}\text { K07374//tubulin } \\
\text { alpha }\end{array}$ & $\begin{array}{l}\text { GO:0000226//microtubule cytoskeleton } \\
\text { organization;GO:0007017//microtubule-based process }\end{array}$ \\
\hline Oasl & -1.92 & 0 & $\begin{array}{l}\text { K14608//2'-5'- } \\
\text { oligoadenylate } \\
\text { synthase-like } \\
\text { protein }\end{array}$ & $\begin{array}{c}\text { GO:0045071//negative regulation of viral genome } \\
\text { replication;GO:0051607//defense response to } \\
\text { virus;GO:0009615//response to virus;GO:0045087//innate immune } \\
\text { response }\end{array}$ \\
\hline Ckmt2 & -1.90 & 0.0002405 & $\begin{array}{c}\text { K00933//creatine } \\
\text { kinase } \\
\text { [EC:2.7.3.2] } \\
\end{array}$ & GO:0006603//phosphocreatine metabolic process \\
\hline Oas1a & -1.89 & $9.94 \mathrm{E}-278$ & $\begin{array}{l}\text { K14216//2'-5'- } \\
\text { oligoadenylate } \\
\text { synthetase } \\
{[\text { EC: } 2.7 .7 .84]}\end{array}$ & $\begin{array}{c}\text { GO:0048525//negative regulation of viral process;GO:0006164//purine } \\
\text { nucleotide biosynthetic process;GO:0051607//defense response to } \\
\text { virus;GO:0009615//response to virus;GO:0045087//innate immune } \\
\text { response }\end{array}$ \\
\hline
\end{tabular}




\begin{tabular}{|c|c|c|c|c|}
\hline $\begin{array}{l}\text { LOC689 } \\
065\end{array}$ & -1.88 & 0.001006 & $\begin{array}{l}\text { K01931//protein } \\
\text { neuralized } \\
\text { [EC:2.3.2.27];K19 } \\
\text { 937//Rab3 } \\
\text { GTPase-activating } \\
\text { protein non- } \\
\text { catalytic } \\
\text { subunit;K01441//a } \\
\text { lkaline ceramidase } \\
\text { [EC:3.5.1.23] }\end{array}$ & GO:0008152//metabolic process \\
\hline Mrvil & -1.88 & $1.39 \mathrm{E}-85$ & $\begin{array}{l}\text { K12337//inositol } \\
1,4,5 \text {-triphosphate } \\
\text { receptor- } \\
\text { associated cGMP } \\
\text { kinase substrate }\end{array}$ & $\begin{array}{c}\text { GO:0045986//negative regulation of smooth muscle } \\
\text { contraction;GO:0019934//cGMP-mediated } \\
\text { signaling;GO:0060087//relaxation of vascular smooth muscle }\end{array}$ \\
\hline Gabra5 & -1.86 & $3.97 \mathrm{E}-21$ & $\begin{array}{l}\text { K05175//gamma- } \\
\text { aminobutyric acid } \\
\text { receptor subunit } \\
\text { alpha }\end{array}$ & $\begin{array}{c}\text { GO:0060384//innervation;GO:0007214//gamma-aminobutyric acid } \\
\text { signaling pathway;GO:0043524//negative regulation of neuron apoptotic } \\
\text { process;GO:0007420//brain development;GO:0048666//neuron } \\
\text { development;GO:0001662//behavioral fear } \\
\text { response;GO:0043523//regulation of neuron apoptotic } \\
\text { process;GO:0007605//sensory perception of } \\
\text { sound;GO:0008306//associative learning;GO:0060119//inner ear receptor } \\
\text { cell development;GO:0007268//chemical synaptic } \\
\text { transmission;GO:0090102//cochlea development }\end{array}$ \\
\hline $\begin{array}{l}\text { RT1- } \\
\text { T24-3 }\end{array}$ & -1.86 & $8.26 \mathrm{E}-45$ & $\begin{array}{l}\text { K06751//major } \\
\text { histocompatibility } \\
\text { complex, class I }\end{array}$ & $\begin{array}{c}\text { GO:0006955//immune response;GO:0002474//antigen processing and } \\
\text { presentation of peptide antigen via MHC class I }\end{array}$ \\
\hline Selenbp1 & -1.86 & $2.46 \mathrm{E}-06$ & $\begin{array}{l}\text { K17285//selenium } \\
\text {-binding protein } 1\end{array}$ & $\begin{array}{c}\text { GO:0050873//brown fat cell differentiation;GO:0015031//protein } \\
\text { transport }\end{array}$ \\
\hline Iqcf3 & -1.86 & $6.76 \mathrm{E}-11$ & $\begin{array}{c}\text { K19538//retinitis } \\
\text { pigmentosa } 1\end{array}$ & NA \\
\hline Gdpd2 & -1.84 & 0.0053579 & $\begin{array}{c}\text { K01124//glycerop } \\
\text { hosphoinositol } \\
\text { inositolphosphodi } \\
\text { esterase } \\
\text { [EC:3.1.4.43] }\end{array}$ & $\begin{array}{l}\text { GO:0090527//actin filament reorganization;GO:0045669//positive } \\
\text { regulation of osteoblast differentiation;GO:0006629//lipid metabolic } \\
\text { process }\end{array}$ \\
\hline
\end{tabular}




\begin{tabular}{|c|c|c|c|c|}
\hline Ifit1 & -1.84 & $4.43 \mathrm{E}-170$ & $\begin{array}{l}\text { K14217//interfero } \\
\text { n-induced protein } \\
\text { with } \\
\text { tetratricopeptide } \\
\text { repeats 1 }\end{array}$ & $\begin{array}{l}\text { GO:0035458//cellular response to interferon-beta;GO:0051607//defense } \\
\text { response to virus;GO:0009615//response to virus;GO:0045087//innate } \\
\text { immune response;GO:0035457//cellular response to interferon-alpha }\end{array}$ \\
\hline $\mathrm{Cd} 248$ & -1.84 & $3.72 \mathrm{E}-38$ & $\begin{array}{l}\mathrm{K} 06706 / / \mathrm{CD} 248 \\
\text { antigen, } \\
\text { endosialin }\end{array}$ & $\begin{array}{c}\text { GO:0016477//cell migration;GO:0060033//anatomical structure } \\
\text { regression;GO:2000353//positive regulation of endothelial cell apoptotic } \\
\text { process;GO:0048535//lymph node development;GO:0008284//positive } \\
\text { regulation of cell proliferation }\end{array}$ \\
\hline Matn4 & -1.83 & 0.0002258 & $\begin{array}{l}\text { K19467//matrilin- } \\
3\end{array}$ & GO:0048678//response to axon injury \\
\hline Acta2 & -1.82 & 0 & $\begin{array}{l}\text { K12313//actin, } \\
\text { aortic smooth } \\
\text { muscle }\end{array}$ & NA \\
\hline Lmod1 & -1.81 & $1.10 \mathrm{E}-99$ & K22030//null & $\begin{array}{l}\text { GO:0007015//actin filament organization;GO:0051694//pointed-end actin } \\
\text { filament capping;GO:0006936//muscle contraction;GO:0030838//positive } \\
\text { regulation of actin filament polymerization;GO:0030239//myofibril } \\
\text { assembly;GO:0045010//actin nucleation }\end{array}$ \\
\hline Apol9a & -1.81 & 0 & $\begin{array}{l}\text { K14480//apolipop } \\
\text { rotein L }\end{array}$ & GO:0006869//lipid transport;GO:0042157//lipoprotein metabolic process \\
\hline Fam163a & -1.81 & $2.31 \mathrm{E}-59$ & NA & NA \\
\hline $\begin{array}{c}\text { Adamts1 } \\
4\end{array}$ & -1.81 & $6.81 \mathrm{E}-127$ & $\begin{array}{c}\text { K08628//a } \\
\text { disintegrin and } \\
\text { metalloproteinase } \\
\text { with } \\
\text { thrombospondin } \\
\text { motifs 14 } \\
\text { [EC:3.4.24.-] }\end{array}$ & NA \\
\hline Misp & -1.79 & $3.75 \mathrm{E}-08$ & $\begin{array}{l}\text { K16519//A-kinase } \\
\text { anchor protein } 2\end{array}$ & GO:0051301//cell division;GO:0007049//cell cycle \\
\hline $\mathrm{Hgd}$ & -1.77 & 0.0017437 & $\begin{array}{l}\text { K00451//homogen } \\
\text { tisate } 1,2- \\
\text { dioxygenase } \\
{[\text { EC: } 1.13 .11 .5]}\end{array}$ & $\begin{array}{l}\text { GO:0006572//tyrosine catabolic process;GO:0006520//cellular amino } \\
\text { acid metabolic process;GO:0006570//tyrosine metabolic } \\
\text { process;GO:0006559//L-phenylalanine catabolic process }\end{array}$ \\
\hline Mir450a1 & -1.77 & 0.0017437 & NA & NA \\
\hline
\end{tabular}




\begin{tabular}{|c|c|c|c|c|}
\hline Cmpk2 & -1.77 & 0 & $\begin{array}{l}\text { K13809//UMP- } \\
\text { CMP kinase 2, } \\
\text { mitochondrial } \\
\text { [EC:2.7.4.14] }\end{array}$ & $\begin{array}{l}\text { GO:0006165//nucleoside diphosphate } \\
\text { phosphorylation;GO:0006233//dTDP biosynthetic } \\
\text { process;GO:0006235//dTTP biosynthetic process;GO:0071222//cellular } \\
\text { response to lipopolysaccharide;GO:0006227//dUDP biosynthetic } \\
\text { process;GO:0009142//nucleoside triphosphate biosynthetic process }\end{array}$ \\
\hline Rac2 & -1.76 & $2.10 \mathrm{E}-32$ & $\begin{array}{l}\text { K07860//Ras- } \\
\text { related C3 } \\
\text { botulinum toxin } \\
\text { substrate } 2\end{array}$ & $\begin{array}{l}\text { GO:1902622//regulation of neutrophil } \\
\text { migration;GO:0071593//lymphocyte aggregation;GO:1903955//positive } \\
\text { regulation of protein targeting to mitochondrion;GO:0060263//regulation } \\
\text { of respiratory burst;GO:0007015//actin filament } \\
\text { organization;GO:0042129//regulation of T cell } \\
\text { proliferation;GO:0007264//small GTPase mediated signal } \\
\text { transduction;GO:0043304//regulation of mast cell } \\
\text { degranulation;GO:0060753//regulation of mast cell } \\
\text { chemotaxis;GO:0006935//chemotaxis;GO:0030031//cell projection } \\
\text { assembly;GO:0045453//bone resorption;GO:0007186//G-protein coupled } \\
\text { receptor signaling pathway;GO:0030036//actin cytoskeleton } \\
\text { organization;GO:0090023//positive regulation of neutrophil } \\
\text { chemotaxis;GO:0010592//positive regulation of lamellipodium } \\
\text { assembly;GO:0010810//regulation of cell-substrate } \\
\text { adhesion;GO:0008284//positive regulation of cell proliferation }\end{array}$ \\
\hline Sparcl1 & -1.75 & 0.0009981 & $\begin{array}{l}\text { K10402//kinesin } \\
\text { family member } \\
\text { 20;K19607//X- } \\
\text { linked retinitis } \\
\text { pigmentosa } \\
\text { GTPase regulator }\end{array}$ & $\begin{array}{c}\text { GO:0007165//signal transduction;GO:0048856//anatomical structure } \\
\text { development }\end{array}$ \\
\hline Rrad & -1.74 & $1.50 \mathrm{E}-05$ & $\begin{array}{l}\text { K07845//Ras- } \\
\text { related associated } \\
\text { with diabetes }\end{array}$ & $\begin{array}{l}\text { GO:1901842//negative regulation of high voltage-gated calcium channel } \\
\text { activity;GO:0007165//signal transduction }\end{array}$ \\
\hline
\end{tabular}




\begin{tabular}{|c|c|c|c|c|}
\hline $\begin{array}{l}\text { RGD130 } \\
9808\end{array}$ & -1.74 & $1.63 \mathrm{E}-234$ & $\begin{array}{l}\text { K14480//apolipop } \\
\text { rotein L }\end{array}$ & GO:0006869//lipid transport;GO:0042157//lipoprotein metabolic process \\
\hline Cox $8 b$ & -1.72 & 0.0003292 & $\begin{array}{l}\text { K02273//cytochro } \\
\text { me c oxidase } \\
\text { subunit } 8\end{array}$ & $\begin{array}{c}\text { GO:0042493//response to drug;GO:1902600//hydrogen ion } \\
\text { transmembrane transport;GO:0006123//mitochondrial electron transport, } \\
\text { cytochrome c to oxygen }\end{array}$ \\
\hline Ldlr & -1.70 & 0 & $\begin{array}{c}\text { K12473//low- } \\
\text { density } \\
\text { lipoprotein } \\
\text { receptor }\end{array}$ & $\begin{array}{c}\text { GO:0010867//positive regulation of triglyceride biosynthetic } \\
\text { process;GO:0043627//response to estrogen;GO:0045807//positive } \\
\text { regulation of endocytosis;GO:0030301//cholesterol } \\
\text { transport;GO:0032355//response to } \\
\text { estradiol;GO:0061889//null;GO:0042157//lipoprotein metabolic } \\
\text { process;GO:1903979//negative regulation of microglial cell } \\
\text { activation;GO:0010628//positive regulation of gene } \\
\text { expression;GO:0001666//response to hypoxia;GO:0090181//regulation of } \\
\text { cholesterol metabolic process;GO:0006898//receptor-mediated } \\
\text { endocytosis;GO:0030299//intestinal cholesterol } \\
\text { absorption;GO:0042159//lipoprotein catabolic } \\
\text { process;GO:2000188//regulation of cholesterol } \\
\text { response to low-density lipoprotein particle } \\
\text { homeostasis;Got//cellular } \\
\text { stimulus;GO:0010898//positive regulation of triglyceride catabolic } \\
\text { process;GO:0008203//cholesterol metabolic process;GO:0097242//beta- } \\
\text { amyloid clearance;GO:0010899//regulation of phosphatidylcholine } \\
\text { catabolic process;GO:0010629//negative regulation of gene } \\
\text { expression;GO:0050729//positive regulation of inflammatory } \\
\text { response;GO:0071398//cellular response to fatty acid;GO:0007616//long- } \\
\text { term memory;GO:0010986//positive regulation of lipoprotein particle } \\
\text { clearance;GO:1900223//positive regulation of beta-amyloid } \\
\text { clearance;GO:0015914//phospholipid transport;GO:0090118//receptor- } \\
\text { mediated endocytosis involved in cholesterol } \\
\text { transport;GO:0006897//endocytosis;GO:0070508//cholesterol } \\
\text { import;GO:0042632//cholesterol homeostasis;GO:0061771//response to } \\
\text { caloric restriction;GO:1905907//null;GO:0034383//low-density } \\
\text { lipoprotein particle clearance;GO:0051246//regulation of protein } \\
\text { metabolic process;GO:0007568//aging;GO:0051248//negative regulation } \\
\text { of protein metabolic process;GO:0033762//response to } \\
\text { glucagon;GO:0009725//response to hormone;GO:1905167//positive } \\
\text { regulation of lysosomal protein catabolic process }\end{array}$ \\
\hline
\end{tabular}




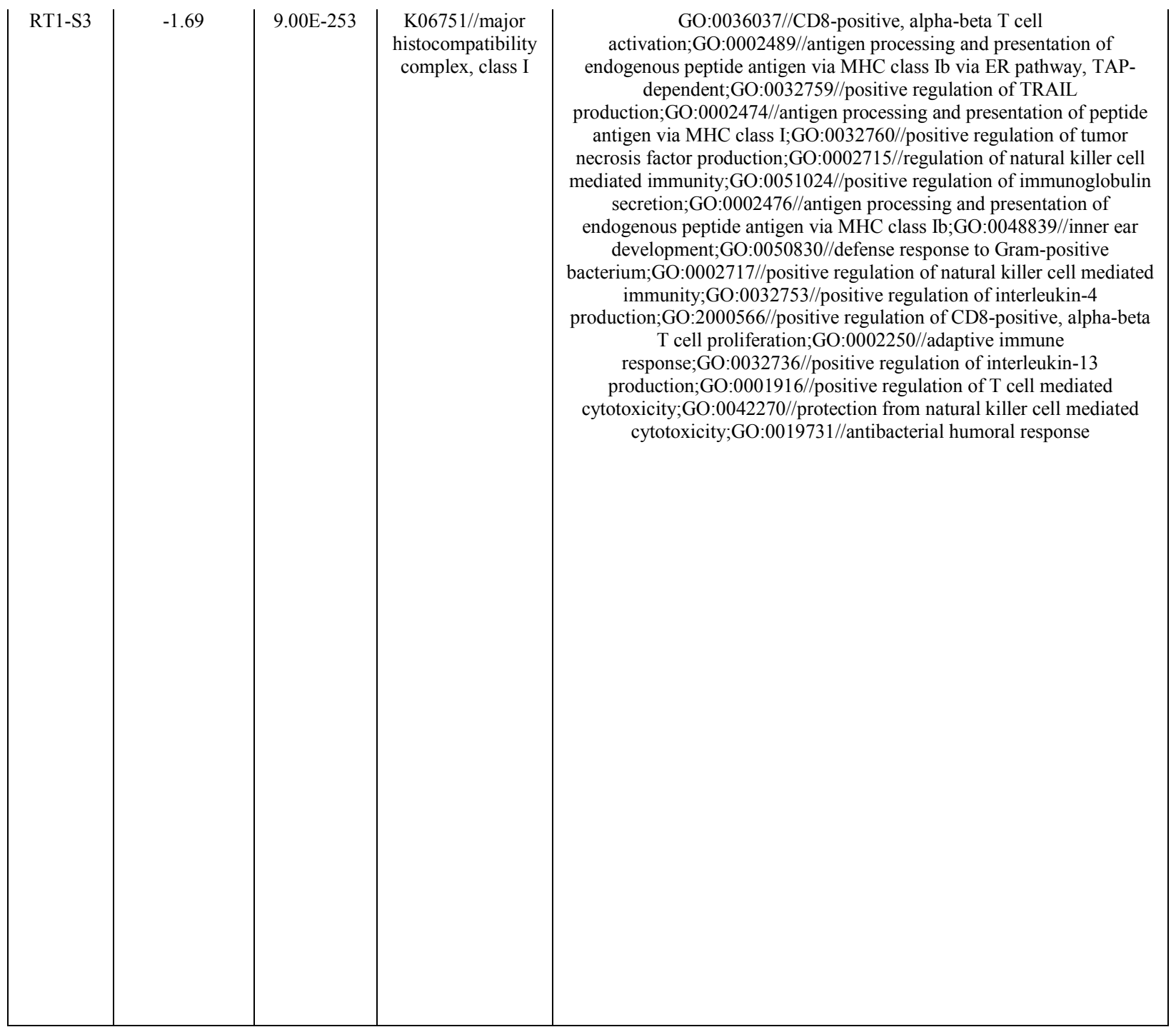




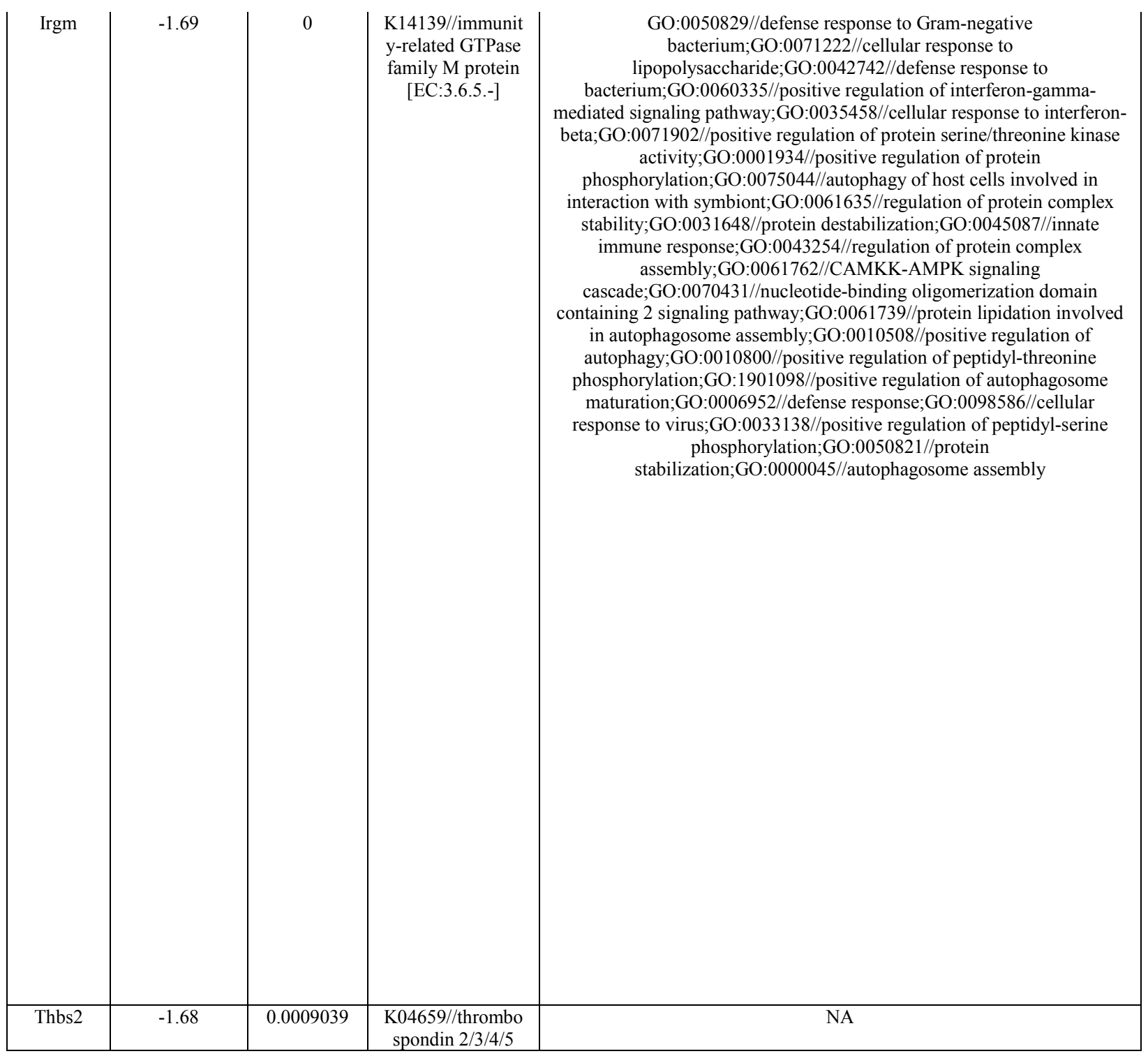




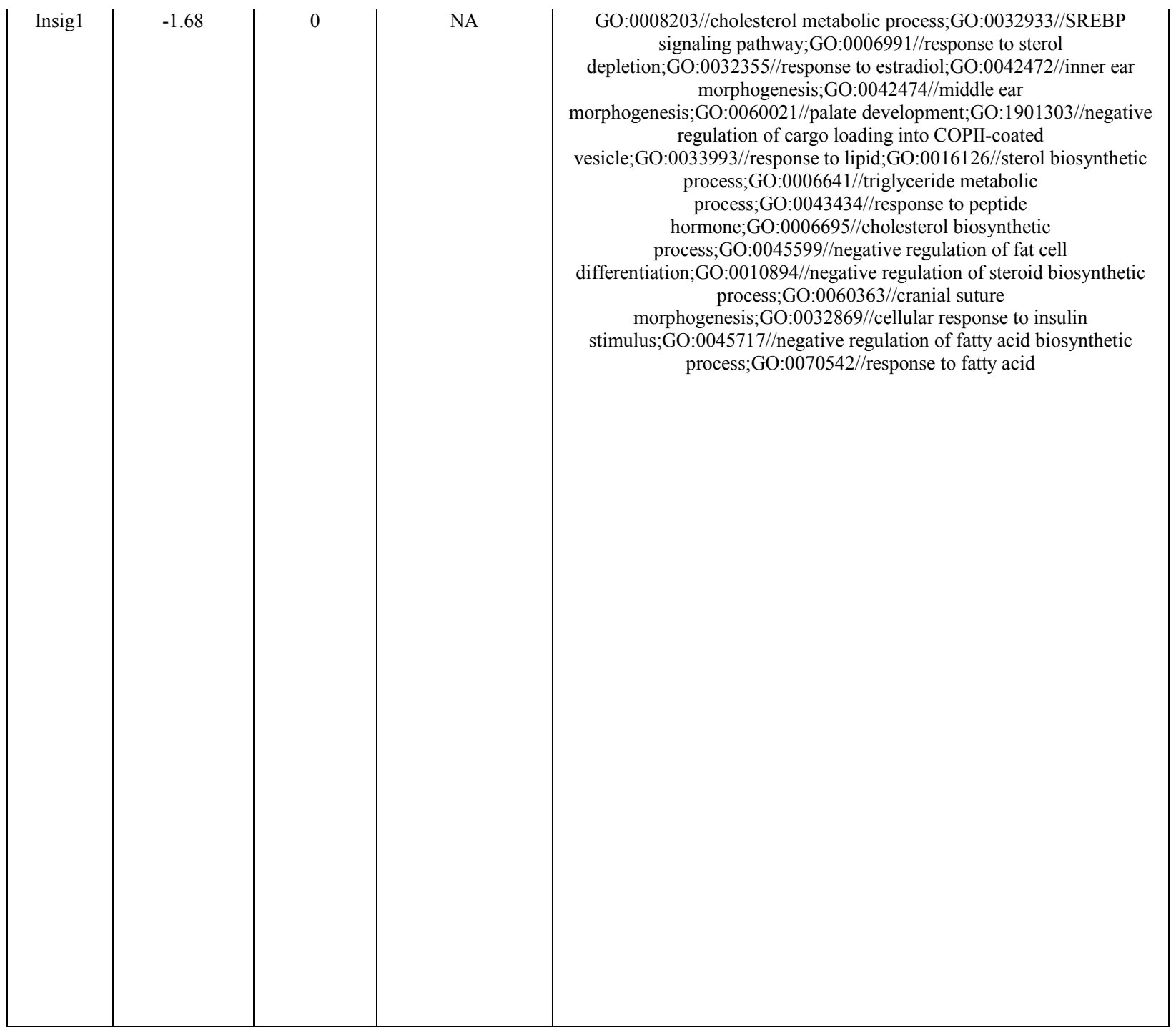




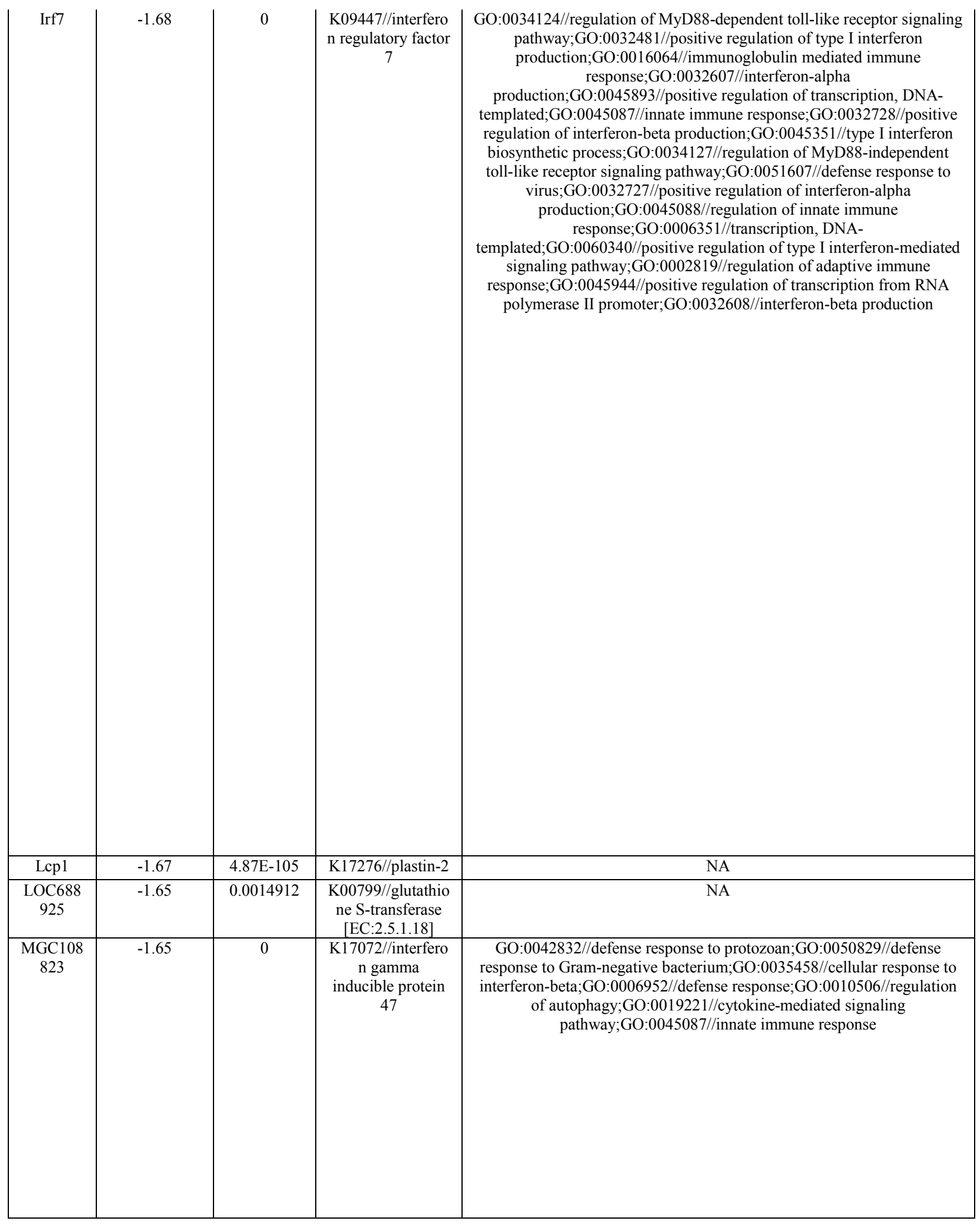




\begin{tabular}{|c|c|c|c|c|}
\hline Itgb6 & -1.64 & $1.90 \mathrm{E}-05$ & $\begin{array}{l}\text { K06589//integrin } \\
\quad \text { beta } 6\end{array}$ & $\begin{array}{c}\text { GO:0007160//cell-matrix adhesion;GO:0038044//transforming growth } \\
\text { factor-beta secretion;GO:0007229//integrin-mediated signaling } \\
\text { pathway;GO:0033627//cell adhesion mediated by } \\
\text { integrin;GO:0006954//inflammatory response }\end{array}$ \\
\hline Epn3 & -1.63 & $3.69 \mathrm{E}-20$ & K12471//epsin & NA \\
\hline Actg2 & -1.63 & $1.07 \mathrm{E}-219$ & $\begin{array}{l}\text { K12315//actin, } \\
\text { gamma-enteric } \\
\text { smooth muscle }\end{array}$ & NA \\
\hline Fyb & -1.63 & 0.0008082 & $\begin{array}{c}\text { K17698//FYN } \\
\text { binding protein }\end{array}$ & $\begin{array}{c}\text { GO:0007165//signal transduction;GO:0072659//protein localization to } \\
\text { plasma membrane;GO:0006955//immune response }\end{array}$ \\
\hline Csrp3 & -1.62 & $2.50 \mathrm{E}-12$ & $\begin{array}{l}\text { K09377//cysteine } \\
\text { and glycine-rich } \\
\text { protein }\end{array}$ & $\begin{array}{c}\text { GO:1903919//negative regulation of actin filament } \\
\text { severing;GO:0048738//cardiac muscle tissue } \\
\text { development;GO:0010831//positive regulation of myotube } \\
\text { differentiation;GO:0051091//positive regulation of sequence-specific } \\
\text { DNA binding transcription factor activity;GO:0060048//cardiac muscle } \\
\text { contraction;GO:0006874//cellular calcium ion } \\
\text { homeostasis;GO:0035995//detection of muscle } \\
\text { stretch;GO:0006351//transcription, DNA-templated;GO:0007517//muscle } \\
\text { organ development;GO:0003300//cardiac muscle } \\
\text { hypertrophy;GO:0001974//blood vessel } \\
\text { remodeling;GO:0002026//regulation of the force of heart } \\
\text { contraction;GO:0045662//negative regulation of myoblast } \\
\text { differentiation;GO:0045944//positive regulation of transcription from } \\
\text { RNA polymerase II promoter;GO:0033365//protein localization to } \\
\text { organelle;GO:1903920//positive regulation of actin filament } \\
\text { severing;GO:0045663//positive regulation of myoblast } \\
\text { differentiation;GO:0055003//cardiac myofibril assembly }\end{array}$ \\
\hline
\end{tabular}




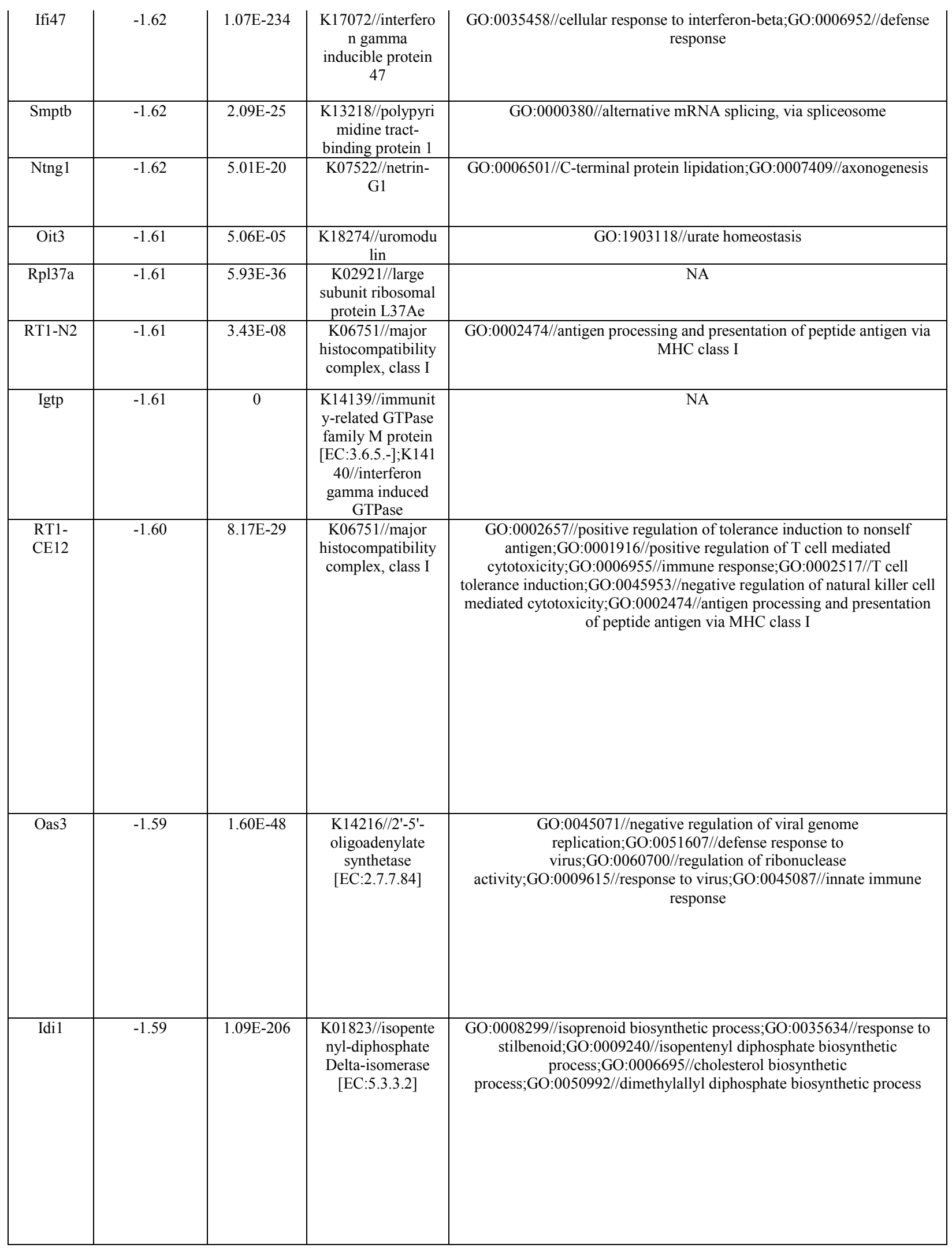




\begin{tabular}{|c|c|c|c|c|}
\hline Stat1 & -1.59 & 0 & $\begin{array}{l}\text { K11220//signal } \\
\text { transducer and } \\
\text { activator of } \\
\text { transcription } 1\end{array}$ & $\begin{array}{c}\text { GO:0032869//cellular response to insulin stimulus;GO:0008015//blood } \\
\text { circulation;GO:0035458//cellular response to interferon- } \\
\text { beta;GO:0006919//activation of cysteine-type endopeptidase activity } \\
\text { involved in apoptotic process }\end{array}$ \\
\hline C1qtnf5 & -1.59 & $1.29 \mathrm{E}-24$ & $\begin{array}{l}\text { K06237//collagen, } \\
\text { type IV, alpha }\end{array}$ & NA \\
\hline Dact3 & -1.58 & $1.11 \mathrm{E}-29$ & K22154//null & $\begin{array}{l}\text { GO:0030308//negative regulation of cell growth;GO:0090090//negative } \\
\text { regulation of canonical Wnt signaling pathway;GO:0035414//negative } \\
\text { regulation of catenin import into nucleus;GO:0030178//negative } \\
\text { regulation of Wnt signaling pathway;GO:0010719//negative regulation of } \\
\text { epithelial to mesenchymal transition;GO:0016055//Wnt signaling } \\
\text { pathway }\end{array}$ \\
\hline $\begin{array}{l}\text { Adamts } 1 \\
9\end{array}$ & -1.58 & $3.20 \mathrm{E}-10$ & $\begin{array}{c}\text { K08633//a } \\
\text { disintegrin and } \\
\text { metalloproteinase } \\
\text { with } \\
\text { thrombospondin } \\
\text { motifs 19 } \\
\text { [EC:3.4.24.-] }\end{array}$ & GO:0007229//integrin-mediated signaling pathway \\
\hline Cdh6 & -1.58 & 0.0039075 & $\begin{array}{l}\text { K06798//cadherin } \\
\text { 6, type } 2, \mathrm{~K}- \\
\text { cadherin }\end{array}$ & $\begin{array}{l}\text { GO:0007156//homophilic cell adhesion via plasma membrane adhesion } \\
\text { molecules }\end{array}$ \\
\hline Dhx58 & -1.58 & $8.38 \mathrm{E}-189$ & $\begin{array}{l}\text { K12649//ATP- } \\
\text { dependent RNA } \\
\text { helicase DHX58 } \\
\text { [EC:3.6.3.14] }\end{array}$ & $\begin{array}{c}\text { GO:0039536//negative regulation of RIG-I signaling } \\
\text { pathway;GO:0045824//negative regulation of innate immune } \\
\text { response;GO:0032481//positive regulation of type I interferon } \\
\text { production;GO:0039534//negative regulation of MDA-5 signaling } \\
\text { pathway;GO:0051607//defense response to virus;GO:0045088//regulation } \\
\text { of innate immune response;GO:1900245//positive regulation of MDA-5 } \\
\text { signaling pathway;GO:1900246//positive regulation of RIG-I signaling } \\
\text { pathway;GO:0032480//negative regulation of type I interferon } \\
\text { production;GO:0009615//response to virus;GO:0045087//innate immune } \\
\text { response }\end{array}$ \\
\hline
\end{tabular}




\begin{tabular}{|c|c|c|c|c|}
\hline Fbxo39 & -1.57 & $5.80 \mathrm{E}-14$ & $\begin{array}{l}\text { K10314//F-box } \\
\text { protein } 39\end{array}$ & $\begin{array}{l}\text { GO:0031146//SCF-dependent proteasomal ubiquitin-dependent protein } \\
\text { catabolic process }\end{array}$ \\
\hline Col8a1 & -1.56 & $1.50 \mathrm{E}-32$ & $\begin{array}{l}\text { K19479//collagen, } \\
\text { type X, alpha }\end{array}$ & $\begin{array}{c}\text { GO:0050673//epithelial cell proliferation;GO:0048593//camera-type eye } \\
\text { morphogenesis;GO:0035987//endodermal cell } \\
\text { differentiation;GO:0010811//positive regulation of cell-substrate } \\
\text { adhesion }\end{array}$ \\
\hline Ryr2 & -1.56 & $1.50 \mathrm{E}-41$ & $\begin{array}{l}\text { K04962//ryanodin } \\
\quad \text { e receptor } 2\end{array}$ & $\begin{array}{c}\text { GO:0010882//regulation of cardiac muscle contraction by calcium ion } \\
\text { signaling;GO:0003143//embryonic heart tube } \\
\text { morphogenesis;GO:0098910//regulation of atrial cardiac muscle cell } \\
\text { action potential;GO:0098904//regulation of AV node cell action } \\
\text { potential;GO:0014850//response to muscle } \\
\text { activity;GO:0031000//response to caffeine;GO:0060048//cardiac muscle } \\
\text { contraction;GO:0005513//detection of calcium } \\
\text { ion;GO:0035994//response to muscle stretch;GO:0098907//regulation of } \\
\text { SA node cell action potential;GO:0097050//type B pancreatic cell } \\
\text { apoptotic process;GO:0071872//cellular response to epinephrine } \\
\text { stimulus;GO:0019722//calcium-mediated } \\
\text { signaling;GO:0055117//regulation of cardiac muscle } \\
\text { contraction;GO:0030509//BMP signaling pathway;GO:0006816//calcium } \\
\text { ion transport;GO:0001666//response to hypoxia;GO:0003300//cardiac } \\
\text { muscle hypertrophy;GO:0051775//response to redox } \\
\text { state;GO:0060402//calcium ion transport into } \\
\text { cytosol;GO:0060070//canonical Wnt signaling } \\
\text { pathway;GO:0060401//cytosolic calcium ion } \\
\text { transport;GO:0051209//release of sequestered calcium ion into } \\
\text { cytosol;GO:0070588//calcium ion transmembrane } \\
\text { transport;GO:0014808//release of sequestered calcium ion into cytosol by } \\
\text { sarcoplasmic reticulum;GO:0098911//regulation of ventricular cardiac } \\
\text { muscle cell action potential;GO:0072599//establishment of protein } \\
\text { localization to endoplasmic reticulum;GO:0051284//positive regulation } \\
\text { of sequestering of calcium ion;GO:0035584//calcium-mediated signaling } \\
\text { using intracellular calcium source;GO:0071313//cellular response to } \\
\text { caffeine;GO:0010881//regulation of cardiac muscle contraction by } \\
\text { regulation of the release of sequestered calcium ion;GO:0006874//cellular } \\
\text { calcium ion homeostasis;GO:0086005//ventricular cardiac muscle cell } \\
\text { action potential;GO:0010460//positive regulation of heart } \\
\text { rate;GO:0086029//Purkinje myocyte to ventricular cardiac muscle cell } \\
\text { signaling;GO:0002027//regulation of heart rate;GO:0003220//left } \\
\text { ventricular cardiac muscle tissue morphogenesis;GO:1901896//positive } \\
\text { regulation of calcium-transporting ATPase activity;GO:0098735//positive } \\
\text { regulation of the force of heart contraction }\end{array}$ \\
\hline $\begin{array}{c}\text { LOC500 } \\
148\end{array}$ & -1.56 & $2.27 \mathrm{E}-05$ & NA & NA \\
\hline
\end{tabular}




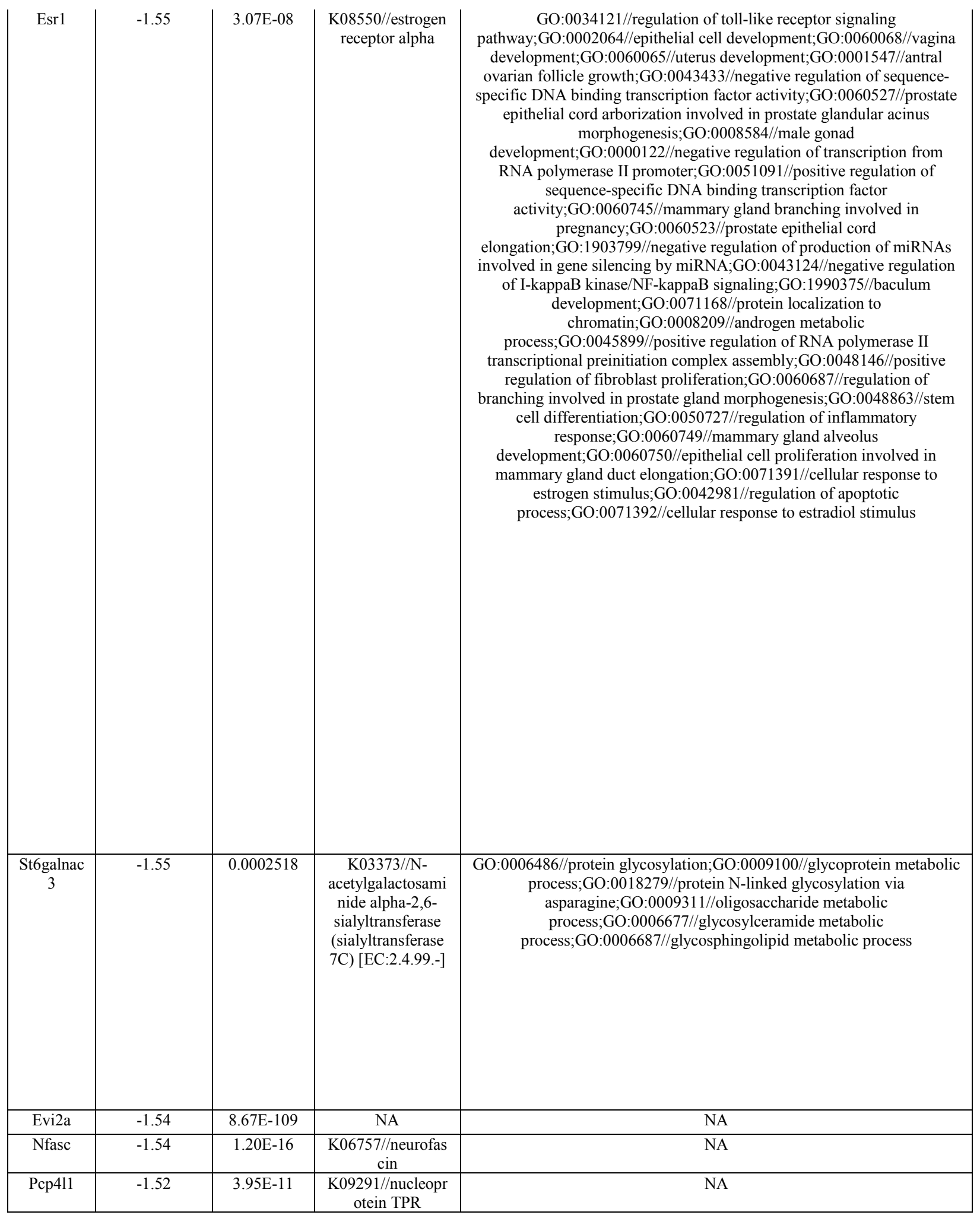




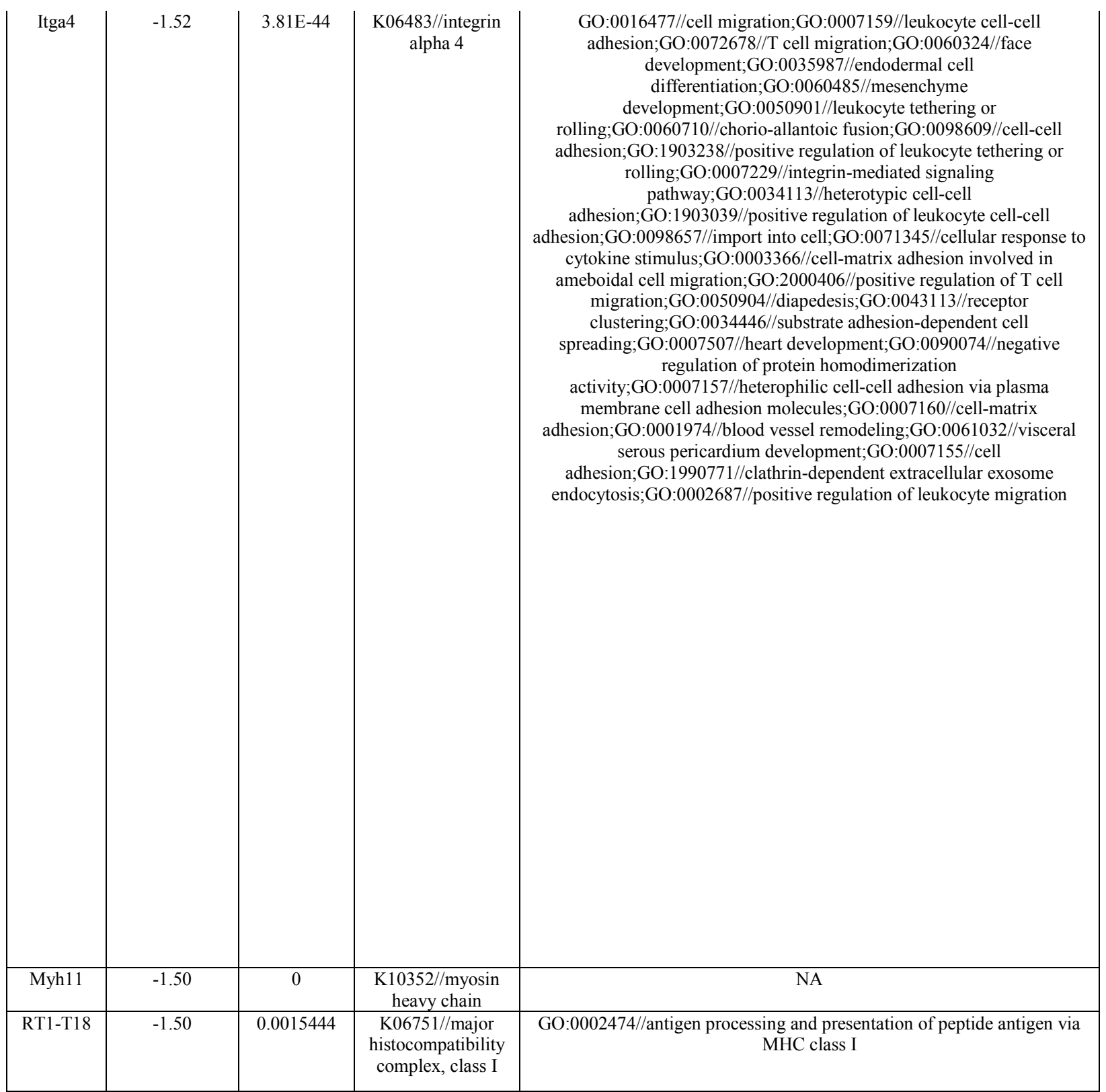




\begin{tabular}{|c|c|c|c|c|}
\hline Id 2 & -1.49 & $5.60 \mathrm{E}-47$ & $\begin{array}{l}\text { K17693//DNA- } \\
\text { binding protein } \\
\text { inhibitor ID2 }\end{array}$ & 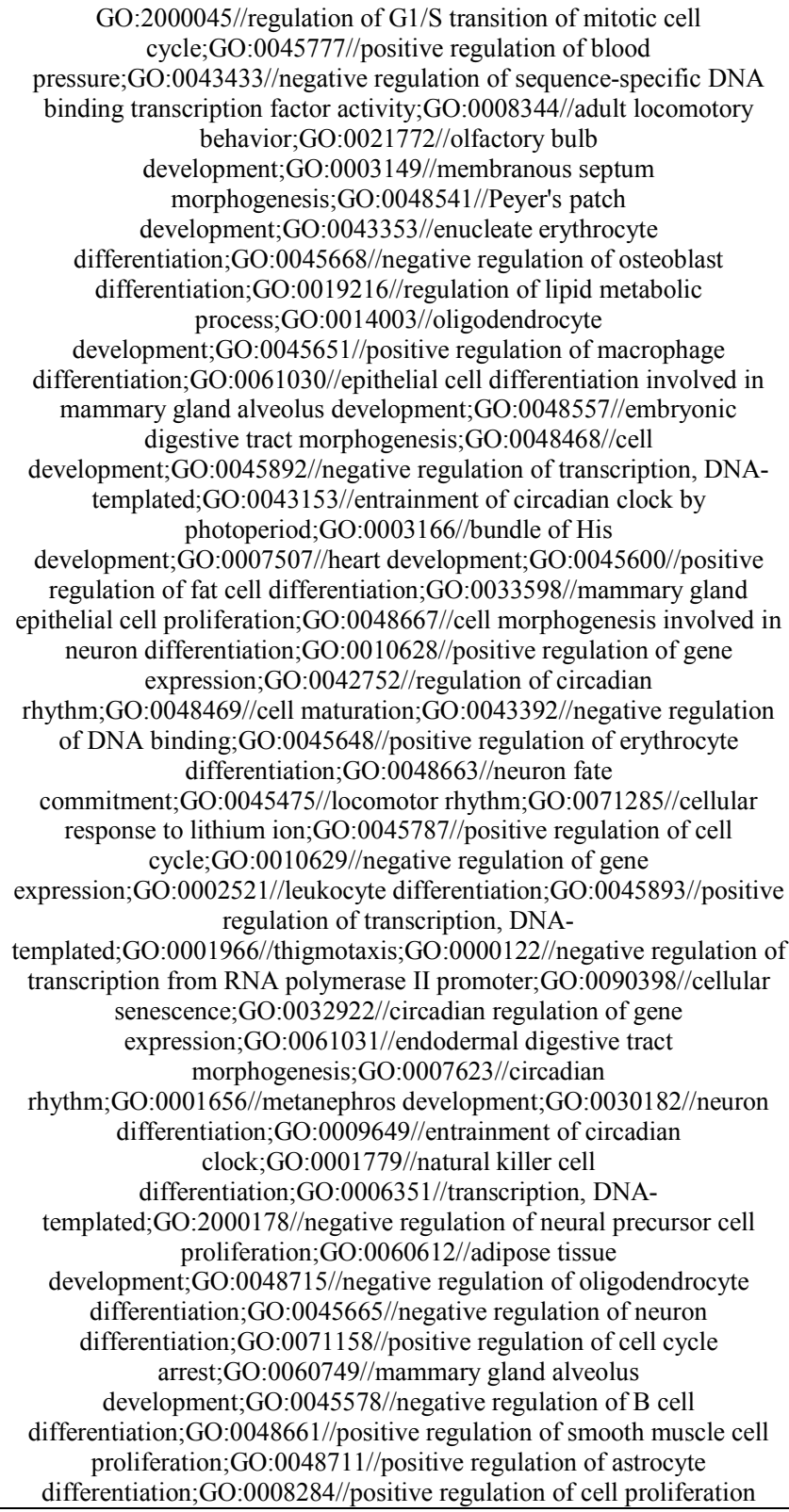 \\
\hline Nr1h4 & -1.49 & 7.44E-18 & $\begin{array}{c}\text { K08537//farnesoid } \\
\text { X receptor }\end{array}$ & $\begin{array}{l}\text { GO:0007043//cell-cell junction assembly;GO:0038183//bile acid } \\
\text { signaling pathway;GO:0008206//bile acid metabolic } \\
\text { process;GO:0071398//cellular response to fatty acid }\end{array}$ \\
\hline Lancl3 & -1.49 & 0.0001574 & $\begin{array}{l}\text { K19522//membra } \\
\text { ne transport } \\
\text { protein XK }\end{array}$ & GO:0007165//signal transduction \\
\hline $\begin{array}{c}\text { LOC498 } \\
231 \\
\end{array}$ & -1.48 & 0.002952 & NA & NA \\
\hline Nap115 & -1.48 & 0.0029645 & $\begin{array}{l}\text { K11281//nucleoso } \\
\text { me assembly } \\
\text { protein 1-like } 3\end{array}$ & NA \\
\hline
\end{tabular}




\begin{tabular}{|c|c|c|c|c|}
\hline Rtp4 & -1.48 & 0 & NA & $\begin{array}{l}\text { GO:0006612//protein targeting to membrane;GO:0051607//defense } \\
\text { response to virus;GO:0001580//detection of chemical stimulus involved } \\
\text { in sensory perception of bitter taste;GO:0051205//protein insertion into } \\
\text { membrane }\end{array}$ \\
\hline Coro6 & -1.47 & $4.79 \mathrm{E}-205$ & $\begin{array}{c}\text { K13886//coronin- } \\
1 \mathrm{~B} / 1 \mathrm{C} / 6 \\
\end{array}$ & NA \\
\hline Sult1a1 & -1.47 & $7.08 \mathrm{E}-09$ & $\begin{array}{c}\text { K01014//aryl } \\
\text { sulfotransferase } \\
{[\text { EC:2.8.2.1] }}\end{array}$ & NA \\
\hline Trpc6 & -1.47 & 0.0008311 & $\begin{array}{l}\text { K04969//transient } \\
\text { receptor potential } \\
\text { cation channel } \\
\text { subfamily C } \\
\text { member } 6\end{array}$ & $\begin{array}{l}\text { GO:0032414//positive regulation of ion transmembrane transporter } \\
\text { activity;GO:0007204//positive regulation of cytosolic calcium ion } \\
\text { concentration;GO:0051928//positive regulation of calcium ion transport }\end{array}$ \\
\hline Oas1b & -1.47 & $7.88 \mathrm{E}-300$ & $\begin{array}{l}\text { K14216//2'-5'- } \\
\text { oligoadenylate } \\
\text { synthetase } \\
\text { [EC:2.7.7.84] }\end{array}$ & $\begin{array}{c}\text { GO:0045071//negative regulation of viral genome } \\
\text { replication;GO:0051607//defense response to } \\
\text { virus;GO:0009615//response to virus;GO:0045087//innate immune } \\
\text { response }\end{array}$ \\
\hline Muc19 & -1.46 & 0.0093003 & K22020//null & $\begin{array}{c}\text { GO:0002244//hematopoietic progenitor cell } \\
\text { differentiation;GO:0060689//cell differentiation involved in salivary } \\
\text { gland development;GO:0050728//negative regulation of inflammatory } \\
\text { response }\end{array}$ \\
\hline
\end{tabular}




\begin{tabular}{|c|c|c|c|c|}
\hline Rnf165 & -1.46 & 0.0093401 & $\begin{array}{l}\text { K17821//RING } \\
\text { finger protein } 165\end{array}$ & $\begin{array}{c}\text { GO:0010259//multicellular organism } \\
\text { aging;GO:0060384//innervation;GO:0008045//motor neuron axon } \\
\text { guidance;GO:0016567//protein ubiquitination;GO:0030513//positive } \\
\text { regulation of BMP signaling pathway;GO:0042787//protein } \\
\text { ubiquitination involved in ubiquitin-dependent protein catabolic } \\
\text { process;GO:0030163//protein catabolic } \\
\text { process;GO:0007409//axonogenesis;GO:0035136//forelimb } \\
\text { morphogenesis;GO:0061061//muscle structure } \\
\text { development;GO:0060173//limb development;GO:0043161//proteasome- } \\
\text { mediated ubiquitin-dependent protein catabolic } \\
\text { process;GO:0000209//protein polyubiquitination }\end{array}$ \\
\hline Ifi44 & -1.45 & 0 & NA & NA \\
\hline Myh8 & -1.45 & 0.0045129 & $\begin{array}{l}\text { K10352//myosin } \\
\text { heavy chain }\end{array}$ & NA \\
\hline Akap12 & -1.45 & 0 & $\begin{array}{l}\text { K16528//A-kinase } \\
\text { anchor protein } 12\end{array}$ & $\begin{array}{c}\text { GO:0006605//protein targeting;GO:0007165//signal } \\
\text { transduction;GO:0090036//regulation of protein kinase C } \\
\text { signaling;GO:0010739//positive regulation of protein kinase A } \\
\text { signaling;GO:0030819//positive regulation of cAMP biosynthetic process }\end{array}$ \\
\hline Znfx1 & -1.44 & 0 & $\begin{array}{l}\text { K14326//regulator } \\
\text { of nonsense } \\
\text { transcripts } 1 \\
\text { [EC:3.6.4.-] }\end{array}$ & NA \\
\hline Camkv & -1.44 & $4.38 \mathrm{E}-11$ & $\begin{array}{l}\text { K08812//CaM } \\
\text { kinase-like } \\
\text { vesicle-associated } \\
\text { [EC:2.7.11.-] }\end{array}$ & $\begin{array}{l}\text { GO:0018107//peptidyl-threonine phosphorylation;GO:0018105//peptidyl- } \\
\text { serine phosphorylation;GO:0035556//intracellular signal transduction }\end{array}$ \\
\hline $\mathrm{Ccl} 28$ & -1.43 & 0.0046833 & $\begin{array}{c}\mathrm{K} 05513 / / \mathrm{C}-\mathrm{C} \\
\text { motif chemokine } \\
28\end{array}$ & NA \\
\hline Clec12b & -1.43 & $9.65 \mathrm{E}-14$ & $\begin{array}{l}\text { K17517//C-type } \\
\text { lectin domain } \\
\text { family } 12 \text { member } \\
\text { B }\end{array}$ & $\begin{array}{c}\text { GO:0002769//natural killer cell inhibitory signaling } \\
\text { pathway;GO:2000272//negative regulation of receptor } \\
\text { activity;GO:0045953//negative regulation of natural killer cell mediated } \\
\text { cytotoxicity }\end{array}$ \\
\hline
\end{tabular}




\begin{tabular}{|c|c|c|c|c|}
\hline Kcnip2 & -1.43 & 0.0012519 & $\begin{array}{l}\text { K19932//neuronal } \\
\text { calcium sensor } \\
1 ; \mathrm{K} 16575 / / \text { centrac } \\
\text { tin }\end{array}$ & $\begin{array}{c}\text { GO:0051291//protein heterooligomerization;GO:0097623//potassium ion } \\
\text { export across plasma membrane;GO:0086009//membrane } \\
\text { repolarization;GO:0045163//clustering of voltage-gated potassium } \\
\text { channels;GO:0071435//potassium ion export;GO:0071805//potassium ion } \\
\text { transmembrane transport;GO:1901379//regulation of potassium ion } \\
\text { transmembrane transport }\end{array}$ \\
\hline Ogn & -1.43 & $3.05 \mathrm{E}-27$ & $\begin{array}{c}\text { K08126//osteogly } \\
\text { cin } \\
\text { (osteoinductive } \\
\text { factor, mimecan) } \\
\end{array}$ & GO:0007409//axonogenesis \\
\hline Pramel & -1.41 & $4.04 \mathrm{E}-13$ & $\begin{array}{l}\text { K10308//F-box } \\
\text { protein } 31\end{array}$ & (9) \\
\hline Helz2 & -1.41 & 0 & $\begin{array}{l}\text { K14326//regulator } \\
\text { of nonsense } \\
\text { transcripts 1 } \\
\text { [EC:3.6.4.-] }\end{array}$ & $\begin{array}{l}\text { GO:0045944//positive regulation of transcription from RNA polymerase } \\
\text { II promoter;GO:0006351//transcription, DNA-templated }\end{array}$ \\
\hline Rgs20 & -1.41 & $5.11 \mathrm{E}-61$ & $\begin{array}{c}\text { K16449//regulator } \\
\text { of G-protein } \\
\text { signaling }\end{array}$ & $\begin{array}{c}\text { GO:0007186//G-protein coupled receptor signaling } \\
\text { pathway;GO:0009968//negative regulation of signal transduction }\end{array}$ \\
\hline Actc1 & -1.40 & $1.88 \mathrm{E}-09$ & $\begin{array}{l}\text { K12314//actin, } \\
\text { alpha cardiac } \\
\text { muscle }\end{array}$ & $\begin{array}{c}\text { GO:0030048//actin filament-based movement;GO:0031032//actomyosin } \\
\text { structure organization;GO:0070252//actin-mediated cell } \\
\text { contraction;GO:0030049//muscle filament sliding;GO:0033275//actin- } \\
\text { myosin filament sliding;GO:0045471//response to } \\
\text { ethanol;GO:0055008//cardiac muscle tissue } \\
\text { morphogenesis;GO:0060048//cardiac muscle } \\
\text { contraction;GO:0042493//response to drug;GO:0043066//negative } \\
\text { regulation of apoptotic process;GO:0010628//positive regulation of gene } \\
\text { expression;GO:0090131//mesenchyme migration;GO:0006915//apoptotic } \\
\text { process;GO:0060047//heart contraction;GO:0030240//skeletal muscle } \\
\text { thin filament assembly;GO:0055003//cardiac myofibril assembly }\end{array}$ \\
\hline
\end{tabular}




\begin{tabular}{|c|c|c|c|c|}
\hline Stat2 & -1.40 & 0 & $\begin{array}{l}\text { K11221//signal } \\
\text { transducer and } \\
\text { activator of } \\
\text { transcription } 2\end{array}$ & $\begin{array}{c}\text { GO:0001932//regulation of protein phosphorylation;GO:0060337//type I } \\
\text { interferon signaling pathway;GO:0090140//regulation of mitochondrial } \\
\text { fission;GO:0051607//defense response to } \\
\text { virus;GO:0006351//transcription, DNA-templated }\end{array}$ \\
\hline Tpm2 & -1.40 & $2.73 \mathrm{E}-199$ & $\begin{array}{l}\text { K10374//tropomy } \\
\text { osin } 2\end{array}$ & $\begin{array}{c}\text { GO:0007015//actin filament organization;GO:0030049//muscle filament } \\
\text { sliding;GO:0006936//muscle contraction;GO:0043462//regulation of } \\
\text { ATPase activity }\end{array}$ \\
\hline Nat8f5 & -1.39 & 0.0001803 & $\begin{array}{l}\text { K20838//N- } \\
\text { acetyltransferase } 8 \\
\text { [EC:2.3.1.80 } \\
2.3 .1 .-]\end{array}$ & $\begin{array}{c}\text { GO:0001702//gastrulation with mouth forming } \\
\text { second;GO:0007368//determination of left/right } \\
\text { symmetry;GO:0007162//negative regulation of cell } \\
\text { adhesion;GO:0007507//heart development }\end{array}$ \\
\hline Msmo1 & -1.39 & $6.33 \mathrm{E}-189$ & $\begin{array}{l}\text { K07750//methylst } \\
\text { erol } \\
\text { monooxygenase } \\
{[\text { EC:1.14.13.72] }}\end{array}$ & GO:0016126//sterol biosynthetic process \\
\hline $\begin{array}{l}\text { LOC100 } \\
302465\end{array}$ & -1.38 & 0.0018741 & $\begin{array}{l}\text { K16773//fragile- } \\
\text { site associated } \\
\text { tumor suppressor }\end{array}$ & $\begin{array}{l}\text { GO:0030308//negative regulation of cell growth;GO:0010212//response } \\
\text { to ionizing radiation;GO:0007095//mitotic G2 DNA damage } \\
\text { checkpoint;GO:0009411//response to UV;GO:0050821//protein } \\
\text { stabilization;GO:0006974//cellular response to DNA damage stimulus }\end{array}$ \\
\hline Synpo2 & -1.37 & $1.54 \mathrm{E}-15$ & $\begin{array}{l}\text { K21112//synaptop } \\
\text { odin }\end{array}$ & $\begin{array}{c}\text { GO:2000298//regulation of Rho-dependent protein serine/threonine } \\
\text { kinase activity;GO:0030335//positive regulation of cell } \\
\text { migration;GO:0032233//positive regulation of actin filament bundle } \\
\text { assembly;GO:0000045//autophagosome assembly }\end{array}$ \\
\hline Sqle & -1.37 & $1.15 \mathrm{E}-174$ & $\begin{array}{l}\text { K00511//squalene } \\
\text { monooxygenase } \\
{[\text { EC:1.14.14.17] }}\end{array}$ & $\begin{array}{l}\text { GO:0016126//sterol biosynthetic process;GO:0008203//cholesterol } \\
\text { metabolic process;GO:0010033//response to organic } \\
\text { substance;GO:0006725//cellular aromatic compound metabolic process }\end{array}$ \\
\hline
\end{tabular}




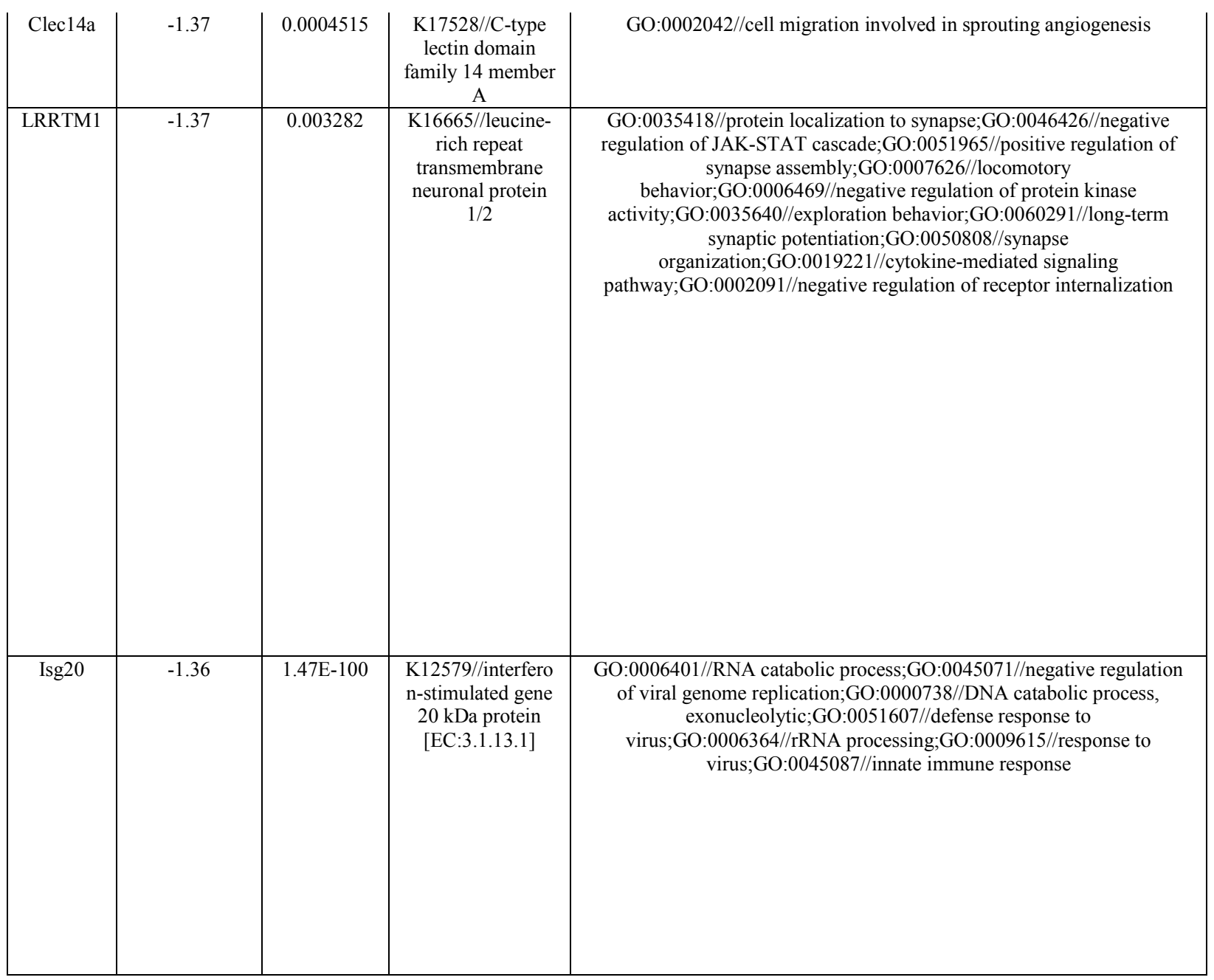




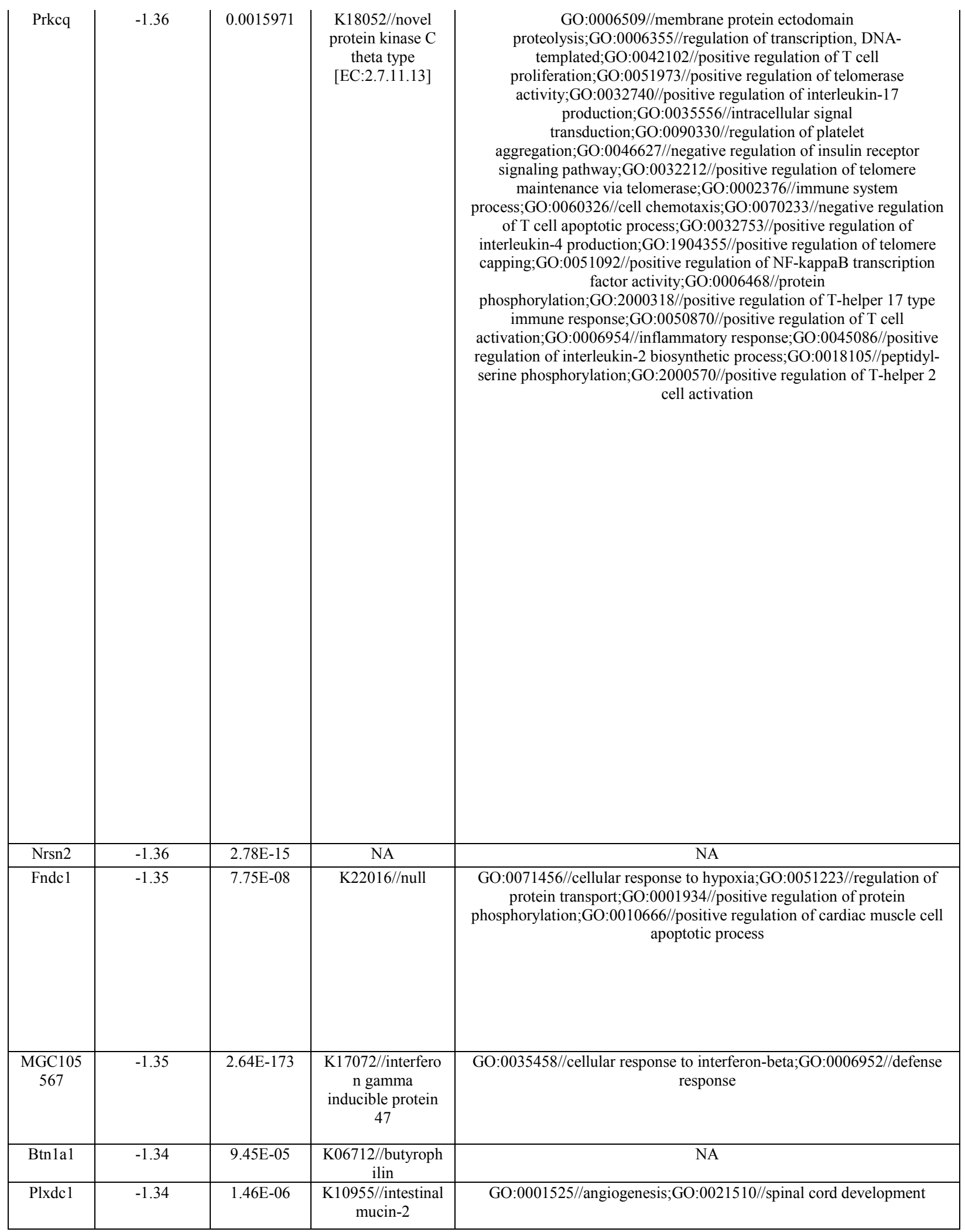




\begin{tabular}{|c|c|c|c|c|}
\hline Esrp1 & -1.33 & 0.000328 & $\begin{array}{c}\text { K14947//epithelial } \\
\text { splicing } \\
\text { regulatory protein } \\
1 / 2\end{array}$ & $\begin{array}{c}\text { GO:0043484//regulation of RNA splicing;GO:0060445//branching } \\
\text { involved in salivary gland morphogenesis;GO:0060441//epithelial tube } \\
\text { branching involved in lung morphogenesis;GO:0000380//alternative } \\
\text { mRNA splicing, via spliceosome;GO:0050679//positive regulation of } \\
\text { epithelial cell proliferation }\end{array}$ \\
\hline Trim34 & -1.33 & 2.63E-278 & $\begin{array}{l}\text { K11999//tripartite } \\
\text { motif-containing } \\
\text { protein } 6 / 22 / 34\end{array}$ & $\begin{array}{c}\text { GO:0051091//positive regulation of sequence-specific DNA binding } \\
\text { transcription factor activity;GO:0070206//protein } \\
\text { trimerization;GO:0051607//defense response to virus }\end{array}$ \\
\hline RT1-N3 & -1.33 & $3.36 \mathrm{E}-71$ & $\begin{array}{l}\text { K06751//major } \\
\text { histocompatibility } \\
\text { complex, class I }\end{array}$ & $\begin{array}{l}\text { GO:0002474//antigen processing and presentation of peptide antigen via } \\
\text { MHC class I }\end{array}$ \\
\hline Tspan11 & -1.33 & $2.52 \mathrm{E}-06$ & $\begin{array}{l}\text { K17352//tetraspan } \\
\text { in-11 }\end{array}$ & GO:0007166//cell surface receptor signaling pathway \\
\hline Wisp1 & -1.33 & $2.29 \mathrm{E}-29$ & $\begin{array}{l}\text { K06827//connecti } \\
\text { ve tissue growth } \\
\text { factor }\end{array}$ & $\begin{array}{c}\text { GO:0007155//cell adhesion;GO:0007165//signal } \\
\text { transduction;GO:0048661//positive regulation of smooth muscle cell } \\
\text { proliferation;GO:0016055//Wnt signaling pathway;GO:0007267//cell-cell } \\
\text { signaling;GO:0060548//negative regulation of cell } \\
\text { death;GO:0061051//positive regulation of cell growth involved in cardiac } \\
\text { muscle cell development }\end{array}$ \\
\hline Clec2dl1 & -1.33 & $3.50 \mathrm{E}-24$ & $\begin{array}{c}\text { K10072//C-type } \\
\text { lectin domain } \\
\text { family } 2 \text { member } \\
\text { D }\end{array}$ & NA \\
\hline Zfp3613 & -1.32 & $1.53 \mathrm{E}-06$ & $\begin{array}{l}\text { K06237//collagen, } \\
\text { type IV, alpha }\end{array}$ & $\begin{array}{c}\text { GO:0061158//3'-UTR-mediated mRNA } \\
\text { destabilization;GO:0000289//nuclear-transcribed mRNA poly(A) tail } \\
\text { shortening }\end{array}$ \\
\hline
\end{tabular}




\begin{tabular}{|c|c|c|c|c|}
\hline Pglyrp1 & -1.32 & $6.86 \mathrm{E}-05$ & $\begin{array}{c}\text { K01446//peptidog } \\
\text { lycan recognition } \\
\text { protein }\end{array}$ & $\begin{array}{c}\text { GO:0032827//negative regulation of natural killer cell differentiation } \\
\text { involved in immune response;GO:0061844//null;GO:0044117//growth of } \\
\text { symbiont in host;GO:0031640//killing of cells of other } \\
\text { organism;GO:0051714//positive regulation of cytolysis in other } \\
\text { organism;GO:0009253//peptidoglycan catabolic } \\
\text { process;GO:0050728//negative regulation of inflammatory } \\
\text { response;GO:0045187//regulation of circadian sleep/wake cycle, } \\
\text { sleep;GO:0006915//apoptotic process;GO:0016045//detection of } \\
\text { bacterium;GO:0006955//immune response;GO:0050830//defense } \\
\text { response to Gram-positive bacterium;GO:0045087//innate immune } \\
\text { response;GO:0032689//negative regulation of interferon-gamma } \\
\text { production }\end{array}$ \\
\hline Rab36 & -1.32 & 0.0048775 & $\begin{array}{l}\text { K07922//Ras- } \\
\text { related protein } \\
\text { Rab-36 }\end{array}$ & GO:0015031//protein transport \\
\hline Adcy5 & -1.31 & $6.52 \mathrm{E}-17$ & $\begin{array}{c}\text { K08045//adenylat } \\
\text { e cyclase 5 } \\
\text { [EC:4.6.1.1] }\end{array}$ & $\begin{array}{l}\text { GO:0007165//signal transduction;GO:1904322//cellular response to } \\
\text { forskolin;GO:0001973//adenosine receptor signaling } \\
\text { pathway;GO:0007195//adenylate cyclase-inhibiting dopamine receptor } \\
\text { signaling pathway;GO:0006171//cAMP biosynthetic } \\
\text { process;GO:0006182//cGMP biosynthetic } \\
\text { process;GO:0007626//locomotory behavior;GO:0061178//regulation of } \\
\text { insulin secretion involved in cellular response to glucose } \\
\text { stimulus;GO:0007204//positive regulation of cytosolic calcium ion } \\
\text { concentration;GO:0007189//adenylate cyclase-activating G-protein } \\
\text { coupled receptor signaling pathway;GO:0007191//adenylate cyclase- } \\
\text { activating dopamine receptor signaling } \\
\text { pathway;GO:0050885//neuromuscular process controlling balance }\end{array}$ \\
\hline
\end{tabular}




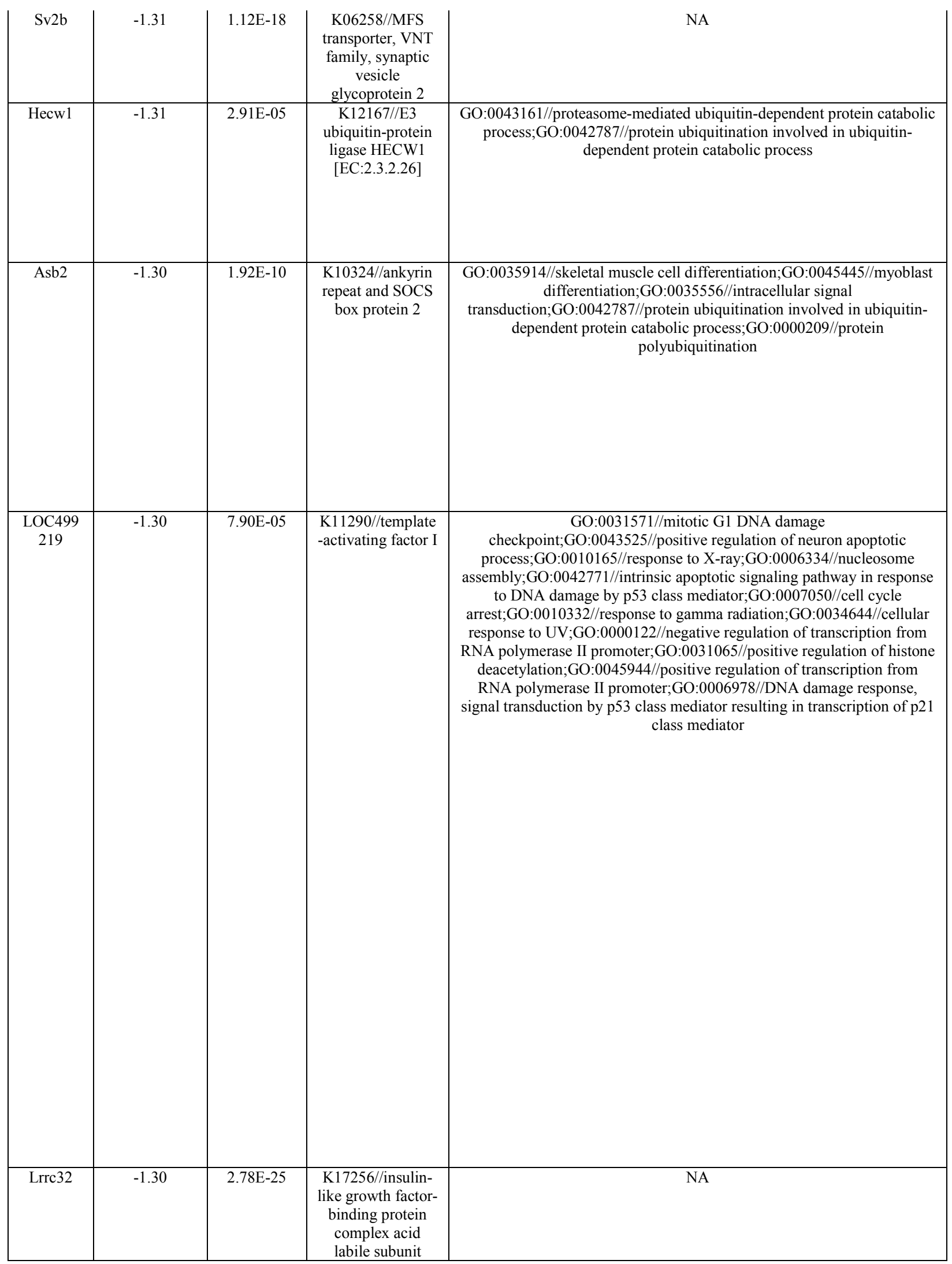




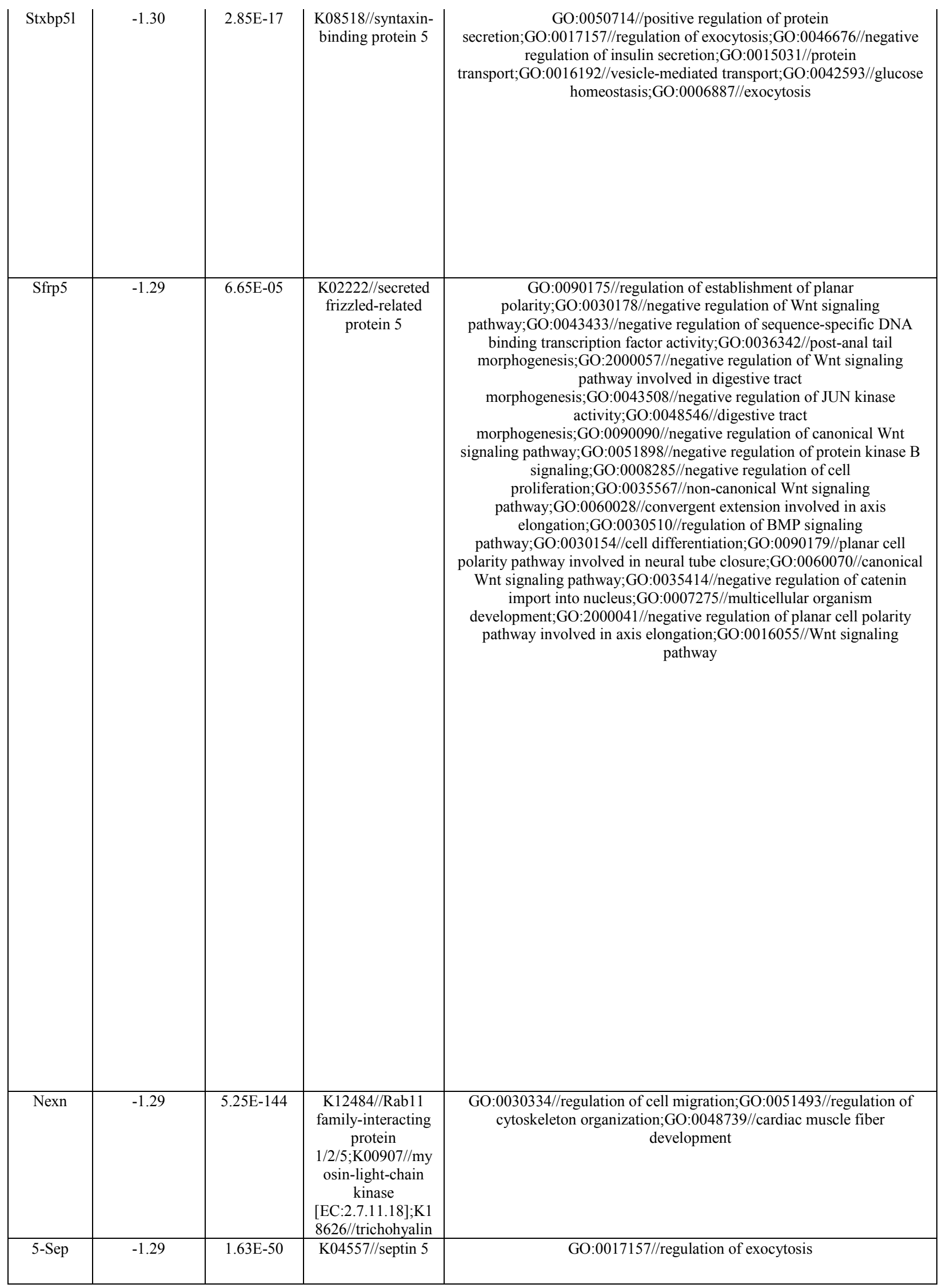




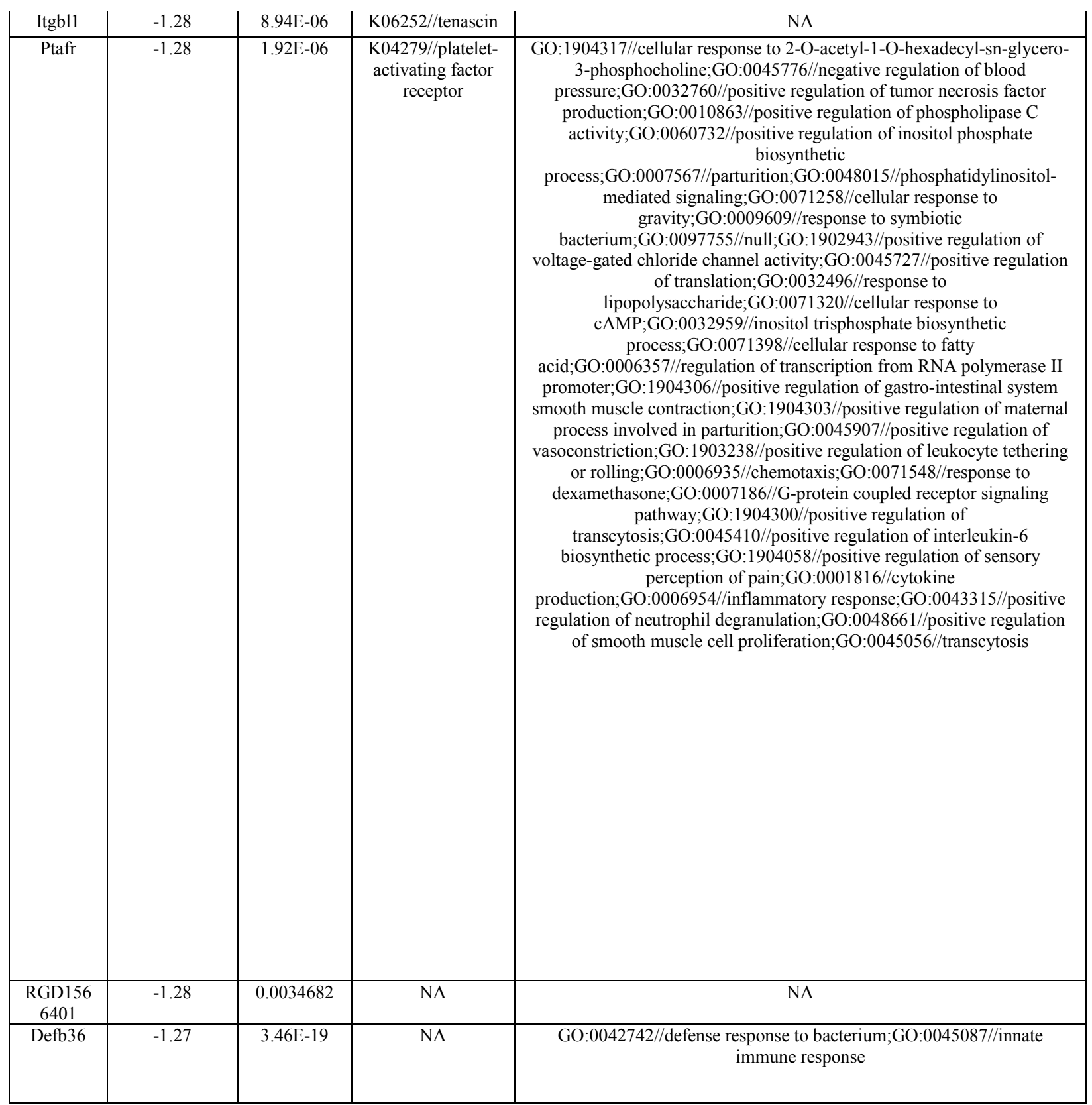




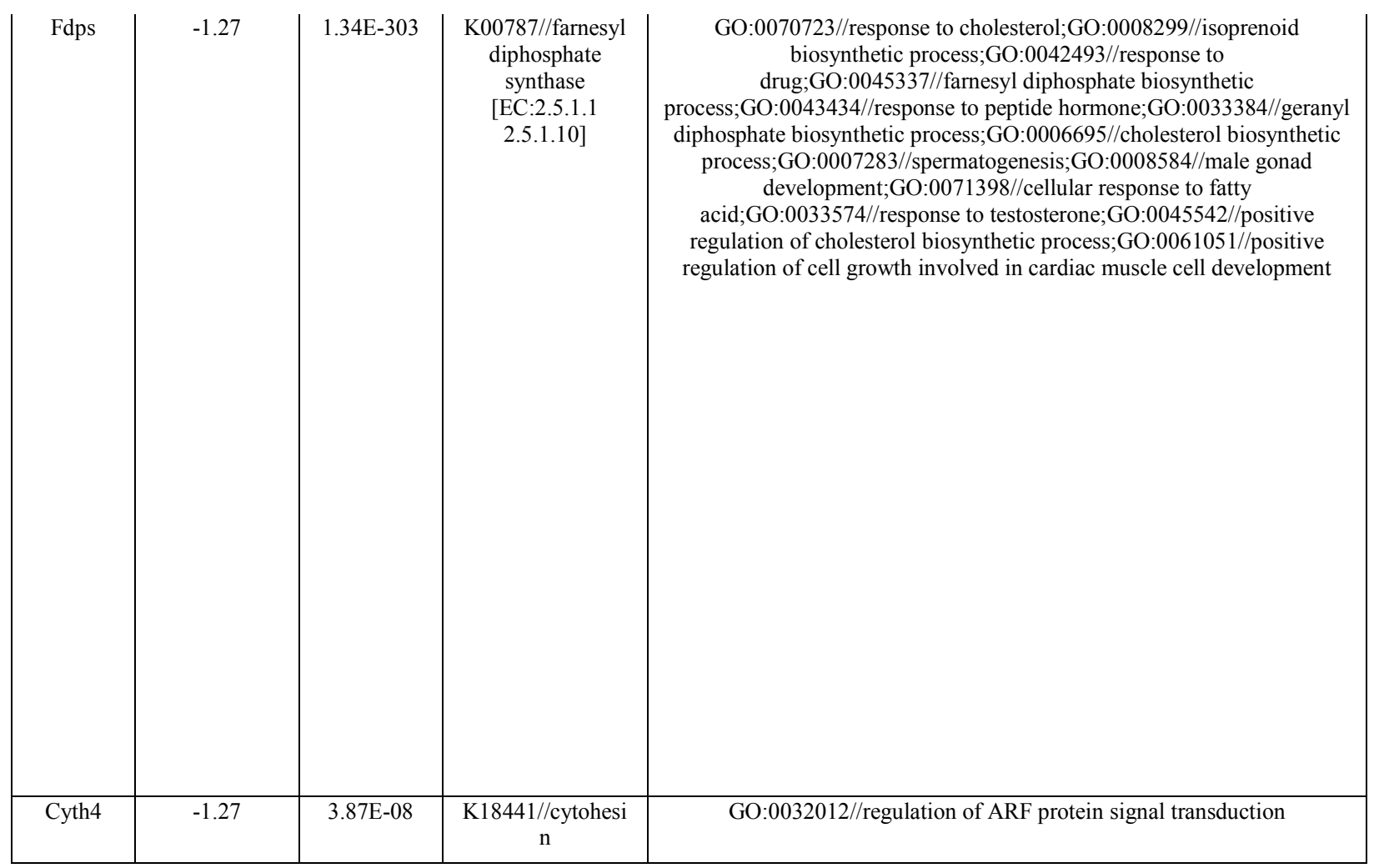




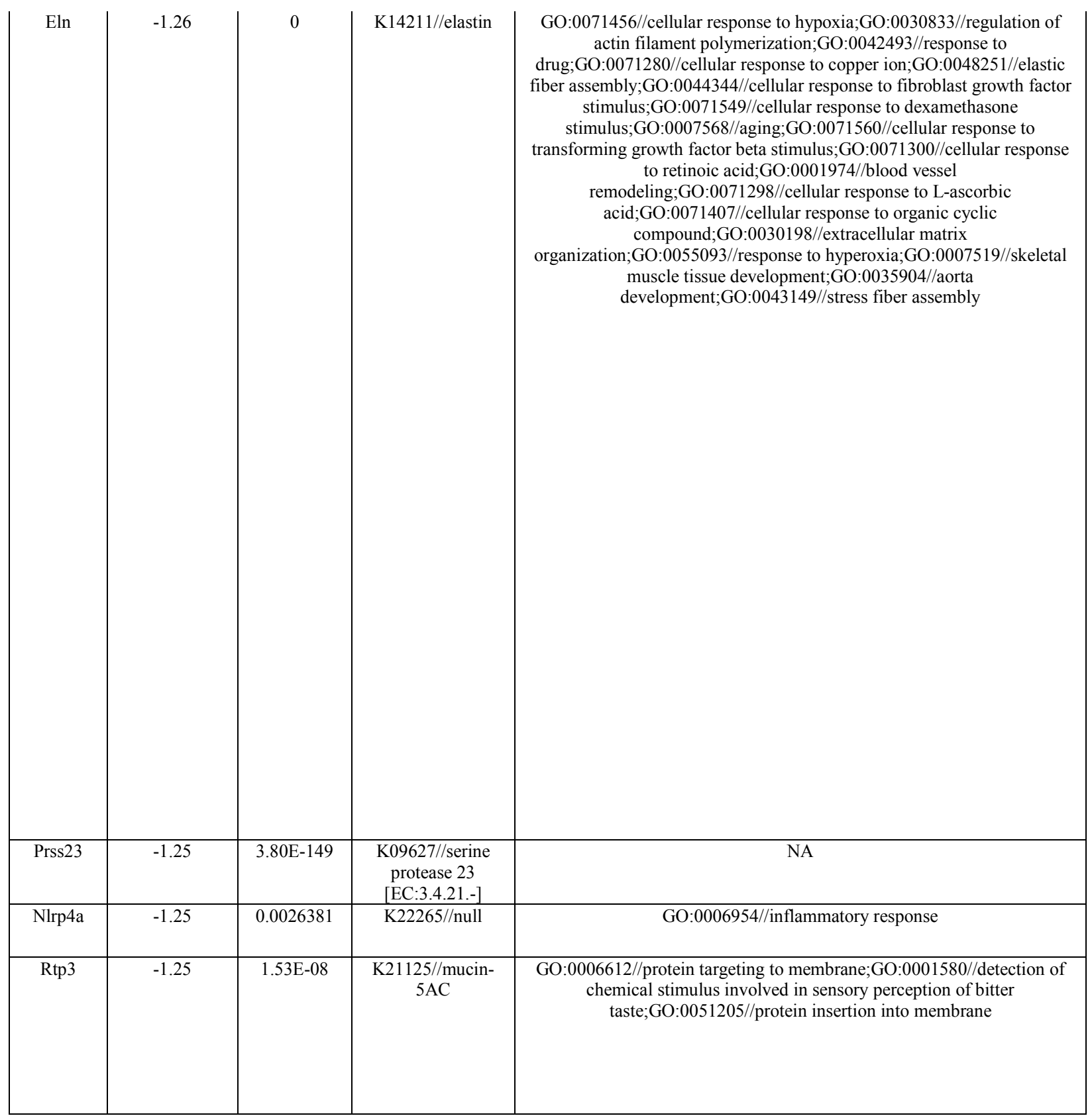




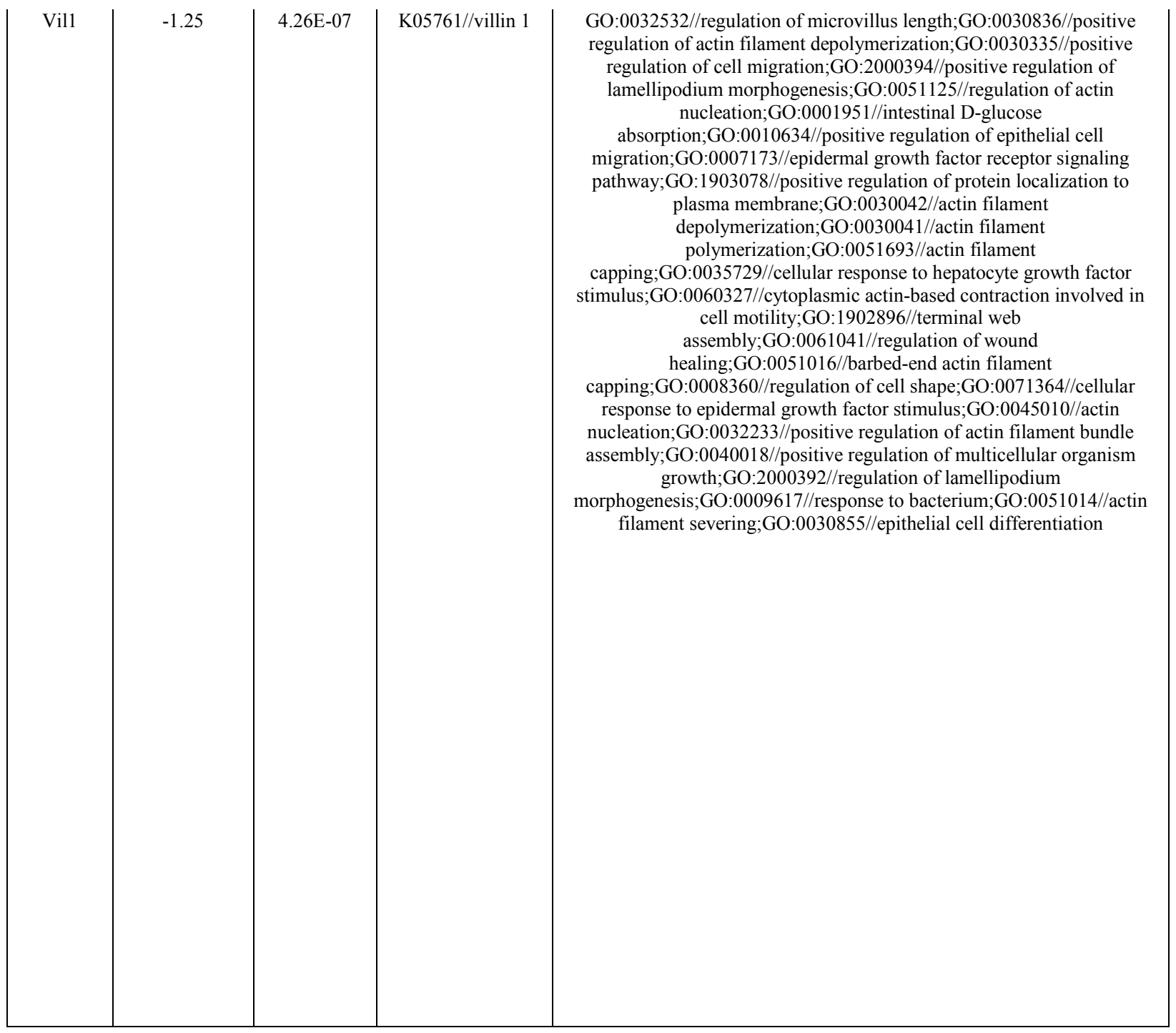




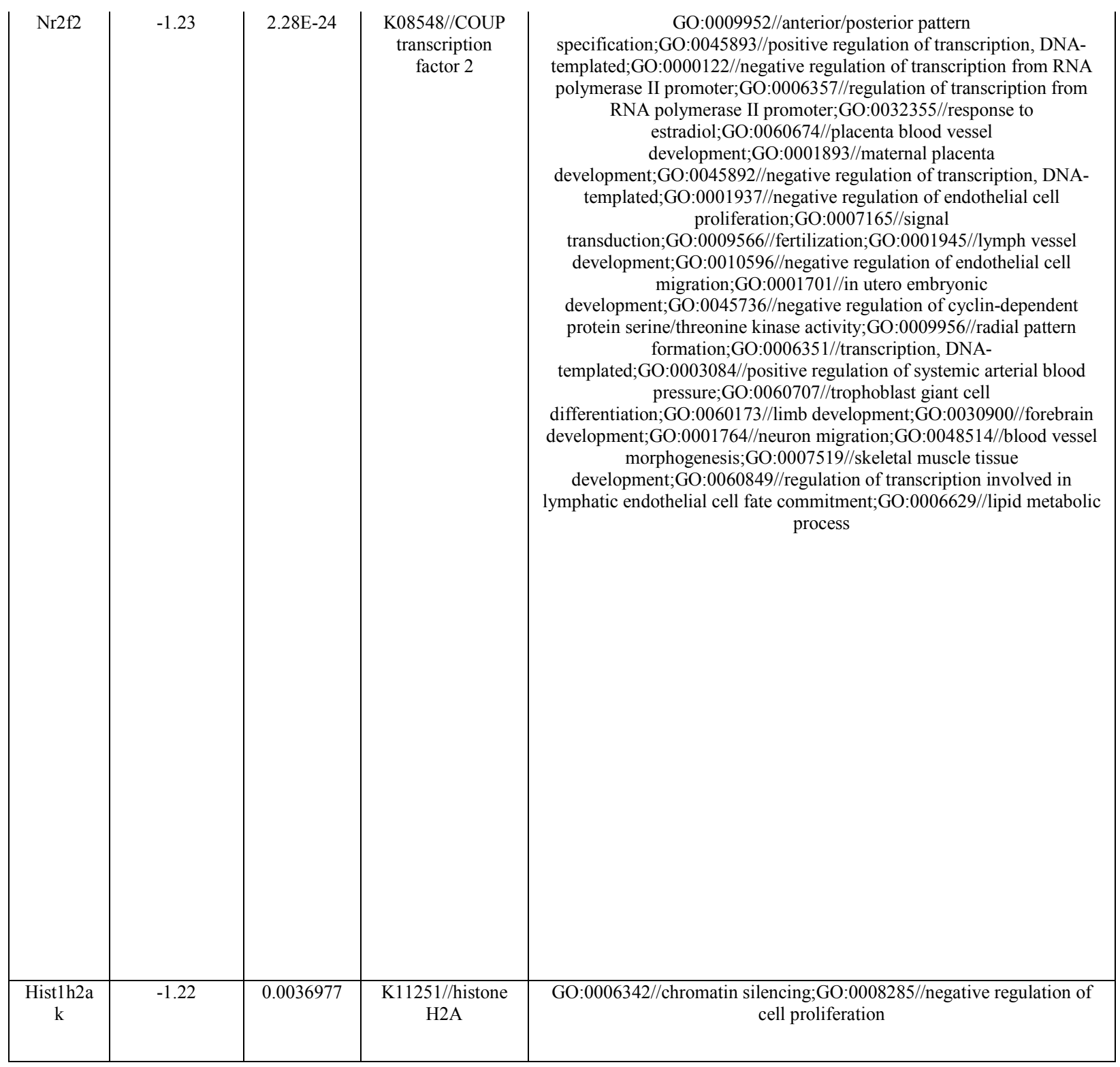




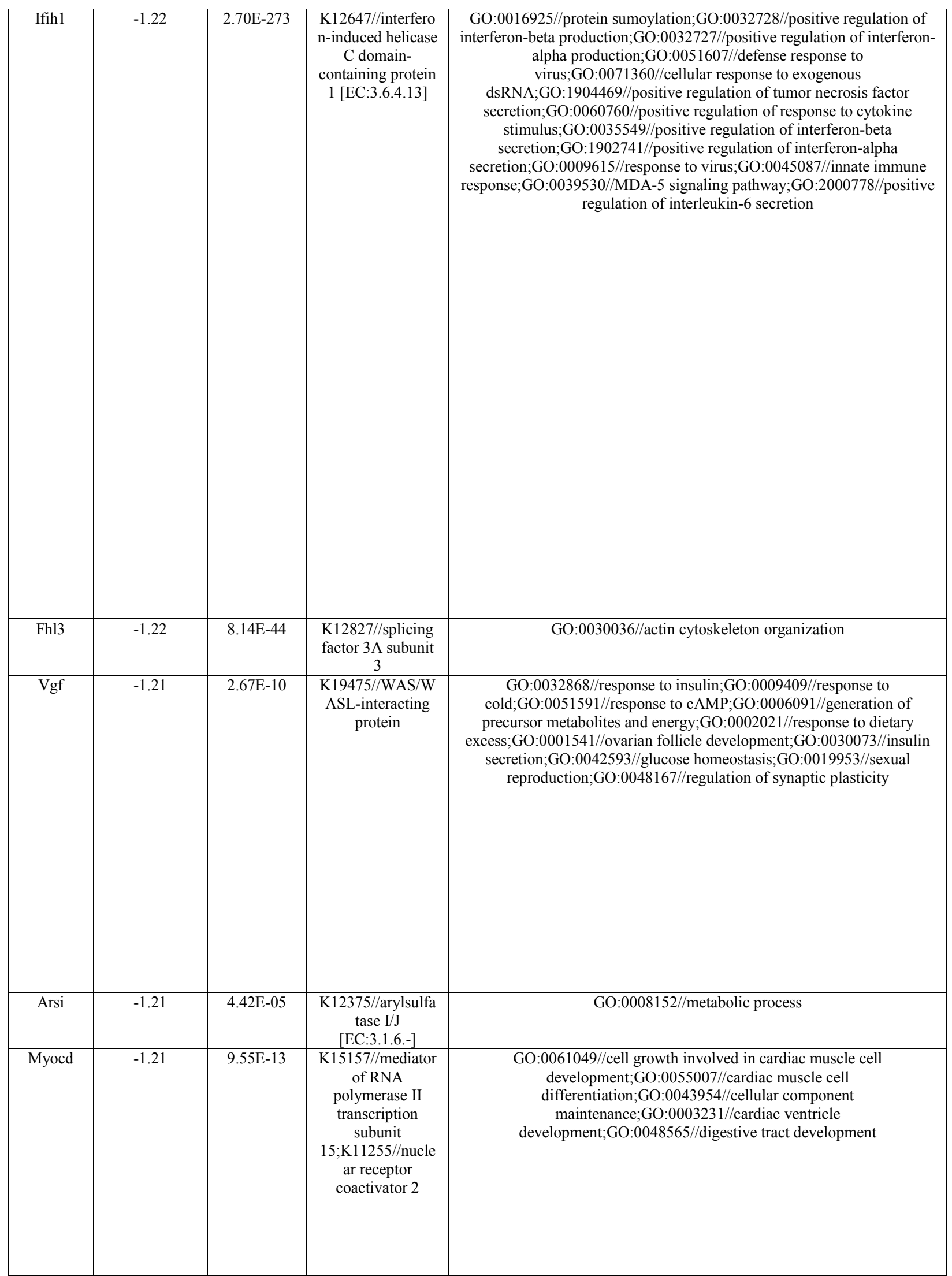




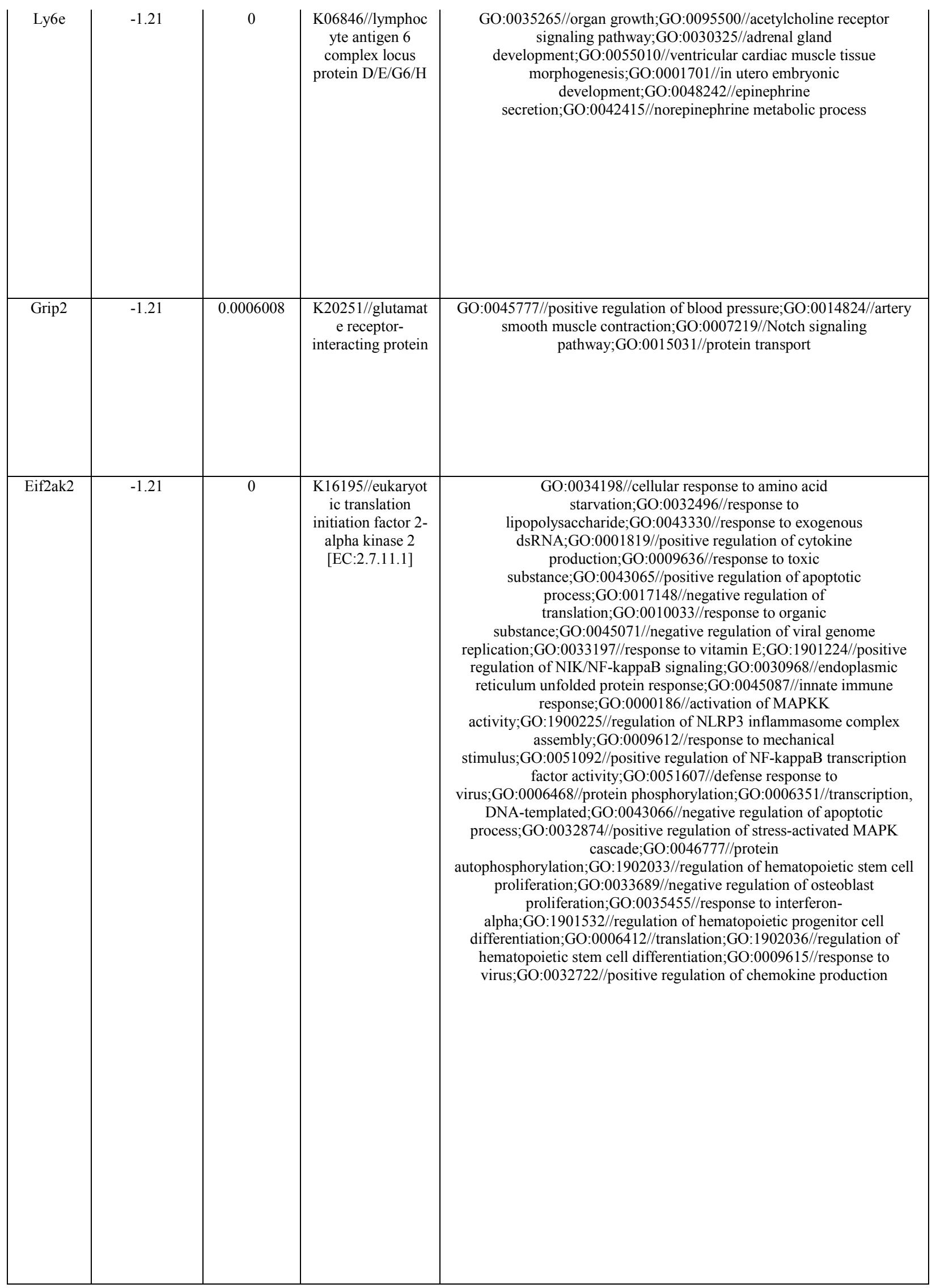




\begin{tabular}{|c|c|c|c|c|}
\hline Pltp & -1.21 & 4.27E-12 & $\begin{array}{l}\text { K08761//phosphol } \\
\text { ipid transfer } \\
\text { protein }\end{array}$ & $\begin{array}{c}\text { GO:0010875//positive regulation of cholesterol } \\
\text { efflux;GO:0030317//flagellated sperm motility;GO:0010189//vitamin E } \\
\text { biosynthetic process;GO:0015914//phospholipid } \\
\text { transport;GO:0006869//lipid transport;GO:0034375//high-density } \\
\text { lipoprotein particle remodeling;GO:0035627//ceramide } \\
\text { transport;GO:0006629//lipid metabolic process }\end{array}$ \\
\hline Kcnmb1 & -1.21 & $8.52 \mathrm{E}-16$ & $\begin{array}{l}\text { K04937//potassiu } \\
\text { m large } \\
\text { conductance } \\
\text { calcium-activated } \\
\text { channel subfamily } \\
\text { M beta member } 1\end{array}$ & $\begin{array}{l}\text { GO:0071456//cellular response to hypoxia;GO:0071361//cellular } \\
\text { response to ethanol;GO:1901381//positive regulation of potassium ion } \\
\text { transmembrane } \\
\text { transport;GO:0097755//null;GO:0007568//aging;GO:0051592//response } \\
\text { to calcium ion;GO:1903413//cellular response to bile } \\
\text { acid;GO:0007268//chemical synaptic } \\
\text { transmission;GO:0005513//detection of calcium ion }\end{array}$ \\
\hline Mitd1 & -1.20 & $1.67 \mathrm{E}-133$ & $\begin{array}{l}\text { K12196//vacuolar } \\
\text { protein-sorting- } \\
\text { associated protein } \\
4 ; \text { K06698//proteas } \\
\text { ome activator } \\
\text { subunit } 3 \text { (PA28 } \\
\text { gamma);K21358// } \\
\text { null } \\
\end{array}$ & $\begin{array}{c}\text { GO:0006810//transport;GO:0000281//mitotic } \\
\text { cytokinesis;GO:0000920//cell separation after } \\
\text { cytokinesis;GO:0032091//negative regulation of protein binding }\end{array}$ \\
\hline $\begin{array}{l}\text { RGD156 } \\
5844\end{array}$ & -1.20 & $3.73 \mathrm{E}-07$ & $\begin{array}{c}\text { K10668//E3 } \\
\text { ubiquitin-protein } \\
\text { ligase RNF138 } \\
\text { [EC:2.3.2.27] }\end{array}$ & $\begin{array}{l}\text { GO:0032436//positive regulation of proteasomal ubiquitin-dependent } \\
\text { protein catabolic process;GO:0000209//protein polyubiquitination }\end{array}$ \\
\hline Tnnt2 & -1.20 & $1.99 \mathrm{E}-31$ & $\begin{array}{c}\text { K10372//troponin } \\
\text { T, slow skeletal } \\
\text { muscle;K12045//tr } \\
\text { oponin T, cardiac } \\
\text { muscle }\end{array}$ & NA \\
\hline
\end{tabular}




\begin{tabular}{|c|c|c|c|c|}
\hline Hsd3b1 & -1.20 & 0.0031719 & $\begin{array}{l}\text { K00070//3beta- } \\
\text { hydroxy-Delta5- } \\
\text { steroid } \\
\text { dehydrogenase / } \\
\text { steroid Delta- } \\
\text { isomerase } \\
\text { [EC:1.1.1.145 } \\
5.3 .3 .1]\end{array}$ & $\begin{array}{c}\text { GO:0034698//response to gonadotropin;GO:0006694//steroid } \\
\text { biosynthetic process;GO:0021766//hippocampus } \\
\text { development;GO:0006702//androgen biosynthetic } \\
\text { process;GO:0034757//negative regulation of iron ion } \\
\text { transport;GO:0046686//response to cadmium ion;GO:0010288//response } \\
\text { to lead ion;GO:0006700//C21-steroid hormone biosynthetic } \\
\text { process;GO:0033327//Leydig cell differentiation;GO:0051412//response } \\
\text { to corticosterone }\end{array}$ \\
\hline Ppp1r1b & -1.20 & $1.72 \mathrm{E}-06$ & $\begin{array}{l}\text { K15494//protein } \\
\text { phosphatase 1 } \\
\text { regulatory subunit } \\
\text { 1B }\end{array}$ & NA \\
\hline Aldoc & -1.19 & $3.41 \mathrm{E}-13$ & $\begin{array}{c}\text { K01623//fructose- } \\
\text { bisphosphate } \\
\text { aldolase, class I } \\
\text { [EC:4.1.2.13] }\end{array}$ & NA \\
\hline Hmges1 & -1.19 & 0 & $\begin{array}{c}\text { K01641//hydroxy } \\
\text { methylglutaryl- } \\
\text { CoA synthase } \\
\text { [EC:2.3.3.10] }\end{array}$ & $\begin{array}{c}\text { GO:0008299//isoprenoid biosynthetic process;GO:0016126//sterol } \\
\text { biosynthetic process }\end{array}$ \\
\hline Hpcal4 & -1.19 & $9.48 \mathrm{E}-06$ & $\begin{array}{l}\text { K19936//visinin- } \\
\text { like protein } 1\end{array}$ & GO:0007165//signal transduction \\
\hline Ptprq & -1.19 & 0.0073253 & $\begin{array}{c}\text { K16910//receptor- } \\
\text { type tyrosine- } \\
\text { protein } \\
\text { phosphatase Q } \\
\text { [EC:3.1.3.48] }\end{array}$ & $\begin{array}{c}\text { GO:0060116//vestibular receptor cell } \\
\text { morphogenesis;GO:0002244//hematopoietic progenitor cell } \\
\text { differentiation;GO:0045598//regulation of fat cell } \\
\text { differentiation;GO:0042472//inner ear } \\
\text { morphogenesis;GO:0050910//detection of mechanical stimulus involved } \\
\text { in sensory perception of sound;GO:0050885//neuromuscular process } \\
\text { controlling balance }\end{array}$ \\
\hline
\end{tabular}




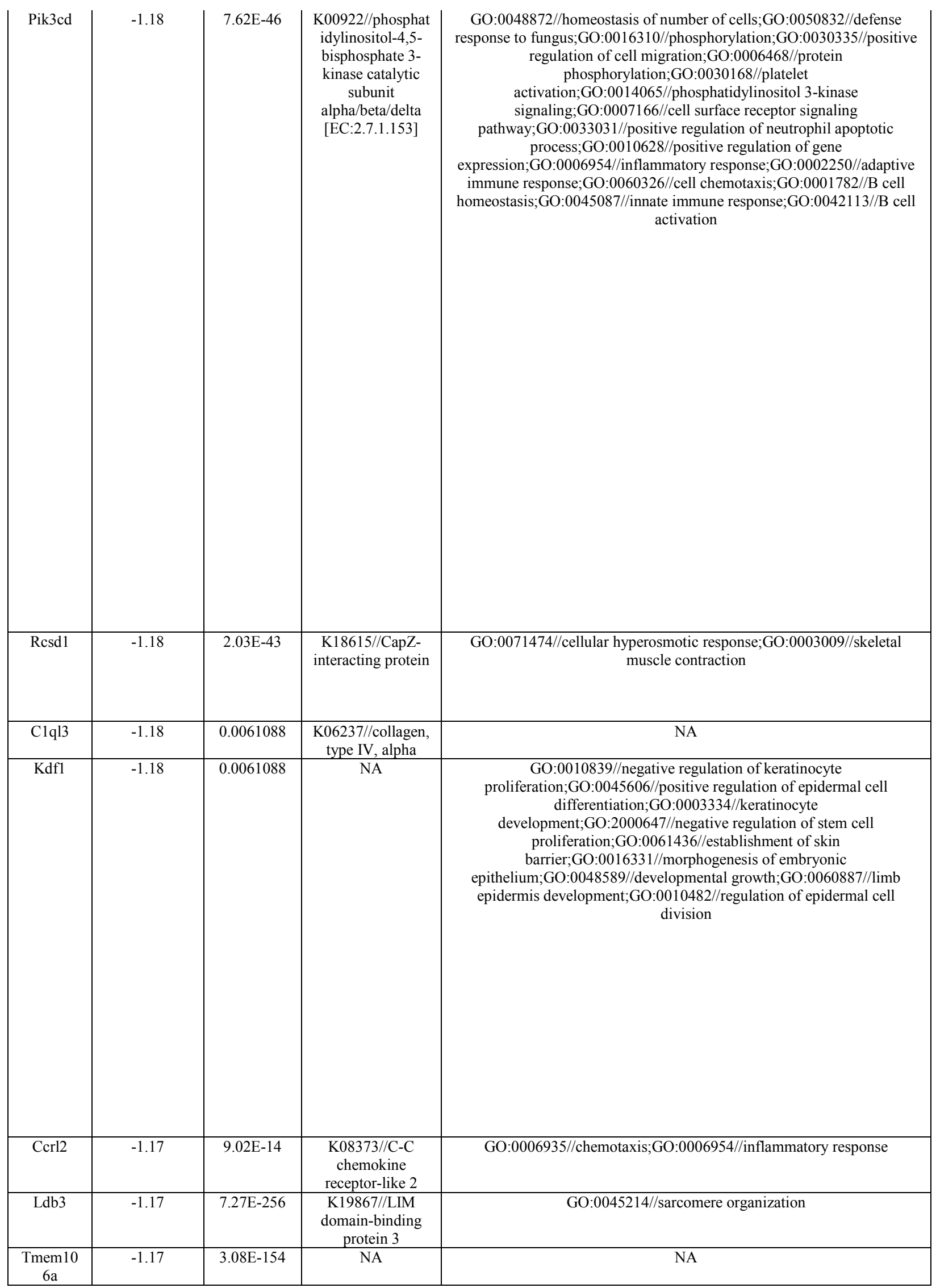




\begin{tabular}{|c|c|c|c|c|}
\hline Des & -1.16 & 4.87E-174 & K07610//desmin & NA \\
\hline Cxcl12 & -1.16 & 0.0006021 & $\begin{array}{l}\text { K10031//C-X-C } \\
\text { motif chemokine } \\
12\end{array}$ & $\begin{array}{c}\text { GO:0031100//animal organ regeneration;GO:0016477//cell } \\
\text { migration;GO:0045666//positive regulation of neuron } \\
\text { differentiation;GO:0030335//positive regulation of cell } \\
\text { migration;GO:0050930//induction of positive } \\
\text { chemotaxis;GO:0008344//adult locomotory behavior;GO:0008354//germ } \\
\text { cell migration;GO:0007420//brain development;GO:0060326//cell } \\
\text { chemotaxis;GO:0048842//positive regulation of axon extension involved } \\
\text { in axon guidance;GO:2000406//positive regulation of T cell } \\
\text { migration;GO:1901741//positive regulation of myoblast } \\
\text { fusion;GO:0009612//response to mechanical } \\
\text { stimulus;GO:1990478//response to ultrasound;GO:0090026//positive } \\
\text { regulation of monocyte chemotaxis;GO:0008045//motor neuron axon } \\
\text { guidance;GO:0070098//chemokine-mediated signaling } \\
\text { pathway;GO:0071542//dopaminergic neuron } \\
\text { differentiation;GO:0009408//response to heat;GO:0001666//response to } \\
\text { hypoxia;GO:0007281//germ cell development;GO:0009314//response to } \\
\text { radiation;GO:0001764//neuron migration;GO:1903237//negative } \\
\text { regulation of leukocyte tethering or rolling;GO:0033603//positive } \\
\text { regulation of dopamine secretion;GO:0001569//branching involved in } \\
\text { blood vessel morphogenesis;GO:0045785//positive regulation of cell } \\
\text { adhesion;GO:0098609//cell-cell adhesion;GO:1902230//negative } \\
\text { regulation of intrinsic apoptotic signaling pathway in response to DNA } \\
\text { damage;GO:0051924//regulation of calcium ion } \\
\text { transport;GO:0090280//positive regulation of calcium ion } \\
\text { import;GO:0030334//regulation of cell migration;GO:0001938//positive } \\
\text { regulation of endothelial cell proliferation;GO:0050965//detection of } \\
\text { temperature stimulus involved in sensory perception of } \\
\text { pain;GO:0022029//telencephalon cell migration;GO:0043434//response } \\
\text { to peptide hormone;GO:0001667//ameboidal-type cell } \\
\text { migration;GO:0042098//T cell proliferation;GO:0006952//defense } \\
\text { response;GO:0006955//immune response;GO:0050966//detection of } \\
\text { mechanical stimulus involved in sensory perception of } \\
\text { pain;GO:2000107//negative regulation of leukocyte apoptotic } \\
\text { process;GO:0008284//positive regulation of cell proliferation }\end{array}$ \\
\hline
\end{tabular}




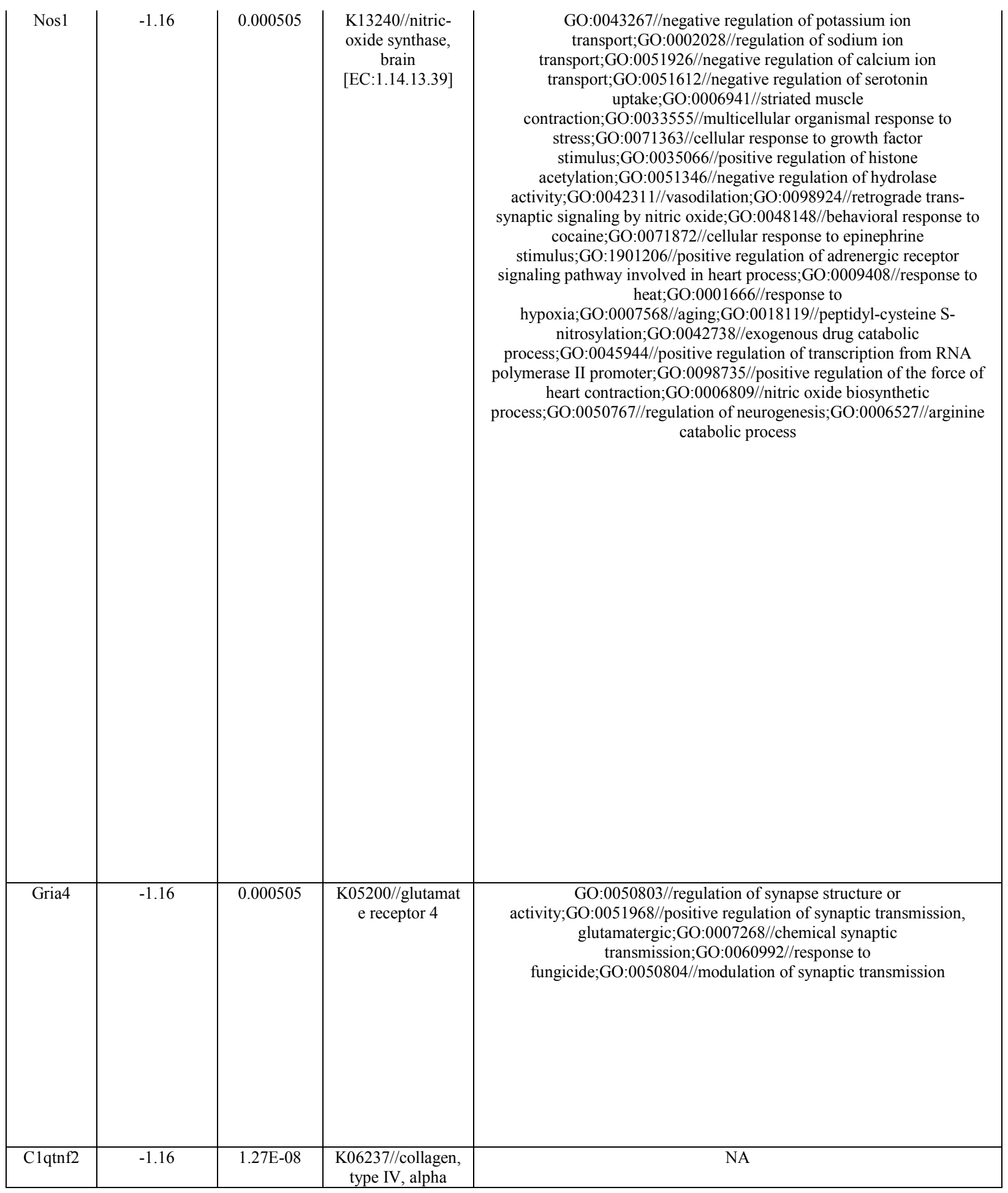




\begin{tabular}{|c|c|c|c|c|}
\hline Rtn4rl1 & -1.16 & $7.05 \mathrm{E}-11$ & $\begin{array}{l}\text { K16660//reticulon } \\
-4 \text { receptor-like } 1\end{array}$ & $\begin{array}{l}\text { GO:0006469//negative regulation of protein kinase } \\
\text { activity;GO:0010977//negative regulation of neuron projection } \\
\text { development;GO:0048681//negative regulation of axon } \\
\text { regeneration;GO:0046426//negative regulation of JAK-STAT } \\
\text { cascade;GO:0019221//cytokine-mediated signaling } \\
\text { pathway;GO:0007166//cell surface receptor signaling } \\
\text { pathway;GO:0022038//corpus callosum development }\end{array}$ \\
\hline Defb24 & -1.15 & $1.79 \mathrm{E}-12$ & NA & $\begin{array}{c}\text { GO:0050829//defense response to Gram-negative } \\
\text { bacterium;GO:0050830//defense response to Gram-positive } \\
\text { bacterium;GO:0042742//defense response to } \\
\text { bacterium;GO:0045087//innate immune response }\end{array}$ \\
\hline Sgcg & -1.15 & $1.02 \mathrm{E}-09$ & $\begin{array}{l}\text { K12564//gamma- } \\
\text { sarcoglycan }\end{array}$ & $\begin{array}{c}\text { GO:0055001//muscle cell development;GO:0060047//heart } \\
\text { contraction;GO:0048738//cardiac muscle tissue } \\
\text { development;GO:0007517//muscle organ } \\
\text { development;GO:0061024//membrane organization }\end{array}$ \\
\hline
\end{tabular}




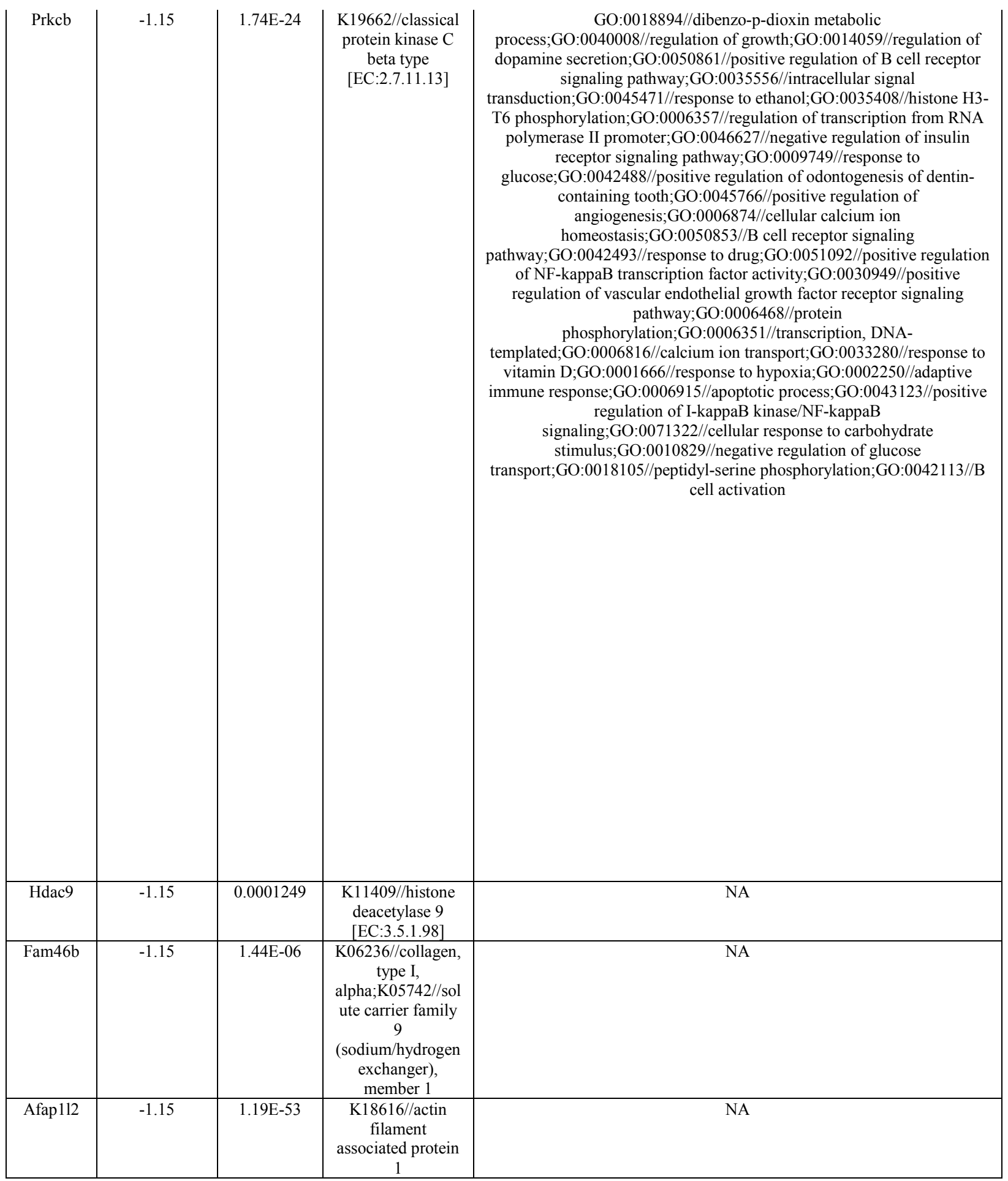




\begin{tabular}{|c|c|c|c|c|}
\hline Thy1 & -1.15 & $1.68 \mathrm{E}-09$ & $\begin{array}{l}\text { K06514//Thy-1 } \\
\text { cell surface } \\
\text { antigen }\end{array}$ & $\begin{array}{c}\text { GO:0050731//positive regulation of peptidyl-tyrosine } \\
\text { phosphorylation;GO:0001952//regulation of cell-matrix } \\
\text { adhesion;GO:2000298//regulation of Rho-dependent protein } \\
\text { serine/threonine kinase activity;GO:0043547//positive regulation of } \\
\text { GTPase activity;GO:0050860//negative regulation of T cell receptor } \\
\text { signaling pathway;GO:0098609//cell-cell adhesion;GO:0002693//positive } \\
\text { regulation of cellular extravasation;GO:0007229//integrin-mediated } \\
\text { signaling pathway;GO:0045576//mast cell activation;GO:0048041//focal } \\
\text { adhesion assembly;GO:0034116//positive regulation of heterotypic cell- } \\
\text { cell adhesion;GO:0043113//receptor clustering;GO:0070571//negative } \\
\text { regulation of neuron projection } \\
\text { regeneration;GO:0001525//angiogenesis;GO:0050852//T cell receptor } \\
\text { signaling pathway;GO:0051894//positive regulation of focal adhesion } \\
\text { assembly;GO:0007267//cell-cell signaling;GO:0051281//positive } \\
\text { regulation of release of sequestered calcium ion into } \\
\text { cytosol;GO:0043066//negative regulation of apoptotic } \\
\text { process;GO:0030336//negative regulation of cell } \\
\text { migration;GO:0050870//positive regulation of T cell } \\
\text { activation;GO:0048147//negative regulation of fibroblast } \\
\text { proliferation;GO:0046777//protein } \\
\text { autophosphorylation;GO:0061099//negative regulation of protein tyrosine } \\
\text { kinase activity;GO:0006469//negative regulation of protein kinase } \\
\text { activity;GO:0050771//negative regulation of } \\
\text { axonogenesis;GO:0007010//cytoskeleton } \\
\text { organization;GO:0046549//retinal cone cell development }\end{array}$ \\
\hline $\begin{array}{c}\text { RGD156 } \\
1157\end{array}$ & -1.15 & $1.83 \mathrm{E}-11$ & NA & NA \\
\hline Runx1t1 & -1.15 & $5.62 \mathrm{E}-32$ & $\begin{array}{l}\mathrm{K} 10053 / / \text { runt- } \\
\text { related } \\
\text { transcription } \\
\text { factor 1; } \\
\text { translocated to, } 1\end{array}$ & $\begin{array}{c}\text { GO:0045892//negative regulation of transcription, DNA- } \\
\text { templated;GO:0010977//negative regulation of neuron projection } \\
\text { development;GO:0006355//regulation of transcription, DNA- } \\
\text { templated;GO:0045444//fat cell } \\
\text { differentiation;GO:0006351//transcription, DNA- } \\
\text { templated;GO:0051101//regulation of DNA } \\
\text { binding;GO:0045599//negative regulation of fat cell differentiation }\end{array}$ \\
\hline Ip6k2 & -1.14 & 0 & $\begin{array}{c}\text { K07756//inositol- } \\
\text { hexakisphosphate } \\
\text { 5-kinase } \\
\text { [EC:2.7.4.21] }\end{array}$ & NA \\
\hline
\end{tabular}




\begin{tabular}{|c|c|c|c|c|}
\hline $\begin{array}{l}\text { LOC500 } \\
956\end{array}$ & -1.14 & $4.01 \mathrm{E}-84$ & $\begin{array}{l}\text { K03903//fibrinoge } \\
\text { n alpha } \\
\text { chain;K10104//fic } \\
\text { olin }\end{array}$ & $\begin{array}{l}\text { GO:0034340//response to type I interferon;GO:0034341//response to } \\
\text { interferon-gamma;GO:0045071//negative regulation of viral genome } \\
\text { replication;GO:0034342//response to type III } \\
\text { interferon;GO:0051607//defense response to virus }\end{array}$ \\
\hline Adm & -1.13 & $2.50 \mathrm{E}-72$ & $\begin{array}{l}\text { K12333//adrenom } \\
\text { edullin }\end{array}$ & $\begin{array}{c}\text { GO:0031100//animal organ regeneration;GO:0031623//receptor } \\
\text { internalization;GO:0045906//negative regulation of } \\
\text { vasoconstriction;GO:0043065//positive regulation of apoptotic } \\
\text { process;GO:0043116//negative regulation of vascular } \\
\text { permeability;GO:0060712//spongiotrophoblast layer } \\
\text { development;GO:0045766//positive regulation of } \\
\text { angiogenesis;GO:0001570//vasculogenesis;GO:0030819//positive } \\
\text { regulation of cAMP biosynthetic process;GO:0008285//negative } \\
\text { regulation of cell proliferation;GO:0009611//response to } \\
\text { wounding;GO:0046879//hormone secretion;GO:0007565//female } \\
\text { pregnancy;GO:0008209//androgen metabolic process;GO:0007507//heart } \\
\text { development;GO:0001666//response to } \\
\text { hypoxia;GO:0042475//odontogenesis of dentin-containing } \\
\text { tooth;GO:0019933//cAMP-mediated signaling;GO:0003073//regulation } \\
\text { of systemic arterial blood pressure;GO:0001843//neural tube } \\
\text { closure;GO:0097084//vascular smooth muscle cell } \\
\text { development;GO:0097755//null;GO:0032496//response to } \\
\text { lipopolysaccharide;GO:0097647//amylin receptor signaling } \\
\text { pathway;GO:0055074//calcium ion homeostasis;GO:0030816//positive } \\
\text { regulation of cAMP metabolic process;GO:0010033//response to organic } \\
\text { substance;GO:0031102//neuron projection } \\
\text { regeneration;GO:0051384//response to } \\
\text { glucocorticoid;GO:0010460//positive regulation of heart } \\
\text { rate;GO:0032868//response to insulin;GO:0009409//response to } \\
\text { cold;GO:0035809//regulation of urine volume;GO:2001214//positive } \\
\text { regulation of vasculogenesis;GO:0006171//cAMP biosynthetic } \\
\text { process;GO:0007568//aging;GO:0002026//regulation of the force of heart } \\
\text { contraction;GO:0060670//branching involved in labyrinthine layer } \\
\text { morphogenesis;GO:0042594//response to } \\
\text { starvation;GO:0048589//developmental growth;GO:0007204//positive } \\
\text { regulation of cytosolic calcium ion concentration;GO:0002031//G-protein } \\
\text { coupled receptor internalization;GO:0008284//positive regulation of cell } \\
\text { proliferation }\end{array}$ \\
\hline Ppp1r14a & -1.13 & $2.56 \mathrm{E}-16$ & $\begin{array}{l}\text { K12328//protein } \\
\text { phosphatase } 1 \\
\text { regulatory subunit } \\
14 \mathrm{~A}\end{array}$ & $\begin{array}{l}\text { GO:0042325//regulation of phosphorylation;GO:0035690//cellular } \\
\text { response to drug }\end{array}$ \\
\hline
\end{tabular}




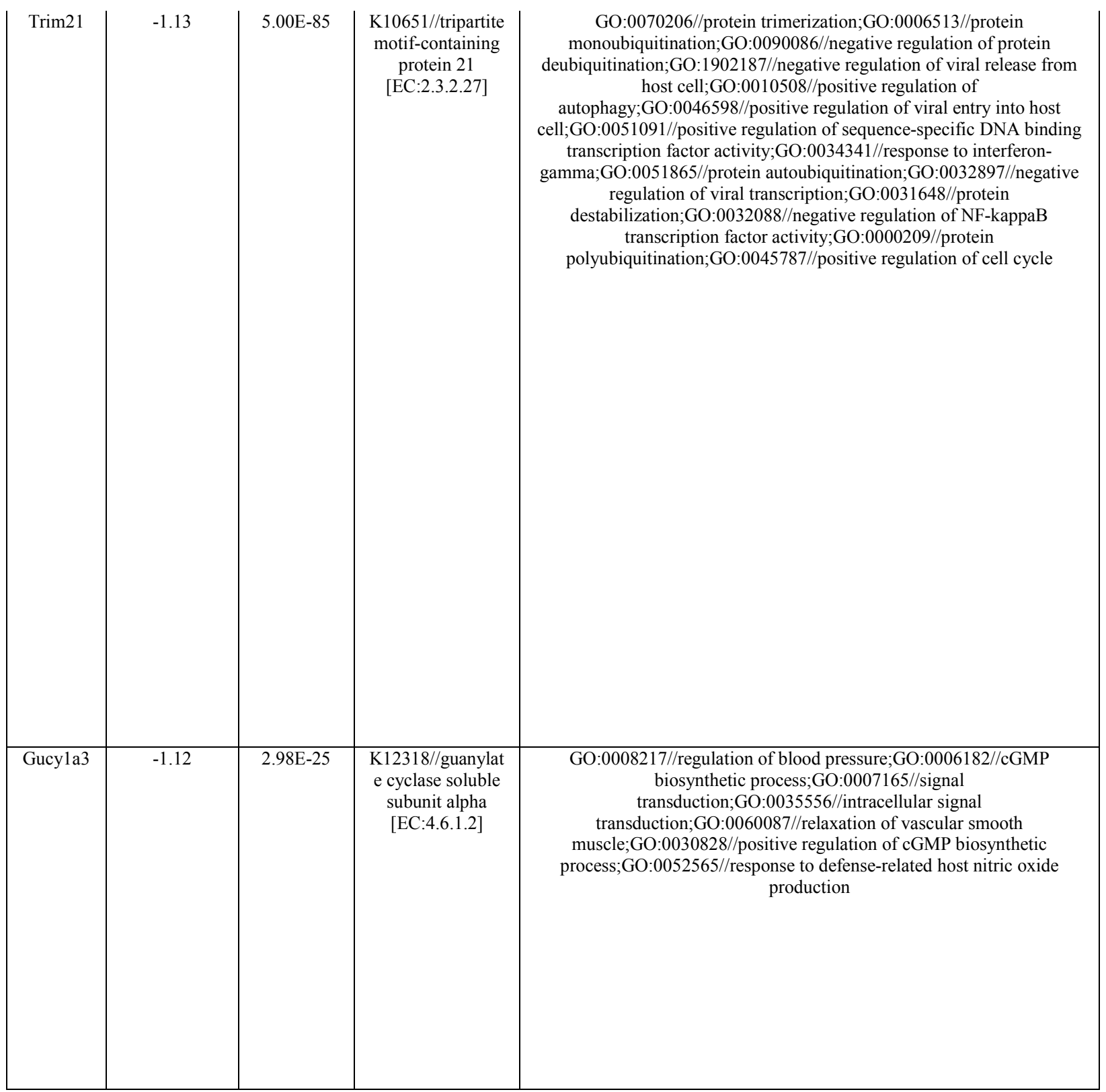




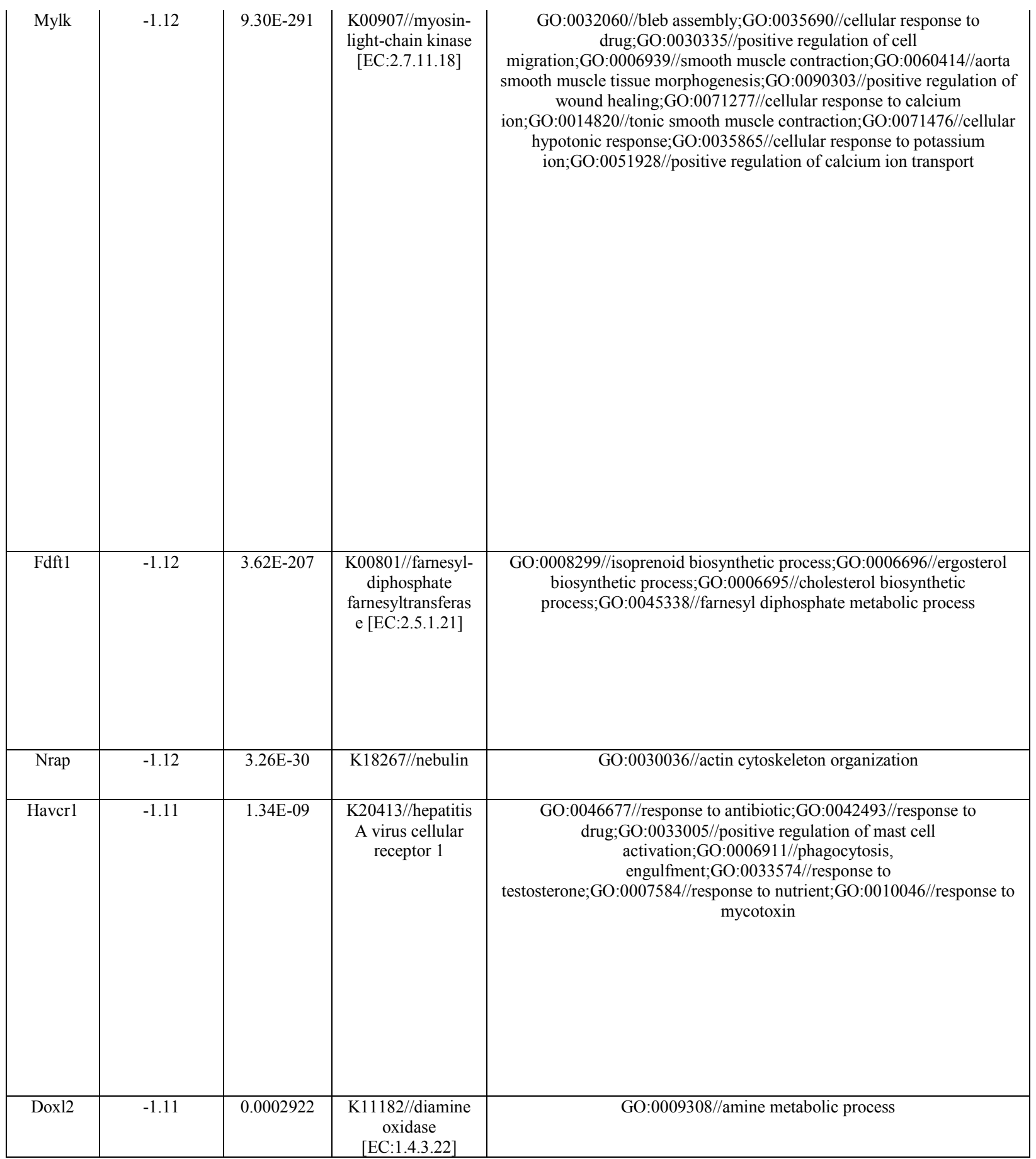




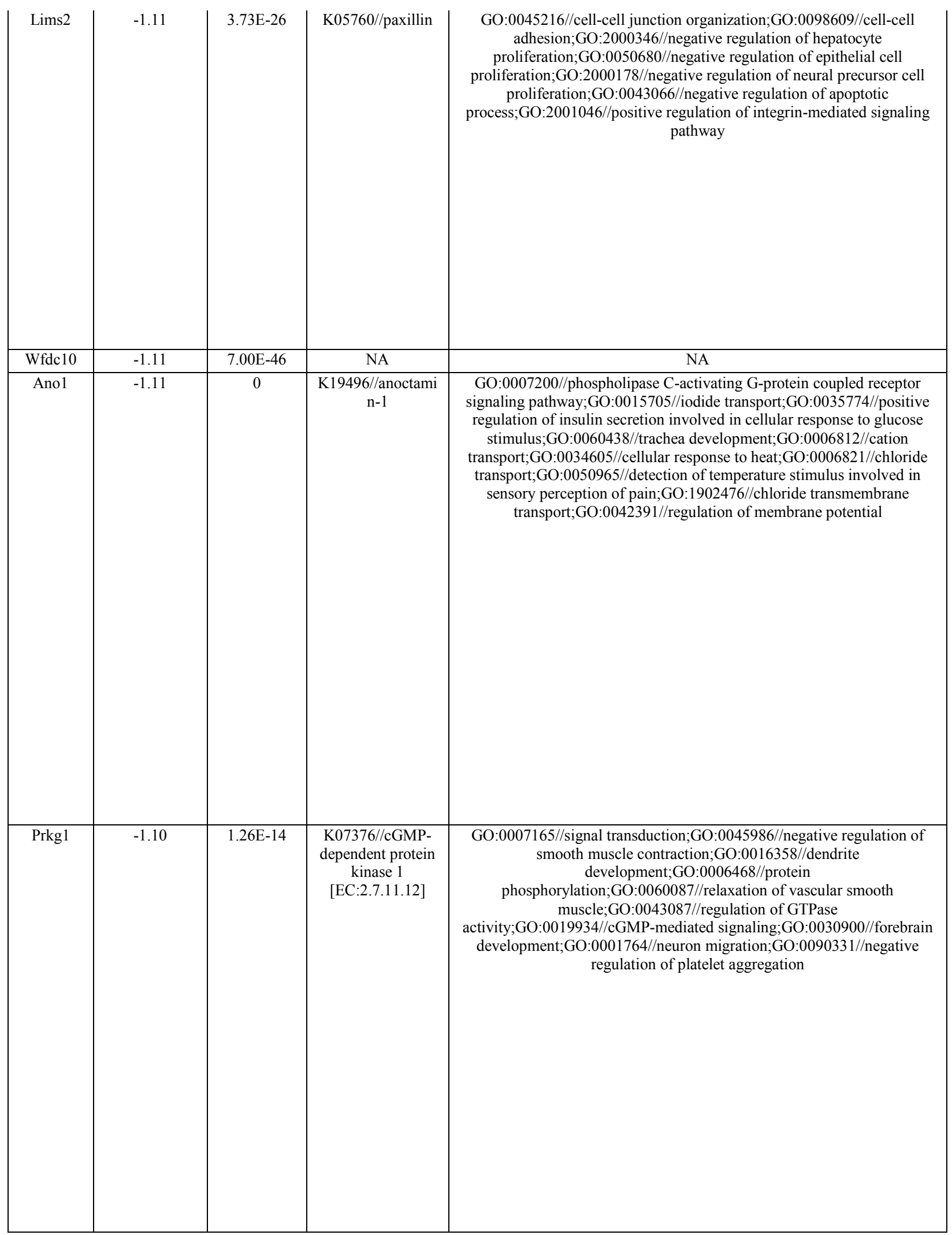




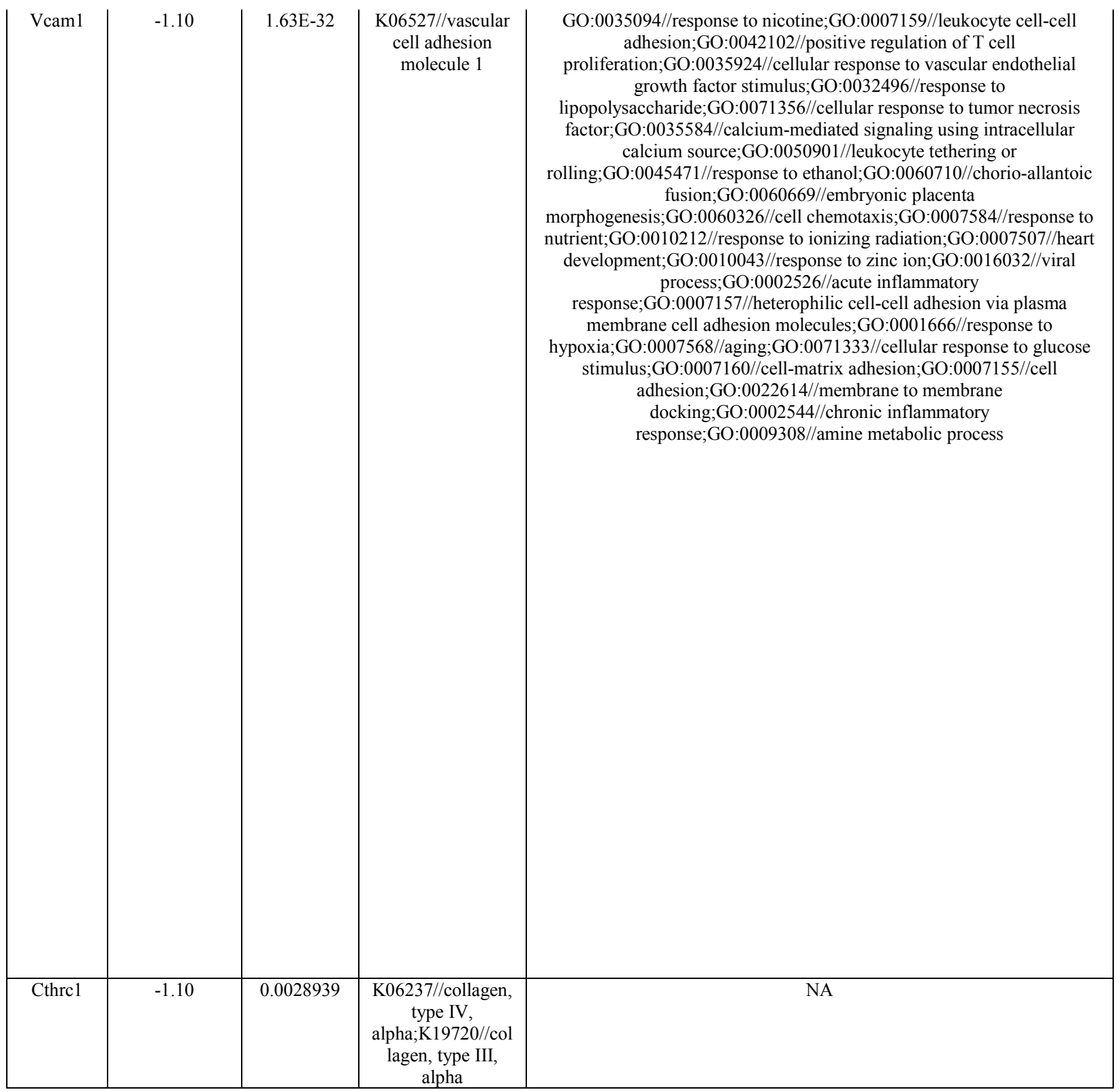




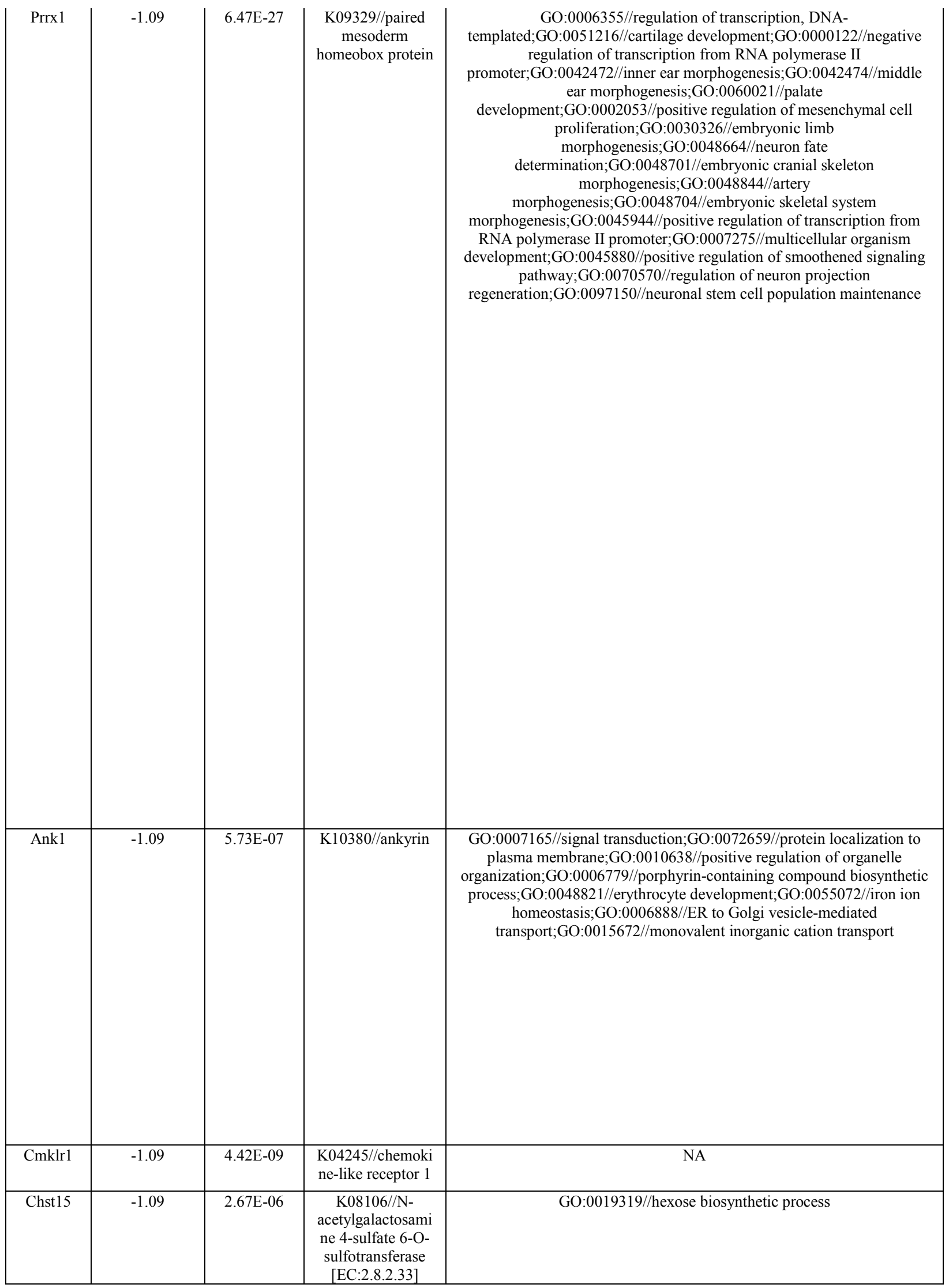




\begin{tabular}{|c|c|c|c|c|}
\hline Tor3a & -1.09 & $3.76 \mathrm{E}-62$ & $\begin{array}{c}\text { K20825//glycosa } \\
\text { minoglycan } \\
\text { xylosylkinase } \\
\text { [EC:2.7.1.-];K010 } \\
\text { 56//peptidyl- } \\
\text { tRNA hydrolase, } \\
\text { PTH1 family } \\
\text { [EC:3.1.1.29];K15 } \\
\text { 199//general } \\
\text { transcription } \\
\text { factor 3C } \\
\text { polypeptide 1 }\end{array}$ & NA \\
\hline Parp14 & -1.08 & 0 & $\begin{array}{l}\text { K15261//poly } \\
\text { [ADP-ribose] } \\
\text { polymerase } \\
10 / 14 / 15 \\
{[\text { EC:2.4.2.30] }}\end{array}$ & $\begin{array}{c}\text { GO:0006355//regulation of transcription, DNA- } \\
\text { templated;GO:0060336//negative regulation of interferon-gamma- } \\
\text { mediated signaling pathway;GO:0006351//transcription, DNA- } \\
\text { templated;GO:0070212//protein poly-ADP- } \\
\text { ribosylation;GO:0010629//negative regulation of gene } \\
\text { expression;GO:0042532//negative regulation of tyrosine phosphorylation } \\
\text { of STAT protein;GO:0042531//positive regulation of tyrosine } \\
\text { phosphorylation of STAT protein;GO:1902216//positive regulation of } \\
\text { interleukin-4-mediated signaling pathway;GO:0006471//protein ADP- } \\
\text { ribosylation }\end{array}$ \\
\hline Xpnpep2 & -1.08 & $2.92 \mathrm{E}-05$ & $\begin{array}{c}\text { K14208//Xaa-Pro } \\
\text { aminopeptidase } 2 \\
\text { [EC:3.4.11.9] }\end{array}$ & NA \\
\hline Arhgdib & -1.08 & 0.0011634 & $\begin{array}{l}\text { K12462//Rho } \\
\text { GDP-dissociation } \\
\text { inhibitor }\end{array}$ & $\begin{array}{l}\text { GO:1901164//negative regulation of trophoblast cell } \\
\text { migration;GO:0035023//regulation of Rho protein signal } \\
\text { transduction;GO:0071461//cellular response to redox } \\
\text { state;GO:2000249//regulation of actin cytoskeleton reorganization }\end{array}$ \\
\hline Olfml2b & -1.07 & 0 & $\begin{array}{c}\text { K04592//latrophili } \\
\text { n 1 }\end{array}$ & GO:0030198//extracellular matrix organization \\
\hline Sepp1 & -1.07 & $6.14 \mathrm{E}-17$ & NA & $\begin{array}{c}\text { GO:0019953//sexual reproduction;GO:0007626//locomotory } \\
\text { behavior;GO:0009791//post-embryonic } \\
\text { development;GO:0010269//response to selenium } \\
\text { ion;GO:0001887//selenium compound metabolic } \\
\text { process;GO:0040007//growth;GO:0007420//brain development }\end{array}$ \\
\hline
\end{tabular}




\begin{tabular}{|c|c|c|c|c|}
\hline Plch1 & -1.07 & 0.0006759 & $\begin{array}{c}\text { K19006//phosphat } \\
\text { idylinositol } \\
\text { phospholipase C, } \\
\text { eta [EC:3.1.4.11] }\end{array}$ & $\begin{array}{l}\text { GO:0016042//lipid catabolic process;GO:0048015//phosphatidylinositol- } \\
\text { mediated signaling }\end{array}$ \\
\hline Il1rl1 & -1.07 & 0.004871 & $\begin{array}{c}\text { K05171//interleuk } \\
\text { in } 1 \text { receptor-like } \\
1\end{array}$ & $\begin{array}{c}\text { GO:0002826//negative regulation of T-helper } 1 \text { type immune } \\
\text { response;GO:0043032//positive regulation of macrophage } \\
\text { activation;GO:1901653//cellular response to } \\
\text { peptide;GO:0090197//positive regulation of chemokine } \\
\text { secretion;GO:0050729//positive regulation of inflammatory } \\
\text { response;GO:0032754//positive regulation of interleukin-5 } \\
\text { production;GO:0043124//negative regulation of I-kappaB kinase/NF- } \\
\text { kappaB signaling;GO:0008285//negative regulation of cell } \\
\text { proliferation;GO:0032689//negative regulation of interferon-gamma } \\
\text { production }\end{array}$ \\
\hline Capn6 & -1.07 & 0.000354 & $\begin{array}{c}\text { K08575//calpain-6 } \\
\text { [EC:3.4.22.-] }\end{array}$ & NA \\
\hline Fblim1 & -1.07 & $8.74 \mathrm{E}-24$ & K06273//zyxin & $\begin{array}{l}\text { GO:0098609//cell-cell adhesion;GO:0033623//regulation of integrin } \\
\text { activation }\end{array}$ \\
\hline Pygm & -1.07 & $5.04 \mathrm{E}-15$ & $\begin{array}{c}\text { K00688//glycogen } \\
\text { phosphorylase } \\
\text { [EC:2.4.1.1] }\end{array}$ & GO:0005975//carbohydrate metabolic process \\
\hline Atp13a4 & -1.06 & $2.97 \mathrm{E}-06$ & $\begin{array}{c}\text { K14951//cation- } \\
\text { transporting } \\
\text { ATPase 13A3/4/5 } \\
\text { [EC:3.6.3.- }\end{array}$ & GO:0006812//cation transport \\
\hline
\end{tabular}




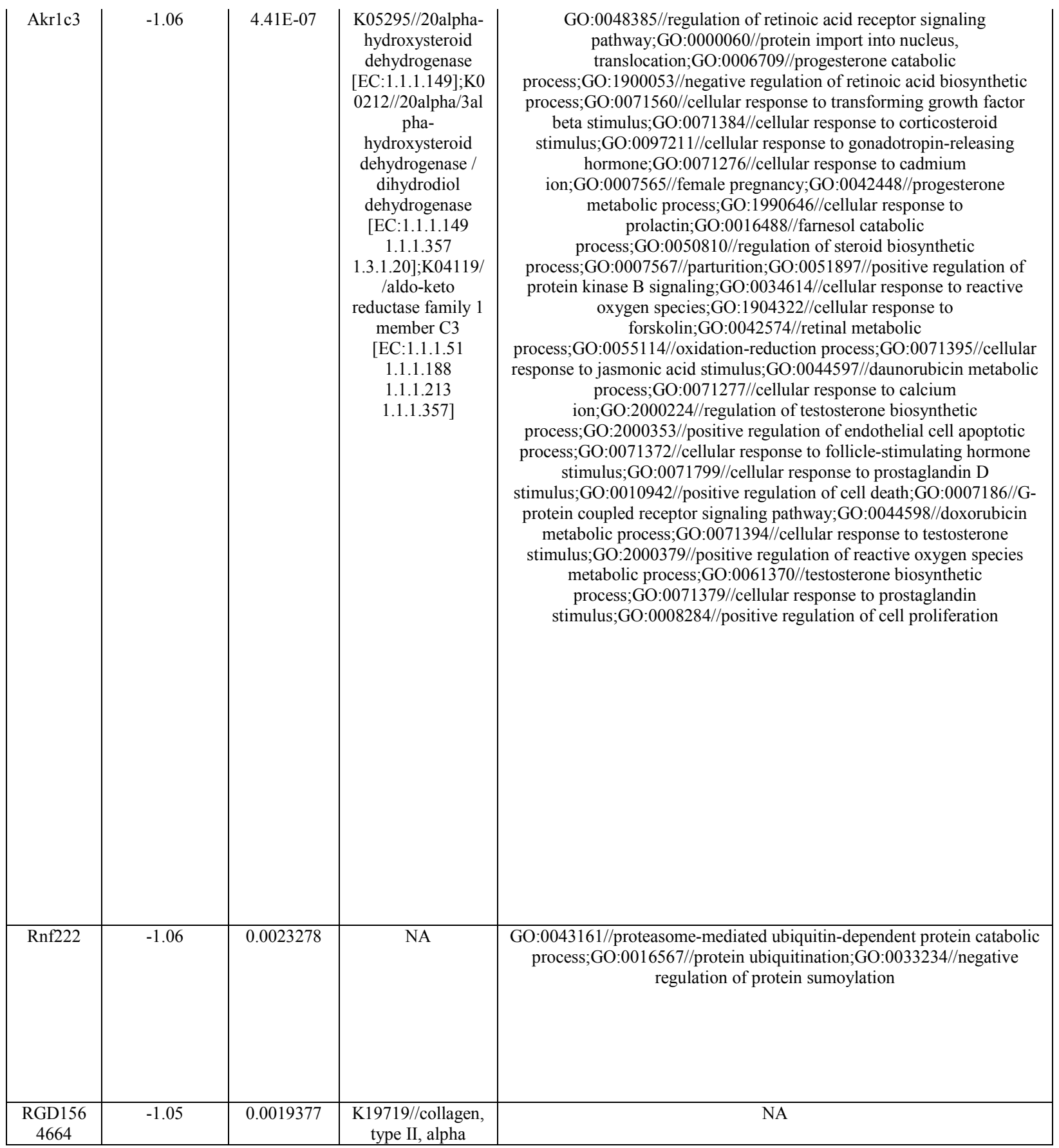




\begin{tabular}{|c|c|c|c|c|}
\hline Spink2 & -1.05 & 4.06E-06 & NA & $\begin{array}{c}\text { GO:0060046//regulation of acrosome reaction;GO:0043065//positive } \\
\text { regulation of apoptotic process;GO:1900004//negative regulation of } \\
\text { serine-type endopeptidase } \\
\text { activity;GO:0009566//fertilization;GO:0072520//seminiferous tubule } \\
\text { development;GO:0007286//spermatid } \\
\text { development;GO:0007283//spermatogenesis;GO:0008584//male gonad } \\
\text { development;GO:0002176//male germ cell } \\
\text { proliferation;GO:0006915//apoptotic process }\end{array}$ \\
\hline Pcdha11 & -1.05 & 0.0041171 & $\begin{array}{l}\text { K16493//protocad } \\
\text { herin alpha }\end{array}$ & NA \\
\hline Prelp & -1.04 & $5.69 \mathrm{E}-24$ & $\begin{array}{l}\mathrm{K} 08125 / / \text { proline } \\
\text { arginine-rich end } \\
\text { leucine-rich repeat } \\
\text { protein }\end{array}$ & GO:0007569//cell aging \\
\hline Kcnj4 & -1.04 & $2.06 \mathrm{E}-14$ & $\begin{array}{l}\text { K04998//potassiu } \\
\text { m inwardly- } \\
\text { rectifying channel } \\
\text { subfamily J } \\
\text { member } 4\end{array}$ & $\begin{array}{l}\text { GO:0071260//cellular response to mechanical } \\
\text { stimulus;GO:0010107//potassium ion import }\end{array}$ \\
\hline Bhmt & -1.03 & 0.0001077 & $\begin{array}{l}\text { K00544//betaine- } \\
\text { homocysteine S- } \\
\text { methyltransferase } \\
\text { [EC:2.1.1.5] }\end{array}$ & $\begin{array}{l}\text { GO:0010243//response to organonitrogen compound;GO:0071267//L- } \\
\text { methionine salvage;GO:0006579//amino-acid betaine catabolic } \\
\text { process;GO:0006479//protein methylation;GO:0006577//amino-acid } \\
\text { betaine metabolic process;GO:0009086//methionine biosynthetic process }\end{array}$ \\
\hline $\mathrm{Il} 11 \mathrm{~b}$ & -1.03 & $1.82 \mathrm{E}-08$ & $\begin{array}{l}\text { K05490//interleuk } \\
\text { in } 17 \mathrm{~B}\end{array}$ & $\begin{array}{c}\text { GO:0030593//neutrophil chemotaxis;GO:1900017//positive regulation of } \\
\text { cytokine production involved in inflammatory } \\
\text { response;GO:0006954//inflammatory response }\end{array}$ \\
\hline Cnn1 & -1.02 & $9.97 \mathrm{E}-100$ & $\begin{array}{l}\text { K09228//KRAB } \\
\text { domain- } \\
\text { containing zinc } \\
\text { finger } \\
\text { protein;K07441//b } \\
\text { eta-1,4-N- } \\
\text { acetylglucosaminy } \\
\text { ltransferase } \\
\text { [EC:2.4.1.141];K2 } \\
0526 / / \text { transgelin } \\
\end{array}$ & $\begin{array}{l}\text { GO:0031032//actomyosin structure organization;GO:1904706//negative } \\
\text { regulation of vascular smooth muscle cell proliferation }\end{array}$ \\
\hline Cfap52 & -1.02 & $4.54 \mathrm{E}-07$ & $\begin{array}{l}\text { K21763//null;K21 } \\
762 / / \text { null;K16482/ }\end{array}$ & NA \\
\hline
\end{tabular}




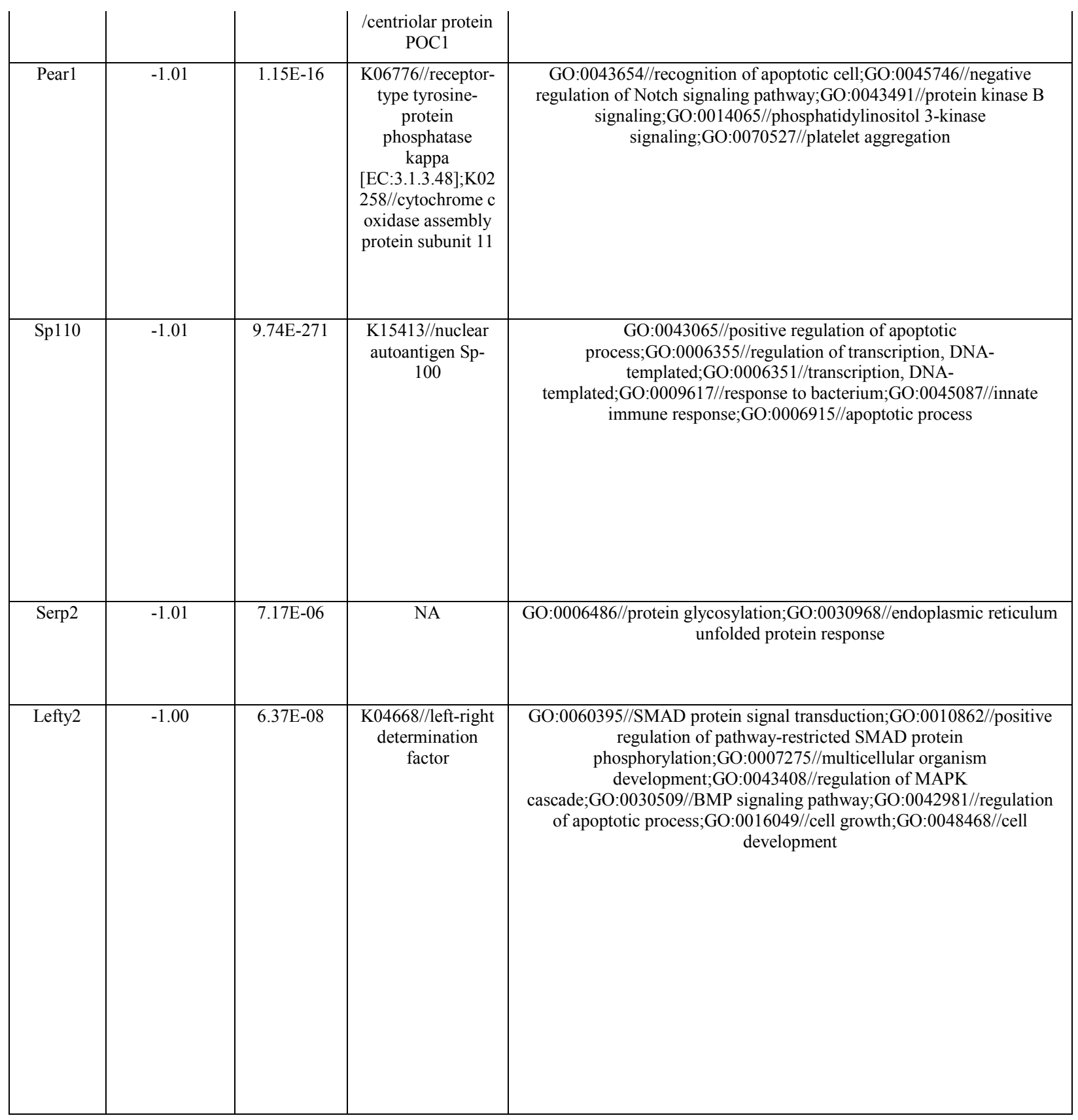




\begin{tabular}{|c|c|c|c|c|}
\hline $\begin{array}{l}\text { LOC367 } \\
975\end{array}$ & -1.00 & $4.63 \mathrm{E}-84$ & $\begin{array}{l}\text { K14443//protein } \\
\text { Tob/BTG }\end{array}$ & $\begin{array}{c}\text { GO:0043434//response to peptide hormone;GO:0006479//protein } \\
\text { methylation;GO:0007286//spermatid } \\
\text { development;GO:0007283//spermatogenesis;GO:0045603//positive } \\
\text { regulation of endothelial cell differentiation;GO:0006979//response to } \\
\text { oxidative stress;GO:0045663//positive regulation of myoblast } \\
\text { differentiation;GO:0045766//positive regulation of } \\
\text { angiogenesis;GO:0008285//negative regulation of cell } \\
\text { proliferation;GO:2000271//positive regulation of fibroblast apoptotic } \\
\text { process }\end{array}$ \\
\hline Pcdh7 & -1.00 & $9.21 \mathrm{E}-47$ & $\begin{array}{l}\text { K16498//protocad } \\
\text { herin delta } 1\end{array}$ & $\begin{array}{c}\text { GO:0007156//homophilic cell adhesion via plasma membrane adhesion } \\
\text { molecules }\end{array}$ \\
\hline Fosb & 1.00 & 0.005035 & $\begin{array}{l}\text { K09029//protein } \\
\text { FosB }\end{array}$ & $\begin{array}{c}\text { GO:0009612//response to mechanical stimulus;GO:0042493//response to } \\
\text { drug;GO:0007565//female pregnancy;GO:0043278//response to } \\
\text { morphine;GO:0051591//response to cAMP;GO:0032570//response to } \\
\text { progesterone;GO:0032870//cellular response to hormone } \\
\text { stimulus;GO:0006366//transcription from RNA polymerase II } \\
\text { promoter;GO:0071277//cellular response to calcium } \\
\text { ion;GO:0045944//positive regulation of transcription from RNA } \\
\text { polymerase II promoter;GO:0051412//response to corticosterone }\end{array}$ \\
\hline Syt3 & 1.00 & 0.0089104 & $\begin{array}{l}\text { K19903//synaptot } \\
\text { agmin-3 }\end{array}$ & $\begin{array}{l}\text { GO:0016079//synaptic vesicle exocytosis;GO:0051592//response to } \\
\text { calcium ion;GO:1903861//positive regulation of dendrite } \\
\text { extension;GO:0031340//positive regulation of vesicle } \\
\text { fusion;GO:0048791//calcium ion-regulated exocytosis of } \\
\text { neurotransmitter;GO:0017158//regulation of calcium ion-dependent } \\
\text { exocytosis;GO:0017156//calcium ion regulated exocytosis }\end{array}$ \\
\hline
\end{tabular}




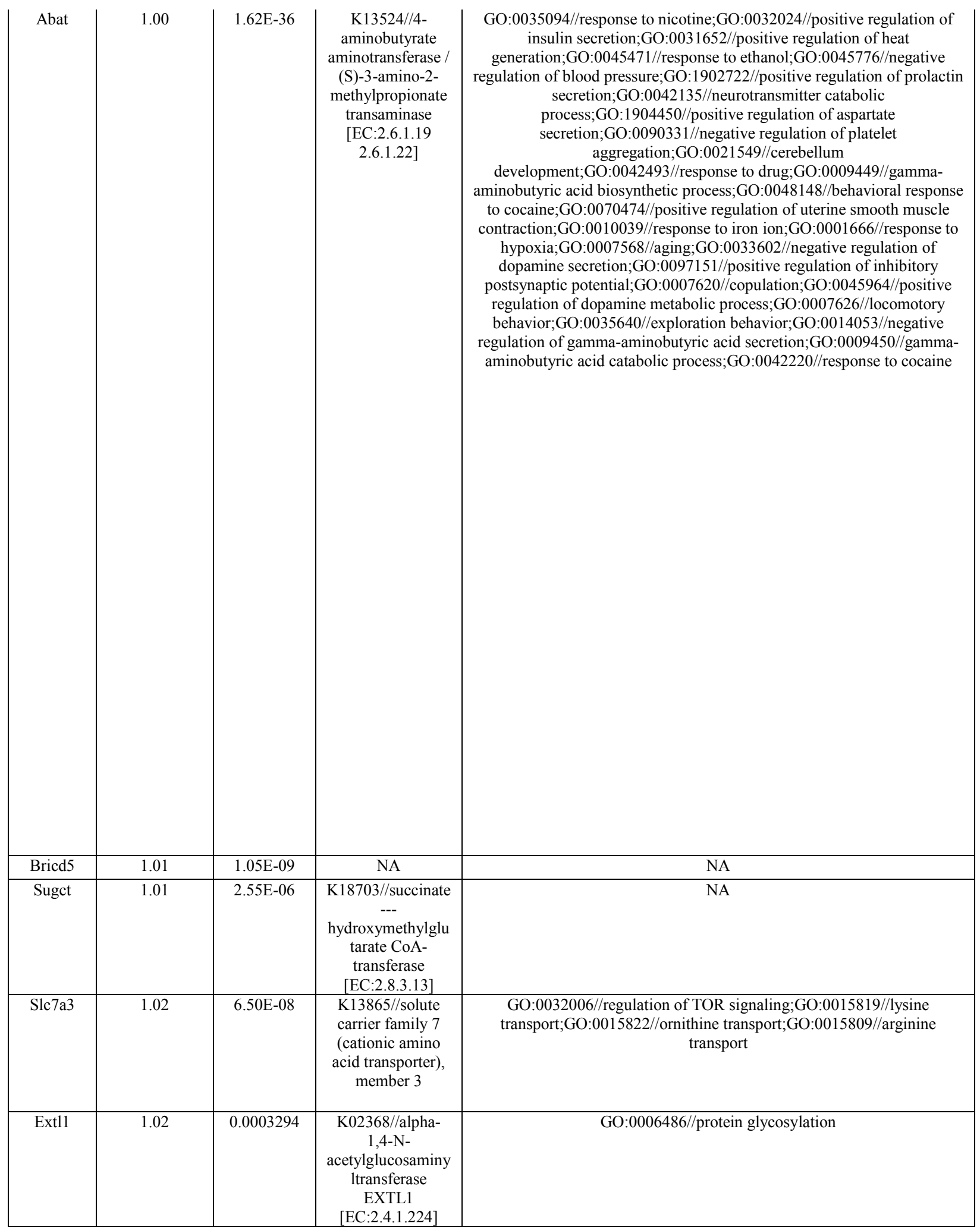




\begin{tabular}{|c|c|c|c|c|}
\hline Chn2 & 1.03 & 0.0014351 & $\begin{array}{l}\text { K20630//chimaeri } \\
\text { n }\end{array}$ & $\begin{array}{l}\text { GO:0001675//acrosome assembly;GO:0043087//regulation of GTPase } \\
\text { activity;GO:0035556//intracellular signal } \\
\text { transduction;GO:0051056//regulation of small GTPase mediated signal } \\
\text { transduction }\end{array}$ \\
\hline Adap1 & 1.03 & 0.0020812 & $\begin{array}{l}\text { K12486//stromal } \\
\text { membrane- } \\
\text { associated } \\
\text { protein;K12491// } \\
\text { Arf-GAP with } \\
\text { GTPase, ANK } \\
\text { repeat and PH } \\
\text { domain- } \\
\text { containing protein } \\
\text { 1/3;K12489//Arf- } \\
\text { GAP with coiled- } \\
\text { coil, ANK repeat } \\
\text { and PH domain- } \\
\text { containing protein }\end{array}$ & $\begin{array}{c}\text { GO:0043087//regulation of GTPase activity;GO:0048016//inositol } \\
\text { phosphate-mediated signaling }\end{array}$ \\
\hline Ill1 & 1.03 & 0.002508 & $\begin{array}{l}\text { K05417//interleuk } \\
\text { in } 11\end{array}$ & $\begin{array}{l}\text { GO:0050731//positive regulation of peptidyl-tyrosine } \\
\text { phosphorylation;GO:0045944//positive regulation of transcription from } \\
\text { RNA polymerase II promoter;GO:0046888//negative regulation of } \\
\text { hormone secretion;GO:0043410//positive regulation of MAPK } \\
\text { cascade;GO:0033138//positive regulation of peptidyl-serine } \\
\text { phosphorylation;GO:0008284//positive regulation of cell proliferation }\end{array}$ \\
\hline
\end{tabular}




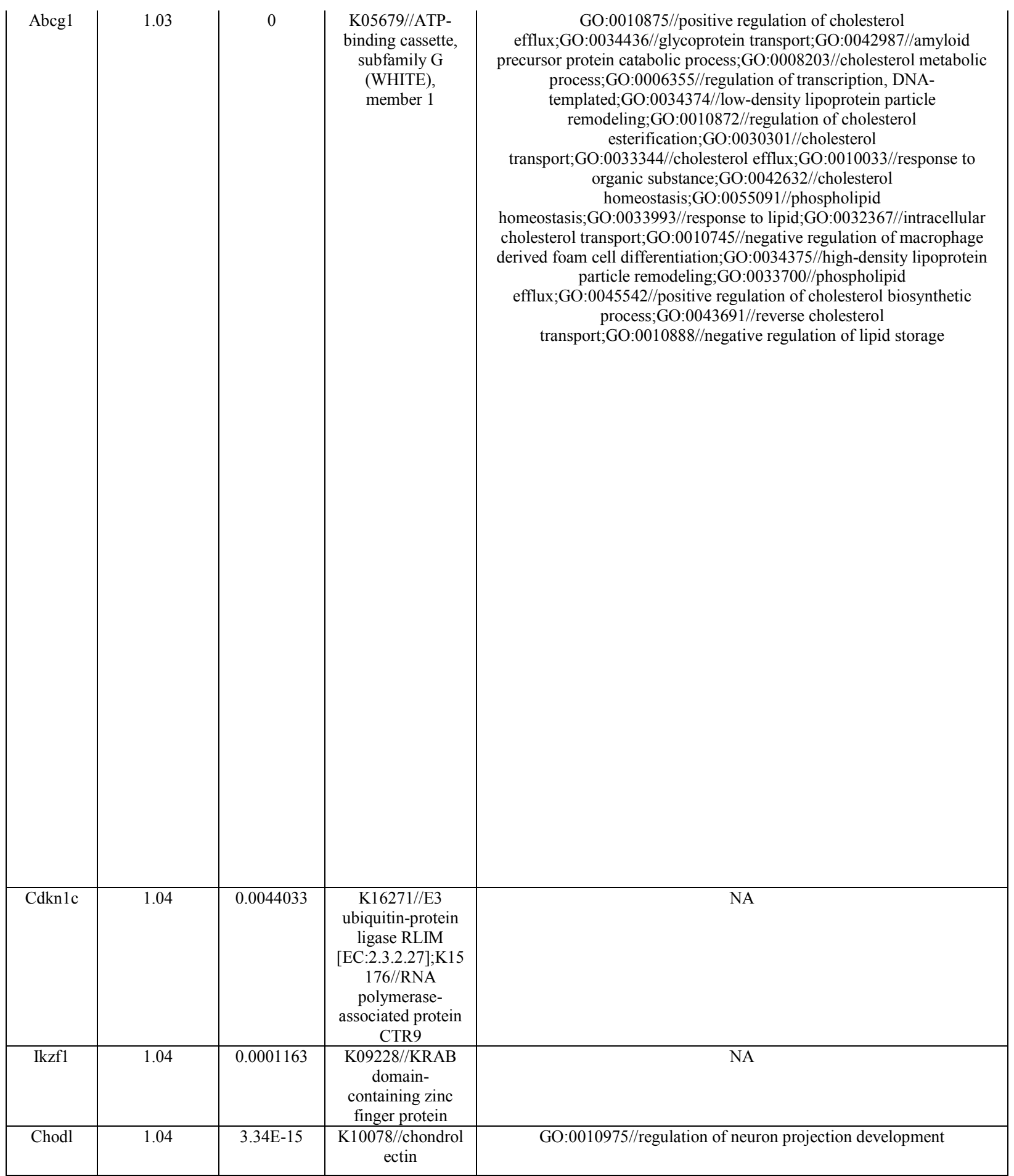




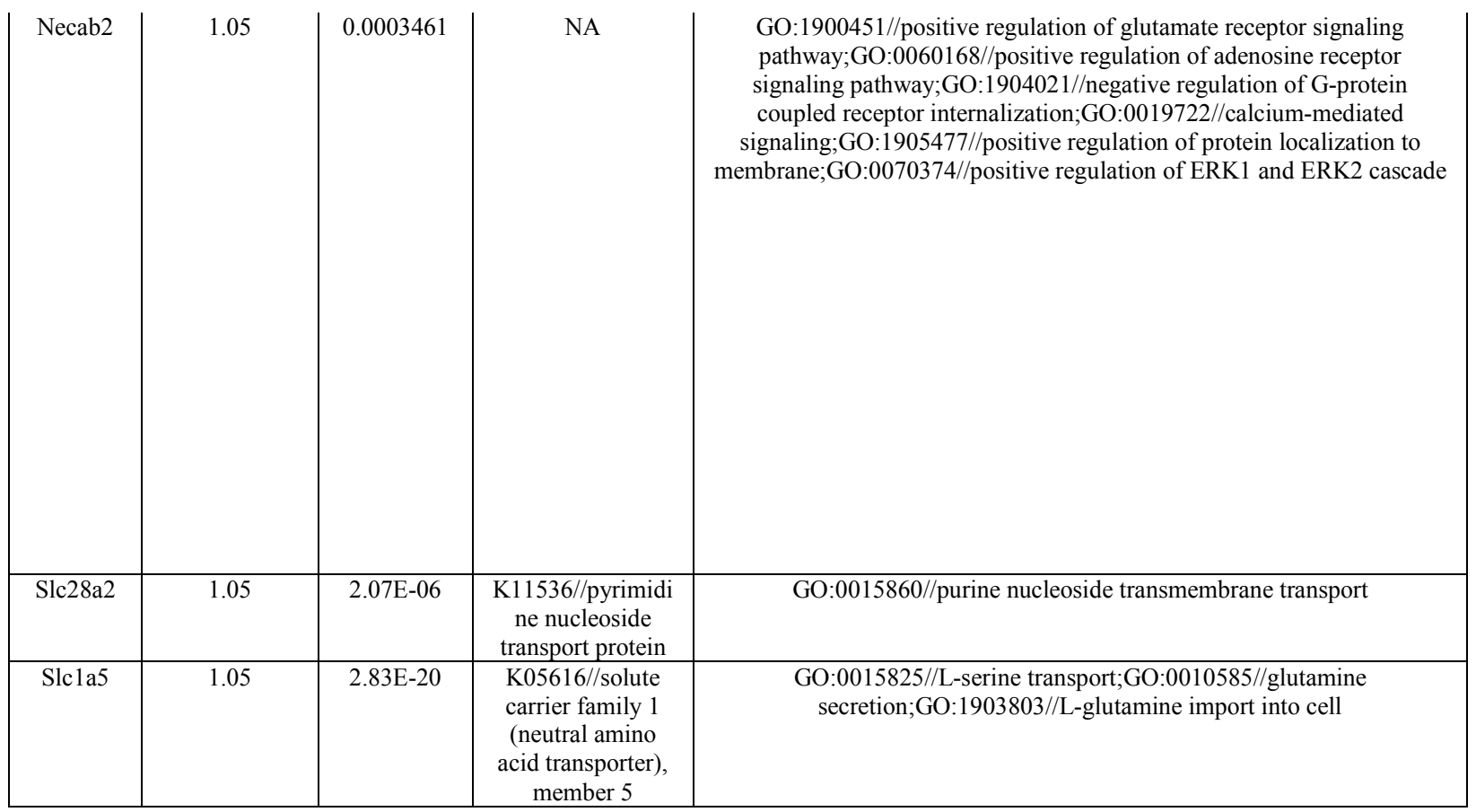




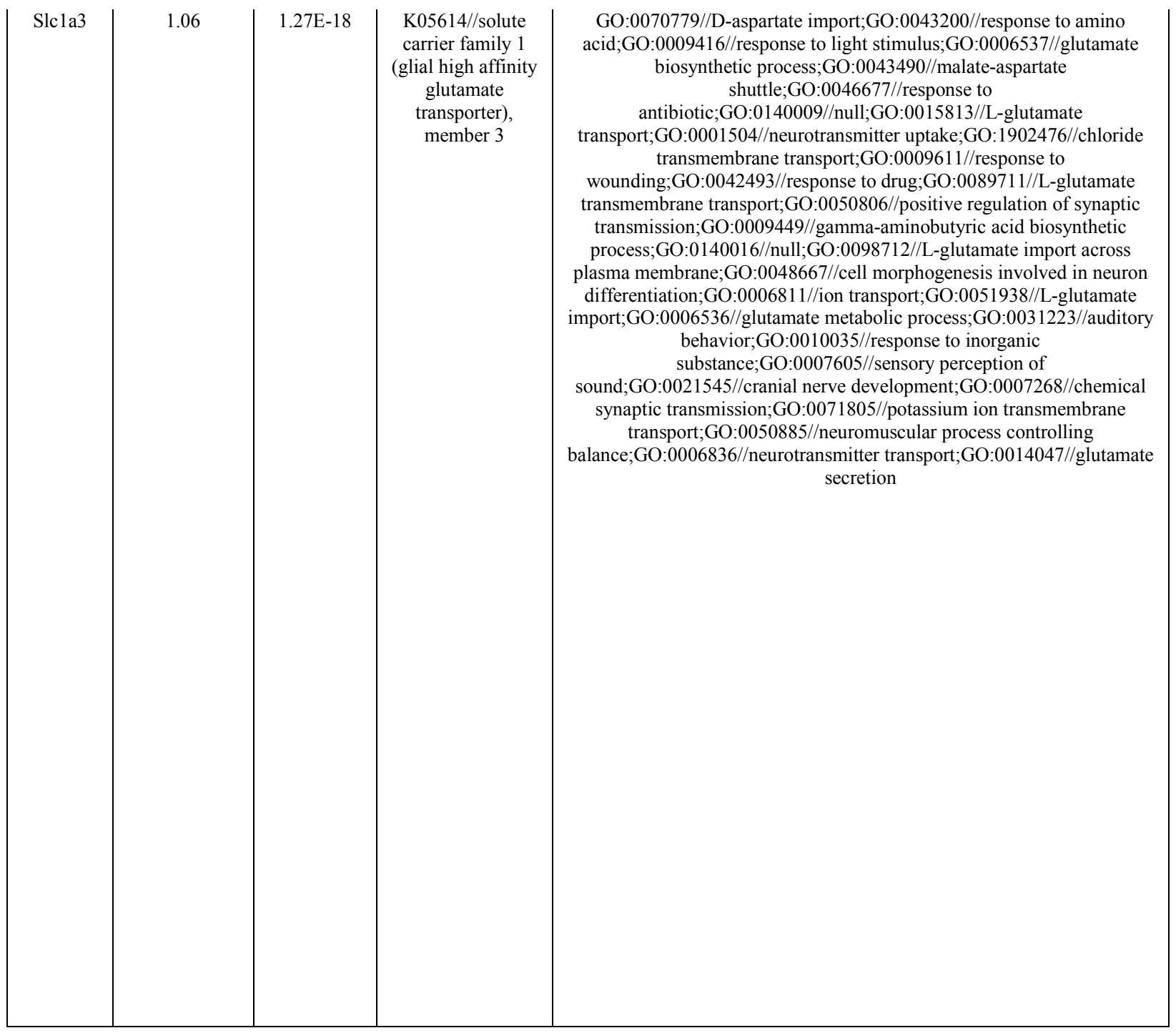




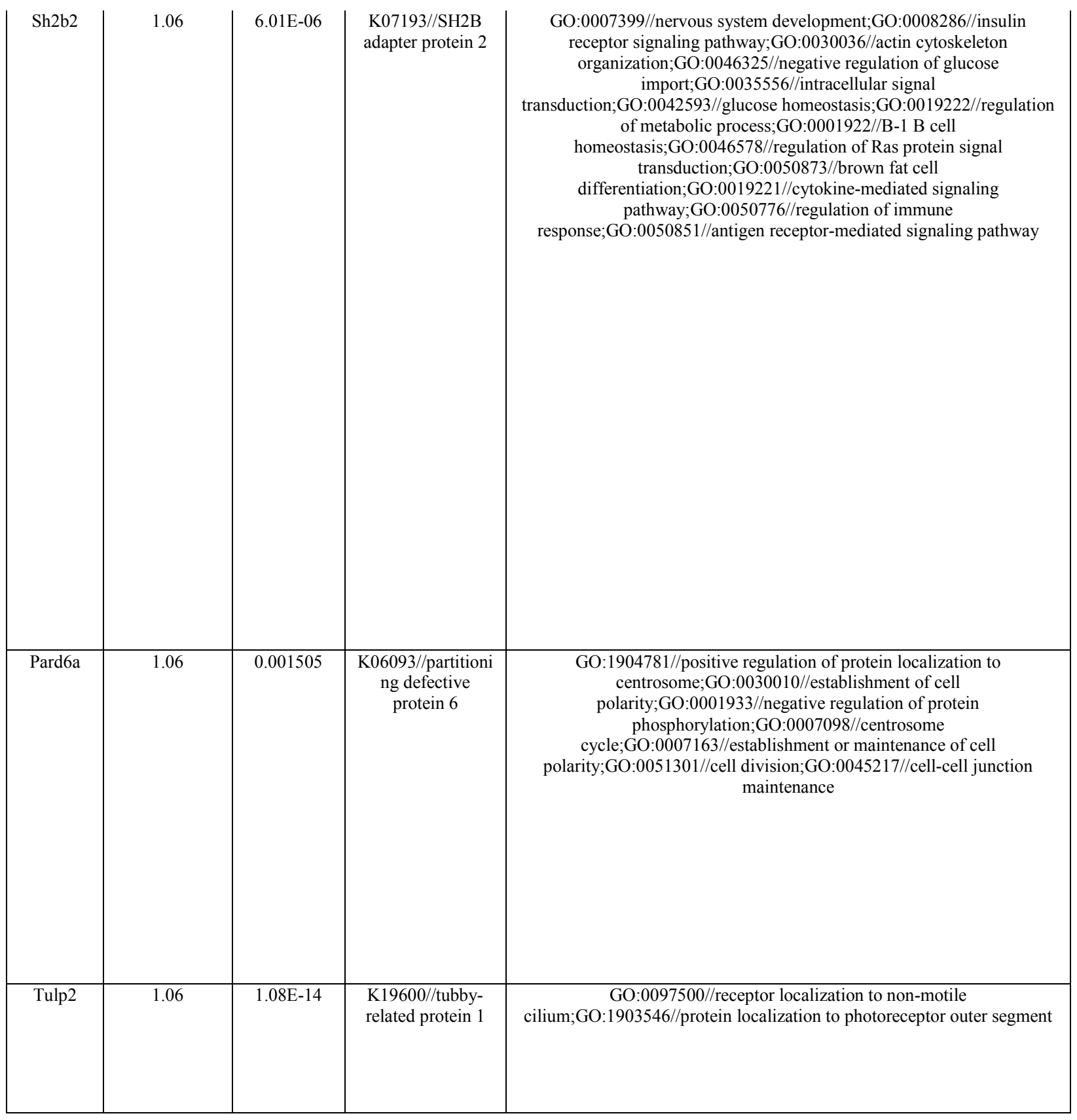




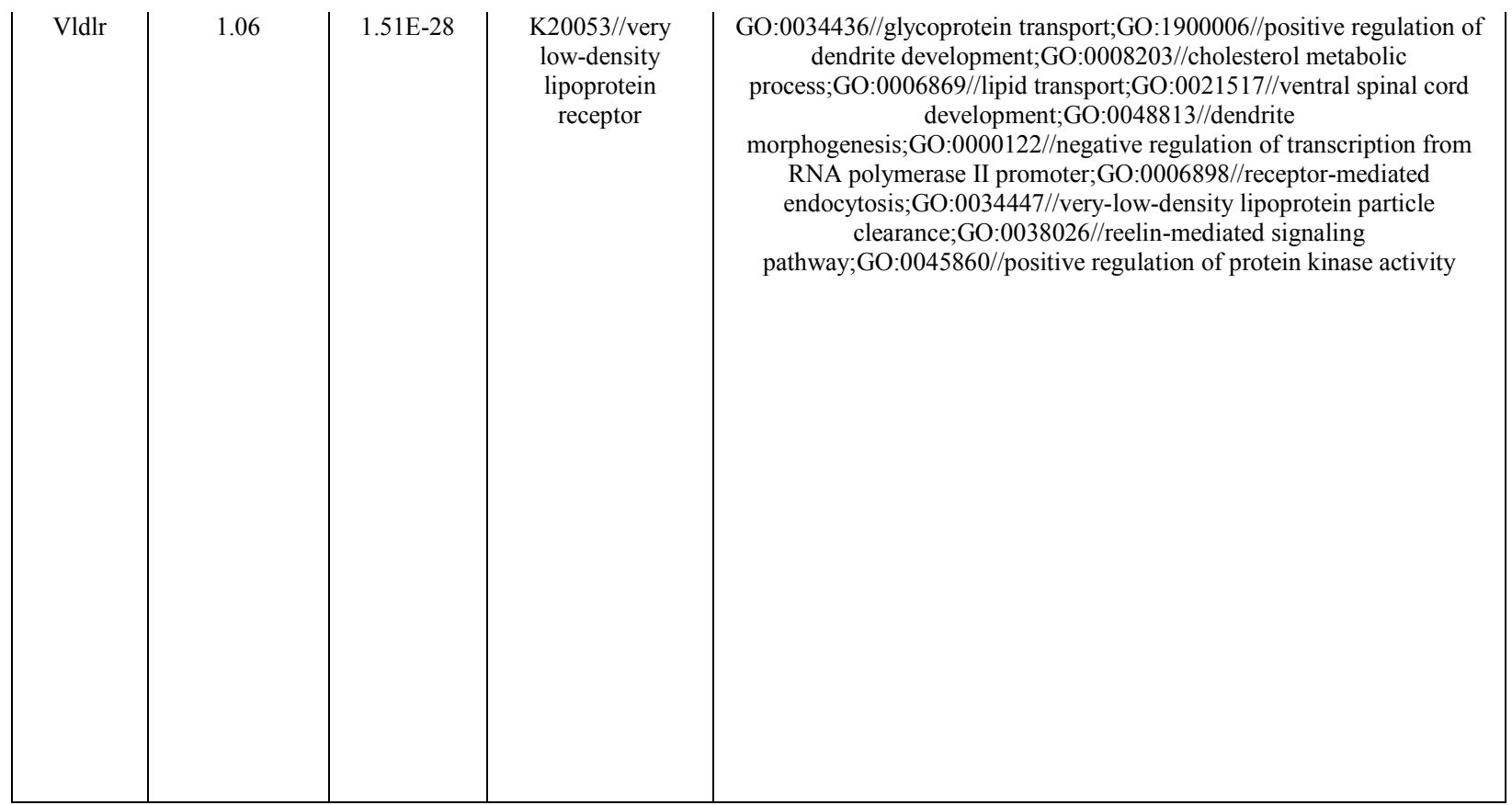




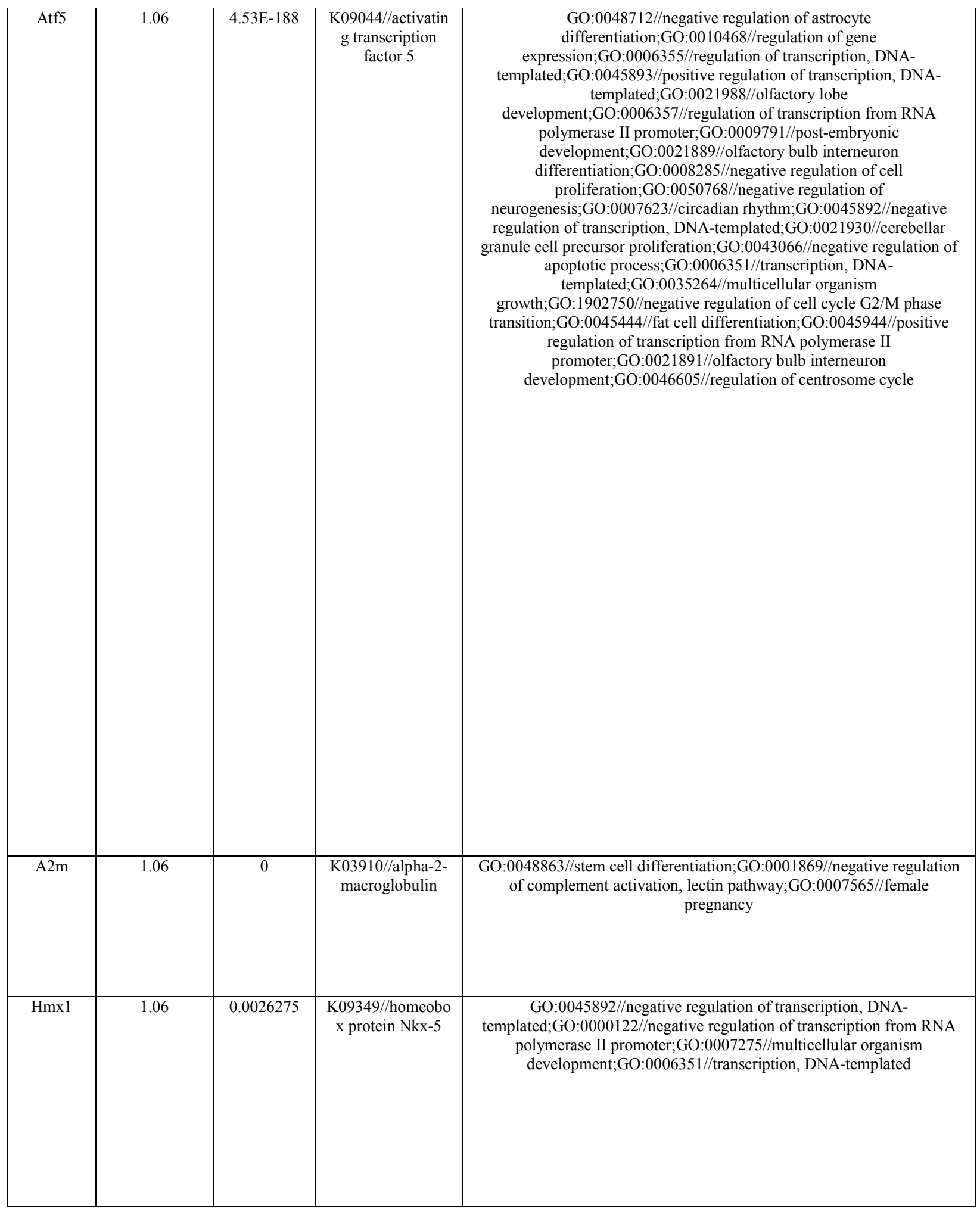




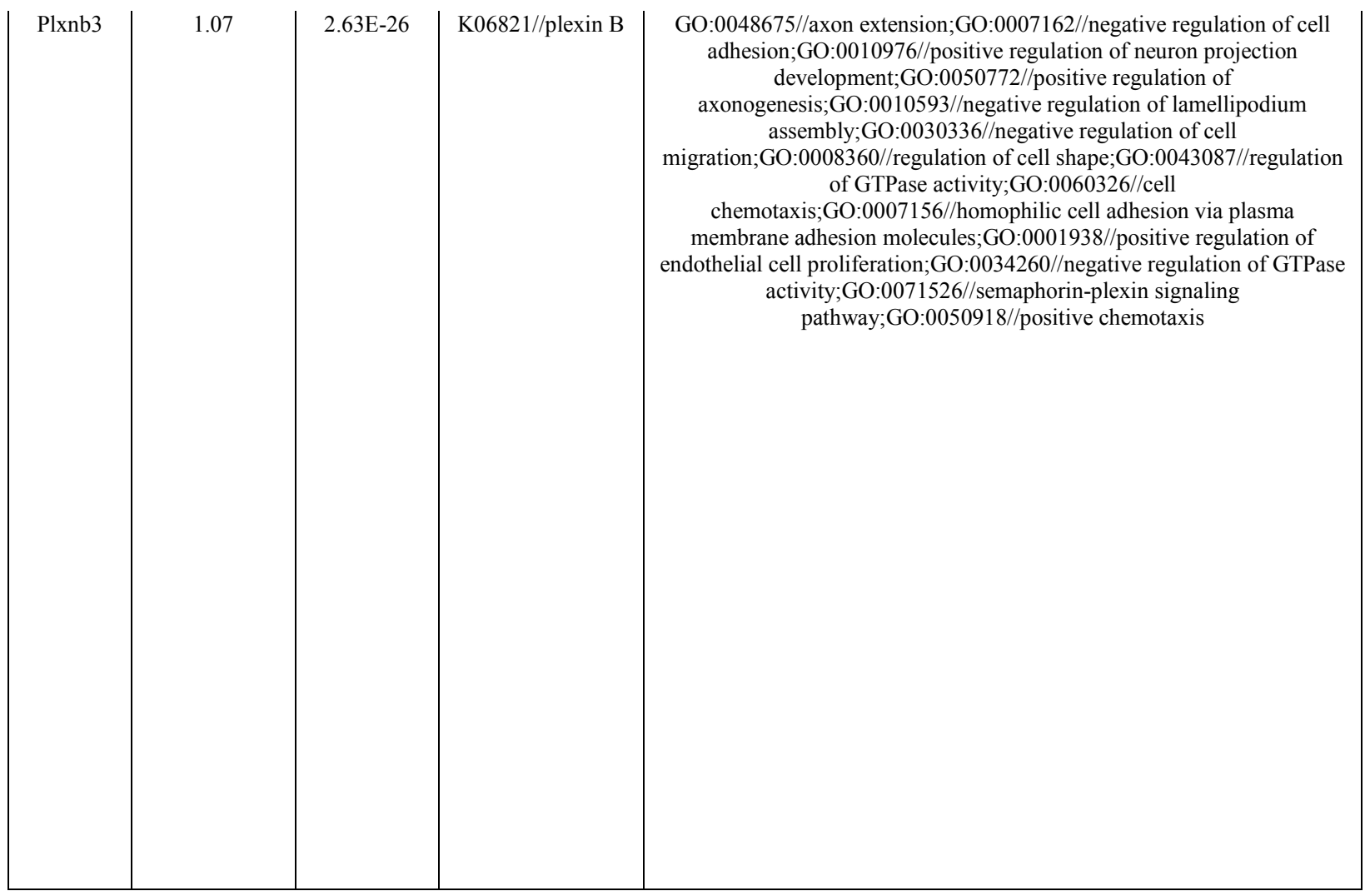




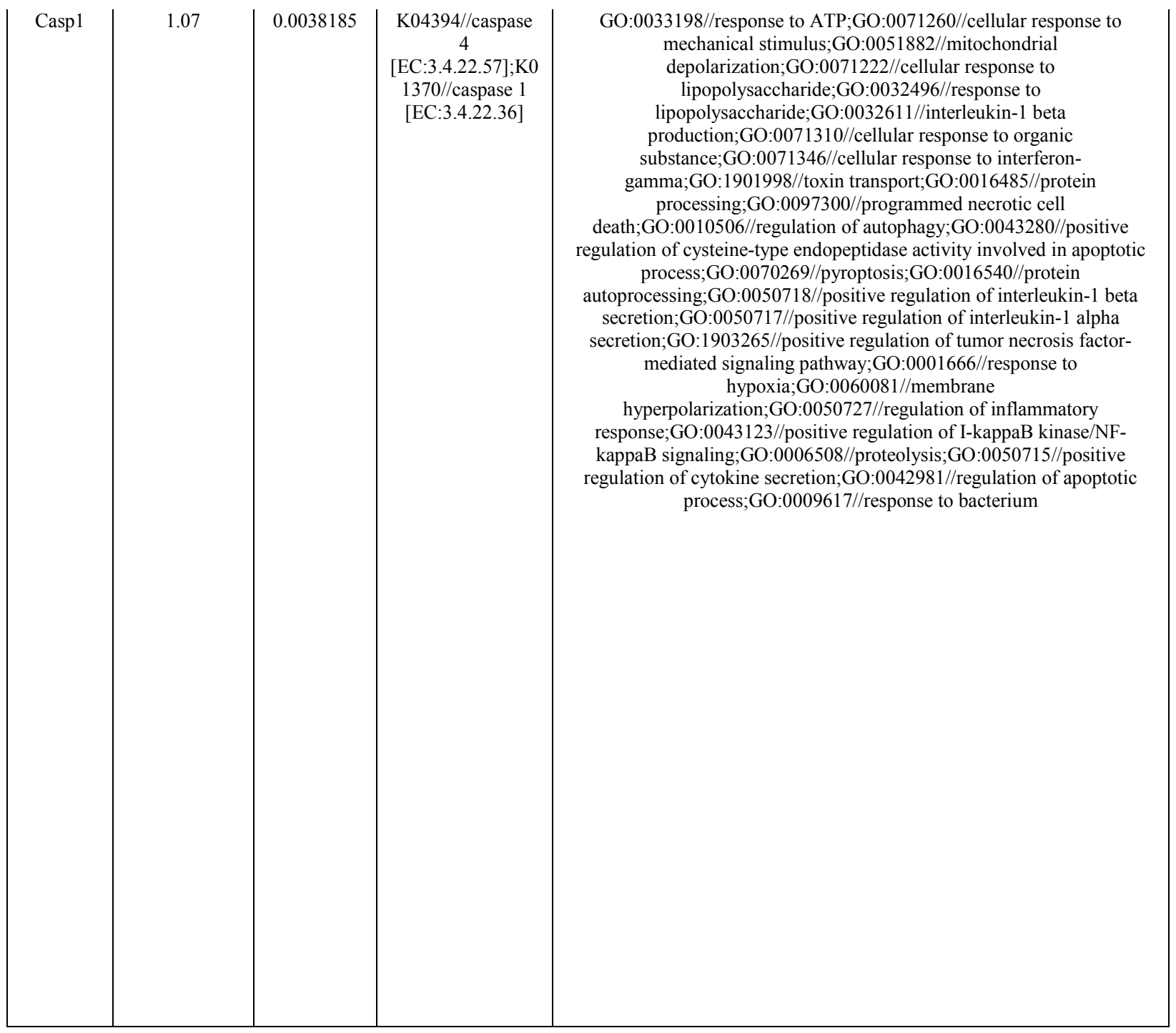




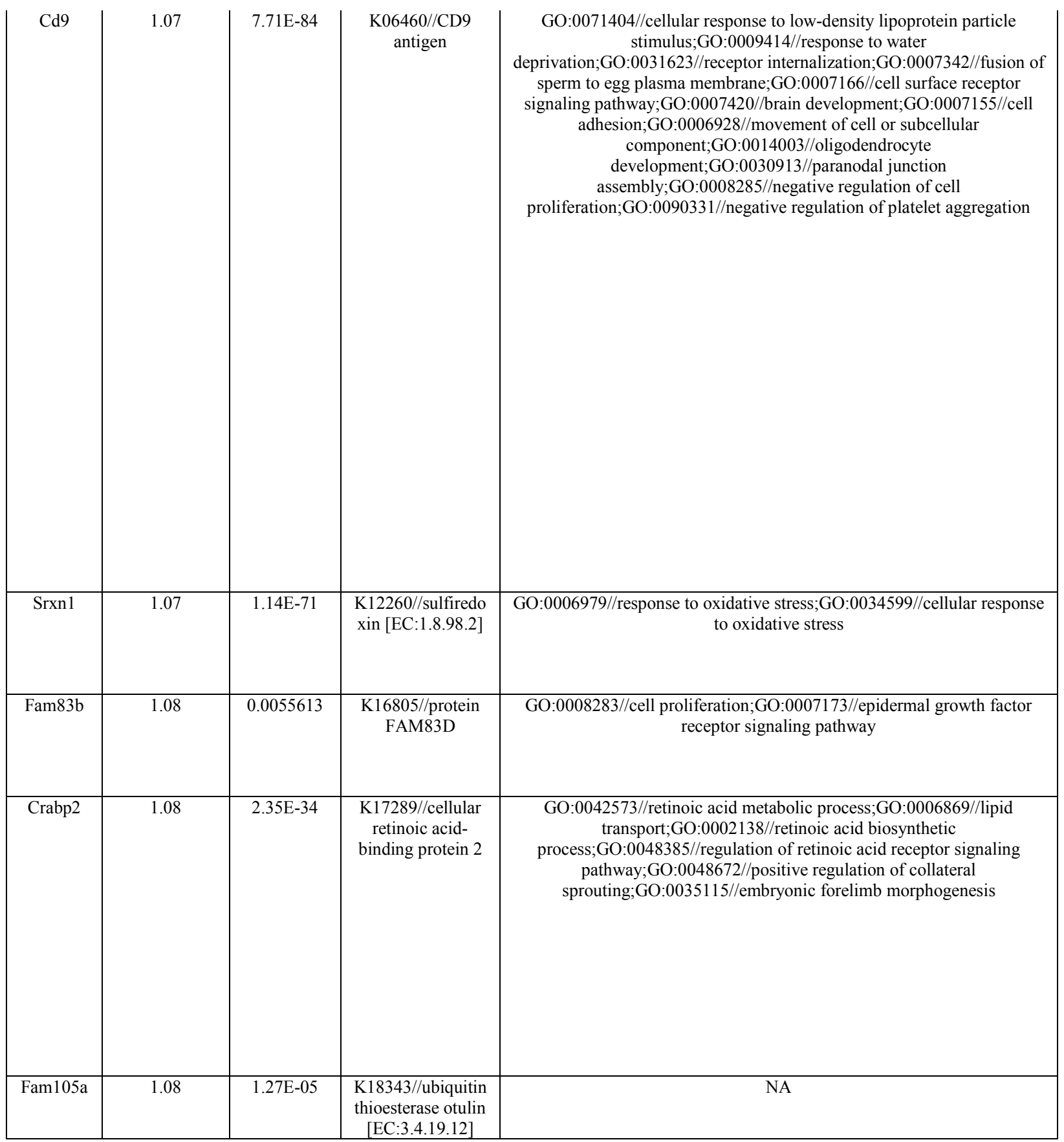




\begin{tabular}{|c|c|c|c|c|}
\hline Creb312 & 1.08 & 4.63E-185 & $\begin{array}{c}\text { K09048//cyclic } \\
\text { AMP-responsive } \\
\text { element-binding } \\
\text { protein } 3\end{array}$ & $\begin{array}{c}\text { GO:0002062//chondrocyte differentiation;GO:0045944//positive } \\
\text { regulation of transcription from RNA polymerase II } \\
\text { promoter;GO:0034976//response to endoplasmic reticulum } \\
\text { stress;GO:0006888//ER to Golgi vesicle-mediated } \\
\text { transport;GO:0051216//cartilage development;GO:0030968//endoplasmic } \\
\text { reticulum unfolded protein response;GO:0045893//positive regulation of } \\
\text { transcription, DNA-templated }\end{array}$ \\
\hline Sarm1 & 1.08 & 0.0001515 & $\begin{array}{c}\text { K22022//null;K22 } \\
016 / / \text { null }\end{array}$ & $\begin{array}{c}\text { GO:0007165//signal transduction;GO:0009749//response to } \\
\text { glucose;GO:1901214//regulation of neuron } \\
\text { death;GO:0048814//regulation of dendrite } \\
\text { morphogenesis;GO:0042981//regulation of apoptotic } \\
\text { process;GO:0045087//innate immune response }\end{array}$ \\
\hline Gstm61 & 1.09 & $9.96 \mathrm{E}-06$ & $\begin{array}{l}\text { K00799//glutathio } \\
\text { ne S-transferase } \\
\text { [EC:2.5.1.18] }\end{array}$ & $\begin{array}{l}\text { GO:0042178//xenobiotic catabolic process;GO:0006749//glutathione } \\
\text { metabolic process;GO:0018916//nitrobenzene metabolic } \\
\text { process;GO:0070458//cellular detoxification of nitrogen compound }\end{array}$ \\
\hline
\end{tabular}




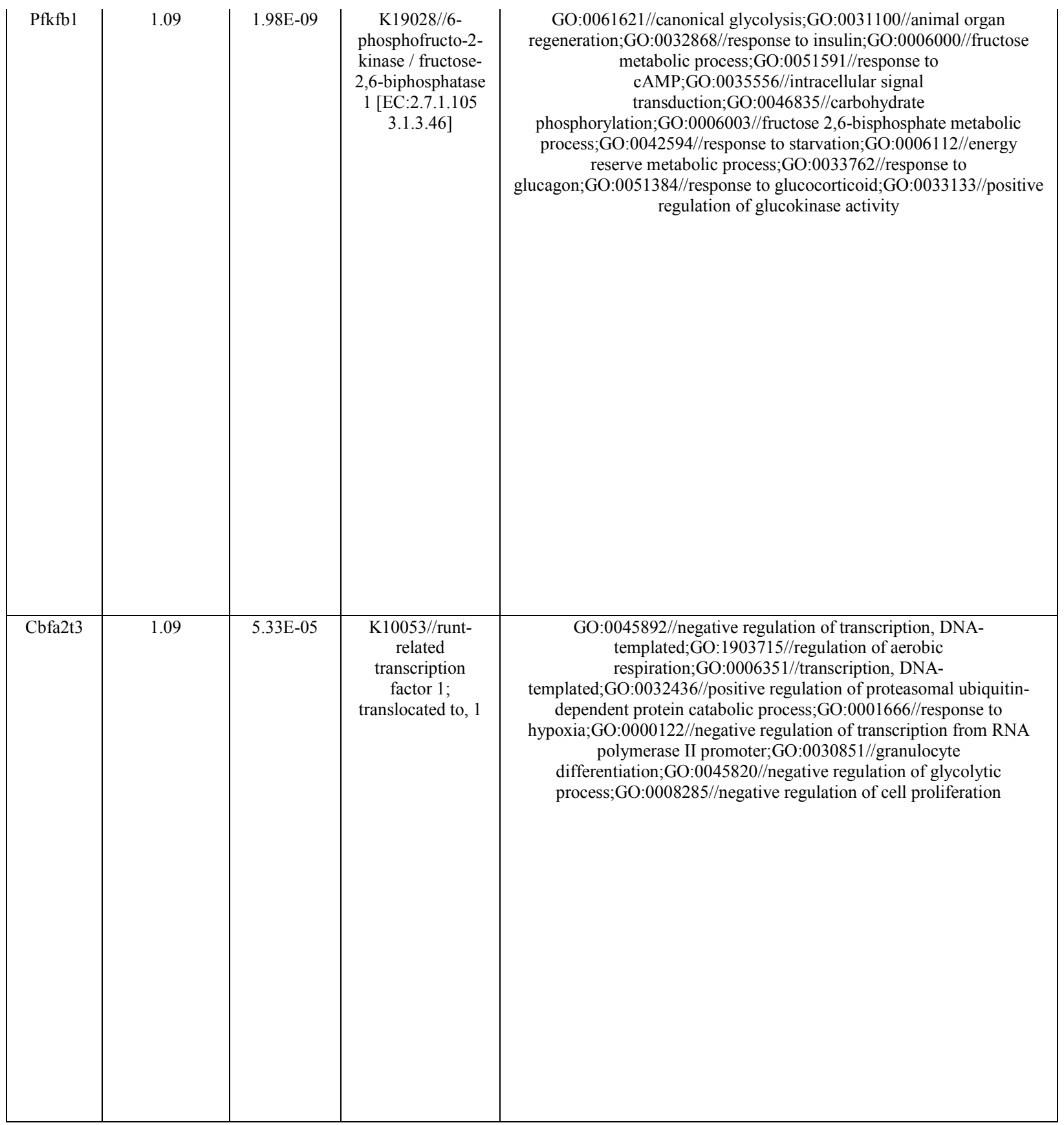




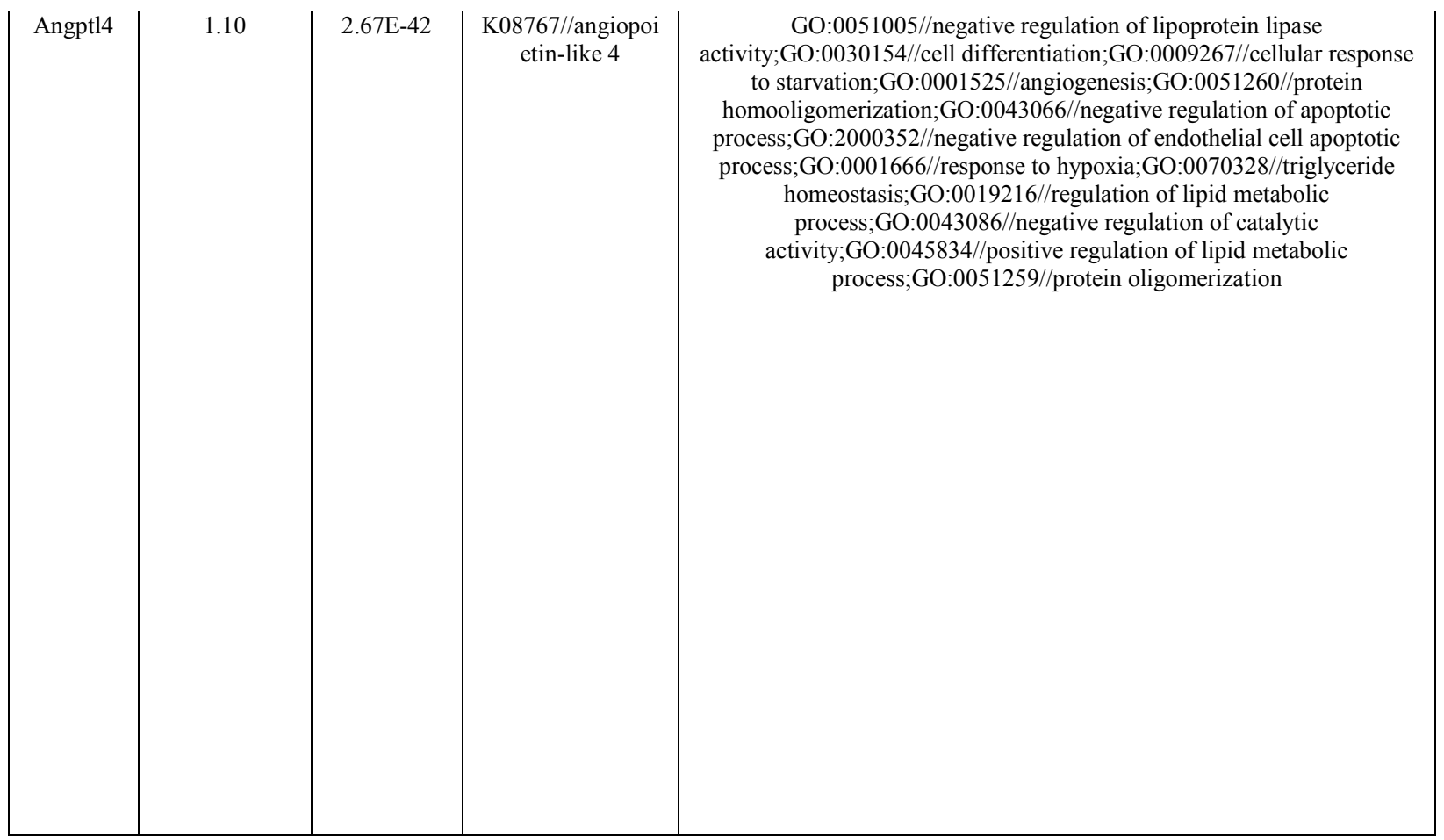




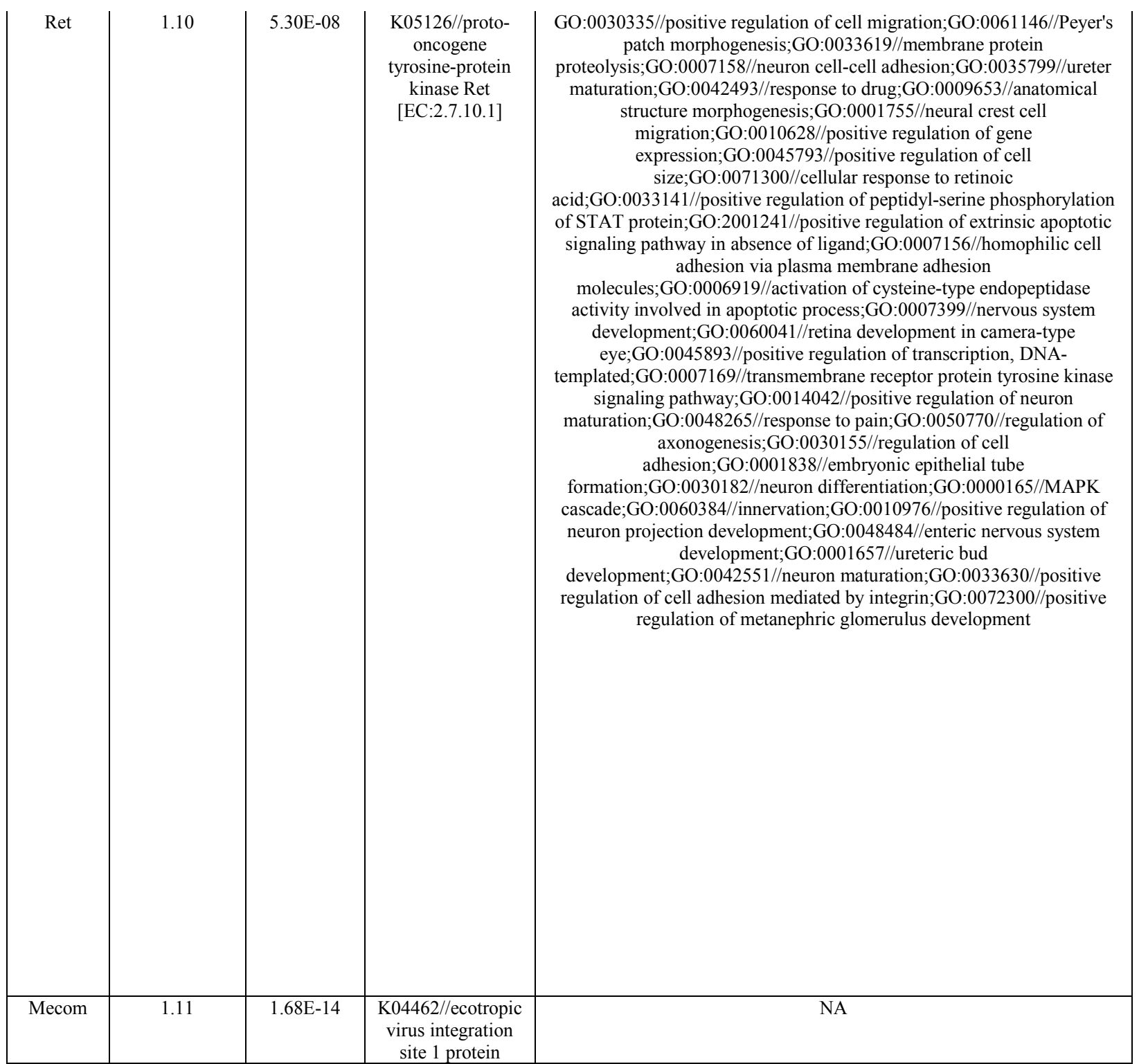




\begin{tabular}{|c|c|c|c|c|}
\hline Pdgfb & 1.11 & $2.21 \mathrm{E}-76$ & $\begin{array}{l}\text { K17386//platelet- } \\
\text { derived growth } \\
\text { factor subunit B }\end{array}$ & 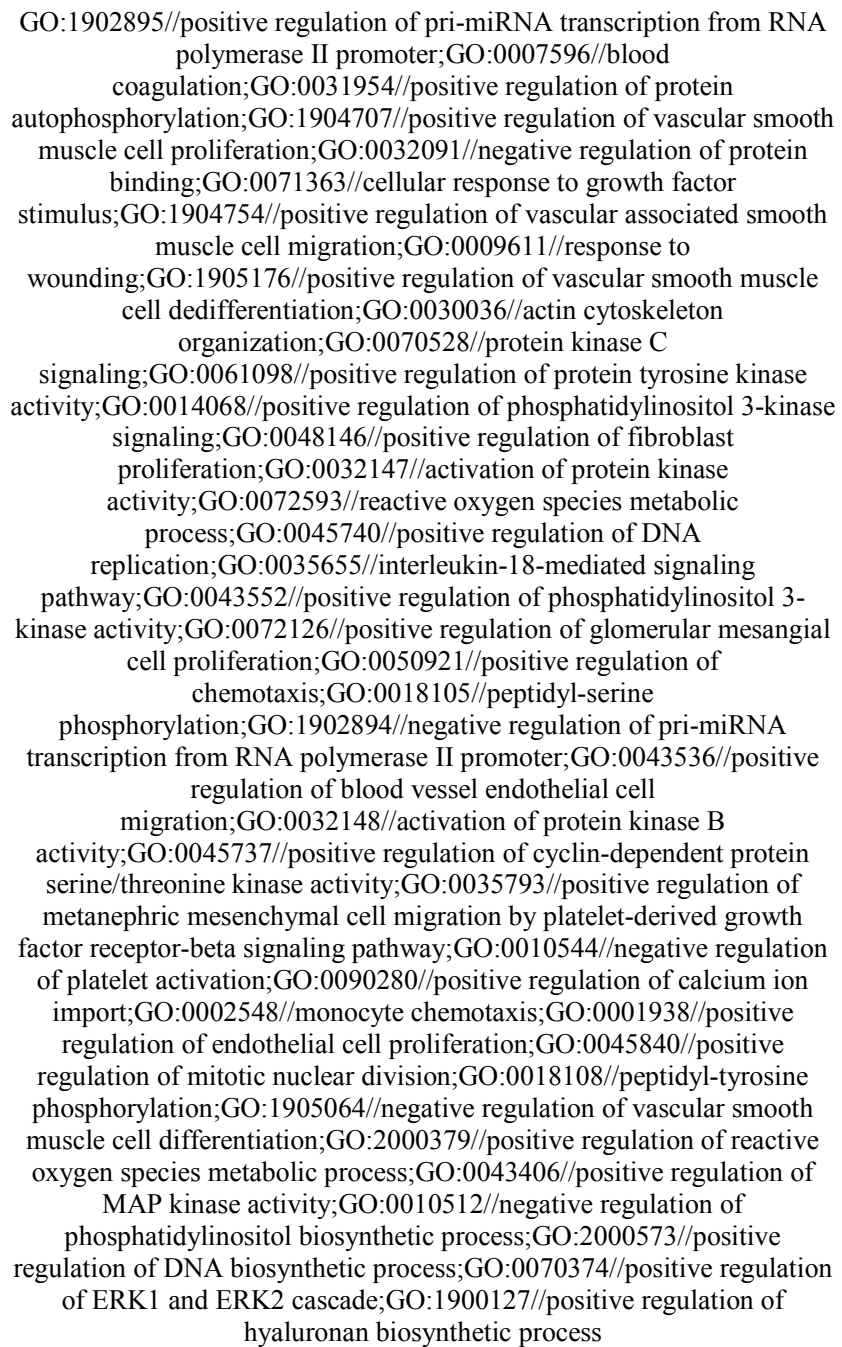 \\
\hline
\end{tabular}




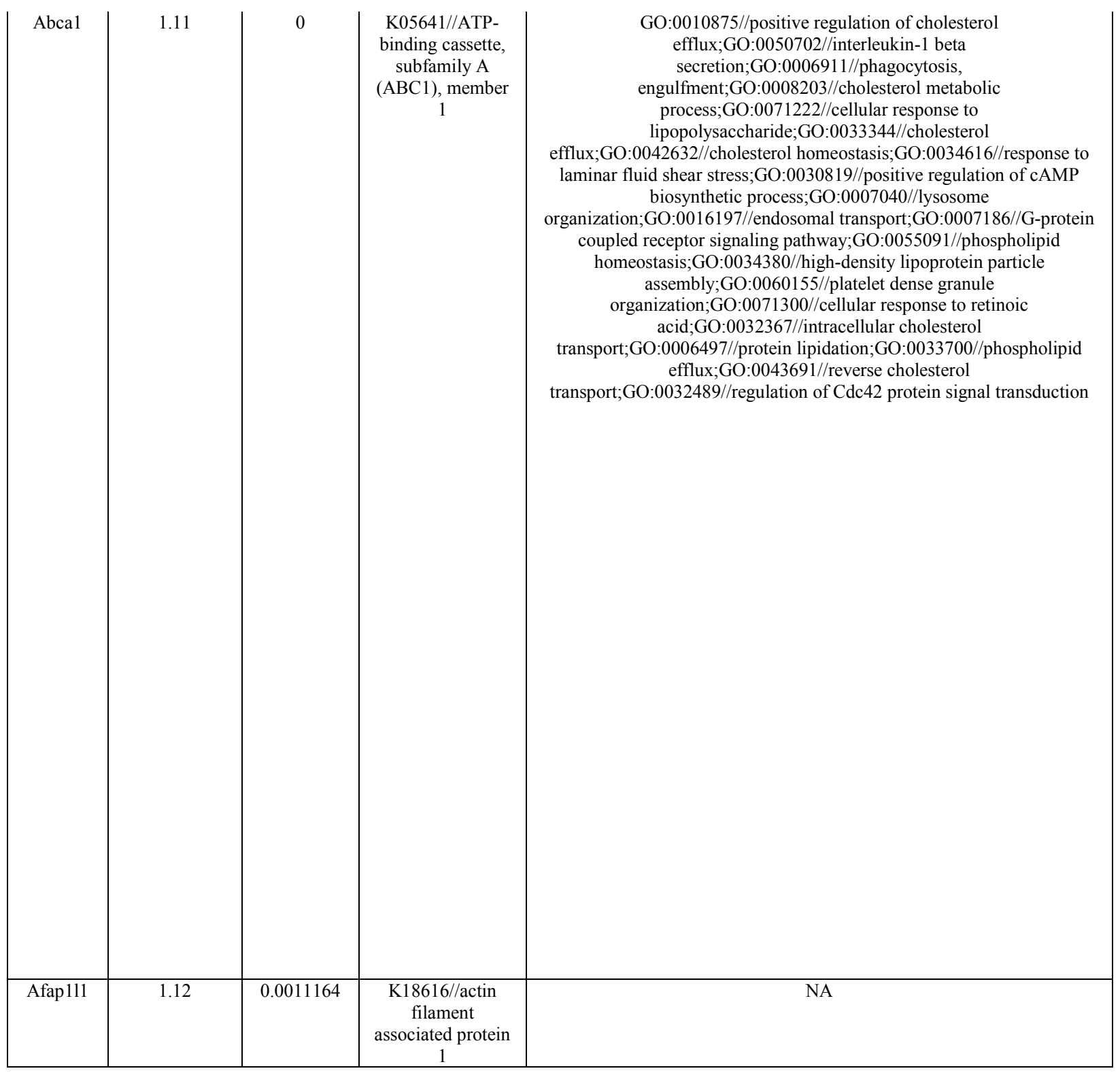




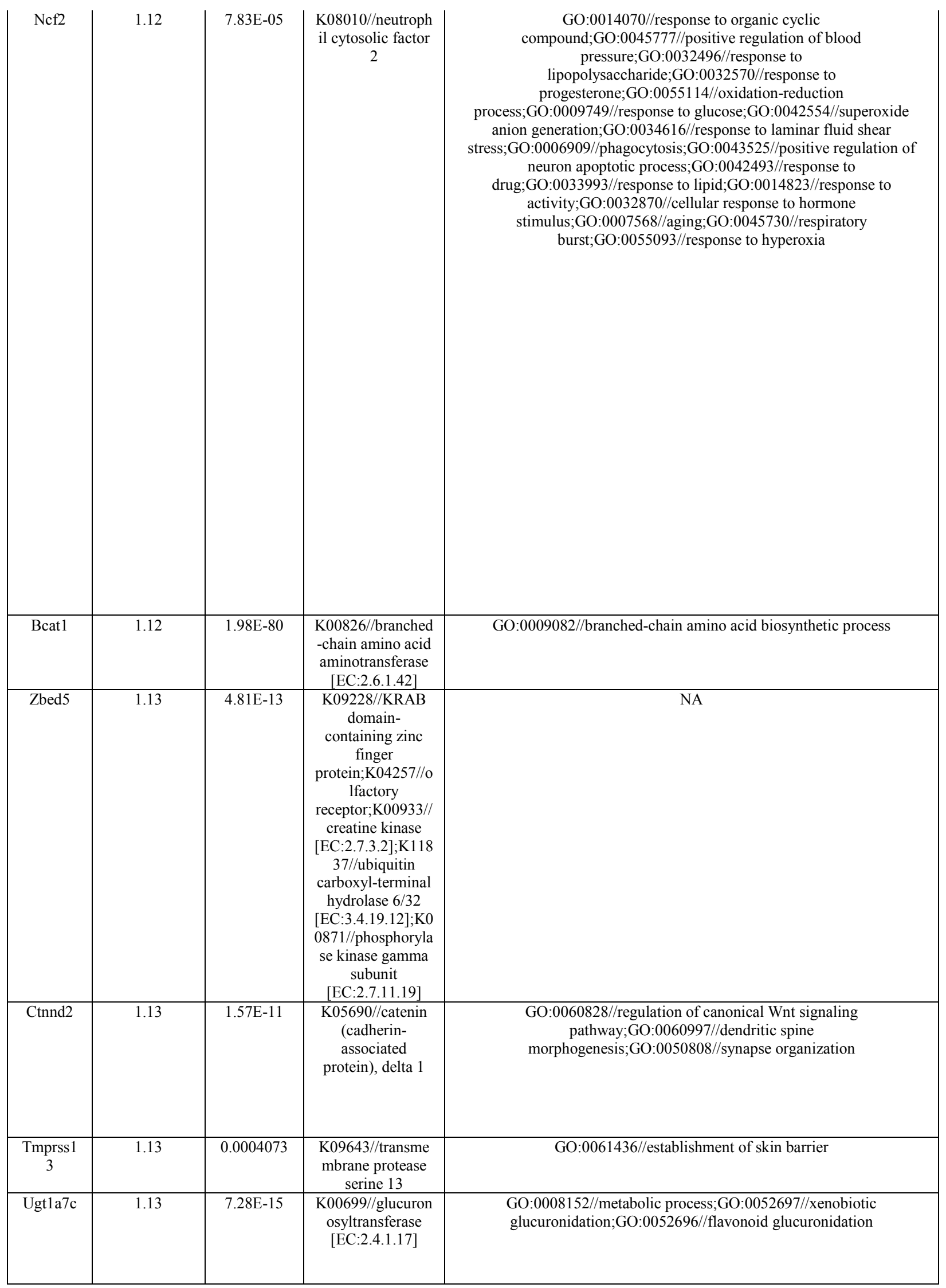




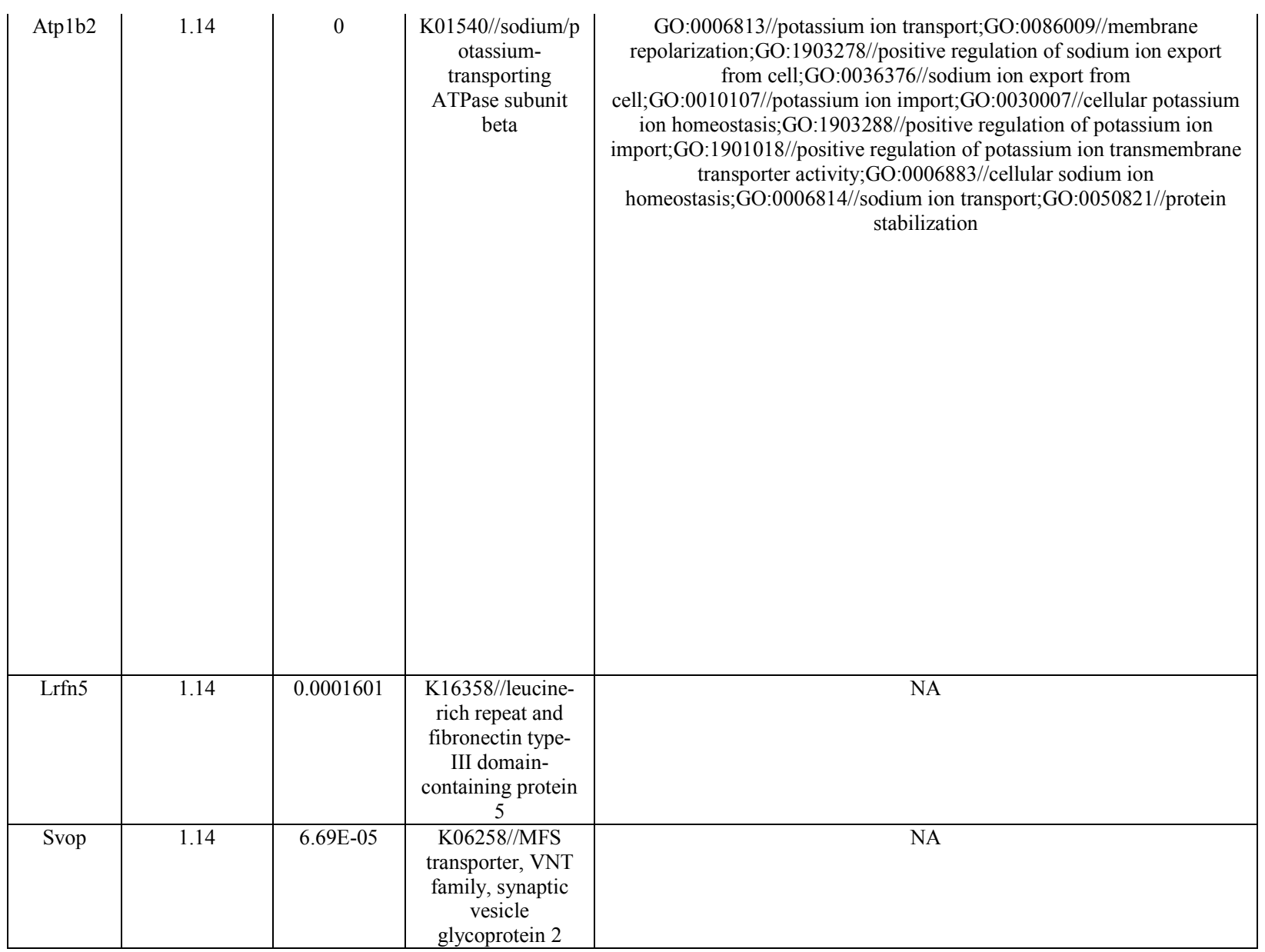




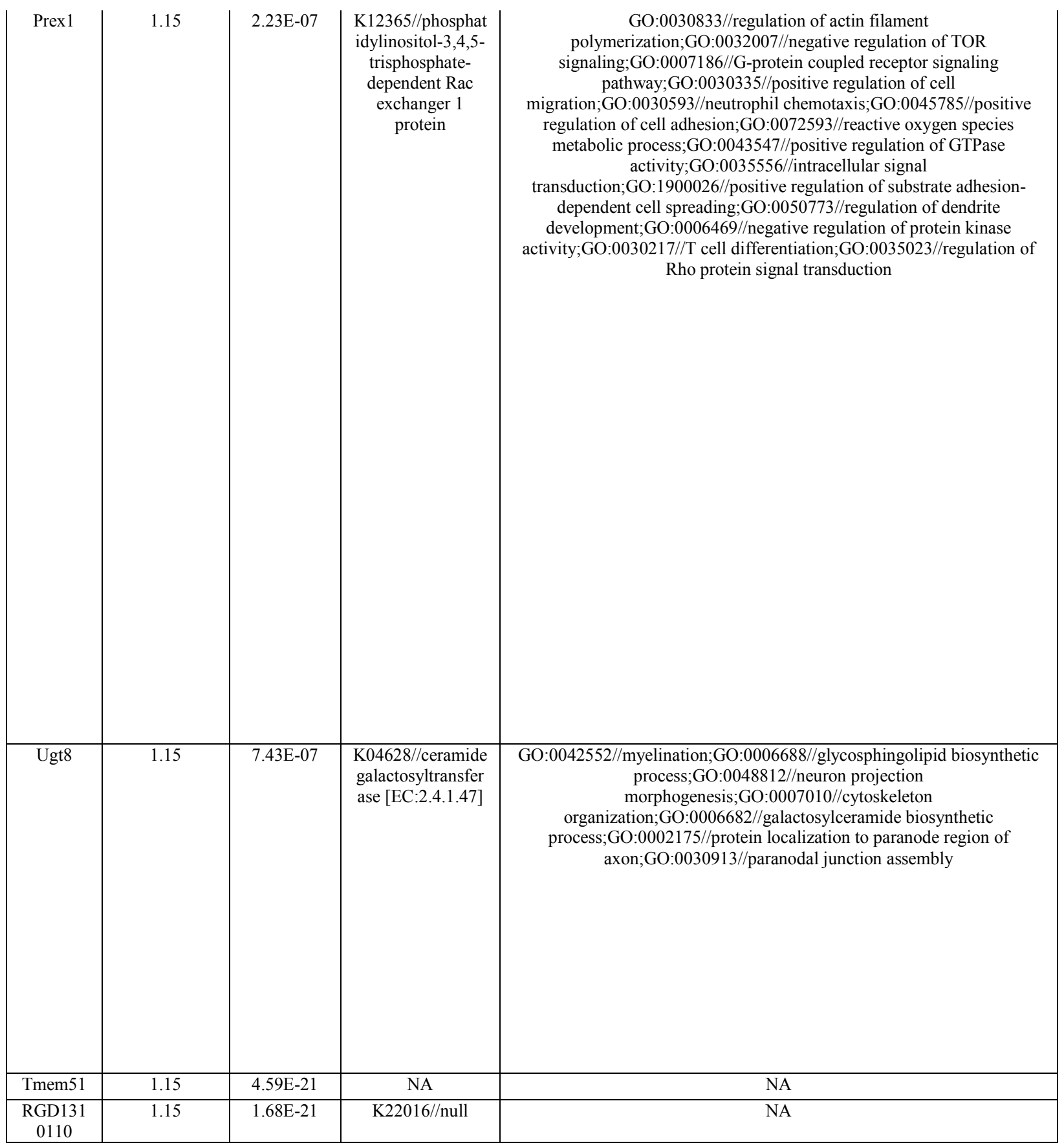




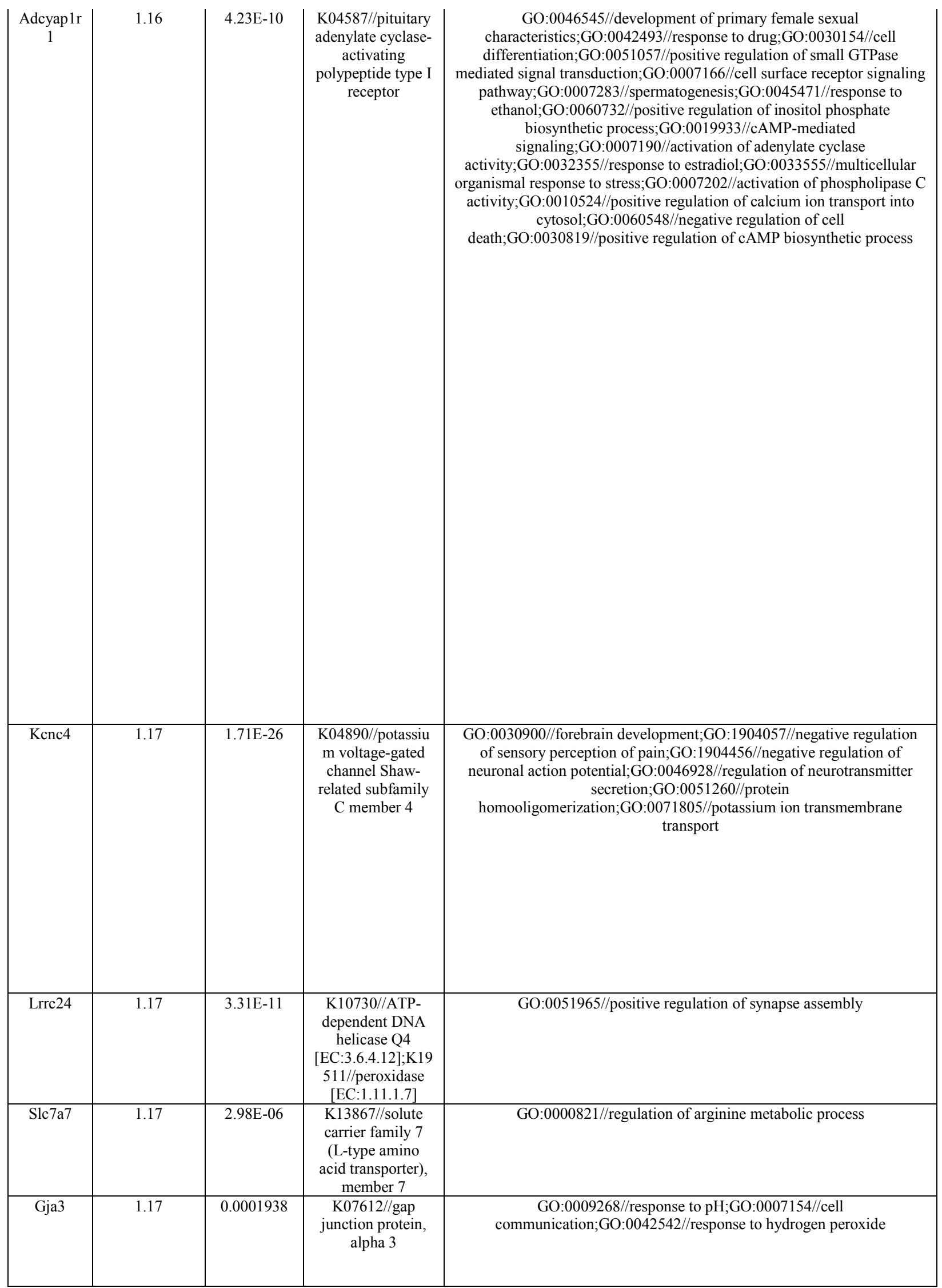




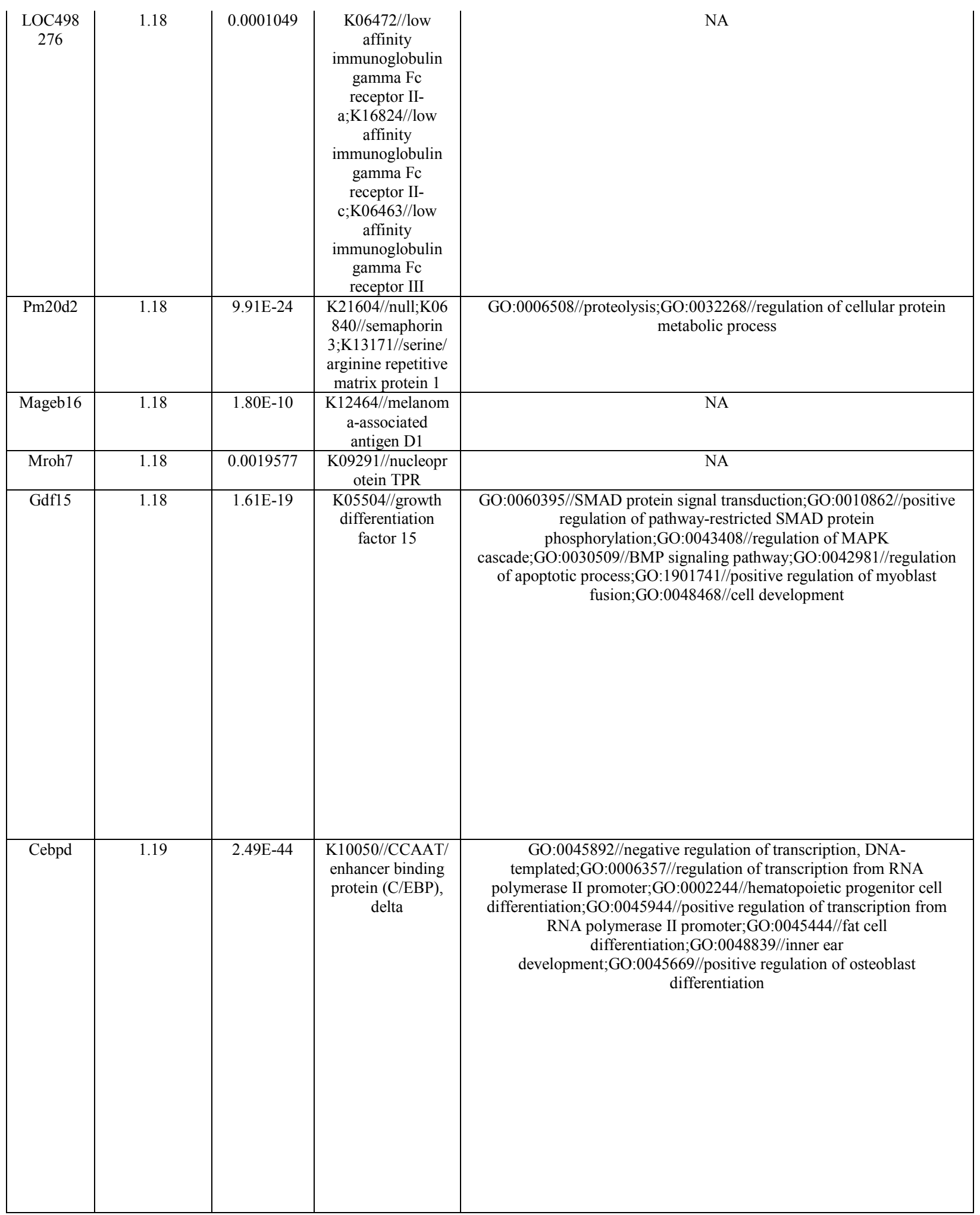




\begin{tabular}{|c|c|c|c|c|}
\hline Chrm5 & 1.19 & $1.15 \mathrm{E}-07$ & $\begin{array}{l}\text { K04133//muscarin } \\
\text { ic acetylcholine } \\
\text { receptor M5 }\end{array}$ & $\begin{array}{c}\text { GO:0007271//synaptic transmission, cholinergic;GO:0007197//adenylate } \\
\text { cyclase-inhibiting G-protein coupled acetylcholine receptor signaling } \\
\text { pathway;GO:0060304//regulation of phosphatidylinositol } \\
\text { dephosphorylation;GO:0019226//transmission of nerve } \\
\text { impulse;GO:0015872//dopamine transport;GO:0007207//phospholipase } \\
\text { C-activating G-protein coupled acetylcholine receptor signaling } \\
\text { pathway;GO:0001696//gastric acid secretion }\end{array}$ \\
\hline Slc7a1 & 1.22 & $6.73 \mathrm{E}-306$ & $\begin{array}{l}\text { K13863//solute } \\
\text { carrier family } 7 \\
\text { (cationic amino } \\
\text { acid transporter), } \\
\text { member } 1\end{array}$ & NA \\
\hline Pck2 & 1.23 & $3.56 \mathrm{E}-76$ & $\begin{array}{c}\text { K01596//phospho } \\
\text { enolpyruvate } \\
\text { carboxykinase } \\
\text { (GTP) } \\
\text { [EC:4.1.1.32] }\end{array}$ & $\begin{array}{c}\text { GO:0032024//positive regulation of insulin } \\
\text { secretion;GO:0006090//pyruvate metabolic } \\
\text { process;GO:0006094//gluconeogenesis;GO:0032496//response to } \\
\text { lipopolysaccharide;GO:0006116//NADH oxidation;GO:0071356//cellular } \\
\text { response to tumor necrosis factor;GO:0071333//cellular response to } \\
\text { glucose stimulus;GO:0006107//oxaloacetate metabolic } \\
\text { process;GO:0071548//response to dexamethasone }\end{array}$ \\
\hline Wnt9b & 1.23 & 0.0035101 & $\begin{array}{l}\text { K01064//wingless } \\
\text {-type MMTV } \\
\text { integration site } \\
\text { family, member } 9\end{array}$ & $\begin{array}{l}\text { GO:0007275//multicellular organism development;GO:0016055//Wnt } \\
\text { signaling pathway }\end{array}$ \\
\hline Slc1a4 & 1.24 & $1.84 \mathrm{E}-65$ & $\begin{array}{c}\text { K05615//solute } \\
\text { carrier family } 1 \\
\text { (glutamate/neutral } \\
\text { amino acid } \\
\text { transporter), } \\
\text { member 4 }\end{array}$ & $\begin{array}{c}\text { GO:0015826//threonine transport;GO:0015825//L-serine } \\
\text { transport;GO:0050890//cognition;GO:0015808//L-alanine } \\
\text { transport;GO:0034589//hydroxyproline transport;GO:0015824//proline } \\
\text { transport;GO:0015811//L-cystine transport }\end{array}$ \\
\hline Gldn & 1.24 & 0 & 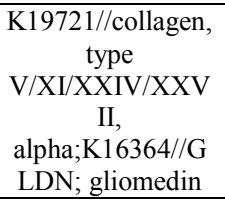 & $\begin{array}{c}\text { GO:0032528//microvillus organization;GO:0045162//clustering of } \\
\text { voltage-gated sodium channels }\end{array}$ \\
\hline
\end{tabular}




\begin{tabular}{|c|c|c|c|c|}
\hline Bspry & 1.25 & 0.0009471 & $\begin{array}{l}\mathrm{K} 12000 / / \text { tripartite } \\
\text { motif-containing } \\
\text { protein } 7\end{array}$ & $\begin{array}{l}\text { GO:1990830//cellular response to leukemia inhibitory } \\
\text { factor;GO:0006816//calcium ion transport }\end{array}$ \\
\hline Fam19a5 & 1.25 & $4.33 \mathrm{E}-61$ & NA & NA \\
\hline NA & 1.25 & $1.60 \mathrm{E}-10$ & $\begin{array}{c}\mathrm{K} 03283 / / \text { heat } \\
\text { shock } 70 \mathrm{kDa} \\
\text { protein } 1 / 8\end{array}$ & $\begin{array}{c}\text { GO:0046034//ATP metabolic process;GO:0006986//response to unfolded } \\
\text { protein;GO:1901673//regulation of mitotic spindle } \\
\text { assembly;GO:0007339//binding of sperm to zona } \\
\text { pellucida;GO:0097201//negative regulation of transcription from RNA } \\
\text { polymerase II promoter in response to stress;GO:0070370//cellular heat } \\
\text { acclimation;GO:0008285//negative regulation of cell } \\
\text { proliferation;GO:0030308//negative regulation of cell } \\
\text { growth;GO:0006281//DNA repair;GO:0009408//response to } \\
\text { heat;GO:0034605//cellular response to heat;GO:0006402//mRNA } \\
\text { catabolic process;GO:0051131//chaperone-mediated protein complex } \\
\text { assembly;GO:0090063//positive regulation of microtubule } \\
\text { nucleation;GO:0042026//protein refolding;GO:0000723//telomere } \\
\text { maintenance }\end{array}$ \\
\hline Slc29a1 & 1.25 & $5.68 \mathrm{E}-222$ & $\begin{array}{l}\text { K15014//solute } \\
\text { carrier family } 29 \\
\text { (equilibrative } \\
\text { nucleoside } \\
\text { transporter), } \\
\text { member } 1 / 2 / 3\end{array}$ & $\begin{array}{l}\text { GO:0007595//lactation;GO:0071456//cellular response to } \\
\text { hypoxia;GO:0071333//cellular response to glucose } \\
\text { stimulus;GO:0015862//uridine } \\
\text { transport;GO:0030431//sleep;GO:0060079//excitatory postsynaptic } \\
\text { potential;GO:0015858//nucleoside transport }\end{array}$ \\
\hline Slc43a3 & 1.25 & 0.0072395 & $\begin{array}{l}\text { K08230//MFS } \\
\text { transporter, LAT3 } \\
\text { family, solute } \\
\text { carrier family } 43 \text {, } \\
\text { member } 3 \\
\end{array}$ & GO:0055085//transmembrane transport \\
\hline Zbtb8b & 1.26 & $9.45 \mathrm{E}-05$ & $\begin{array}{l}\text { K10495//zinc } \\
\text { finger and BTB } \\
\text { domain- } \\
\text { containing protein } \\
\quad 8 \\
\end{array}$ & NA \\
\hline Olr154 & 1.26 & 0.0057676 & $\begin{array}{l}\text { K04257//olfactory } \\
\text { receptor }\end{array}$ & NA \\
\hline Ntng2 & 1.26 & 0.0002274 & $\begin{array}{l}\text { K16359//netrin- } \\
\text { G2 }\end{array}$ & GO:0007409//axonogenesis \\
\hline
\end{tabular}




\begin{tabular}{|c|c|c|c|c|}
\hline Arhgef19 & 1.26 & $2.05 \mathrm{E}-06$ & $\begin{array}{l}\text { K20691//Rho } \\
\text { guanine } \\
\text { nucleotide } \\
\text { exchange factor } \\
19\end{array}$ & $\begin{array}{l}\text { GO:0042060//wound healing;GO:0035023//regulation of Rho protein } \\
\text { signal transduction;GO:0043547//positive regulation of GTPase } \\
\text { activity;GO:0032956//regulation of actin cytoskeleton organization }\end{array}$ \\
\hline Cxcr4 & 1.27 & $5.15 \mathrm{E}-07$ & $\begin{array}{l}\text { K04189//C-X-C } \\
\text { chemokine } \\
\text { receptor type } 4\end{array}$ & $\begin{array}{l}\text { GO:0050920//regulation of chemotaxis;GO:0019722//calcium-mediated } \\
\text { signaling;GO:0006935//chemotaxis;GO:0001666//response to hypoxia }\end{array}$ \\
\hline Cilp2 & 1.28 & 0.0006532 & $\begin{array}{c}\text { K05141//tumor } \\
\text { necrosis factor } \\
\text { receptor } \\
\text { superfamily } \\
\text { member } \\
\text { 1B;K13172//serin } \\
\text { e/arginine } \\
\text { repetitive matrix } \\
\text { protein 2 }\end{array}$ & NA \\
\hline Dmrt3 & 1.28 & $3.11 \mathrm{E}-13$ & $\begin{array}{l}\text { K19490//doublese } \\
\text { X- and mab-3- } \\
\text { related } \\
\text { transcription } \\
\text { factor } 3\end{array}$ & $\begin{array}{c}\text { GO:0042487//regulation of odontogenesis of dentin-containing } \\
\text { tooth;GO:0019226//transmission of nerve impulse;GO:0007628//adult } \\
\text { walking behavior;GO:0021521//ventral spinal cord interneuron } \\
\text { specification;GO:0006351//transcription, DNA- } \\
\text { templated;GO:0046661//male sex differentiation }\end{array}$ \\
\hline Atp2a3 & 1.29 & $1.89 \mathrm{E}-26$ & $\begin{array}{l}\text { K05853//Ca2+ } \\
\text { transporting } \\
\quad \text { ATPase, } \\
\text { sarcoplasmic/endo } \\
\text { plasmic reticulum } \\
\text { [EC:3.6.3.8] }\end{array}$ & NA \\
\hline Ptpru & 1.29 & $7.75 \mathrm{E}-05$ & $\begin{array}{c}\text { K16662//receptor- } \\
\text { type tyrosine- } \\
\text { protein } \\
\text { phosphatase U } \\
\text { [EC:3.1.3.48] }\end{array}$ & NA \\
\hline
\end{tabular}




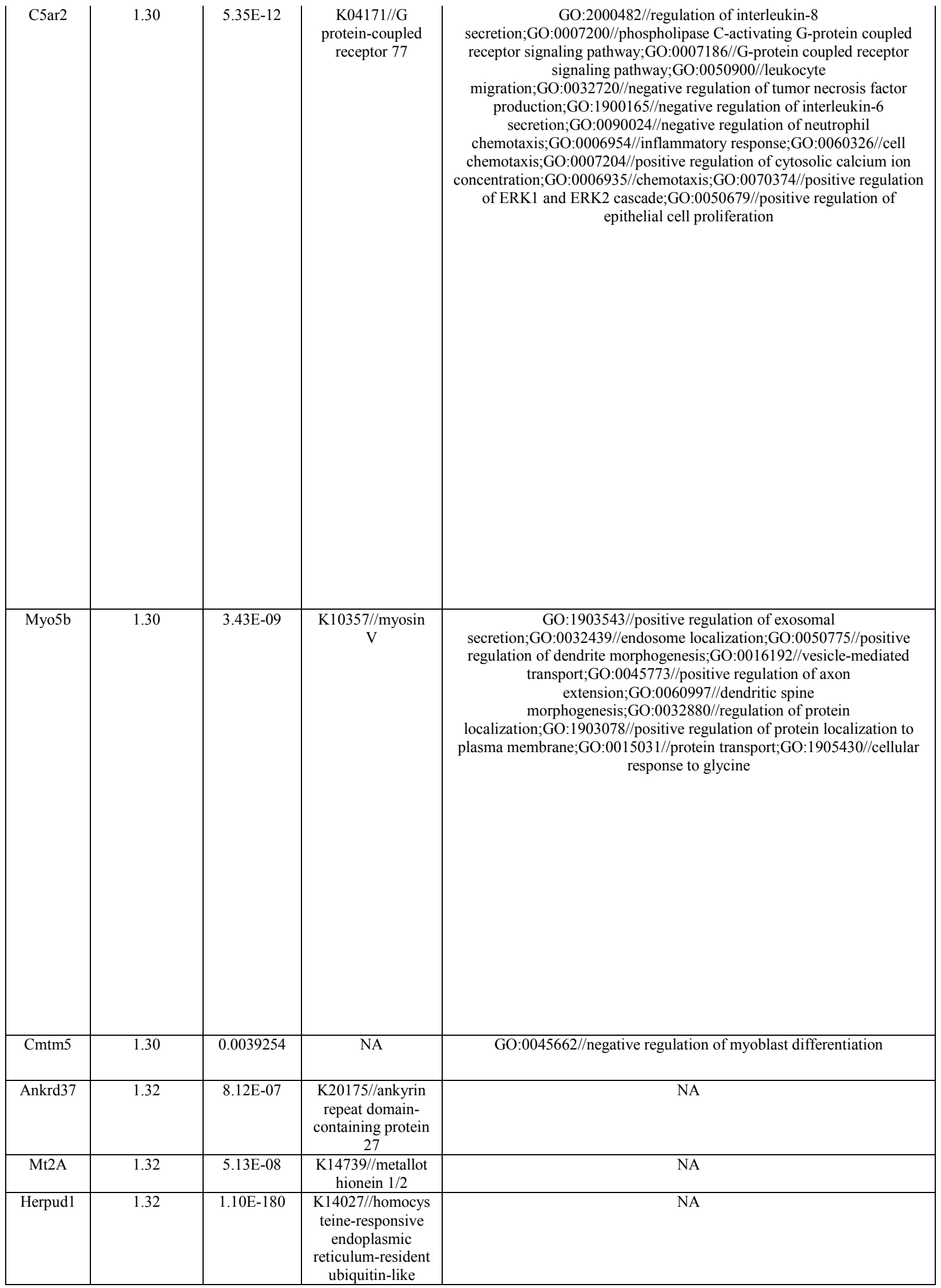




\begin{tabular}{|c|c|c|c|c|}
\hline & & & $\begin{array}{c}\text { domain member } 1 \\
\text { protein }\end{array}$ & \\
\hline Megf10 & 1.33 & $1.13 \mathrm{E}-11$ & $\begin{array}{c}\text { K02258//cytochro } \\
\text { me c oxidase } \\
\text { assembly protein } \\
\text { subunit } \\
11 ; \mathrm{K} 02599 / / \text { Notch } \\
1\end{array}$ & $\begin{array}{c}\text { GO:0042552//myelination;GO:0048641//regulation of skeletal muscle } \\
\text { tissue development;GO:0055001//muscle cell } \\
\text { development;GO:0043652//engulfment of apoptotic } \\
\text { cell;GO:1902742//apoptotic process involved in } \\
\text { development;GO:0014841//skeletal muscle satellite cell } \\
\text { proliferation;GO:0043654//recognition of apoptotic } \\
\text { cell;GO:0014719//skeletal muscle satellite cell } \\
\text { activation;GO:0033002//muscle cell } \\
\text { proliferation;GO:0034109//homotypic cell-cell } \\
\text { adhesion;GO:0051451//myoblast migration;GO:0051147//regulation of } \\
\text { muscle cell differentiation;GO:0014816//skeletal muscle satellite cell } \\
\text { differentiation }\end{array}$ \\
\hline Mett17b & 1.34 & 0.0060155 & NA & NA \\
\hline Mmp28 & 1.35 & $3.71 \mathrm{E}-17$ & $\begin{array}{c}\text { K08006//matrix } \\
\text { metalloproteinase- } \\
28 \text { (epilysin) } \\
\text { [EC:3.4.24.-] }\end{array}$ & GO:0010760//negative regulation of macrophage chemotaxis \\
\hline Akr1c12 & 1.36 & 0.0012635 & $\begin{array}{c}\text { K13374//aldo- } \\
\text { keto reductase } \\
\text { family } 1 \text { member } \\
\text { C13 } \\
\text { [EC:1.1.1.218];K0 } \\
\text { 4119//aldo-keto } \\
\text { reductase family } 1 \\
\text { member C3 } \\
\text { [EC:1.1.1.51 } \\
1.1 .1 .188 \\
1.1 .1 .213 \\
1.1 .1 .357]\end{array}$ & GO:0006805//xenobiotic metabolic process \\
\hline
\end{tabular}




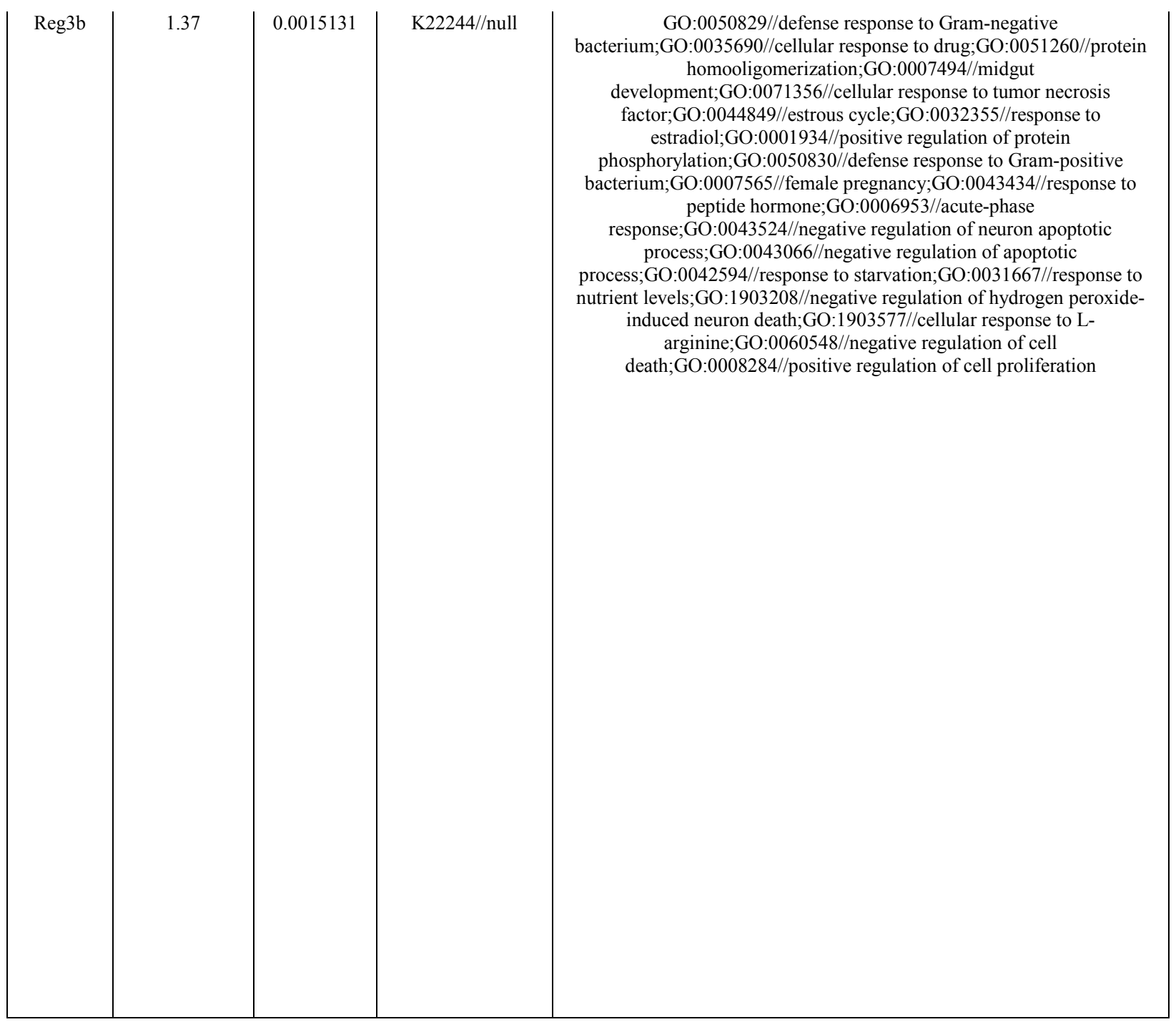




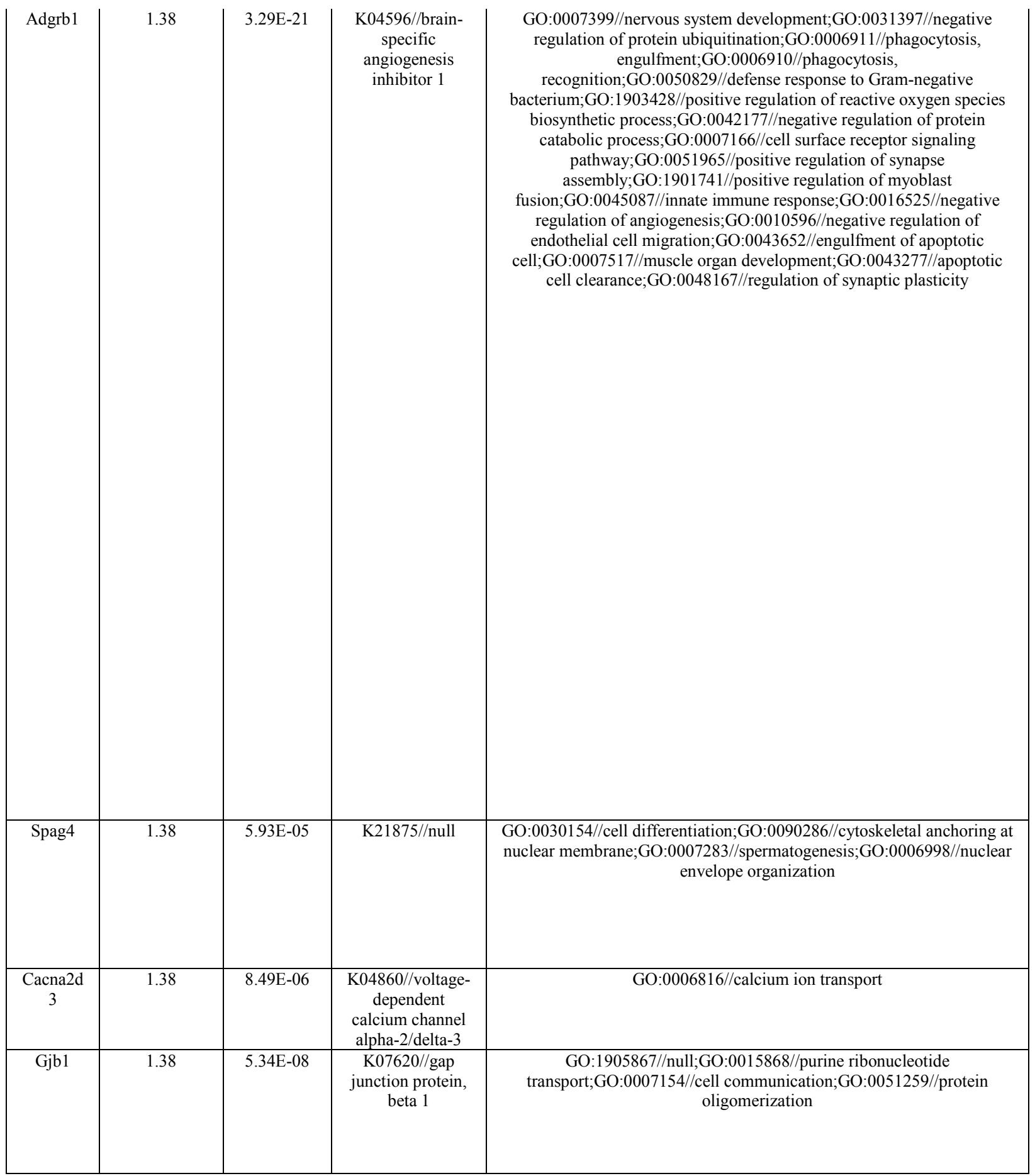




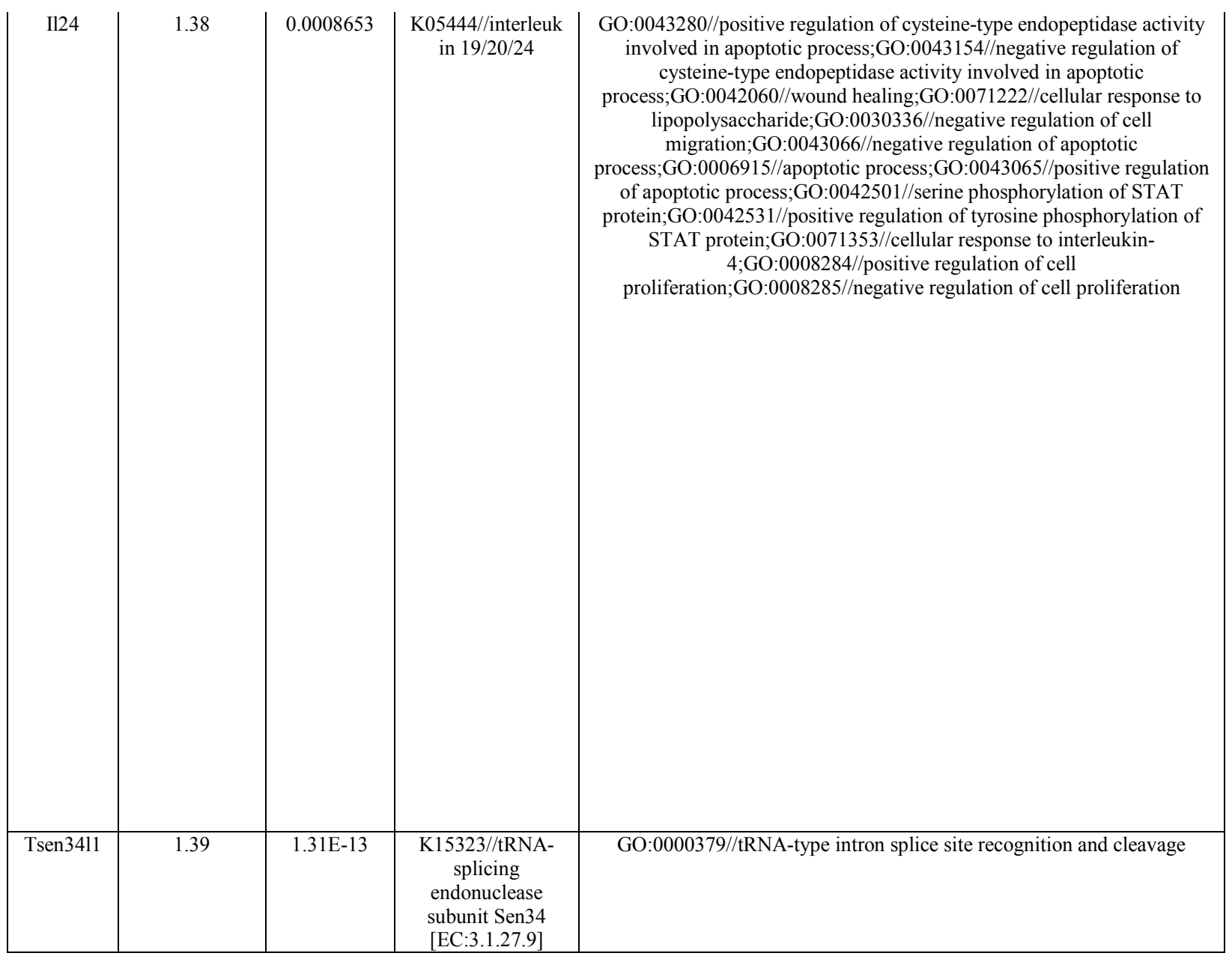




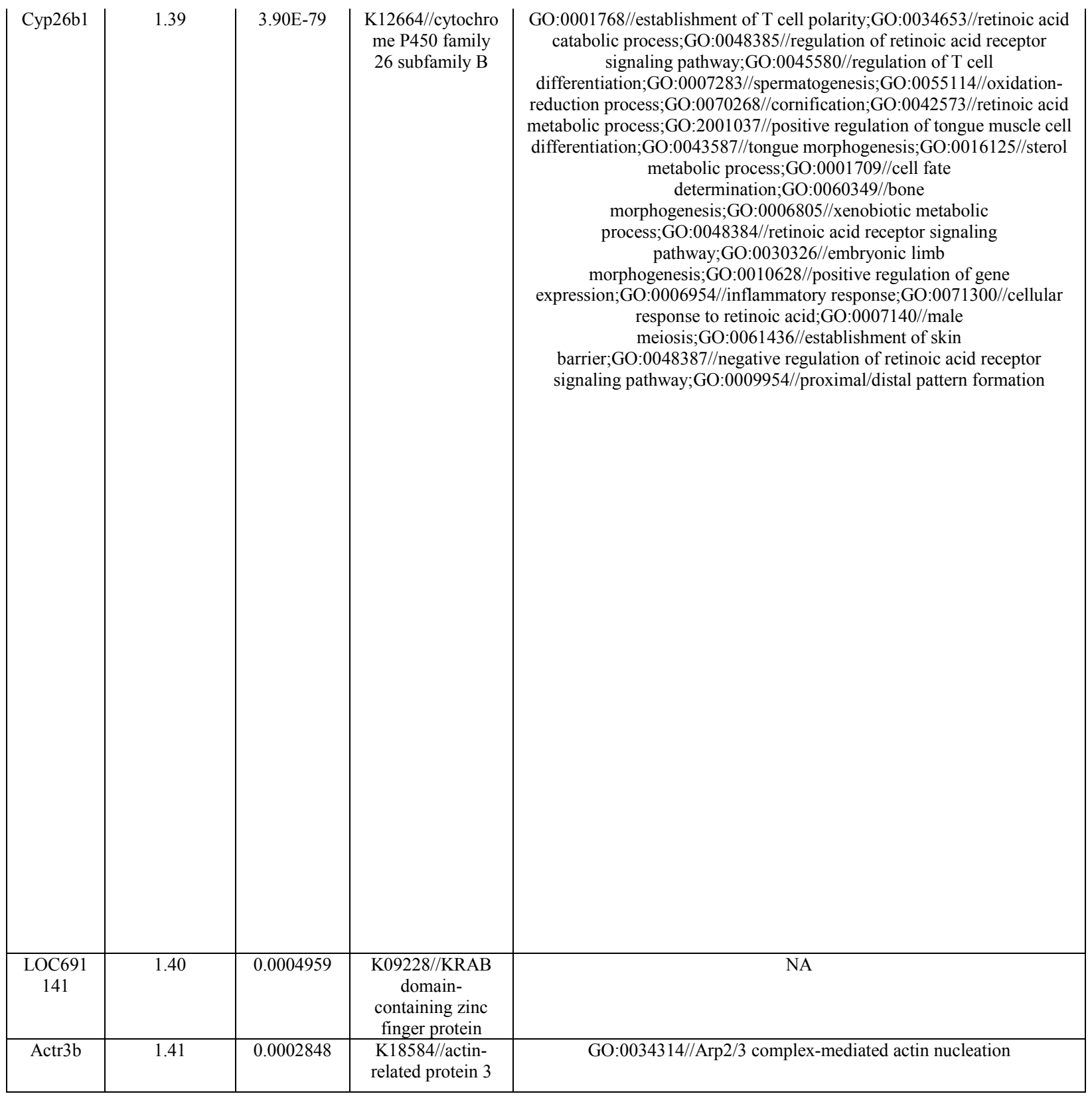




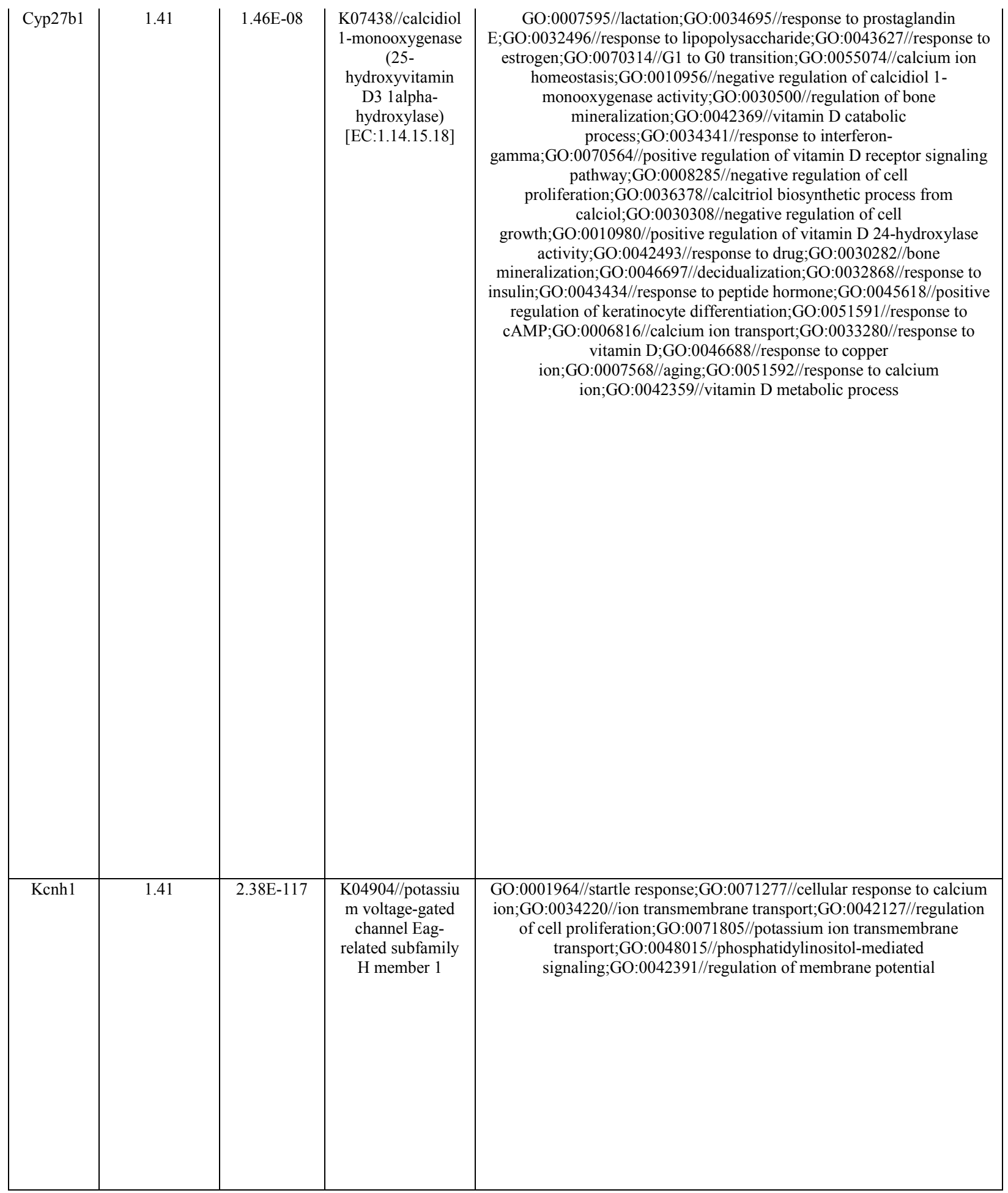




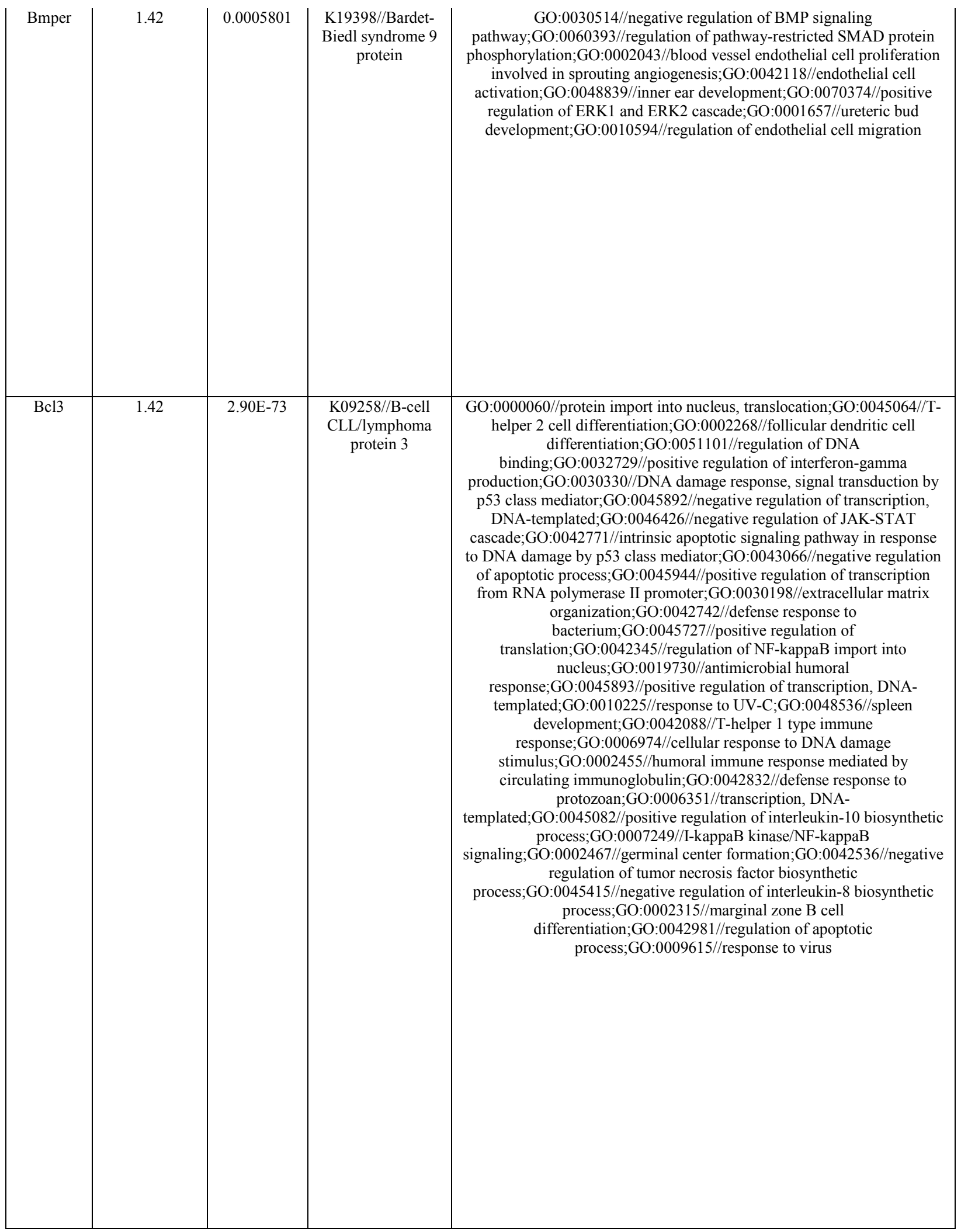




\begin{tabular}{|c|c|c|c|c|}
\hline Elov14 & 1.42 & $1.84 \mathrm{E}-13$ & $\begin{array}{c}\text { K10249//elongatio } \\
\text { n of very long } \\
\text { chain fatty acids } \\
\text { protein } 4 \\
\text { [EC:2.3.1.199] }\end{array}$ & $\begin{array}{c}\text { GO:0019367//fatty acid elongation, saturated fatty } \\
\text { acid;GO:0006636//unsaturated fatty acid biosynthetic } \\
\text { process;GO:0034626//fatty acid elongation, polyunsaturated fatty } \\
\text { acid;GO:0030148//sphingolipid biosynthetic process;GO:0035338//long- } \\
\text { chain fatty-acyl-CoA biosynthetic process;GO:0042761//very long-chain } \\
\text { fatty acid biosynthetic process;GO:0034625//fatty acid elongation, } \\
\text { monounsaturated fatty acid }\end{array}$ \\
\hline Nxf3 & 1.43 & $3.15 \mathrm{E}-10$ & $\begin{array}{l}\text { K14284//nuclear } \\
\text { RNA export factor }\end{array}$ & $\begin{array}{c}\text { GO:0016973//poly(A)+ mRNA export from } \\
\text { nucleus;GO:0006406//mRNA export from nucleus }\end{array}$ \\
\hline Pcdh15 & 1.44 & 0.0043212 & $\begin{array}{l}\text { K16500//protocad } \\
\text { herin-15 }\end{array}$ & $\begin{array}{c}\text { GO:0002009//morphogenesis of an epithelium;GO:0060088//auditory } \\
\text { receptor cell stereocilium organization;GO:0050973//detection of } \\
\text { mechanical stimulus involved in equilibrioception;GO:0007601//visual } \\
\text { perception;GO:0007015//actin filament } \\
\text { organization;GO:0050953//sensory perception of light } \\
\text { stimulus;GO:0051017//actin filament bundle } \\
\text { assembly;GO:0048839//inner ear development;GO:0001964//startle } \\
\text { response;GO:0007267//cell-cell signaling;GO:1905515//non-motile } \\
\text { cilium assembly;GO:0045494//photoreceptor cell } \\
\text { maintenance;GO:0035264//multicellular organism } \\
\text { growth;GO:0060122//inner ear receptor stereocilium } \\
\text { organization;GO:0051592//response to calcium ion;GO:0007155//cell } \\
\text { adhesion;GO:0050957//equilibrioception;GO:0007626//locomotory } \\
\text { behavior;GO:0042491//auditory receptor cell } \\
\text { differentiation;GO:0050910//detection of mechanical stimulus involved } \\
\text { in sensory perception of sound;GO:0007605//sensory perception of } \\
\text { sound;GO:0007628//adult walking behavior;GO:0007156//homophilic } \\
\text { cell adhesion via plasma membrane adhesion } \\
\text { molecules;GO:0060013//righting reflex }\end{array}$ \\
\hline
\end{tabular}




\begin{tabular}{|c|c|c|c|c|}
\hline $\mathrm{I} 11 \mathrm{r} 2$ & 1.44 & $3.14 \mathrm{E}-05$ & $\begin{array}{c}\text { K04387//interleuk } \\
\text { in } 1 \text { receptor type } \\
\text { II }\end{array}$ & $\begin{array}{l}\text { GO:0010955//negative regulation of protein } \\
\text { processing;GO:0050712//negative regulation of interleukin-1 alpha } \\
\text { secretion;GO:2000660//negative regulation of interleukin-1-mediated } \\
\text { signaling pathway;GO:1900016//negative regulation of cytokine } \\
\text { production involved in inflammatory response }\end{array}$ \\
\hline Glrb & 1.45 & 0.0001097 & $\begin{array}{l}\text { K05196//glycine } \\
\text { receptor beta }\end{array}$ & $\begin{array}{c}\text { GO:0051291//protein heterooligomerization;GO:0007399//nervous } \\
\text { system development;GO:0001964//startle } \\
\text { response;GO:0043200//response to amino acid;GO:0007601//visual } \\
\text { perception;GO:0006811//ion transport;GO:0060012//synaptic } \\
\text { transmission, glycinergic;GO:0007340//acrosome } \\
\text { reaction;GO:0097112//gamma-aminobutyric acid receptor } \\
\text { clustering;GO:0007628//adult walking behavior;GO:0060013//righting } \\
\text { reflex;GO:0007268//chemical synaptic } \\
\text { transmission;GO:0050905//neuromuscular } \\
\text { process;GO:0007218//neuropeptide signaling } \\
\text { pathway;GO:0042391//regulation of membrane } \\
\text { potential;GO:1902476//chloride transmembrane transport }\end{array}$ \\
\hline Reln & 1.45 & $1.72 \mathrm{E}-17$ & $\begin{array}{l}\text { K06249//reelin } \\
\text { [EC:3.4.21.-] }\end{array}$ & $\begin{array}{c}\text { GO:0007155//cell adhesion;GO:0008306//associative } \\
\text { learning;GO:0007420//brain development;GO:0007411//axon guidance }\end{array}$ \\
\hline Shc4 & 1.45 & $2.02 \mathrm{E}-67$ & $\begin{array}{c}\mathrm{K} 17449 / / \mathrm{SHC}- \\
\text { transforming } \\
\text { protein } 4\end{array}$ & $\begin{array}{c}\text { GO:0048863//stem cell differentiation;GO:0007169//transmembrane } \\
\text { receptor protein tyrosine kinase signaling } \\
\text { pathway;GO:0010468//regulation of gene } \\
\text { expression;GO:0035556//intracellular signal } \\
\text { transduction;GO:0008284//positive regulation of cell } \\
\text { proliferation;GO:0006915//apoptotic process }\end{array}$ \\
\hline
\end{tabular}




\begin{tabular}{|c|c|c|c|c|}
\hline Ednrb & 1.46 & $2.46 \mathrm{E}-24$ & $\begin{array}{l}\text { K04198//endotheli } \\
\text { n receptor type B }\end{array}$ & $\begin{array}{c}\text { GO:0008217//regulation of blood pressure;GO:0014043//negative } \\
\text { regulation of neuron maturation;GO:0006885//regulation of } \\
\text { pH;GO:0071222//cellular response to } \\
\text { lipopolysaccharide;GO:0048066//developmental } \\
\text { pigmentation;GO:0019233//sensory perception of } \\
\text { pain;GO:0048246//macrophage chemotaxis;GO:0060406//positive } \\
\text { regulation of penile erection;GO:0001755//neural crest cell } \\
\text { migration;GO:0019722//calcium-mediated } \\
\text { signaling;GO:0086100//endothelin receptor signaling } \\
\text { pathway;GO:0043066//negative regulation of apoptotic } \\
\text { process;GO:0050678//regulation of epithelial cell } \\
\text { proliferation;GO:0051930//regulation of sensory perception of } \\
\text { pain;GO:0007422//peripheral nervous system } \\
\text { development;GO:0007200//phospholipase C-activating G-protein } \\
\text { coupled receptor signaling pathway;GO:0014070//response to organic } \\
\text { cyclic compoun;;GO:0042310//vasoconstriction;GO:0032496//response } \\
\text { to lipopolysaccharide;GO:0035645//enteric smooth muscle cell } \\
\text { differentiation;GO:0000122//negative regulation of transcription from } \\
\text { RNA polymerase II promoter;GO:0014826//vein smooth muscle } \\
\text { contraction;GO:0042045//epithelial fluid transport;GO:0019934///GMP- } \\
\text { mediated signaling;GO:0048265//response to pain;GO:0001934//positive } \\
\text { regulation of protein phosphorylation;GO:0031620//regulation of fever } \\
\text { generation;GO:0030318//melanocyte } \\
\text { differentiation;GO:0042311//vasodilation;GO:0007186//G-protein } \\
\text { coupled receptor signaling pathway;GO:0007497//posterior midgut } \\
\text { development;GO:0032269//negative regulation of cellular protein } \\
\text { metabolic process;GO:0007568//aging;GO:0048484//enteric nervous } \\
\text { system development;GO:0043473//pigmentation;GO:0035815//positive } \\
\text { regulation of renal sodium excretion;GO:0007204//positive regulation of } \\
\text { cytosolic calcium ion concentration;GO:0035810//positive regulation of } \\
\text { urine volume;GO:0008284//positive regulation of cell proliferation }\end{array}$ \\
\hline Slc16a14 & 1.47 & $6.00 \mathrm{E}-07$ & $\begin{array}{c}\text { K08190//MFS } \\
\text { transporter, MCP } \\
\text { family, solute } \\
\text { carrier family } 16 \\
\text { (monocarboxylic } \\
\text { acid transporters), } \\
\text { member } 14\end{array}$ & GO:0055085//transmembrane transport \\
\hline Dsc3 & 1.50 & $8.43 \mathrm{E}-05$ & $\begin{array}{l}\text { K07602//desmoco } \\
\quad \text { llin } 3\end{array}$ & $\begin{array}{c}\text { GO:0007156//homophilic cell adhesion via plasma membrane adhesion } \\
\text { molecules;GO:0001701//in utero embryonic } \\
\text { development;GO:0050821//protein stabilization }\end{array}$ \\
\hline Dbil5 & 1.53 & 0.0058445 & $\begin{array}{l}\text { K08762//diazepa } \\
\text { m-binding } \\
\text { inhibitor (GABA } \\
\text { receptor } \\
\text { modulator, acyl- } \\
\text { CoA-binding } \\
\text { protein) }\end{array}$ & $\begin{array}{l}\text { GO:0006810//transport;GO:0007283//spermatogenesis;GO:0006637//acy } \\
\text { 1-CoA metabolic process }\end{array}$ \\
\hline
\end{tabular}




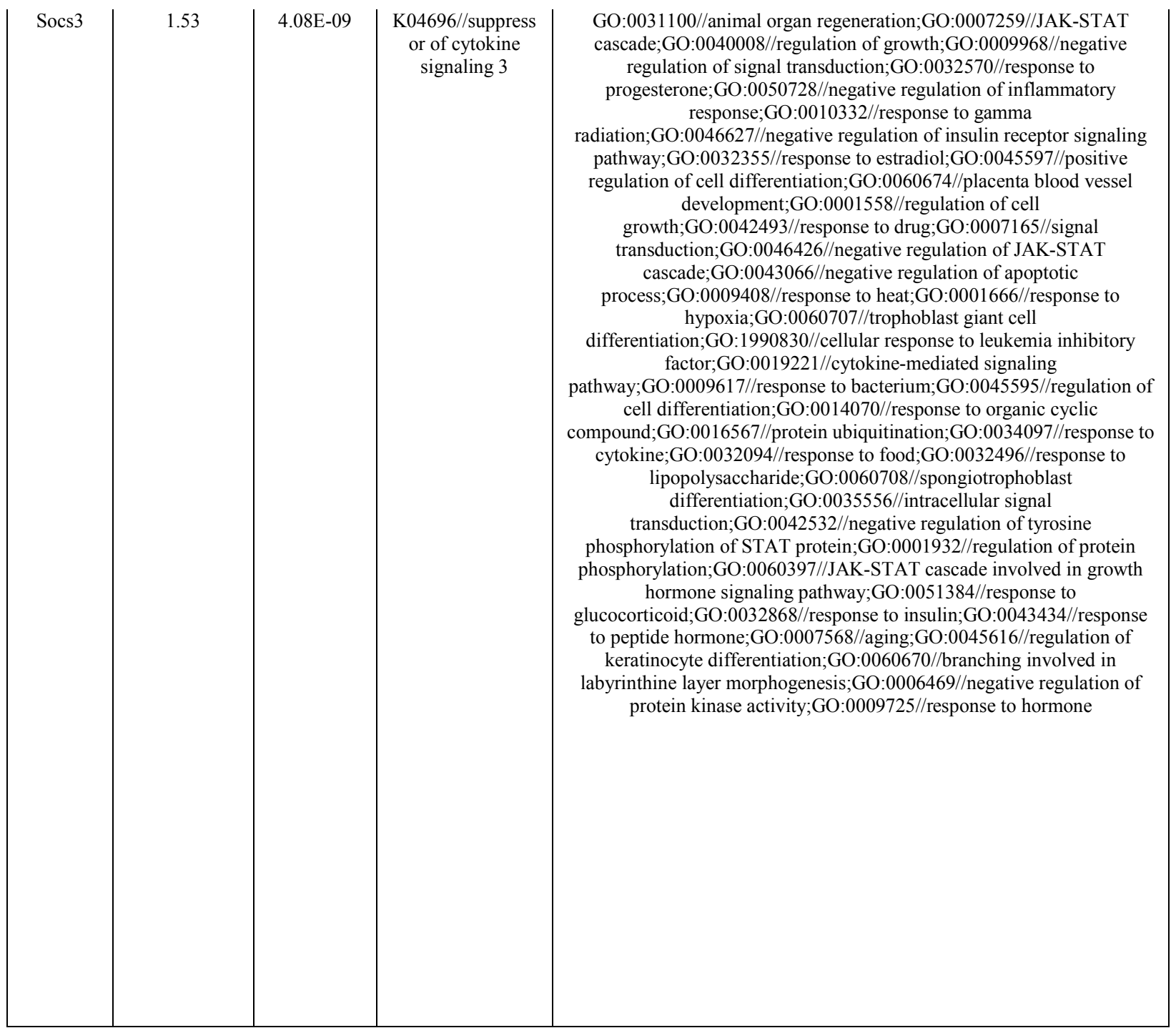




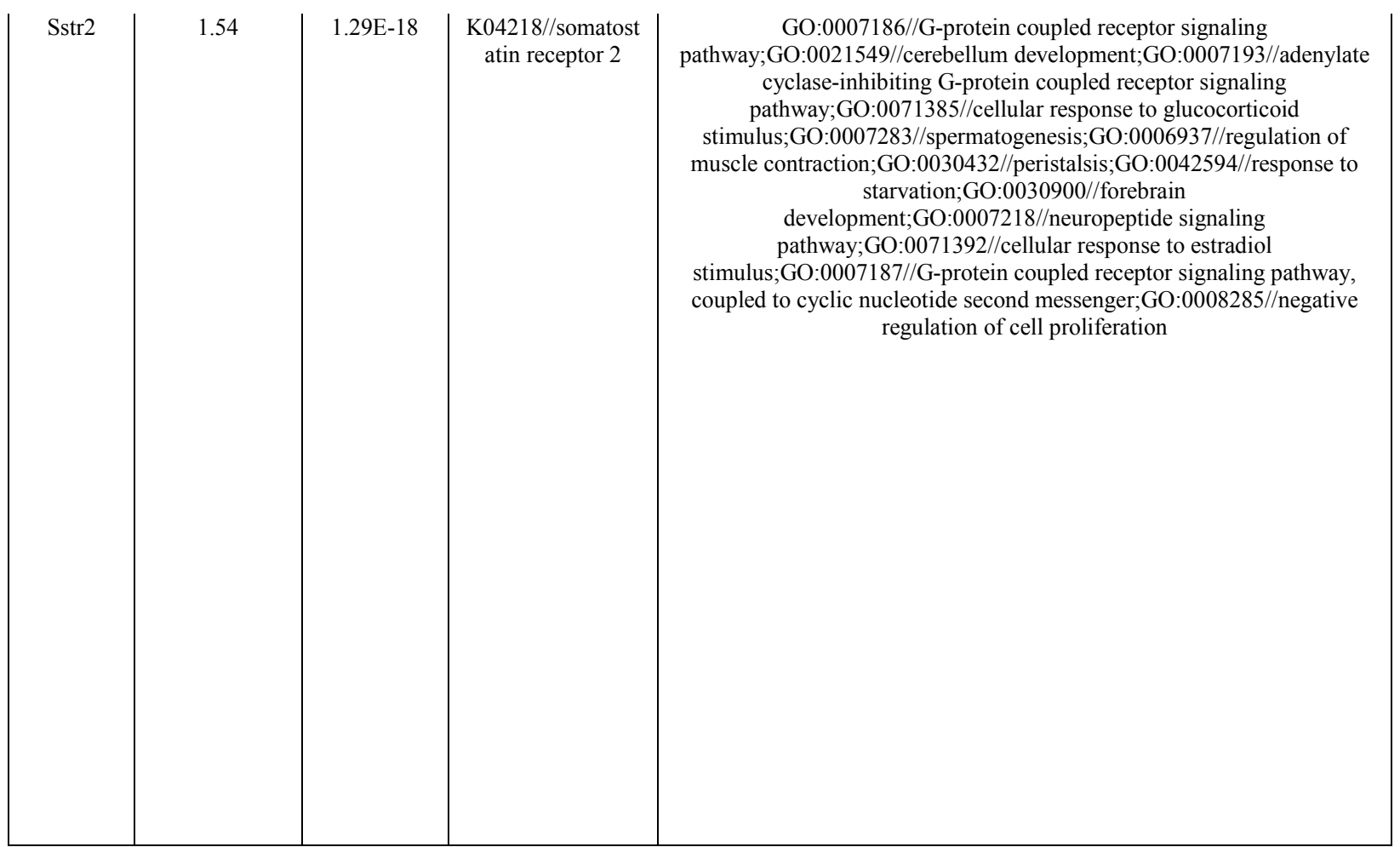




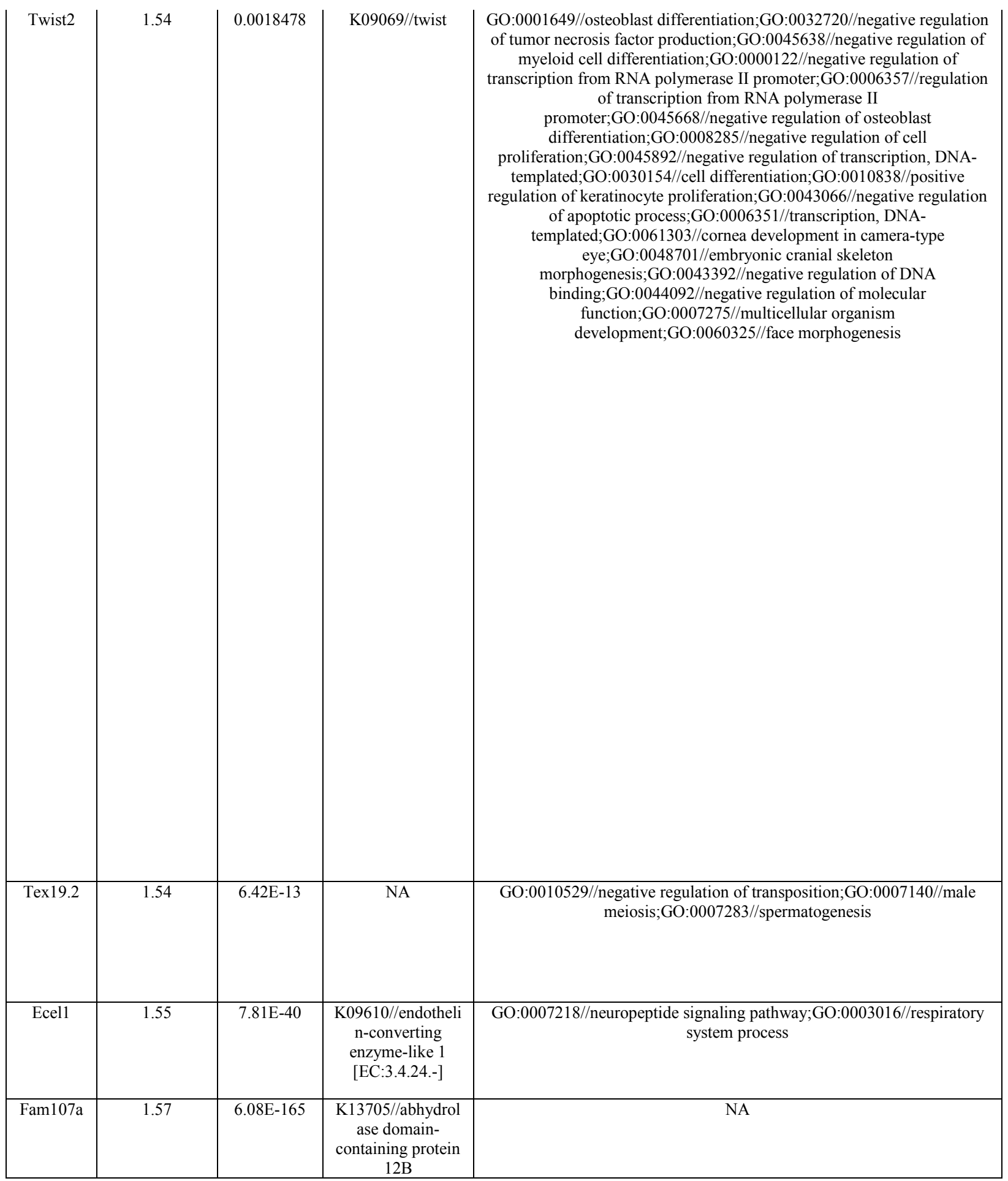




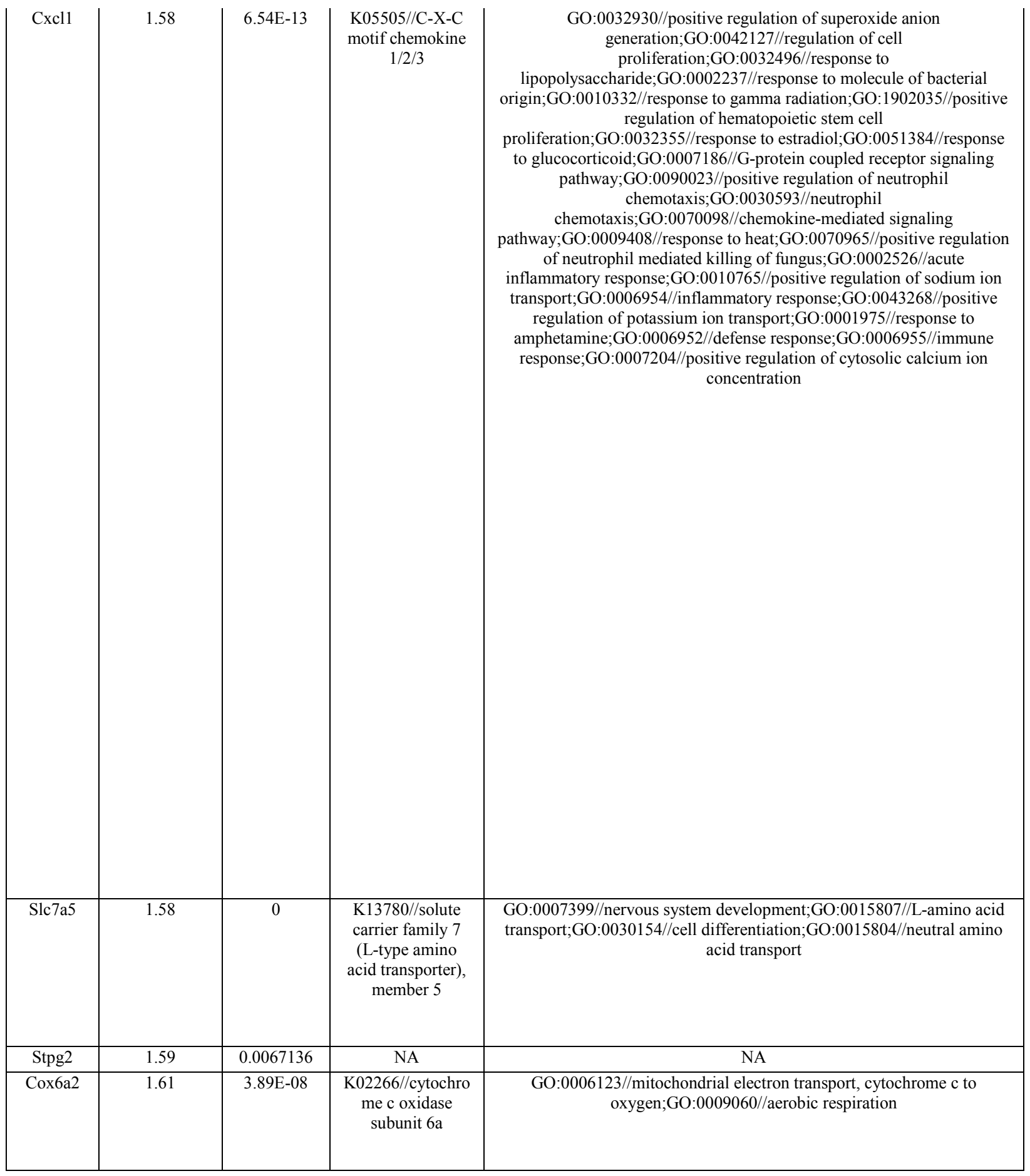




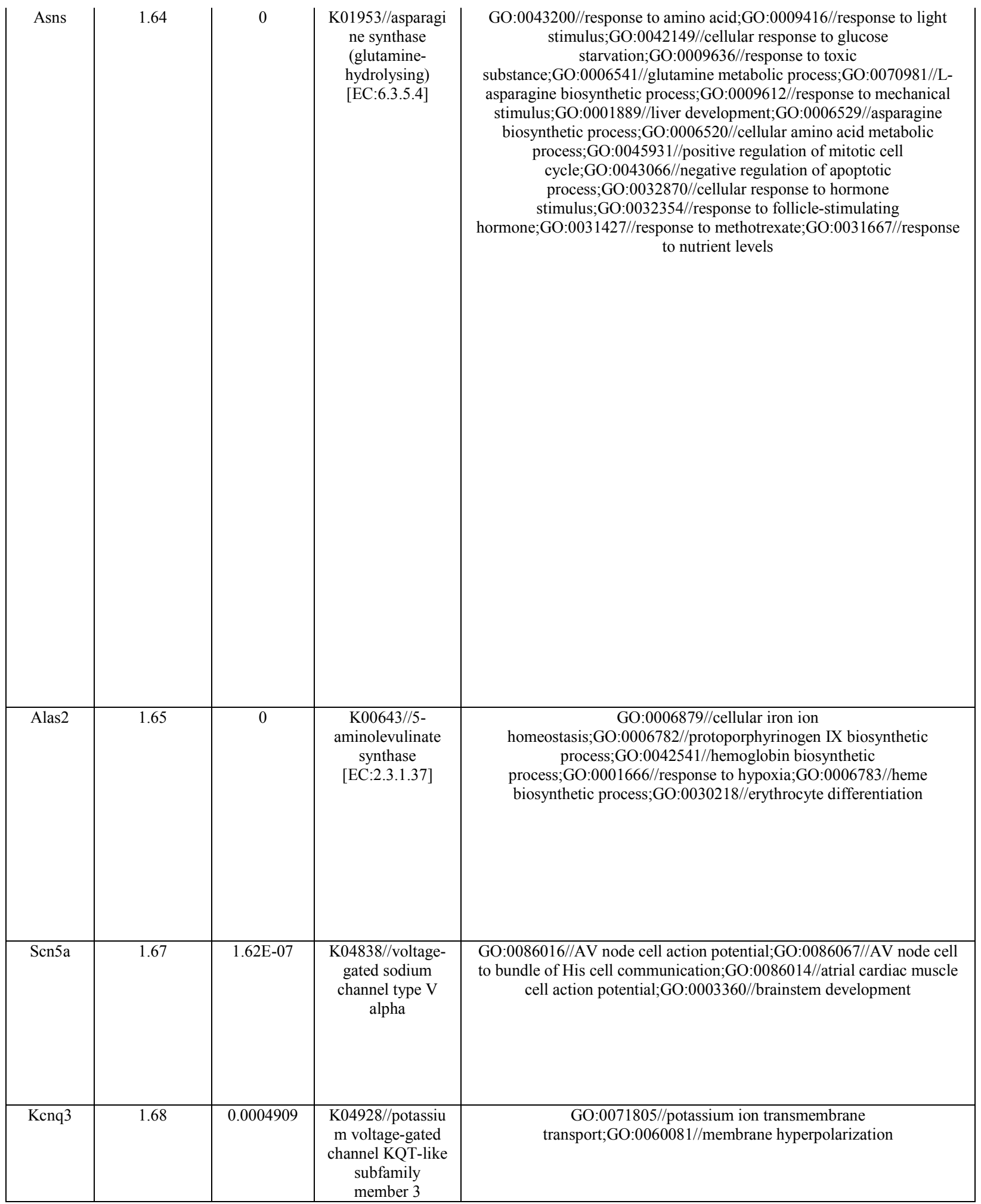




\begin{tabular}{|c|c|c|c|c|}
\hline Kenmal & 1.69 & 0.0006385 & $\begin{array}{c}\text { K04936//potassiu } \\
\text { m large } \\
\text { conductance } \\
\text { calcium-activated } \\
\text { channel subfamily } \\
\text { M alpha member } \\
1\end{array}$ & $\begin{array}{c}\text { GO:0046541//saliva secretion;GO:0051260//protein } \\
\text { homooligomerization;GO:0043627//response to } \\
\text { estrogen;GO:0060087//relaxation of vascular smooth } \\
\text { muscle;GO:0060083//smooth muscle contraction involved in } \\
\text { micturition;GO:0043065//positive regulation of apoptotic } \\
\text { process;GO:0032344//regulation of aldosterone metabolic } \\
\text { process;GO:0097746//regulation of blood vessel } \\
\text { diameter;GO:0006813//potassium ion transport;GO:0009268//response to } \\
\text { pH;GO:0051289//protein homotetramerization;GO:0001666//response to } \\
\text { hypoxia;GO:0031960//response to corticosteroid;GO:0048469//cell } \\
\text { maturation;GO:0051592//response to calcium ion;GO:0042491//auditory } \\
\text { receptor cell differentiation;GO:0007628//adult walking } \\
\text { behavior;GO:0045475//locomotor rhythm;GO:0050885//neuromuscular } \\
\text { process controlling } \\
\text { balance;GO:0060073//micturition;GO:0097755//null;GO:0006970//respo } \\
\text { nse to osmotic stress;GO:0034465//response to carbon } \\
\text { monoxide;GO:0030007//cellular potassium ion } \\
\text { homeostasis;GO:0019228//neuronal action } \\
\text { potential;GO:0042311//vasodilation;GO:0042391//regulation of } \\
\text { membrane potential;GO:0007623//circadian } \\
\text { rhythm;GO:0043525//positive regulation of neuron apoptotic } \\
\text { process;GO:0045794//negative regulation of cell } \\
\text { volume;GO:0060082//eye blink } \\
\text { reflex;GO:0007568//aging;GO:0007605//sensory perception of } \\
\text { sound;GO:0007268//chemical synaptic } \\
\text { transmission;GO:1904348//negative regulation of small intestine smooth } \\
\text { muscle contraction }\end{array}$ \\
\hline Dpysl5 & 1.69 & $2.50 \mathrm{E}-135$ & $\begin{array}{l}\text { K07529//dihydrop } \\
\text { yrimidinase-like } 5\end{array}$ & GO:0007411//axon guidance \\
\hline Trpv3 & 1.74 & $6.53 \mathrm{E}-05$ & $\begin{array}{l}\text { K04972//transient } \\
\text { receptor potential } \\
\text { cation channel } \\
\text { subfamily V } \\
\text { member } 3\end{array}$ & $\begin{array}{c}\text { GO:0090280//positive regulation of calcium ion } \\
\text { import;GO:0042636//negative regulation of hair } \\
\text { cycle;GO:0009408//response to heat;GO:0009266//response to } \\
\text { temperature stimulus }\end{array}$ \\
\hline Kif19 & 1.74 & 0.0047546 & $\begin{array}{l}\text { K10401//kinesin } \\
\text { family member } \\
18 / 19\end{array}$ & $\begin{array}{c}\text { GO:0007018//microtubule-based movement;GO:0060404//axonemal } \\
\text { microtubule depolymerization;GO:0070462//plus-end specific } \\
\text { microtubule depolymerization }\end{array}$ \\
\hline
\end{tabular}




\begin{tabular}{|c|c|c|c|c|}
\hline Mreg & 1.74 & 0.0047546 & NA & $\begin{array}{c}\text { GO:0043473//pigmentation;GO:0048066//developmental } \\
\text { pigmentation;GO:0032402//melanosome } \\
\text { transport;GO:0030318//melanocyte differentiation }\end{array}$ \\
\hline Slc17a9 & 1.78 & $5.43 \mathrm{E}-30$ & $\begin{array}{l}\text { K12303//MFS } \\
\text { transporter, ACS } \\
\text { family, solute } \\
\text { carrier family } 17 \\
\text { (sodium- } \\
\text { dependent } \\
\text { inorganic } \\
\text { phosphate } \\
\text { cotransporter), } \\
\text { member } 9\end{array}$ & $\begin{array}{c}\text { GO:0006820//anion transport;GO:0055085//transmembrane } \\
\text { transport;GO:1903955//positive regulation of protein targeting to } \\
\text { mitochondrion;GO:1903146//regulation of } \\
\text { mitophagy;GO:0006887//exocytosis }\end{array}$ \\
\hline Pycr1 & 1.79 & $1.17 \mathrm{E}-15$ & $\begin{array}{l}\text { K00286//pyrroline } \\
\text {-5-carboxylate } \\
\text { reductase } \\
\text { [EC:1.5.1.2] }\end{array}$ & $\begin{array}{l}\text { GO:0006561//proline biosynthetic process;GO:1903206//negative } \\
\text { regulation of hydrogen peroxide-induced cell death;GO:0055129//L- } \\
\text { proline biosynthetic process;GO:0034599//cellular response to oxidative } \\
\text { stress;GO:0051881//regulation of mitochondrial membrane potential }\end{array}$ \\
\hline Chac1 & 1.80 & $3.88 \mathrm{E}-121$ & $\begin{array}{l}\text { K07232//cation } \\
\text { transport protein } \\
\text { ChaC }\end{array}$ & NA \\
\hline Adm2 & 1.84 & $6.11 \mathrm{E}-08$ & $\begin{array}{l}\text { K21125//mucin- } \\
5 \mathrm{AC}\end{array}$ & $\begin{array}{l}\text { GO:0001525//angiogenesis;GO:0007586//digestion;GO:0006468//protein } \\
\text { phosphorylation;GO:0010628//positive regulation of gene } \\
\text { expression;GO:0045776//negative regulation of blood } \\
\text { pressure;GO:0007631//feeding behavior;GO:0007189//adenylate cyclase- } \\
\text { activating G-protein coupled receptor signaling } \\
\text { pathway;GO:0045766//positive regulation of angiogenesis }\end{array}$ \\
\hline Magea11 & 1.85 & $1.57 \mathrm{E}-30$ & $\begin{array}{l}\mathrm{K} 12464 / / \text { melanom } \\
\text { a-associated } \\
\text { antigen D1 }\end{array}$ & NA \\
\hline Aldh112 & 1.85 & $1.82 \mathrm{E}-95$ & $\begin{array}{l}\text { K00289//formyltet } \\
\text { rahydrofolate } \\
\text { dehydrogenase } \\
\text { [EC:1.5.1.6] }\end{array}$ & $\begin{array}{l}\text { GO:0009058//biosynthetic process;GO:0006730//one-carbon metabolic } \\
\text { process;GO:0009258//10-formyltetrahydrofolate catabolic process }\end{array}$ \\
\hline Olr155 & 1.85 & $1.29 \mathrm{E}-06$ & $\begin{array}{l}\text { K04257//olfactory } \\
\text { receptor }\end{array}$ & NA \\
\hline Ttc30a1 & 1.88 & 0.0005514 & $\begin{array}{l}\text { K19683//tetratrico } \\
\text { peptide repeat } \\
\text { protein } 30\end{array}$ & GO:0060271//cilium assembly;GO:0042073//intraciliary transport \\
\hline
\end{tabular}




\begin{tabular}{|c|c|c|c|c|}
\hline Fut1 & 1.91 & $6.38 \mathrm{E}-06$ & $\begin{array}{c}\text { K00718//galactosi } \\
\text { de } 2 \text {-L- } \\
\text { fucosyltransferase } \\
1 / 2 \text { [EC:2.4.1.69] }\end{array}$ & $\begin{array}{l}\text { GO:0006486//protein } \\
\text { glycosylation;GO:0036065//fucosylation;GO:0005975//carbohydrate } \\
\text { metabolic process }\end{array}$ \\
\hline Lhx4 & 1.91 & 0.0091655 & $\begin{array}{c}\text { K09374//LIM } \\
\text { homeobox protein } \\
3 / 4\end{array}$ & GO:0006355//regulation of transcription, DNA-templated \\
\hline Serpinb2 & 1.96 & 0.0001404 & $\begin{array}{l}\text { K19821//plasmino } \\
\text { gen activator } \\
\text { inhibitor } 2\end{array}$ & $\begin{array}{c}\text { GO:0042060//wound healing;GO:0043066//negative regulation of } \\
\text { apoptotic process }\end{array}$ \\
\hline Cxcr5 & 1.97 & $1.84 \mathrm{E}-05$ & $\begin{array}{l}\mathrm{K} 04190 / / \mathrm{C}-\mathrm{X}-\mathrm{C} \\
\text { chemokine } \\
\text { receptor type } 5\end{array}$ & $\begin{array}{c}\text { GO:0032467//positive regulation of cytokinesis;GO:0030595//leukocyte } \\
\text { chemotaxis;GO:0006955//immune response;GO:0048535//lymph node } \\
\text { development;GO:0042113//B cell activation }\end{array}$ \\
\hline Olr1423 & 1.97 & 0.0006078 & $\begin{array}{l}\text { K04257//olfactory } \\
\text { receptor }\end{array}$ & $\begin{array}{l}\text { GO:0007186//G-protein coupled receptor signaling } \\
\text { pathway;GO:0007608//sensory perception of smell }\end{array}$ \\
\hline Slc7a11 & 2.01 & $3.14 \mathrm{E}-175$ & $\begin{array}{c}\text { K13869//solute } \\
\text { carrier family } 7 \\
\text { (L-type amino } \\
\text { acid transporter), } \\
\text { member } 11 \\
\end{array}$ & NA \\
\hline B4galnt3 & 2.02 & $6.71 \mathrm{E}-22$ & $\begin{array}{c}\text { K09656//beta-1,4- } \\
\text { N- } \\
\text { acetylgalactosami } \\
\text { nyltransferase } 3 \\
\text { [EC:2.4.1.244] }\end{array}$ & NA \\
\hline Hmgcs2 & 2.02 & $5.64 \mathrm{E}-35$ & $\begin{array}{c}\text { K01641//hydroxy } \\
\text { methylglutaryl- } \\
\text { CoA synthase } \\
\text { [EC:2.3.3.10] }\end{array}$ & $\begin{array}{c}\text { GO:0008299//isoprenoid biosynthetic process;GO:0016126//sterol } \\
\text { biosynthetic process }\end{array}$ \\
\hline
\end{tabular}




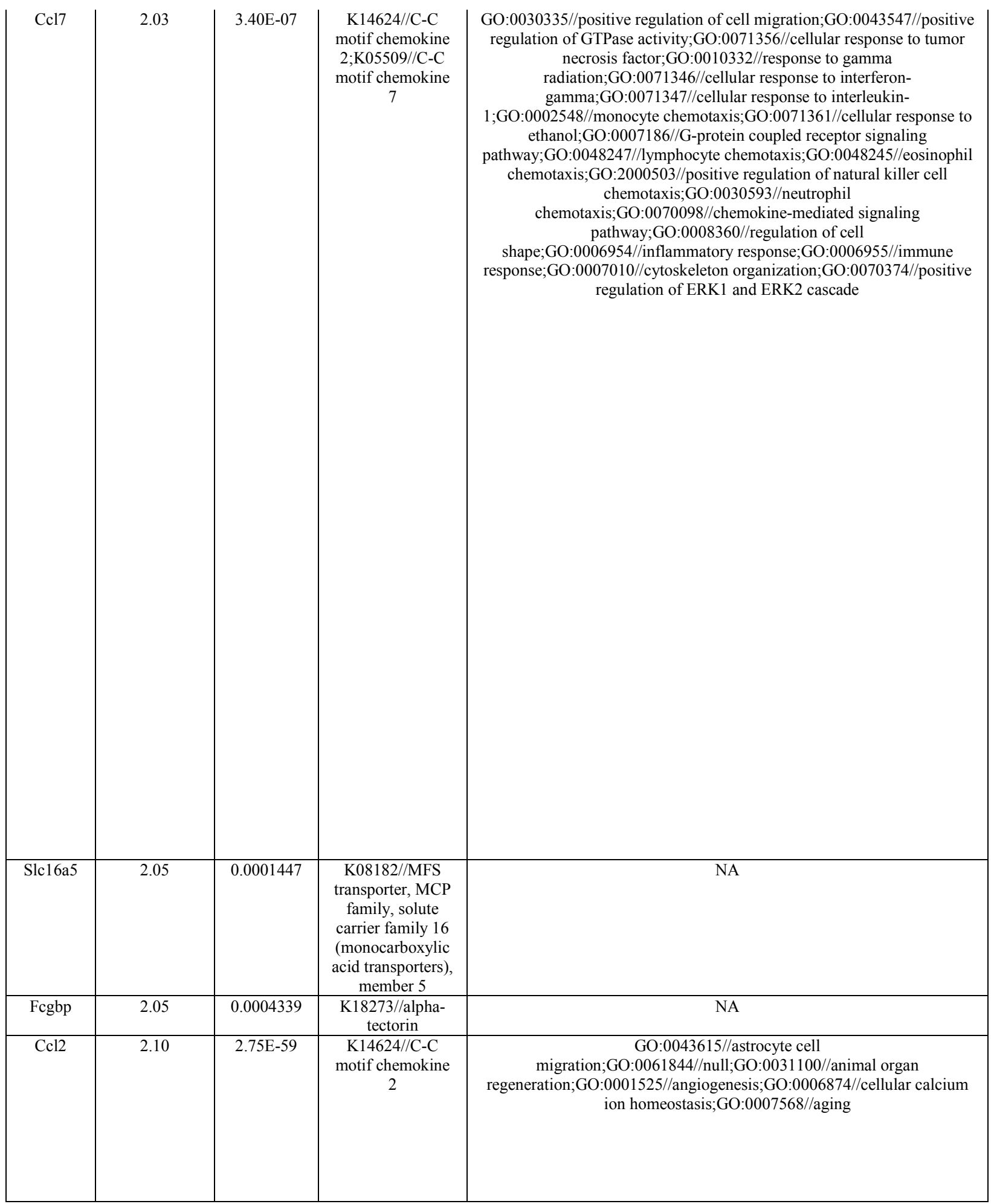




\begin{tabular}{|c|c|c|c|c|}
\hline Gata2 & 2.10 & $4.03 \mathrm{E}-12$ & $\begin{array}{l}\text { K17894//GATA- } \\
\text { binding protein } 2\end{array}$ & $\begin{array}{c}\text { GO:0060100//positive regulation of phagocytosis, } \\
\text { engulfment;GO:0045666//positive regulation of neuron } \\
\text { differentiation;GO:0035019//somatic stem cell population } \\
\text { maintenance;GO:0001892//embryonic placenta } \\
\text { development;GO:0035854//eosinophil fate } \\
\text { commitment;GO:0010725//regulation of primitive erythrocyte } \\
\text { differentiation;GO:0042472//inner ear morphogenesis;GO:0021533//cell } \\
\text { differentiation in hindbrain;GO:0021983//pituitary gland } \\
\text { development;GO:0045766//positive regulation of } \\
\text { angiogenesis;GO:0006909//phagocytosis;GO:0033993//response to } \\
\text { lipid;GO:0035065//regulation of histone acetylation;GO:0030154//cell } \\
\text { differentiation;GO:0045599//negative regulation of fat cell } \\
\text { differentiation;GO:0048469//cell maturation;GO:0001764//neuron } \\
\text { migration;GO:0045944//positive regulation of transcription from RNA } \\
\text { polymerase II promoter;GO:0045648//positive regulation of erythrocyte } \\
\text { differentiation;GO:0048663//neuron fate } \\
\text { commitment;GO:0048873//homeostasis of number of cells within a } \\
\text { tissue;GO:0045638//negative regulation of myeloid cell } \\
\text { differentiation;GO:0045654//positive regulation of megakaryocyte } \\
\text { differentiation;GO:2000977//regulation of forebrain neuron } \\
\text { differentiation;GO:0000122//negative regulation of transcription from } \\
\text { RNA polymerase II promoter;GO:0050766//positive regulation of } \\
\text { phagocytosis;GO:0021902//commitment of neuronal cell to specific } \\
\text { neuron type in forebrain;GO:0060216//definitive } \\
\text { hemopoiesis;GO:0070345//negative regulation of fat cell } \\
\text { proliferation;GO:0045650//negative regulation of macrophage } \\
\text { differentiation;GO:0030097//hemopoiesis;GO:0001709//cell fate } \\
\text { determination;GO:0030182//neuron } \\
\text { differentiation;GO:0001655//urogenital system } \\
\text { development;GO:0043306//positive regulation of mast cell } \\
\text { degranulation;GO:0021954//central nervous system neuron } \\
\text { development;GO:0006351//transcription, DNA- } \\
\text { templated;GO:2000178//negative regulation of neural precursor cell } \\
\text { proliferation;GO:0060872//semicircular canal } \\
\text { development;GO:0097154//GABAergic neuron } \\
\text { pathway;GO:0007204//positive regulation of cytosolic calcium ion } \\
\text { concentration;GO:0090102//cochlea development;GO:0021514//ventral } \\
\text { spinal cord interneuron differentiation }\end{array}$ \\
\hline Sall3 & 2.12 & 0.0002423 & $\begin{array}{l}\text { K19871//sal-like } \\
\text { protein }\end{array}$ & NA \\
\hline Ms4a15 & 2.17 & 0.0019165 & K22190//null & NA \\
\hline
\end{tabular}




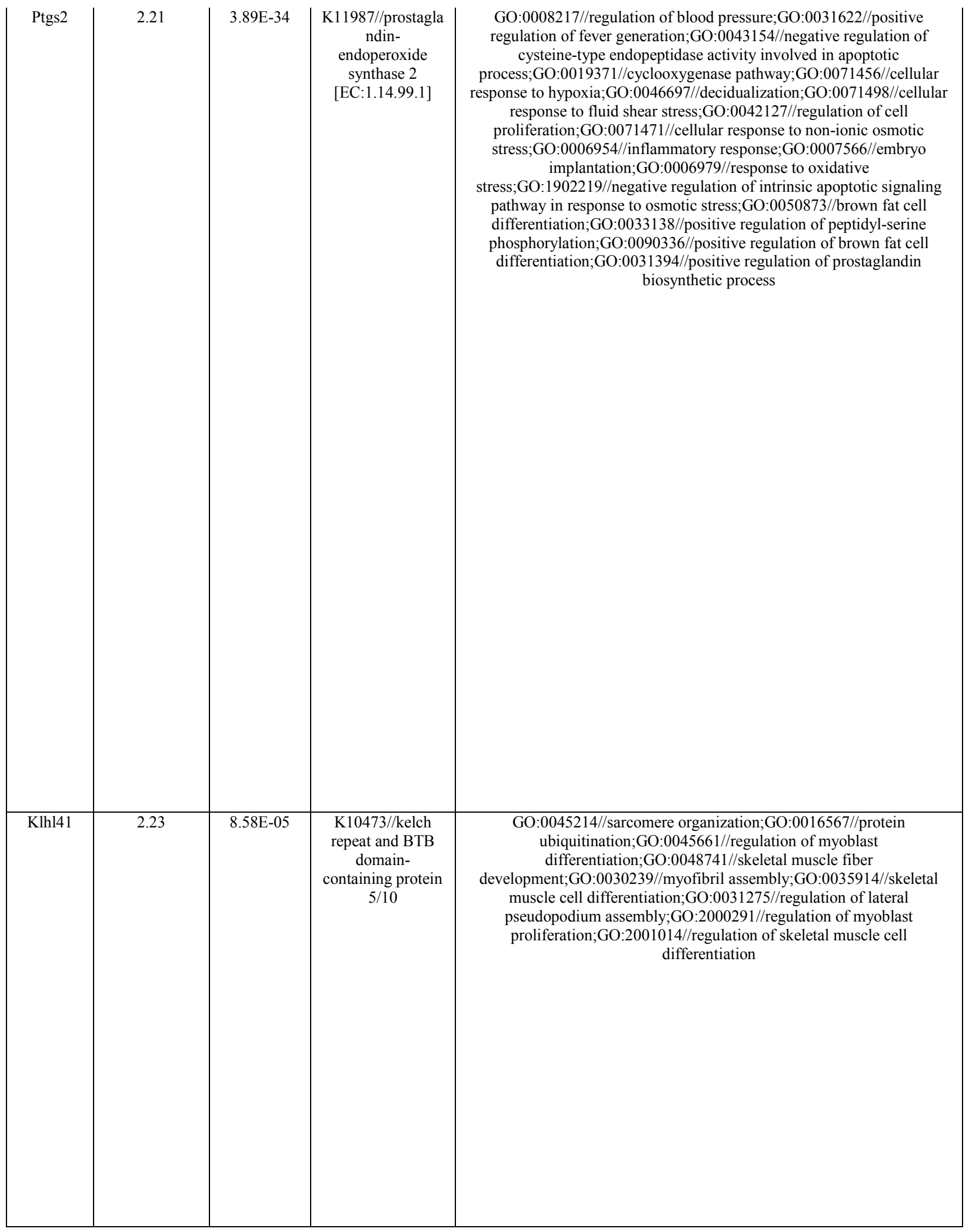




\begin{tabular}{|c|c|c|c|c|}
\hline Slc34a2 & 2.25 & $3.21 \mathrm{E}-13$ & $\begin{array}{l}\text { K14683//solute } \\
\text { carrier family } 34 \\
\text { (sodium- } \\
\text { dependent } \\
\text { phosphate } \\
\text { cotransporter) }\end{array}$ & $\begin{array}{c}\text { GO:0006817//phosphate ion transport;GO:0032355//response to } \\
\text { estradiol;GO:0030643//cellular phosphate ion } \\
\text { homeostasis;GO:0001701//in utero embryonic } \\
\text { development;GO:0009750//response to fructose;GO:0043627//response } \\
\text { to estrogen;GO:0007568//aging }\end{array}$ \\
\hline Abhd15 & 2.26 & 0.0009188 & $\begin{array}{l}\text { K13707//abhydrol } \\
\text { ase domain- } \\
\text { containing protein } \\
15\end{array}$ & GO:0044255//cellular lipid metabolic process \\
\hline Tnfsf9 & 2.33 & 0.0031587 & $\begin{array}{l}\text { K05472//tumor } \\
\text { necrosis factor } \\
\text { ligand } \\
\text { superfamily } \\
\text { member } 9\end{array}$ & $\begin{array}{l}\text { GO:0032755//positive regulation of interleukin-6 } \\
\text { production;GO:0042127//regulation of cell } \\
\text { proliferation;GO:0007267//cell-cell signaling;GO:0045585//positive } \\
\text { regulation of cytotoxic T cell differentiation;GO:0032735//positive } \\
\text { regulation of interleukin-12 production;GO:0006955//immune } \\
\text { response;GO:0043011//myeloid dendritic cell } \\
\text { differentiation;GO:0042104//positive regulation of activated T cell } \\
\text { proliferation;GO:0032729//positive regulation of interferon-gamma } \\
\text { production }\end{array}$ \\
\hline Mmp13 & 2.33 & 0.0031587 & $\begin{array}{c}\text { K07994//matrix } \\
\text { metalloproteinase- } \\
13 \text { (collagenase } 3 \text { ) } \\
\text { [EC:3.4.24.- }]\end{array}$ & $\begin{array}{c}\text { GO:0001958//endochondral ossification;GO:0030282//bone } \\
\text { mineralization;GO:0060349//bone morphogenesis;GO:0051216//cartilage } \\
\text { development;GO:0044267//cellular protein metabolic } \\
\text { process;GO:0022617//extracellular matrix } \\
\text { disassembly;GO:0006508//proteolysis;GO:0003417//growth plate } \\
\text { cartilage development;GO:0030574//collagen catabolic process }\end{array}$ \\
\hline
\end{tabular}




\begin{tabular}{|c|c|c|c|c|}
\hline Abcb1 & 2.33 & $6.95 \mathrm{E}-19$ & $\begin{array}{c}\text { K05658//ATP- } \\
\text { binding cassette, } \\
\text { subfamily B } \\
\text { (MDR/TAP), } \\
\text { member } 1 \\
\text { [EC:3.6.3.44] }\end{array}$ & 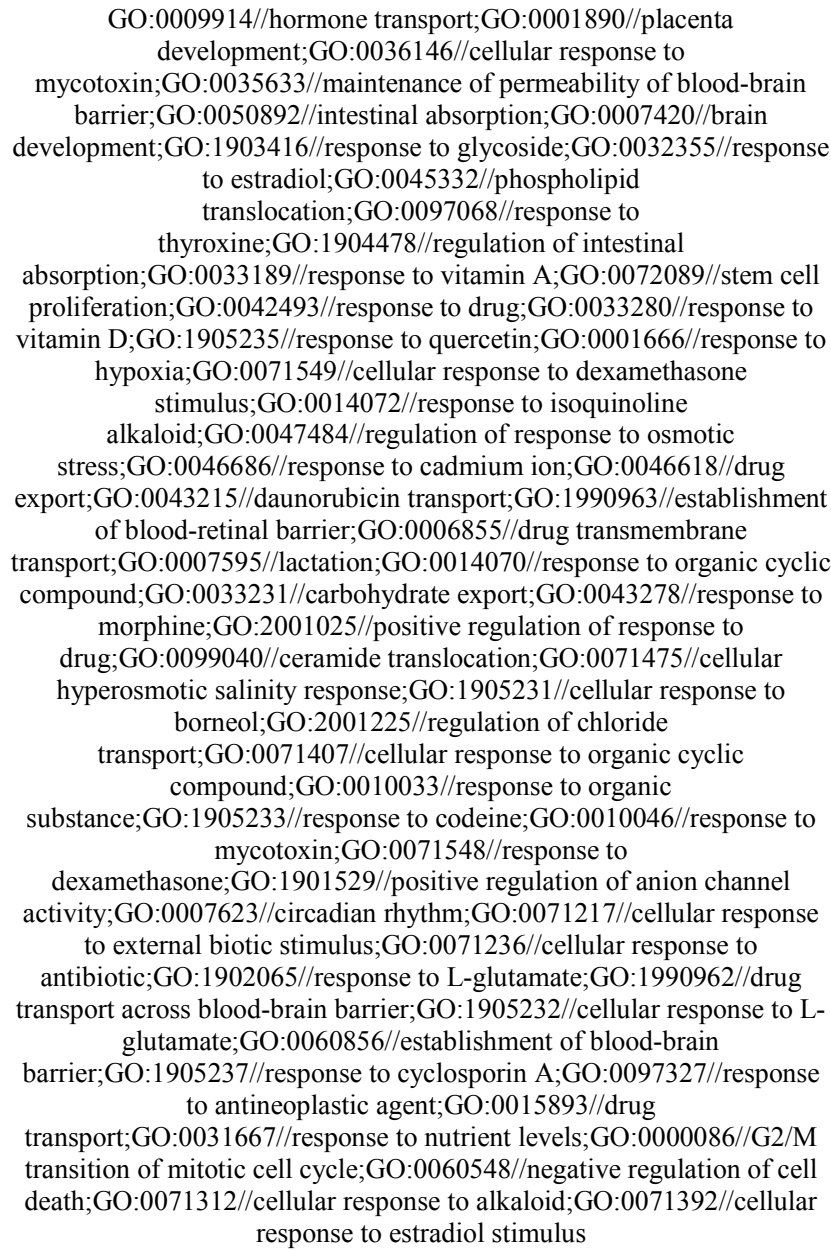 \\
\hline
\end{tabular}




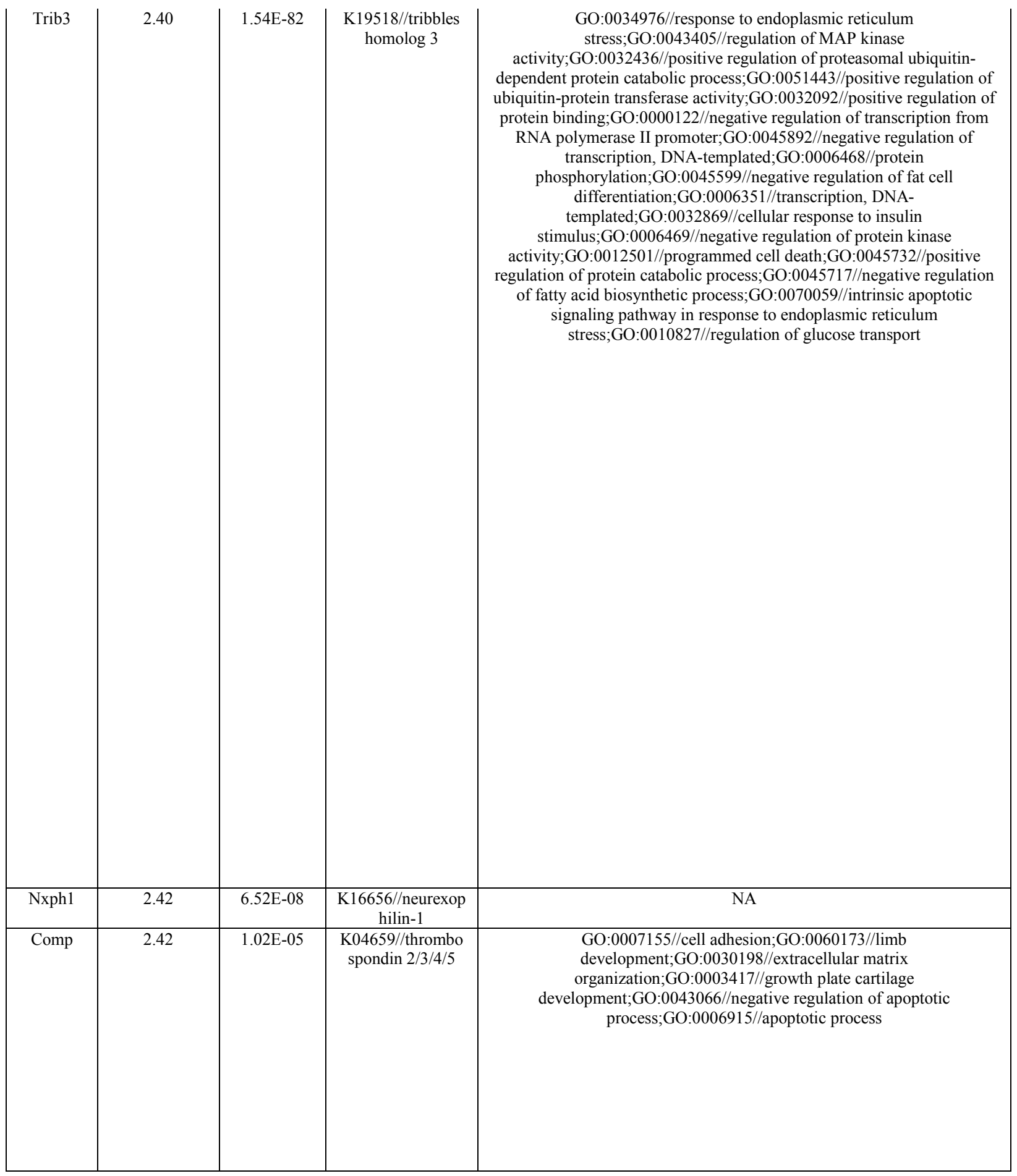




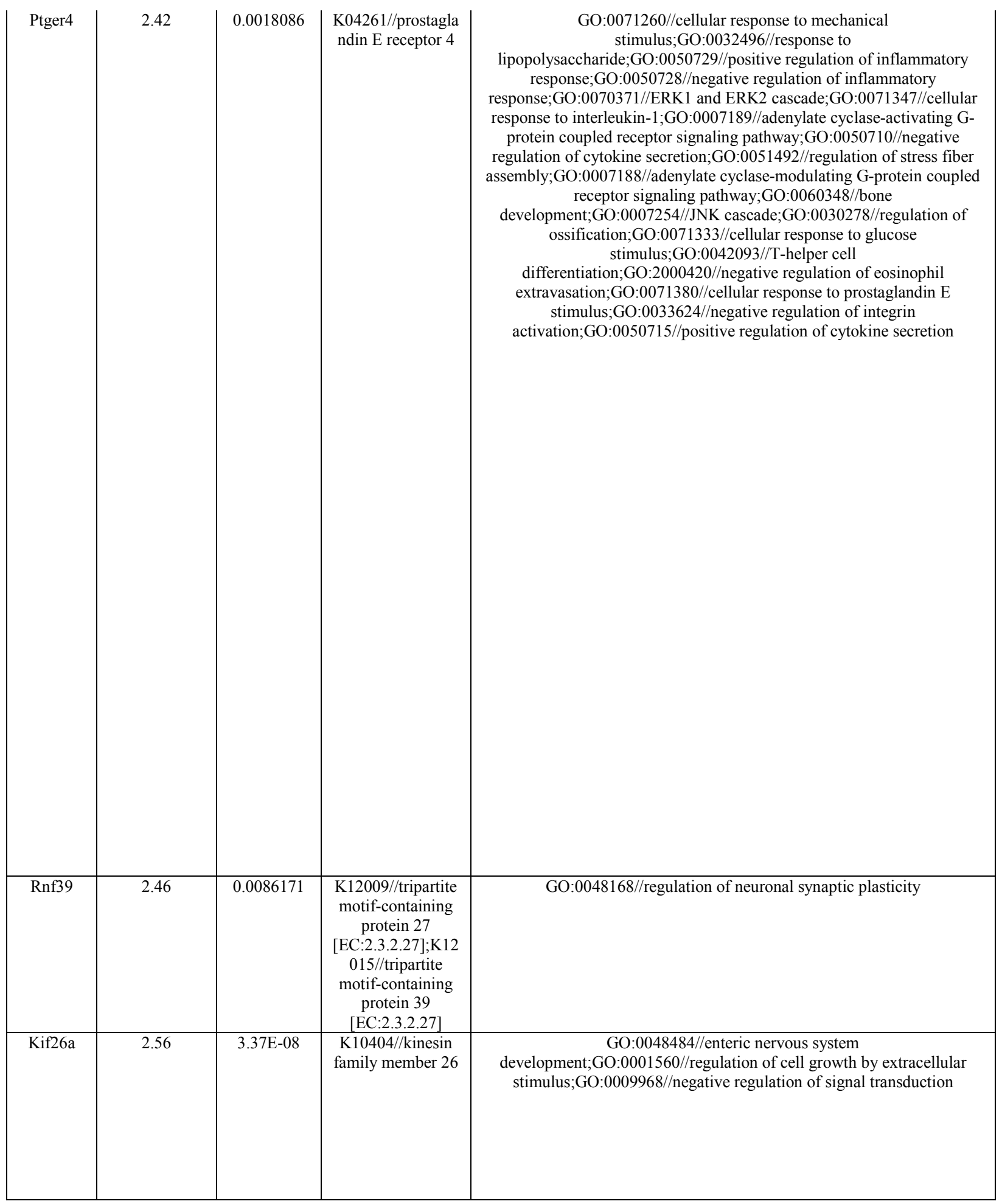




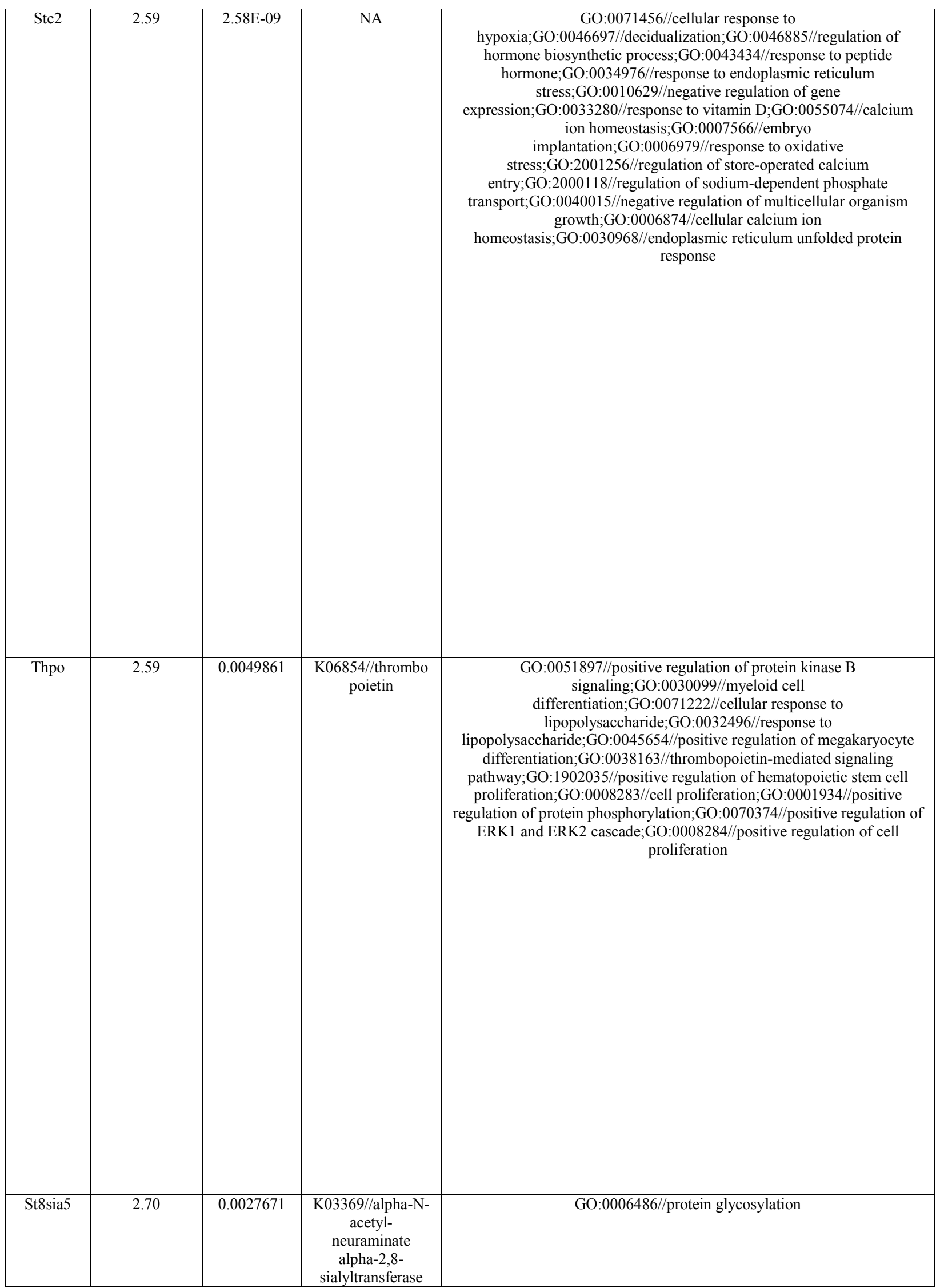




\begin{tabular}{|c|c|c|c|c|}
\hline & & & $\begin{array}{l}\text { (sialyltransferase } \\
8 \mathrm{E})[\mathrm{EC}: 2.4 .99 .-]\end{array}$ & \\
\hline Myod1 & 2.73 & 0.0024917 & $\begin{array}{l}\text { K09064//myogeni } \\
\text { c factor } 3\end{array}$ & $\begin{array}{l}\text { GO:0014902//myotube differentiation;GO:0009267//cellular response to } \\
\text { starvation;GO:0000381//regulation of alternative mRNA splicing, via } \\
\text { spliceosome;GO:0007518//myoblast fate } \\
\text { determination;GO:0014908//myotube differentiation involved in skeletal } \\
\text { muscle regeneration;GO:0045445//myoblast } \\
\text { differentiation;GO:1901741//positive regulation of myoblast } \\
\text { fusion;GO:0035994//response to muscle stretch;GO:0048743//positive } \\
\text { regulation of skeletal muscle fiber development;GO:0055007//cardiac } \\
\text { muscle cell differentiation;GO:2000818//negative regulation of myoblast } \\
\text { proliferation;GO:0014732//skeletal muscle atrophy;GO:0035914//skeletal } \\
\text { muscle cell differentiation;GO:0045944//positive regulation of } \\
\text { transcription from RNA polymerase II promoter;GO:0045663//positive } \\
\text { regulation of myoblast differentiation;GO:0071453//cellular response to } \\
\text { oxygen levels;GO:0007519//skeletal muscle tissue } \\
\text { development;GO:0010468//regulation of gene } \\
\text { expression;GO:0051146//striated muscle cell } \\
\text { differentiation;GO:0043403//skeletal muscle tissue } \\
\text { regeneration;GO:0071385//cellular response to glucocorticoid } \\
\text { stimulus;GO:0014904//myotube cell development;GO:0045893//positive } \\
\text { regulation of transcription, DNA-templated;GO:0006357//regulation of } \\
\text { transcription from RNA polymerase II promoter;GO:0043967//histone } \\
\text { H4 acetylation;GO:0043415//positive regulation of skeletal muscle tissue } \\
\text { regeneration;GO:0043484//regulation of RNA } \\
\text { splicing;GO:0007520//myoblast fusion;GO:0006351//transcription, } \\
\text { DNA-templated;GO:0007517//muscle organ } \\
\text { development;GO:0048741//skeletal muscle fiber } \\
\text { development;GO:0043503//skeletal muscle fiber } \\
\text { adaptation;GO:0051149//positive regulation of muscle cell } \\
\text { differentiation;GO:0043966//histone H3 } \\
\text { acetylation;GO:0071392//cellular response to estradiol stimulus }\end{array}$ \\
\hline $\begin{array}{l}\text { LOC306 } \\
079\end{array}$ & 2.76 & 4.68E-07 & $\begin{array}{l}\text { K02875//large } \\
\text { subunit ribosomal } \\
\text { protein L14e }\end{array}$ & $\begin{array}{l}\text { GO:0006412//translation;GO:0006364//rRNA } \\
\text { processing;GO:0042273//ribosomal large subunit biogenesis }\end{array}$ \\
\hline Dpys14 & 2.88 & $5.81 \mathrm{E}-05$ & $\begin{array}{l}\text { K07528//dihydrop } \\
\text { yrimidinase-like } 2\end{array}$ & GO:0070997//neuron death;GO:0097485//neuron projection guidance \\
\hline $\begin{array}{l}\text { LOC688 } \\
613\end{array}$ & 3.00 & $1.80 \mathrm{E}-05$ & NA & NA \\
\hline C1qtnf3 & 3.00 & 0.0004633 & $\begin{array}{l}\text { K06237//collagen, } \\
\text { type IV, alpha }\end{array}$ & NA \\
\hline Plppr1 & 3.17 & 0.0070619 & $\begin{array}{l}\text { K19581//lipid } \\
\text { phosphate } \\
\text { phosphatase- } \\
\text { related protein } \\
\text { type } 1 / 2 / 5\end{array}$ & $\begin{array}{l}\text { GO:0007399//nervous system development;GO:0007165//signal } \\
\text { transduction;GO:0046839//phospholipid } \\
\text { dephosphorylation;GO:0006644//phospholipid metabolic process }\end{array}$ \\
\hline
\end{tabular}




\begin{tabular}{|c|c|c|c|c|}
\hline Asphd2 & 3.17 & 0.0070619 & $\begin{array}{c}\text { K00476//aspartate } \\
\text { beta-hydroxylase } \\
\text { [EC:1.14.11.16] }\end{array}$ & GO:0018193//peptidyl-amino acid modification \\
\hline Dlk1 & 3.46 & 0.0019954 & K06051//delta & $\begin{array}{c}\text { GO:0010468//regulation of gene expression;GO:0001649//osteoblast } \\
\text { differentiation;GO:0030282//bone mineralization;GO:0030154//cell } \\
\text { differentiation;GO:0045599//negative regulation of fat cell } \\
\text { differentiation;GO:0001819//positive regulation of cytokine } \\
\text { production;GO:0001503//ossification;GO:0045780//positive regulation of } \\
\text { bone resorption;GO:0035264//multicellular organism } \\
\text { growth;GO:0009791//post-embryonic } \\
\text { development;GO:0048706//embryonic skeletal system } \\
\text { development;GO:0045746//negative regulation of Notch signaling } \\
\text { pathway;GO:0007219//Notch signaling pathway }\end{array}$ \\
\hline
\end{tabular}




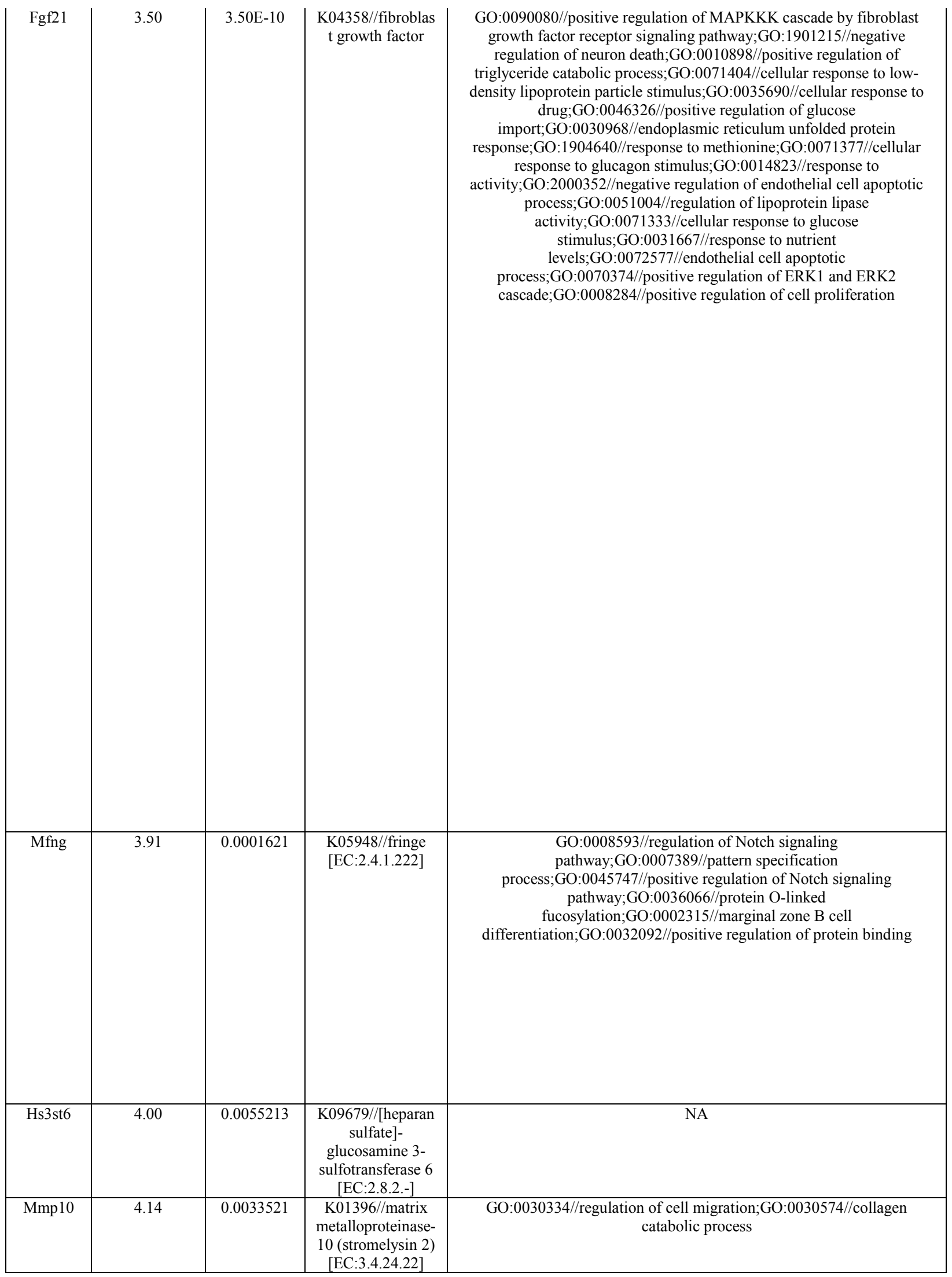




\begin{tabular}{|c|c|c|c|c|}
\hline Inhbe & 4.17 & $2.52 \mathrm{E}-05$ & $\begin{array}{l}\text { K04667//inhibin, } \\
\text { beta }\end{array}$ & $\begin{array}{c}\text { GO:0060395//SMAD protein signal transduction;GO:0010862//positive } \\
\text { regulation of pathway-restricted SMAD protein } \\
\text { phosphorylation;GO:0043408//regulation of MAPK } \\
\text { cascade;GO:0042981//regulation of apoptotic process;GO:0048468//cell } \\
\text { development }\end{array}$ \\
\hline Mttp & 4.17 & 0.0028904 & $\begin{array}{l}\text { K14463//microso } \\
\text { mal triglyceride } \\
\text { transfer protein } \\
\text { large subunit }\end{array}$ & $\begin{array}{c}\text { GO:0007623//circadian rhythm;GO:0008203//cholesterol metabolic } \\
\text { process;GO:0006869//lipid transport;GO:0034197//triglyceride } \\
\text { transport;GO:0006641//triglyceride metabolic } \\
\text { process;GO:0034377//plasma lipoprotein particle } \\
\text { assembly;GO:0051592//response to calcium ion;GO:0009306//protein } \\
\text { secretion;GO:0006497//protein lipidation;GO:0015914//phospholipid } \\
\text { transport;GO:0042632//cholesterol homeostasis;GO:0042953//lipoprotein } \\
\text { transport;GO:0042157//lipoprotein metabolic process;GO:0006629//lipid } \\
\text { metabolic process }\end{array}$ \\
\hline Sidt1 & 4.33 & 0.001524 & $\begin{array}{c}\text { K20526//transgeli } \\
n\end{array}$ & GO:0033227//dsRNA transport \\
\hline Mmp3 & 6.14 & 8.47E-35 & $\begin{array}{c}\text { K01394//matrix } \\
\text { metalloproteinase- } \\
3 \text { (stromelysin 1, } \\
\text { progelatinase) } \\
\text { [EC:3.4.24.17] }\end{array}$ & $\begin{array}{c}\text { GO:0030163//protein catabolic process;GO:0071230//cellular response to } \\
\text { amino acid stimulus;GO:0022617//extracellular matrix } \\
\text { disassembly;GO:0032461//positive regulation of protein } \\
\text { oligomerization;GO:0030334//regulation of cell } \\
\text { migration;GO:0006508//proteolysis;GO:1903209//positive regulation of } \\
\text { oxidative stress-induced cell death;GO:0010727//negative regulation of } \\
\text { hydrogen peroxide metabolic process;GO:0051898//negative regulation } \\
\text { of protein kinase B signaling;GO:0030574//collagen catabolic process }\end{array}$ \\
\hline
\end{tabular}




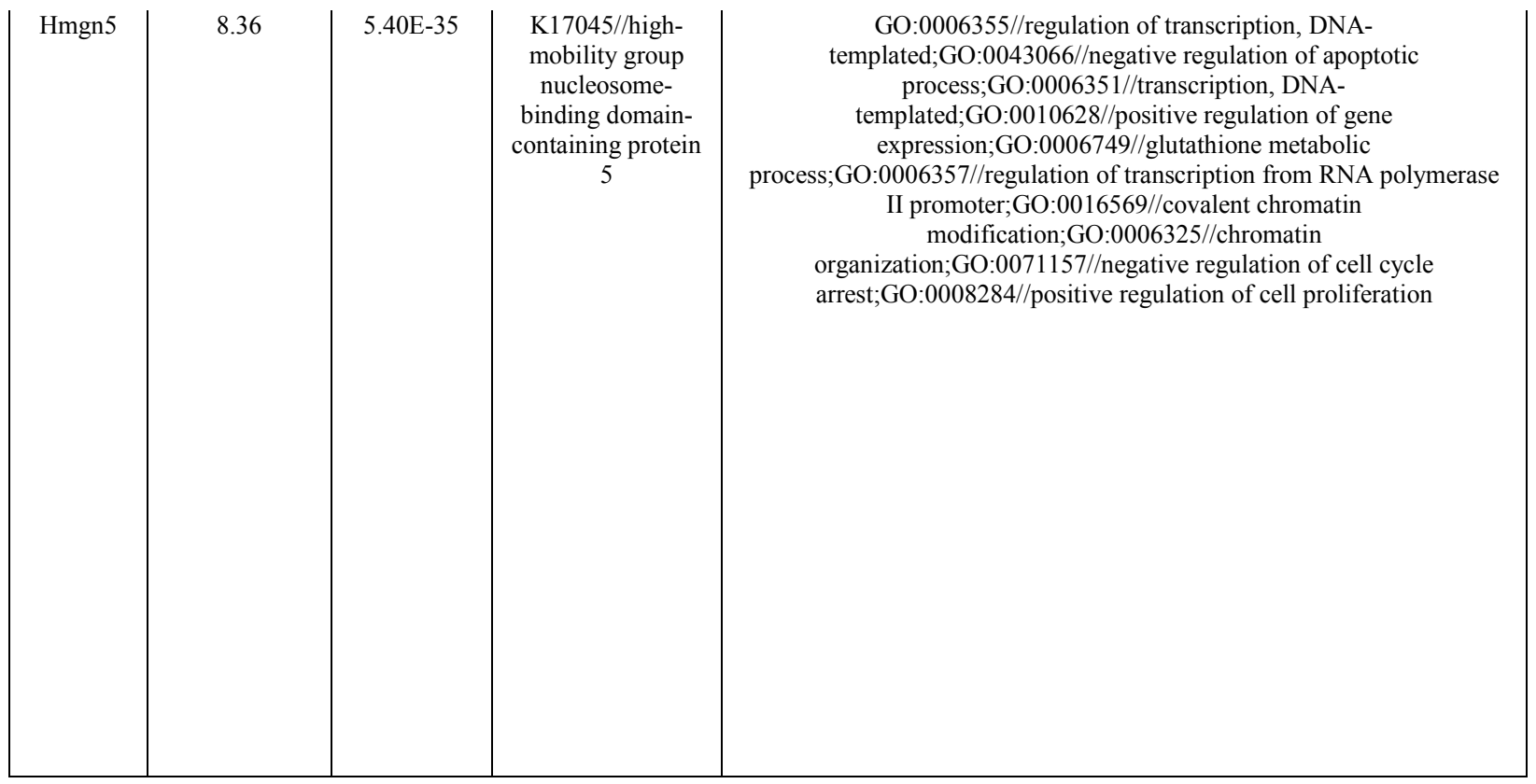


Supplementary Table S3. Altered IPA canonical pathways in sertoli cells by PFOA treatment.

\begin{tabular}{|c|c|c|}
\hline Ingenuity Canonical Pathways & p-value & Molecules \\
\hline Granulocyte Adhesion and Diapedesis & 0.0027 & IL1R2,IL1RL1,Ccl2,Ccl7 \\
\hline Agranulocyte Adhesion and Diapedesis & 0.0034 & MYH2,Ccl2,ACTC1,Ccl7 \\
\hline Glycine Biosynthesis III & 0.0063 & AGXT2 \\
\hline Corticotropin Releasing Hormone Signaling & 0.01 & NOS1,CRHR2,BDNF \\
\hline Citrulline-Nitric Oxide Cycle & 0.016 & NOS1 \\
\hline IL-10 Signaling & 0.0204 & IL1R2,IL1RL1 \\
\hline Agrin Interactions at Neuromuscular Junction & 0.02 & MUSK,ACTC1 \\
\hline Hepatic Fibrosis / Hepatic Stellate Cell Activation & 0.022 & IL1R2,MYH2,IL1RL1 \\
\hline Endothelin-1 Signaling & 0.023 & NOS1,ECE2,CASP1 \\
\hline TREM1 Signaling & 0.024 & IL1RL1,CASP1 \\
\hline Osteoarthritis Pathway & 0.03 & IL1R2,IL1RL1,CASP1 \\
\hline Ketogenesis & 0.032 & HMGCS2 \\
\hline PEDF Signaling & 0.032 & HNF1B,BDNF \\
\hline Crosstalk between Dendritic Cells and Natural Killer Cells & 0.033 & FSCN2,ACTC1 \\
\hline LPS/IL-1 Mediated Inhibition of RXR Function & 0.034 & IL1R2,IL1RL1,HMGCS2 \\
\hline Mineralocorticoid Biosynthesis & 0.035 & Hsd3b1 \\
\hline $\begin{array}{c}\text { Fc } \gamma \text { Receptor-mediated Phagocytosis in Macrophages and } \\
\text { Monocytes }\end{array}$ & 0.035 & FYB1,ACTC1 \\
\hline Actin Cytoskeleton Signaling & 0.036 & MYH2,ACTC1,MATK \\
\hline PPAR Signaling & 0.037 & IL1R2,IL1RL1 \\
\hline Glucocorticoid Biosynthesis & 0.038 & Hsd3b1 \\
\hline $\begin{array}{l}\text { Role of Osteoblasts, Osteoclasts and Chondrocytes in } \\
\text { Rheumatoid Arthritis }\end{array}$ & 0.039 & IL1R2,SFRP2,IL1RL1 \\
\hline Mevalonate Pathway I & 0.041 & HMGCS2 \\
\hline Androgen Biosynthesis & 0.044 & Hsd3b1 \\
\hline Superpathway of Citrulline Metabolism & 0.047 & NOS1 \\
\hline Amyotrophic Lateral Sclerosis Signaling & 0.049 & NOS1,CASP1 \\
\hline
\end{tabular}


Supplementary Table S4. Altered IPA canonical pathways in sertoli cells by PFOS treatment.

\begin{tabular}{|c|c|c|}
\hline Ingenuity Canonical Pathways & p-value & $\begin{array}{ll}\text { Molecules } \\
\end{array}$ \\
\hline Agranulocyte Adhesion and Diapedesis & $2.512 \mathrm{E}-07$ & $\begin{array}{l}\text { AOC3,VCAM1,MMP28,MMP3,MYH8,CXCR4,CXCL12,MMP10,MM } \\
\text { P13,MYH11,ACTA2,Cc12,CCL28,ACTG2,CXCL2,ACTC1,Cc17,ITGA4 }\end{array}$ \\
\hline Superpathway of Cholesterol Biosynthesis & $1.778 \mathrm{E}-06$ & FDPS,FDFT1,SQLE,IDI,MSMO1,HMGCS2,HMGCS1 \\
\hline $\begin{array}{l}\text { Role of Pattern Recognition Receptors in } \\
\text { Recognition of Bacteria and Viruses }\end{array}$ & $1.82 \mathrm{E}-06$ & $\begin{array}{c}\text { OAS1,Oas1h,PRKCQ,OAS2,Oas1b,OAS3,IL17B,IFIH1,IRF7,CASP1,PI } \\
\text { K3CD,EIF2AK2,PRKCB,IL11 }\end{array}$ \\
\hline Leukocyte Extravasation Signaling & 4.074E-06 & $\begin{array}{l}\text { RAC2,VCAM1,PRKCQ,MMP28,MMP3,CXCR4,CXCL12,MMP10,MM } \\
\text { P13,THY1,ACTA2,NCF2,PIK3CD,ACTG2,ACTC1,ITGA4,PRKCB }\end{array}$ \\
\hline Granulocyte Adhesion and Diapedesis & $1.072 \mathrm{E}-05$ & $\begin{array}{l}\text { VCAM1,MMP28,MMP3,IL1RL1,CXCR4,CXCL12,MMP10,MMP13,T } \\
\text { HY1,IL1R2,Cc12,CCL28,CXCL2,Ccl7,ITGA4 }\end{array}$ \\
\hline Gap Junction Signaling & 0.0001 & $\begin{array}{l}\text { PRKCQ,GUCY1A1,GRIA4,PLCH1,PRKG1,TUBA8,ACTA2,ADCY5,G } \\
\text { JA3,PIK3CD,ACTG2,GJB1,ACTC1,PRKCB }\end{array}$ \\
\hline $\begin{array}{l}\text { LPS/IL-1 Mediated Inhibition of RXR } \\
\text { Function }\end{array}$ & 0.00011 & $\begin{array}{l}\text { ABCB1,IL1RL1,NR1H4,CYP2C9,ABCG1,NDST4,HMGCS2,CHST15, } \\
\text { ABCA1,IL1R2,ALDH1L2,PLTP,HS3ST6,CYP2B6,HMGCS1 }\end{array}$ \\
\hline Interferon Signaling & 0.00011 & IFIT3,OAS1,MX1,STAT2,STAT1,ISG15 \\
\hline Cellular Effects of Sildenafil (Viagra) & 0.00014 & $\begin{array}{l}\text { PRKG1,ACTA2,GUCY1A1,MYH8,ADCY5,KCNQ3,MYLK,ACTG2,M } \\
\text { YH11,ACTC1,PLCH1 }\end{array}$ \\
\hline Inhibition of Matrix Metalloproteases & 0.00018 & MMP28,MMP3,THBS2,MMP13,MMP10,A2M \\
\hline $\begin{array}{l}\text { Hepatic Fibrosis / Hepatic Stellate Cell } \\
\text { Activation }\end{array}$ & 0.00025 & $\begin{array}{l}\text { VCAM1,EDNRB,MYH8,IL1RL1,COL8A1,MMP13,MYH11,PDGFB,IL } \\
\text { 1R2,ACTA2,IL10RA,STAT1,A2M }\end{array}$ \\
\hline $\begin{array}{l}\text { Dopamine-DARPP32 Feedback in cAMP } \\
\text { Signaling }\end{array}$ & 0.00026 & $\begin{array}{c}\text { NOS1,KCNJ4,PRKG1,PRKCQ,GUCY1A1,PPP1R1B,ADCY5,PPP1R3C } \\
\text { „PPP1R14A,ATP2A3,PLCH1,PRKCB }\end{array}$ \\
\hline LXR/RXR Activation & 0.00032 & $\begin{array}{l}\text { IL1R2,FDFT1,SCD,LDLR,NR1H4,IL1RL1,ABCG1,PLTP,PTGS2,ABC } \\
\text { A1 }\end{array}$ \\
\hline $\begin{array}{l}\text { Superpathway of Geranylgeranyldiphosphate } \\
\text { Biosynthesis I (via Mevalonate) }\end{array}$ & 0.00043 & FDPS,IDI1,HMGCS2,HMGCS1 \\
\hline $\begin{array}{l}\text { Activation of IRF by Cytosolic Pattern } \\
\text { Recognition Receptors }\end{array}$ & 0.00043 & IFIH1,DHX58,IRF7,ZBP1,STAT2,STAT1,ISG15 \\
\hline Epoxysqualene Biosynthesis & 0.00048 & FDFT1,SQLE \\
\hline Virus Entry via Endocytic Pathways & 0.00068 & $\begin{array}{c}\text { RAC2,PRKCQ,ACTA2,PIK3CD,ACTG2,ITGB6,ACTC1,ITGA4,PRKC } \\
\text { B }\end{array}$ \\
\hline $\begin{array}{l}\text { Fc } \gamma \text { Receptor-mediated Phagocytosis in } \\
\text { Macrophages and Monocytes }\end{array}$ & 0.00095 & RAC2,PRKCQ,ACTA2,FCGR2A,ACTG2,FYB1,ACTC1,PRKCB \\
\hline Axonal Guidance Signaling & 0.001 & $\begin{array}{l}\text { RAC2,PRKCQ,ECEL1,WNT9B,MMP3,CXCR4,CXCL12,MMP10,MM } \\
\text { P13,DPYSL5,PDGFB,PLCH1,NTNG1,GNB3,TUBA8,ECE2,NTNG2,PI } \\
\text { K3CD,PLXNB3,ITGA4,PRKCB }\end{array}$ \\
\hline Signaling by Rho Family GTPases & 0.0013 & $\begin{array}{c}\text { ARHGEF19,SEPT5,GNB3,ACTA2,CDH20,NCF2,CDH6,MYLK,PIK3C } \\
\text { D,ACTG2,DES,ACTC1,PARD6A,ITGA4 }\end{array}$ \\
\hline $\begin{array}{l}\text { Role of Macrophages, Fibroblasts and } \\
\text { Endothelial Cells in Rheumatoid Arthritis }\end{array}$ & 0.0015 & $\begin{array}{l}\text { SOCS3,VCAM1,PRKCQ,WNT9B,MMP3,IL1RL1,CXCL12,CEBPD,M } \\
\text { MP13,PDGFB,PLCH1,IL1R2,DKK2,SFRP5,PIK3CD,PRKCB }\end{array}$ \\
\hline Mechanisms of Viral Exit from Host Cells & 0.0019 & PRKCQ,ACTA2,ACTG2,ACTC1,PRKCB \\
\hline Calcium Signaling & 0.0019 & $\begin{array}{l}\text { HDAC9,ACTA2,MYH8,RYR2,TNNT2,ATP2A3,TRPC6,MYH11,GRIA } \\
\text { 4,Tpm2,ACTC1,CACNA2D3 }\end{array}$ \\
\hline Cholesterol Biosynthesis I & 0.0025 & FDFT1,SQLE,MSMO1 \\
\hline Mevalonate Pathway I & 0.0025 & IDI1,HMGCS2,HMGCS1 \\
\hline
\end{tabular}




\begin{tabular}{|c|c|c|}
\hline $\begin{array}{l}\text { Cholesterol Biosynthesis II (via 24,25- } \\
\text { dihydrolanosterol) }\end{array}$ & 0.0025 & FDFT1,SQLE,MSMO1 \\
\hline $\begin{array}{l}\text { Cholesterol Biosynthesis III (via } \\
\text { Desmosterol) }\end{array}$ & 0.0025 & FDFT1,SQLE,MSMO1 \\
\hline Th1 and Th2 Activation Pathway & 0.0025 & $\begin{array}{l}\text { SOCS3,NOTCH3,PRKCQ,CXCR4,IL1RL1,IL10RA,CD274,PIK3CD,ST } \\
\text { AT1,DLL4,IL24 }\end{array}$ \\
\hline Hepatic Cholestasis & 0.0028 & $\begin{array}{l}\text { IL1R2,ABCB1,PRKCQ,NR1H4,ADCY5,IL1RL1,ESR1,IL17B,PRKCB,I } \\
\text { L11 }\end{array}$ \\
\hline PXR/RXR Activation & 0.0029 & SCD,ABCB1,PCK2,CYP2C9,CYP2B6,HMGCS2 \\
\hline Endothelin-1 Signaling & 0.0031 & $\begin{array}{l}\text { NOS1,PRKCQ,GUCY1A1,EDNRB,ECE2,ADCY5,CASP1,PIK3CD,PT } \\
\text { GS2,PLCH1,PRKCB }\end{array}$ \\
\hline $\begin{array}{c}\text { Nitric Oxide Signaling in the Cardiovascular } \\
\text { System }\end{array}$ & 0.0033 & $\begin{array}{l}\text { PRKG1,PRKCQ,GUCY1A1,RYR2,SLC7A1,ATP2A3,PIK3CD,PRKCB } \\
\end{array}$ \\
\hline ILK Signaling & 0.0041 & $\begin{array}{l}\text { FBLIM1,ACTA2,LIMS2,MYH8,SH2B2,PIK3CD,ACTG2,MYH11,PTG } \\
\text { S2,ITGB6,ACTC1 }\end{array}$ \\
\hline Tec Kinase Signaling & 0.0042 & $\begin{array}{l}\text { PRKCQ,GNB3,ACTA2,STAT2,PIK3CD,ACTG2,STAT1,ACTC1,ITGA } \\
\text { 4,PRKCB }\end{array}$ \\
\hline $\begin{array}{l}\text { Trans, trans-farnesyl Diphosphate } \\
\text { Biosynthesis }\end{array}$ & 0.0046 & FDPS,IDI1 \\
\hline RhoGDI Signaling & 0.0056 & $\begin{array}{l}\text { ARHGEF19,GNB3,ACTA2,CDH20,CDH6,ACTG2,ESR1,ACTC1,ARH } \\
\text { GDIB,ITGA4 }\end{array}$ \\
\hline Sertoli Cell-Sertoli Cell Junction Signaling & 0.0058 & $\begin{array}{l}\text { NOS1,EPN3,PRKG1,ACTA2,GUCY1A1,TUBA8,ACTG2,ACTC1,A2M } \\
\text { „ITGA4 }\end{array}$ \\
\hline Th1 Pathway & 0.0095 & SOCS3,NOTCH3,PRKCQ,IL10RA,CD274,PIK3CD,STAT1,DLL4 \\
\hline Growth Hormone Signaling & 0.011 & SOCS3,PRKCQ,PIK3CD,STAT1,A2M,PRKCB \\
\hline Actin Cytoskeleton Signaling & 0.011 & $\begin{array}{l}\text { RAC2,FGF21,ACTA2,MYH8,MYLK,PIK3CD,ACTG2,MYH1 1,ACTC1 } \\
\text {,PDGFB,ITGA4 }\end{array}$ \\
\hline NF- $\kappa$ B Activation by Viruses & 0.012 & PRKCQ,PIK3CD,CXCR5,EIF2AK2,ITGA4,PRKCB \\
\hline Estrogen Biosynthesis & 0.012 & CYP4F8,AKR1C3,CYP2C9,CYP2B6 \\
\hline Cardiac $\beta$-adrenergic Signaling & 0.012 & AKAP12,TULP2,GNB3,ADCY5,PPP1R3C,RYR2,PPP1R14A,ATP2A3 \\
\hline eNOS Signaling & 0.013 & $\begin{array}{l}\text { PRKG1,PRKCQ,GUCY1A1,ADCY5,SLC7A1,PIK3CD,ESR1,PRKCB, } \\
\text { CHRM5 }\end{array}$ \\
\hline Thrombopoietin Signaling & 0.013 & THPO,PRKCQ,PIK3CD,STAT1,PRKCB \\
\hline Melatonin Degradation I & 0.013 & CYP4F8,Ugt1a7c,CYP2C9,Sult1a1,CYP2B6 \\
\hline Regulation of Actin-based Motility by Rho & 0.014 & RAC2,ACTA2,MYLK,ACTG2,ACTC1,ITGA4 \\
\hline Synaptic Long Term Depression & 0.014 & $\begin{array}{l}\text { NOS1,PRKG1,PRKCQ,GUCY1A1,RYR2,GRIA4,CACNA2D3,PLCH1, } \\
\text { PRKCB }\end{array}$ \\
\hline Epithelial Adherens Junction Signaling & 0.015 & EPN3,NOTCH3,ACTA2,TUBA8,MYH8,ACTG2,MYH11,ACTC1 \\
\hline Protein Kinase A Signaling & 0.015 & $\begin{array}{l}\text { AKAP12,PRKCQ,PTPRQ,PPP1R1B,PPP1R3C,RYR2,PPP1R14A,MYL } \\
\text { K,PLCH1,TULP2,PYGM,GNB3,PTPRU,ADCY5,PTGS2,PRKCB }\end{array}$ \\
\hline IL-9 Signaling & 0.016 & SOCS3,BCL3,PIK3CD,STAT1 \\
\hline Bupropion Degradation & 0.017 & CYP4F8,CYP2C9,CYP2B6 \\
\hline IL-10 Signaling & 0.017 & IL1R2,SOCS3,FCGR2A,IL1RL1,IL10RA \\
\hline $\begin{array}{l}\text { Agrin Interactions at Neuromuscular } \\
\text { Junction }\end{array}$ & 0.017 & RAC2,ACTA2,ACTG2,ACTC1,ITGA4 \\
\hline PPAR $\alpha / R X R \alpha$ Activation & 0.017 & $\begin{array}{l}\text { IL1R2,HELZ2,ADCY5,IL1RL1,CYP2C9,BCL3,PLCH1,ABCA1,PRKC } \\
\text { B }\end{array}$ \\
\hline Opioid Signaling Pathway & 0.018 & $\begin{array}{c}\text { FOSB,NOS1,RAC2,RGS20,PRKCQ,GNB3,ADCY5,RYR2,RGS4,CAC } \\
\text { NA2D3,PRKCB }\end{array}$ \\
\hline Superpathway of Melatonin Degradation & 0.018 & CYP4F8,Ugt1a7c,CYP2C9,Sult1a1,CYP2B6 \\
\hline nNOS Signaling in Neurons & 0.019 & NOS1,CAPN6,PRKCQ,PRKCB \\
\hline
\end{tabular}




\begin{tabular}{|c|c|c|}
\hline Ketogenesis & 0.019 & HMGCS2,HMGCS1 \\
\hline Caveolar-mediated Endocytosis Signaling & 0.019 & ACTA2,ACTG2,ITGB6,ACTC1,ITGA4 \\
\hline Neuroinflammation Signaling Pathway & 0.019 & $\begin{array}{c}\text { VCAM1,GABRA5,MMP3,SLC1A3,CXCL12,IRF7,IL34,NCF2,CASP1, } \\
\text { PIK3CD,PTGS2,STAT1,GJB1 }\end{array}$ \\
\hline Colorectal Cancer Metastasis Signaling & 0.02 & $\begin{array}{l}\text { GNB3,MMP28,WNT9B,MMP3,ADCY5,MMP13,MMP10,PIK3CD,PTG } \\
\text { S2,STAT1,PTGER4 }\end{array}$ \\
\hline FAK Signaling & 0.021 & CAPN6,ACTA2,PIK3CD,ACTG2,ACTC1,ITGA4 \\
\hline Atherosclerosis Signaling & 0.021 & VCAM1,MMP3,CXCR4,CXCL12,MMP13,PDGFB,ITGA4 \\
\hline Asparagine Biosynthesis I & 0.022 & ASNS \\
\hline Integrin Signaling & 0.022 & $\begin{array}{l}\text { RAC2,CAPN6,ACTA2,MYLK,PIK3CD,ACTG2,ITGB6,ACTC1,PDGF } \\
\text { B,ITGA4 }\end{array}$ \\
\hline $\begin{array}{l}\text { Antiproliferative Role of Somatostatin } \\
\text { Receptor } 2\end{array}$ & 0.025 & NOS1,GNB3,GUCY1A1,SSTR2,PIK3CD \\
\hline VEGF Signaling & 0.025 & SH2D2A,ACTA2,PIK3CD,ACTG2,ACTC1,PRKCB \\
\hline Xenobiotic Metabolism Signaling & 0.026 & $\begin{array}{c}\text { ABCB1,PRKCQ,ALDH1L2,Ugt1a7c,CYP2C9,UGT8,PIK3CD,HS3ST6, } \\
\text { NDST4,CYP2B6,CHST15,PRKCB }\end{array}$ \\
\hline Acetone Degradation I (to Methylglyoxal) & 0.027 & CYP4F8,CYP2C9,CYP2B6 \\
\hline Cdc42 Signaling & 0.03 & $\begin{array}{l}\text { RT1-A3 (includes others),H2-T22,H2-T24,H2- } \\
\text { T3,MYLK,PARD6A,HLA-E,ITGA4 }\end{array}$ \\
\hline Macropinocytosis Signaling & 0.032 & PRKCQ,PIK3CD,ITGB6,PDGFB,PRKCB \\
\hline Corticotropin Releasing Hormone Signaling & 0.033 & NOS1,PRKCQ,GUCY1A1,ADCY5,PTGS2,CACNA2D3,PRKCB \\
\hline Nicotine Degradation III & 0.034 & CYP4F8,Ugt1a7c,CYP2C9,CYP2B6 \\
\hline Amyotrophic Lateral Sclerosis Signaling & 0.035 & NOS1,CAPN6,HECW1,CASP1,PIK3CD,GRIA4 \\
\hline Prolactin Signaling & 0.035 & SOCS3,PRKCQ,PIK3CD,STAT1,PRKCB \\
\hline Thrombin Signaling & 0.035 & $\begin{array}{l}\text { GATA1,PRKCQ,GNB3,ADCY5,MYLK,PIK3CD,GATA2,PLCH1,PRK } \\
\text { CB }\end{array}$ \\
\hline Glutamate Receptor Signaling & 0.035 & SLC1A4,GNB3,SLC1A3,GRIA4 \\
\hline Germ Cell-Sertoli Cell Junction Signaling & 0.036 & EPN3,RAC2,ACTA2,TUBA8,PIK3CD,ACTG2,ACTC1,A2M \\
\hline Breast Cancer Regulation by Stathmin 1 & 0.036 & $\begin{array}{l}\text { ARHGEF19,PRKCQ,GNB3,TUBA8,ADCY5,PPP1R3C,PPP1R14A,PIK } \\
\text { 3CD,PRKCB }\end{array}$ \\
\hline Androgen Biosynthesis & 0.036 & AKR1C3,Hsd3b1 \\
\hline Paxillin Signaling & 0.037 & ACTA2,PIK3CD,ACTG2,ITGB6,ACTC1,ITGA4 \\
\hline Oncostatin M Signaling & 0.037 & MMP3,MMP13,STAT1 \\
\hline $\begin{array}{l}\text { Role of JAK2 in Hormone-like Cytokine } \\
\text { Signaling }\end{array}$ & 0.037 & SOCS3,SH2B2,STAT1 \\
\hline Allograft Rejection Signaling & 0.038 & RT1-A3 (includes others),H2-T22,H2-T24,H2-T3,HLA-E \\
\hline $\begin{array}{c}\text { Neuropathic Pain Signaling In Dorsal Horn } \\
\text { Neurons }\end{array}$ & 0.04 & PRKCQ,KCNQ3,PIK3CD,GRIA4,PLCH1,PRKCB \\
\hline$\alpha$-Adrenergic Signaling & 0.042 & PRKCQ,GNB3,PYGM,ADCY5,PRKCB \\
\hline$\beta$-alanine Degradation I & 0.043 & ABAT \\
\hline Glycine Biosynthesis III & 0.043 & AGXT2 \\
\hline Bladder Cancer Signaling & 0.044 & FGF21,MMP28,MMP3,MMP13,MMP10 \\
\hline HER-2 Signaling in Breast Cancer & 0.044 & PRKCQ,PIK3CD,ITGB6,PARD6A,PRKCB \\
\hline Osteoarthritis Pathway & 0.044 & IL1R2,MMP3,IL1RL1,CASP1,MMP13,MMP10,WISP1,PTGS2,ITGA4 \\
\hline HIF1 $\alpha$ Signaling & 0.045 & NOS1,MMP28,MMP3,MMP13,MMP10,PIK3CD \\
\hline Th2 Pathway & 0.047 & SOCS3,NOTCH3,PRKCQ,CXCR4,IL1RL1,PIK3CD,IL24 \\
\hline PDGF Signaling & 0.047 & PIK3CD,EIF2AK2,STAT1,PDGFB,PRKCB \\
\hline OX40 Signaling Pathway & 0.049 & RT1-A3 (includes others),H2-T22,H2-T24,H2-T3,HLA-E \\
\hline Notch Signaling & 0.049 & NOTCH3,MFNG,DLL4 \\
\hline
\end{tabular}


Supplementary Table S5. Common DEGs in sertoli cells caused by PFOA and PFOS treatment.

\begin{tabular}{|c|c|c|c|c|}
\hline $\begin{array}{c}\text { Gene } \\
\text { symbol }\end{array}$ & $\begin{array}{l}\text { PFOA/Ctrl } \\
\text { expression } \\
\text { (log2 fold } \\
\text { change) }\end{array}$ & $\begin{array}{l}\text { PFOS/Ctrl } \\
\text { expression } \\
\text { (log2 fold } \\
\text { change) }\end{array}$ & Biological Process & Kegg Orthology \\
\hline Angpt14 & 1.73 & 1.10 & $\begin{array}{l}\text { GO:0051005//negative regulation of lipoprotein lipase } \\
\text { activity;GO:0030154//cell } \\
\text { differentiation;GO:0009267//cellular response to } \\
\text { starvation;GO:0001525//angiogenesis;GO:0051260//protein } \\
\text { homooligomerization;GO:0043066//negative regulation of } \\
\text { apoptotic process;GO:2000352//negative regulation of } \\
\text { endothelial cell apoptotic process;GO:0001666//response to } \\
\text { hypoxia;GO:0070328//triglyceride } \\
\text { homeostasis;GO:0019216//regulation of lipid metabolic } \\
\text { process;GO:0043086//negative regulation of catalytic } \\
\text { activity;GO:0045834//positive regulation of lipid metabolic } \\
\text { process;GO:0051259//protein oligomerization }\end{array}$ & K08767//angiopoietin-like 4 \\
\hline Casp1 & 1.04 & 1.07 & $\begin{array}{c}\text { GO:0033198//response to ATP;GO:0071260//cellular } \\
\text { response to mechanical } \\
\text { stimulus;GO:0051882//mitochondrial } \\
\text { depolarization;GO:0071222//cellular response to } \\
\text { lipopolysaccharide;GO:0032496//response to } \\
\text { lipopolysaccharide;GO:0032611//interleukin-1 beta } \\
\text { production;GO:0071310//cellular response to organic } \\
\text { substance;GO:0071346//cellular response to interferon- } \\
\text { gamma;GO:1901998//toxin transport;GO:0016485//protein } \\
\text { processing;GO:0097300//programmed necrotic cell } \\
\text { death;GO:0010506//regulation of } \\
\text { autophagy;GO:0043280//positive regulation of cysteine- } \\
\text { type endopeptidase activity involved in apoptotic } \\
\text { process;GO:0070269//pyroptosis;GO:0016540//protein } \\
\text { autoprocessing;GO:0050718//positive regulation of } \\
\text { interleukin-1 beta secretion;GO:0050717//positive } \\
\text { regulation of interleukin-1 alpha } \\
\text { secretion;GO:1903265//positive regulation of tumor } \\
\text { necrosis factor-mediated signaling } \\
\text { pathway;GO:0001666//response to } \\
\text { hypoxia;GO:0060081//membrane } \\
\text { hyperpolarization;GO:0050727//regulation of inflammatory } \\
\text { response;GO:0043123//positive regulation of I-kappaB } \\
\text { kinase/NF-kappaB } \\
\text { signaling;GO:0006508//proteolysis;GO:0050715//positive } \\
\text { regulation of cytokine secretion;GO:0042981//regulation of } \\
\text { apoptotic process;GO:0009617//response to bacterium }\end{array}$ & $\begin{array}{c}\text { K04394//caspase } 4 \\
{[\text { EC:3.4.22.57];K01370//caspas }} \\
\text { e } 1[\text { EC:3.4.22.36] }\end{array}$ \\
\hline $\mathrm{Ccl} 2$ & 1.01 & 2.10 & $\begin{array}{c}\text { GO:0043615//astrocyte cell } \\
\text { migration;GO:0061844//null;GO:0031100//animal organ } \\
\text { regeneration;GO:0001525//angiogenesis;GO:0006874//cellu } \\
\text { lar calcium ion homeostasis;GO:0007568//aging }\end{array}$ & $\begin{array}{c}\text { K14624//C-C motif chemokine } \\
2\end{array}$ \\
\hline
\end{tabular}




\begin{tabular}{|c|c|c|c|c|}
\hline $\mathrm{Ccl} 7$ & 1.34 & 2.03 & $\begin{array}{c}\text { GO:0030335//positive regulation of cell } \\
\text { migration;GO:0043547//positive regulation of GTPase } \\
\text { activity;GO:0071356//cellular response to tumor necrosis } \\
\text { factor;GO:0010332//response to gamma } \\
\text { radiation;GO:0071346//cellular response to interferon- } \\
\text { gamma;GO:0071347//cellular response to interleukin- } \\
\text { 1;GO:0002548//monocyte } \\
\text { chemotaxis;GO:0071361//cellular response to } \\
\text { ethanol;GO:0007186//G-protein coupled receptor signaling } \\
\text { pathway;GO:0048247//lymphocyte } \\
\text { chemotaxis;GO:0048245//eosinophil } \\
\text { chemotaxis;GO:2000503//positive regulation of natural } \\
\text { killer cell chemotaxis;GO:0030593//neutrophil } \\
\text { chemotaxis;GO:0070098//chemokine-mediated signaling } \\
\text { pathway;GO:0008360//regulation of cell } \\
\text { shape;GO:0006954//inflammatory } \\
\text { response;GO:0006955//immune } \\
\text { response;GO:0007010//cytoskeleton } \\
\text { ERK2 cascade }\end{array}$ & $\begin{array}{c}\mathrm{K} 14624 / / \mathrm{C}-\mathrm{C} \text { motif chemokine } \\
2 ; \mathrm{K} 05509 / / \mathrm{C}-\mathrm{C} \text { motif } \\
\text { chemokine } 7\end{array}$ \\
\hline Cilp2 & 1.25 & 1.28 & NA & $\begin{array}{l}\text { K05141//tumor necrosis factor } \\
\text { receptor superfamily member } \\
\text { 1B;K13172//serine/arginine } \\
\text { repetitive matrix protein } 2\end{array}$ \\
\hline Comp & 1.70 & 2.42 & $\begin{array}{c}\text { GO:0007155//cell adhesion;GO:0060173//limb } \\
\text { development;GO:0030198//extracellular matrix } \\
\text { organization;GO:0003417//growth plate cartilage } \\
\text { development;GO:0043066//negative regulation of apoptotic } \\
\text { process;GO:0006915//apoptotic process }\end{array}$ & $\begin{array}{c}\text { K04659//thrombospondin } \\
2 / 3 / 4 / 5\end{array}$ \\
\hline Hmgcs2 & 2.21 & 2.02 & $\begin{array}{c}\text { GO:0008299//isoprenoid biosynthetic } \\
\text { process;GO:0016126//sterol biosynthetic process }\end{array}$ & $\begin{array}{c}\text { K01641//hydroxymethylglutary } \\
\text { 1-CoA synthase [EC:2.3.3.10] }\end{array}$ \\
\hline Il1r2 & 1.07 & 1.44 & $\begin{array}{c}\text { GO:0010955//negative regulation of protein } \\
\text { processing;GO:0050712//negative regulation of interleukin- } \\
1 \text { alpha secretion;GO:2000660//negative regulation of } \\
\text { interleukin-1-mediated signaling } \\
\text { pathway;GO:1900016//negative regulation of cytokine } \\
\text { production involved in inflammatory response }\end{array}$ & $\begin{array}{l}\text { K04387//interleukin } 1 \text { receptor } \\
\text { type II }\end{array}$ \\
\hline Klhl41 & 2.09 & 2.23 & $\begin{array}{c}\text { GO:0045214//sarcomere organization;GO:0016567//protein } \\
\text { ubiquitination;GO:0045661//regulation of myoblast } \\
\text { differentiation;GO:0048741//skeletal muscle fiber } \\
\text { development;GO:0030239//myofibril } \\
\text { assembly;GO:0035914//skeletal muscle cell } \\
\text { differentiation;GO:0031275//regulation of lateral } \\
\text { pseudopodium assembly;GO:2000291//regulation of } \\
\text { myoblast proliferation;GO:2001014//regulation of skeletal } \\
\text { muscle cell differentiation }\end{array}$ & $\begin{array}{l}\text { K10473//kelch repeat and BTB } \\
\text { domain-containing protein } 5 / 10\end{array}$ \\
\hline Magea11 & 1.07 & 1.85 & NA & $\begin{array}{c}\text { K12464//melanoma-associated } \\
\text { antigen D1 }\end{array}$ \\
\hline Mroh7 & 1.11 & 1.18 & NA & K09291//nucleoprotein TPR \\
\hline
\end{tabular}




\begin{tabular}{|c|c|c|c|c|}
\hline Tsen3411 & 1.03 & 1.39 & $\begin{array}{l}\text { GO:0000379//tRNA-type intron splice site recognition and } \\
\text { cleavage }\end{array}$ & $\begin{array}{c}\text { K15323//tRNA-splicing } \\
\text { endonuclease subunit Sen34 } \\
\text { [EC:3.1.27.9] }\end{array}$ \\
\hline Actc1 & -1.41 & -1.40 & $\begin{array}{c}\text { GO:0030048//actin filament-based } \\
\text { movement;GO:0031032//actomyosin structure } \\
\text { organization;GO:0070252//actin-mediated cell } \\
\text { contraction;GO:0030049//muscle filament } \\
\text { sliding;GO:0033275//actin-myosin filament } \\
\text { sliding;GO:0045471//response to } \\
\text { ethanol;GO:0055008//cardiac muscle tissue } \\
\text { morphogenesis;GO:0060048//cardiac muscle } \\
\text { contraction;GO:0042493//response to } \\
\text { drug;GO:0043066//negative regulation of apoptotic } \\
\text { process;GO:0010628//positive regulation of gene } \\
\text { expression;GO:0090131//mesenchyme } \\
\text { migration;GO:0006915//apoptotic } \\
\text { process;GO:0060047//heart } \\
\text { contraction;GO:0030240//skeletal muscle thin filament } \\
\text { assembly;GO:0055003//cardiac myofibril assembly }\end{array}$ & $\begin{array}{l}\text { K12314//actin, alpha cardiac } \\
\text { muscle }\end{array}$ \\
\hline Agxt2 & -3.13 & -3.17 & $\begin{array}{c}\text { GO:0019265//glycine biosynthetic process, by } \\
\text { transamination of glyoxylate;GO:0045429//positive } \\
\text { regulation of nitric oxide biosynthetic } \\
\text { process;GO:0009436//glyoxylate catabolic } \\
\text { process;GO:0019481//L-alanine catabolic process, by } \\
\text { transamination }\end{array}$ & $\begin{array}{c}\text { K00827//alanine-glyoxylate } \\
\text { transaminase / (R)-3-amino-2- } \\
\text { methylpropionate-pyruvate } \\
\text { transaminase [EC:2.6.1.44 } \\
\text { 2.6.1.40] }\end{array}$ \\
\hline Atp1a3 & -1.38 & -2.26 & NA & $\begin{array}{l}\text { K01539//sodium/potassium- } \\
\text { transporting ATPase subunit } \\
\text { alpha [EC:3.6.3.9] }\end{array}$ \\
\hline Cdh6 & -2.23 & -1.58 & $\begin{array}{c}\text { GO:0007156//homophilic cell adhesion via plasma } \\
\text { membrane adhesion molecules }\end{array}$ & $\begin{array}{c}\text { K06798//cadherin 6, type 2, K- } \\
\text { cadherin }\end{array}$ \\
\hline Cox4i2 & -2.70 & -2.00 & $\begin{array}{c}\text { GO:0071456//cellular response to } \\
\text { hypoxia;GO:0006123//mitochondrial electron transport, } \\
\text { cytochrome c to oxygen }\end{array}$ & $\begin{array}{l}\text { K02263//cytochrome c oxidase } \\
\text { subunit } 4\end{array}$ \\
\hline Ece2 & -1.55 & -2.00 & $\begin{array}{c}\text { GO:0016486//peptide hormone } \\
\text { processing;GO:0007507//heart } \\
\text { development;GO:0010002//cardioblast } \\
\text { differentiation;GO:0007420//brain development }\end{array}$ & $\begin{array}{l}\text { K01415//endothelin-converting } \\
\text { enzyme [EC:3.4.24.71] }\end{array}$ \\
\hline
\end{tabular}




\begin{tabular}{|c|c|c|c|c|}
\hline Foxn1 & -1.77 & -2.39 & $\begin{array}{c}\text { GO:1902232//regulation of positive thymic T cell } \\
\text { selection;GO:0010468//regulation of gene } \\
\text { expression;GO:0030216//keratinocyte } \\
\text { differentiation;GO:0033081//regulation of T cell } \\
\text { differentiation in thymus;GO:0035878//nail } \\
\text { development;GO:0008283//cell } \\
\text { proliferation;GO:0051798//positive regulation of hair } \\
\text { follicle development;GO:0030858//positive regulation of } \\
\text { epithelial cell } \\
\text { differentiation;GO:0030097//hemopoiesis;GO:0050673//epit } \\
\text { helial cell proliferation;GO:0097535//lymphoid lineage cell } \\
\text { migration into thymus;GO:0097536//thymus epithelium } \\
\text { morphogenesis;GO:0048538//thymus } \\
\text { development;GO:0008544//epidermis } \\
\text { development;GO:0043029//T cell } \\
\text { homeostasis;GO:0048514//blood vessel } \\
\text { morphogenesis;GO:0045944//positive regulation of } \\
\text { transcription from RNA polymerase II } \\
\text { promoter;GO:0002260//lymphocyte } \\
\text { homeostasis;GO:0002360//T cell lineage } \\
\text { commitment;GO:0001942//hair follicle development }\end{array}$ & $\begin{array}{c}\text { K09407//forkhead box protein } \\
\text { N }\end{array}$ \\
\hline Fyb & -1.75 & -1.63 & $\begin{array}{c}\text { GO:0007165//signal transduction;GO:0072659//protein } \\
\text { localization to plasma membrane;GO:0006955//immune } \\
\text { response }\end{array}$ & K17698//FYN binding protein \\
\hline G0s2 & -1.46 & -2.63 & $\begin{array}{l}\text { GO:0097191//extrinsic apoptotic signaling } \\
\text { pathway;GO:2001238//positive regulation of extrinsic } \\
\text { apoptotic signaling pathway;GO:0007049//cell cycle }\end{array}$ & NA \\
\hline Gckr & -1.73 & -2.28 & $\begin{array}{c}\text { GO:0006006//glucose metabolic } \\
\text { process;GO:0000060//protein import into nucleus, } \\
\text { translocation;GO:0009750//response to } \\
\text { fructose;GO:0051594//detection of } \\
\text { glucose;GO:1901135//carbohydrate derivative metabolic } \\
\text { process;GO:0001678//cellular glucose } \\
\text { homeostasis;GO:0070328//triglyceride } \\
\text { homeostasis;GO:0034504//protein localization to } \\
\text { nucleus;GO:0033132//negative regulation of glucokinase } \\
\text { activity;GO:1903300//negative regulation of hexokinase } \\
\text { activity;GO:0046415//urate metabolic } \\
\text { process;GO:0033133//positive regulation of glucokinase } \\
\text { activity }\end{array}$ & NA \\
\hline Hoxb8 & -2.96 & -3.00 & $\begin{array}{c}\text { GO:0009952//anterior/posterior pattern } \\
\text { specification;GO:0021516//dorsal spinal cord } \\
\text { development;GO:0008344//adult locomotory } \\
\text { behavior;GO:0006351//transcription, DNA- } \\
\text { templated;GO:0045638//negative regulation of myeloid cell } \\
\text { differentiation;GO:0000122//negative regulation of } \\
\text { transcription from RNA polymerase II } \\
\text { promoter;GO:0007275//multicellular organism } \\
\text { development;GO:0048704//embryonic skeletal system } \\
\text { morphogenesis;GO:0019233//sensory perception of } \\
\text { pain;GO:0007625//grooming } \\
\text { behavior;GO:0048705//skeletal system morphogenesis }\end{array}$ & $\begin{array}{c}\text { K09308//homeobox protein } \\
\text { HoxB/C/D8 }\end{array}$ \\
\hline
\end{tabular}




\begin{tabular}{|c|c|c|c|c|}
\hline Il1rl1 & -1.36 & -1.07 & $\begin{array}{l}\text { GO:0002826//negative regulation of T-helper } 1 \text { type } \\
\text { immune response;GO:0043032//positive regulation of } \\
\text { macrophage activation;GO:1901653//cellular response to } \\
\text { peptide;GO:0090197//positive regulation of chemokine } \\
\text { secretion;GO:0050729//positive regulation of inflammatory } \\
\text { response;GO:0032754//positive regulation of interleukin-5 } \\
\text { production;GO:0043124//negative regulation of I-kappaB } \\
\text { kinase/NF-kappaB signaling;GO:0008285//negative } \\
\text { regulation of cell proliferation;GO:0032689//negative } \\
\text { regulation of interferon-gamma production }\end{array}$ & $\begin{array}{l}\text { K05171//interleukin } 1 \text { receptor- } \\
\text { like } 1\end{array}$ \\
\hline Lgr5 & -3.13 & -3.17 & $\begin{array}{c}\text { GO:0007186//G-protein coupled receptor signaling } \\
\text { pathway;GO:2001013//epithelial cell proliferation involved } \\
\text { in renal tubule morphogenesis;GO:0009994//oocyte } \\
\text { differentiation;GO:0042127//regulation of cell } \\
\text { proliferation;GO:0048839//inner ear } \\
\text { development;GO:0001942//hair follicle } \\
\text { development;GO:0090263//positive regulation of canonical } \\
\text { Wnt signaling pathway }\end{array}$ & $\begin{array}{l}\text { K04308//leucine-rich repeat- } \\
\text { containing G protein-coupled } \\
\text { receptor } 5\end{array}$ \\
\hline Myo16 & -1.60 & -3.80 & $\begin{array}{c}\text { GO:0021549//cerebellum } \\
\text { development;GO:0048812//neuron projection } \\
\text { morphogenesis;GO:0014065//phosphatidylinositol 3-kinase } \\
\text { signaling;GO:2000134//negative regulation of G1/S } \\
\text { transition of mitotic cell cycle;GO:0008285//negative } \\
\text { regulation of cell proliferation }\end{array}$ & K17481//myosin XVI \\
\hline
\end{tabular}




\begin{tabular}{|c|c|c|c|c|}
\hline Nos1 & -1.13 & -1.16 & $\begin{array}{c}\text { GO:0043267//negative regulation of potassium ion } \\
\text { transport;GO:0002028//regulation of sodium ion } \\
\text { transport;GO:0051926//negative regulation of calcium ion } \\
\text { transport;GO:0051612//negative regulation of serotonin } \\
\text { uptake;GO:0006941//striated muscle } \\
\text { contraction;GO:0033555//multicellular organismal response } \\
\text { to stress;GO:0071363//cellular response to growth factor } \\
\text { stimulus;GO:0035066//positive regulation of histone } \\
\text { acetylation;GO:0051346//negative regulation of hydrolase } \\
\text { activity;GO:0042311//vasodilation;GO:0098924//retrograde } \\
\text { trans-synaptic signaling by nitric } \\
\text { oxide;GO:0048148//behavioral response to } \\
\text { cocaine;GO:0071872//cellular response to epinephrine } \\
\text { stimulus;GO:1901206//positive regulation of adrenergic } \\
\text { receptor signaling pathway involved in heart } \\
\text { process;GO:0009408//response to } \\
\text { heat;GO:0001666//response to } \\
\text { hypoxia;GO:0007568//aging;GO:0018119//peptidyl- } \\
\text { cysteine S-nitrosylation;GO:0042738//exogenous drug } \\
\text { catabolic process;GO:0045944//positive regulation of } \\
\text { transcription from RNA polymerase II } \\
\text { promoter;GO:0098735//positive regulation of the force of } \\
\text { heart contraction;GO:0006809//nitric oxide biosynthetic } \\
\text { process;GO:0050767//regulation of } \\
\text { neurogenesis;GO:0006527//arginine catabolic process }\end{array}$ & $\begin{array}{c}\text { K13240//nitric-oxide synthase } \\
\text { brain [EC:1.14.13.39] }\end{array}$ \\
\hline Pmch & -4.02 & -4.05 & $\begin{array}{c}\text { GO:0007595//lactation;GO:0009409//response to } \\
\text { cold;GO:0002027//regulation of heart } \\
\text { rate;GO:0032227//negative regulation of synaptic } \\
\text { transmission, dopaminergic;GO:0042593//glucose } \\
\text { homeostasis;GO:0045776//negative regulation of blood } \\
\text { pressure;GO:0042756//drinking } \\
\text { behavior;GO:0048168//regulation of neuronal synaptic } \\
\text { plasticity;GO:0046005//positive regulation of circadian } \\
\text { sleep/wake cycle, REM sleep;GO:0007631//feeding } \\
\text { behavior;GO:0007204//positive regulation of cytosolic } \\
\text { calcium ion concentration;GO:0007268//chemical synaptic } \\
\text { transmission;GO:0007218//neuropeptide signaling } \\
\text { pathway;GO:0007611//learning or memory }\end{array}$ & $\begin{array}{l}\text { K05229//pro-melanin- } \\
\text { concentrating hormone }\end{array}$ \\
\hline Sntg1 & -3.55 & -3.58 & NA & $\begin{array}{c}\text { K20251//glutamate receptor- } \\
\text { interacting } \\
\text { protein;K12196//vacuolar } \\
\text { protein-sorting-associated } \\
\text { protein } 4\end{array}$ \\
\hline
\end{tabular}




\begin{tabular}{|c|c|c|c|c|}
\hline Vil1 & -1.39 & -1.25 & $\begin{array}{c}\text { GO:0032532//regulation of microvillus } \\
\text { length;GO:0030836//positive regulation of actin filament } \\
\text { depolymerization;GO:0030335//positive regulation of cell } \\
\text { migration;GO:2000394//positive regulation of } \\
\text { lamellipodium morphogenesis;GO:0051125//regulation of } \\
\text { actin nucleation;GO:0001951//intestinal D-glucose } \\
\text { absorption;GO:0010634//positive regulation of epithelial } \\
\text { cell migration;GO:0007173//epidermal growth factor } \\
\text { receptor signaling pathway;GO:1903078//positive } \\
\text { regulation of protein localization to plasma } \\
\text { membrane;GO:0030042//actin filament } \\
\text { depolymerization;GO:0030041//actin filament } \\
\text { polymerization;GO:0051693//actin filament } \\
\text { capping;GO:0035729//cellular response to hepatocyte } \\
\text { growth factor stimulus;GO:0060327//cytoplasmic actin- } \\
\text { based contraction involved in cell } \\
\text { motility;GO:1902896//terminal web } \\
\text { assembly;GO:0061041//regulation of wound } \\
\text { healing;GO:0051016//barbed-end actin filament } \\
\text { capping;GO:0008360//regulation of cell } \\
\text { shape;GO:0071364//cellular response to epidermal growth } \\
\text { factor stimulus;GO:0045010//actin } \\
\text { nucleation;GO:0032233//positive regulation of actin } \\
\text { filament bundle assembly;GO:0040018//positive regulation } \\
\text { of multicellular organism growth;GO:2000392//regulation } \\
\text { of lamellipodium morphogenesis;GO:0009617//response to } \\
\text { bacterium;GO:0051014//actin filament } \\
\text { severing;GO:0030855//epithelial cell differentiation }\end{array}$ & K05761//villin 1 \\
\hline Zfp3613 & -1.05 & -1.32 & $\begin{array}{c}\text { GO:0061158//3'-UTR-mediated mRNA } \\
\text { destabilization;GO:0000289//nuclear-transcribed mRNA } \\
\text { poly(A) tail shortening }\end{array}$ & $\begin{array}{l}\text { K06237//collagen, type IV } \\
\text { alpha }\end{array}$ \\
\hline
\end{tabular}

